Routledge Advances in Sociology

\title{
THE CLASS STRUCTURE OF CAPITALIST SOCIETIES
}

VOLUME 1: A SPACE OF BOUNDED VARIETY

\author{
Will Atkinson
}




\section{The Class Structure of Capitalist Societies}

This first volume of The Class Structure of Capitalist Societies offers a bold and wide-ranging assessment of the shape and effects of class systems across a diverse range of capitalist nations. Plumbing a trove of data and deploying cutting-edge techniques, it carefully maps the distribution of the key sources of power and documents the major convergences and divergences between market societies old and new.

Establishing that the multidimensional vision of class proposed decades ago by Pierre Bourdieu appears to hold good throughout Europe, parts of the wider Western world and Eastern Asia, the book goes on to examine a number of significant themes: the relationship between class and occupation; the intersection of class with gender, religion, geography and age; the correspondences between social position and political attitudes; selfpositioning in the class structure; and the extent of belief in meritocracy. For all the striking cross-national commonalities, however, the book unearths consistent variations seemingly linked to distinct politico-economic regimes.

This title will appeal to scholars and advanced undergraduate and postgraduate students interested in sociology, politics and demography, and is essential reading for all those interested in social class across the globe.

Will Atkinson is Reader in Sociology in the School of Sociology, Politics and International Studies at the University of Bristol, UK.
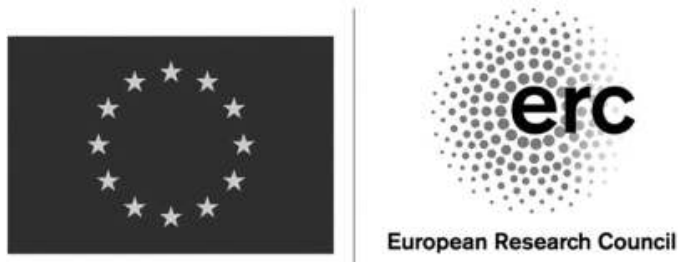
Routledge Advances in Sociology

\section{Queer Campus Climate}

An Ethnographic Fantasia

Benjamin Arnberg

\section{I Children in Social Movements}

Rethinking Agency, Mobilization and Rights

Diane M. Rodgers

\section{The Global Citizenship Nexus}

Critical Studies

Edited by Debra D. Chapman, Tania Ruiz-Chapman and Peter Eglin

\section{People, Care and Work in the Home}

Edited by Mohamed Gamal Abdelmonem and Antonio Argandona

\section{Europe In Love}

Binational Couples and Cosmopolitan Society Juan Díez Medrano

\section{Neurodiversity Studies}

A New Critical Paradigm

Edited by Hanna Bertilsdotter Rosqvist, Nick Chown and Anna

Stenning

\section{The Class Structure of Capitalist Societies \\ Volume I: A Space of Bounded Variety \\ Will Atkinson}

For more information about this series, please visit: www.routledge.com/ Routledge-Advances-in-Sociology/book-series/SE0511 


\title{
The Class Structure of Capitalist Societies
}

\section{Volume I: A Space of Bounded Variety}

\section{Will Atkinson}


First published 2020

by Routledge

2 Park Square, Milton Park, Abingdon, Oxon OXI4 4RN

and by Routledge

52 Vanderbilt Avenue, New York, NY 10017

Routledge is an imprint of the Taylor \& Francis Group, an informa business

(C) 2020 Will Atkinson

The right of Will Atkinson to be identified as author of this work has been asserted by him in accordance with sections 77 and 78 of the Copyright, Designs and Patents Act 1988.

With the exception of Chapter 3, no part of this book may be reprinted or reproduced or utilised in any form or by any electronic, mechanical, or other means, now known or hereafter invented, including photocopying and recording, or in any information storage or retrieval system, without permission in writing from the publishers.

Chapter 3 of this book is available for free in PDF format as Open Access from the individual product page at www. routledge.com. It has been made available under a Creative Commons Attribution-Non Commercial-No Derivatives 4.0 license

Trademark notice: Product or corporate names may be trademarks or registered trademarks, and are used only for identification and explanation without intent to infringe.

British Library Cataloguing-in-Publication Data

A catalogue record for this book is available from the British Library

Library of Congress Cataloging-in-Publication Data

A catalog record has been requested for this book

ISBN: 978-I-I38-34253-8 (hbk)

ISBN: 978-0-429-43972-8 (ebk)

Typeset in Times New Roman by codeMantra 


\section{Contents}

List of figures

vii

List of tables

Acknowledgements

1 Introduction

2 Constructing the spaces 18

3 Social spaces $\quad 37$

4 The division of labour of domination 61

5 Homologies 86

6 Trajectories 111

7 Political position-takings 134

8 Class sense and symbolic violence 158

9 Conclusion 181

References $\quad 189$

Index 203 

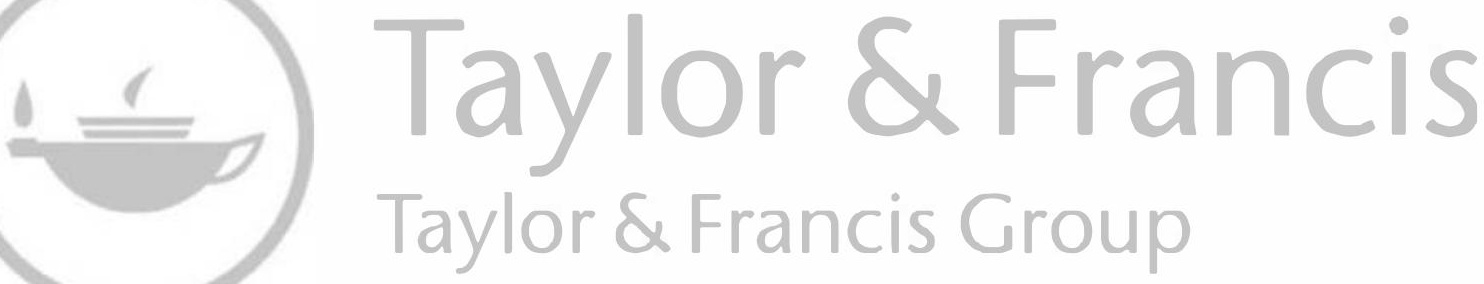
http://taylorandfrancis.com 


\section{Figures}

2.1 Two transformation plots 32

3.1 Average factor loadings on Axes 1 and 2

3.2 Average modelled vectors for capital volume and capital composition

3.3 Degrees of rotation between CatPCA axes and modelled vectors for capital volume and composition $\quad 48$

3.4 Two spaces of individuals 49

3.5 Average means and standard deviations of axis terciles on Axes 1 and 2

4.1 The division of labour of domination in the social space (aggregate model) 74

4.2 The field of power and the social space (aggregate model) 78

5.1 Partner's occupation in the social space (aggregate model) 96

5.2 Place of residence in the social space (aggregate model) 106

6.1 Age groups in the social space (aggregate model) 116

6.2 Age and the division of labour in the social space (aggregate model) 120

7.1 Party affiliations in the social space (aggregate model) 145

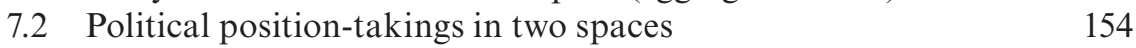

8.1 Perceived place in the social space (aggregate model) 162

8.2 Perceptions of what it takes to 'get ahead' in the social space (aggregate model) 169 $\begin{array}{ll}8.3 & \text { Is the rich paying for education just or unjust? } \\ \text { (aggregate model) }\end{array}$ 

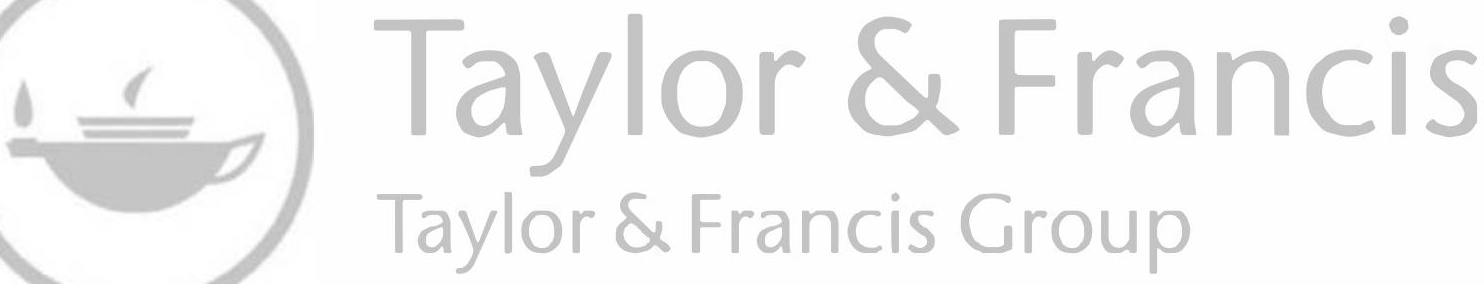
http://taylorandfrancis.com 


\section{Tables}

2.1 Some features of the countries studied 21

2.2 Sample size and number of variable categories in the models 33

3.1 Eigenvalues and inertia in the models 39

3.2 Factor loadings on Axes 1 and 2

3.3 Relative contributions of variables to Axes 1 and 2

3.4 Tercile means on Axes 1 and $2 \quad 50$

3.5 Tercile standard deviations on Axes 1 and 2

3.6 Axis correlations 57

4.1 The distribution of individuals within the division of labour
of domination

4.2 Coordinates of occupational categories on Axis $1 \quad 70$

4.3 Coordinates of occupational categories on Axis $2 \quad 73$

4.4 The distribution of individuals across fields of power 77

4.5 Coordinates of occupational categories (field of power) on Axis $1 \quad 80$

4.6 Coordinates of occupational categories (field of power)
on Axis 2

5.1 Women and the division of labour of domination 89

5.2 Coordinates of men, women and household formations
on Axes 1 and 2

5.3 Coordinates of partner's occupation on Axis $1 \quad 94$

5.4 Coordinates of partner's occupation on Axis $2 \quad 95$

5.5 The distribution of religious affiliations 100

5.6 Coordinates of religious identity on Axis $1 \quad 102$

5.7 Coordinates of religious identity on Axis 2

5.8 Coordinates of place of residence on Axes 1 and $2 \quad 107$

6.1 Coordinates of age categories on Axes 1 and 2

6.2 Age profiles of occupational categories 118

6.3 Factor loadings and contributions of variables on Axis $3 \quad 124$

6.4 Vector coordinates of mother's occupation on Axis $3 \quad 125$

$\begin{array}{lll}6.5 & \text { Factors associated with Axis 3 I } & 127\end{array}$

6.6 Factors associated with Axis 3 II 130 
7.1 The distribution of party affiliations

7.2 Coordinates of party affiliations on Axes 1 and 2

7.3 Left/right index scores across national samples for four questions

7.4 Coordinates of political position-takings on Axis 1

7.5 Coordinates of political position-takings on Axis 2

8.1 Coordinates of perceived social position on Axes 1 and 2

8.2 The importance of various factors in getting ahead 167

8.3 Factors involved in 'getting ahead', coordinates on Axis $1 \quad 170$

8.4 Factors involved in 'getting ahead', coordinates on Axis 2

8.5 The distribution of responses to the rich paying for better education

8.6 Coordinates on Axes 1 and 2 of responses to the rich paying for better education 


\section{Acknowledgements}

The research underpinning this book forms a component part of a larger project funded by the European Research Council under the European Union's Horizon 2020 research and innovation programme (Grant agreement no. 677055). The expectation is that this is the first of a three-volume series of books on the class structure of capitalist societies based on this research, the second volume exploring the cases of Germany, Sweden and the US in much greater depth with a bespoke survey, and a third focussing on the everyday experience of class and its interaction with other fields in shaping individual lifeworlds.

Thanks are due to all those who provided assistance and guidance in making sure the project got off the ground, particularly Tom Bowker, Gregor McLennan, Eric Herring, Esther Dermott and Morag McDermont. Laurie Hanquinet, Johs Hjellbrekke, Piotr Marzec, Gregor McLennan, Steve Roberts, Mike Savage, Greg Schwartz and several reviewers for Routledge were all kind enough to read over the manuscript at various stages of development and give sound advice, wake-up calls and/or encouragement when needed. Conversations with Paula Surridge also steered me away from certain blind alleys, and Junko Yamashita offered useful advice on research on East Asia. None of this absolves me of the blame for the mistakes and wrong turns that doubtless remain. This book has been a long time in the making and travelled a rocky road to say the least. Whether it will be worth it in the end I don't know, but I am grateful to Emily Briggs and her team at Routledge for their flexibility and understanding. Most importantly, however, I am forever indebted to Vikki for simply putting up with me during this book's long gestation and to Phoebe for the much-needed levity. 

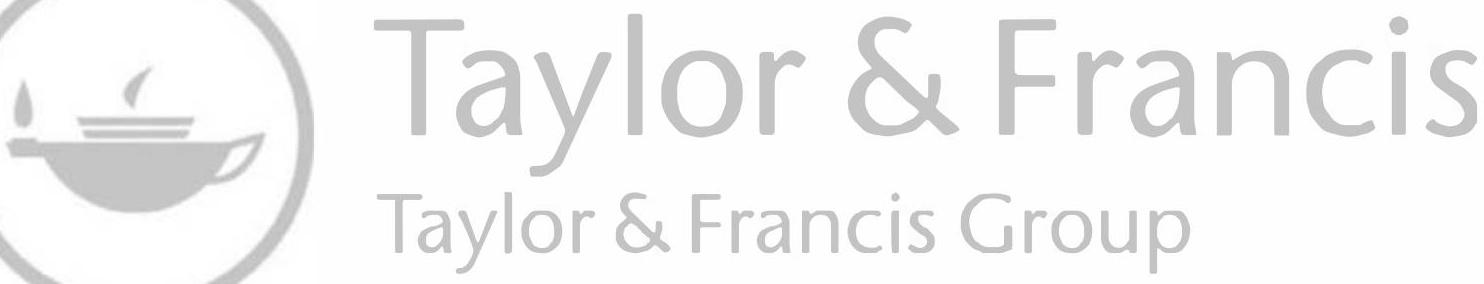
http://taylorandfrancis.com 


\section{Chapter I}

\section{Introduction}

The degree to which the structure and effects of class are 'the same' or 'different' across capitalist nations has occupied scholarly minds for centuries. Witness Marx and Engels's eager dissections of the events that exploded across Europe and America in the nineteenth century, with all their considerations of the size and power of this or that class, or Max Weber ranging over East and West in his meticulous documentation of the relationship between class and religion. Towards the latter part of the twentieth century, moreover, it seemed a relatively easy question to answer. Most assumed it to be a case of determining how many people fall into separate pre-defined 'slots' in the capitalist production process or occupational structure - a case of jobs and industries, in other words. Perhaps the nature of the economy in one nation, thanks to its position within the global division of labour, or the 'world-system', means it has a larger and more diversified body of capitalists than others, or specific industrial specialisations like agriculture, finance, hi-tech manufacturing and so on swell or shrink the ranks of various socio-professional categories. If one has the data available, and a preferred means of assigning people to boxes, then all that needs to be done is to work out how many people fit into each box. From there follows scrutiny of the socio-political consequences - political polarisation following economic polarisation, for example, or liberalism flourishing with the expansion of the educated 'middle class'. Others less keen on the logic and language of 'class', whether on methodological or political grounds, but still covering the same intellectual ground, might take a slightly different tack, reducing 'stratification' down to a universal scale of socio-economic standing whose components - relative income, educational attainment, occupational prestige, etc. - are always so closely connected that capitalist social orders, or 'industrial societies' as they preferred to call them, can, for practical purposes, be defined by a single dimension of difference.

Forty years ago, however, a different way of seeing things emerged. A fat tome summarising a decade or more of research and reflection on French society fell from the printing press. The book was Distinction, and though it was a collaborative effort, implicating the labours of many colleagues at the 
Parisian research centre from which it sprang, it carried the name of just one man, its self-styled 'stage-manager' (le metteur en scene): Pierre Bourdieu. ${ }^{1}$ At its core, underpinning the sundry assertions and asides with which it brimmed, it proffered a novel, distinctive vision of social class. Occupation was not the backbone, as Frank Parkin (1972: 18) had famously summed up the prevailing orthodoxy of the day, but simply a proxy for possession of other properties. If among those properties were economic resources, moreover, then these were reducible to neither wealth disparities, as those of a radical bent might have it, or income differentials, as the advocates of scales would have it, but incorporated both. Not only that, but there were other resources the dispossession of which rendered suffering and constraint. These included the cachet of connections and club membership but also, and especially, mastery of the cultural or symbolic codes deemed legitimate within the social order and practically approximated, but not exhausted, by education level. Yet those various resources, or 'capitals', were not directly correlated, as generations of research on social stratification claimed. They constituted sources of polarisation and antagonism, distributing people within a multidimensional 'social space' on the basis of not just their overall stocks of capital but the degree to which either cultural or economic capital form the bulk of those stocks. Ultimately, this novel reimaging of class was rooted in the founding premise that the concept made famous by Karl Marx and Max Weber was not, at base, about exploitation or life chances, even if they are rolled up in it, but about misrecognition. That is to say, certain arbitrary properties - money and what it buys, symbolic mastery and its associated goods and practices - and their possessors are seen as inherently worthy, legitimate, authoritative and so on. Having those properties or not thus become the fundamental shapers of conditions of existence and, through the experiences and opportunities attending them, of tastes, desires and ethos - or, to use Bourdieu's celebrated term, habitus - but also of one's sense of place and value relative to others.

Surprisingly, however, research to test whether and to what extent this multipolar image of the class structure applies beyond late twentieth-century France is patchy to say the least. There has been some work in Europe, most notably the Nordic countries, but, despite the frequent reference to the concept among those inspired by Bourdieu (e.g. Wacquant, 2009), little has been done elsewhere to scrutinise empirically whether class takes the form of a social space, whether its axes are the same as those found in Bourdieu's home country and whether it translates into cross-cutting divergences of ethos and distributions of self-worth. Most scholars engaging with Bourdieu on class tend to ignore or dismiss the notion, instead showing interest only in testing his supposed thesis that there is a one-to-one correspondence between class and lifestyles using their own ill-fitting measures of class or stratification and suboptimal analytical techniques. At the same time this dearth means we have no way of knowing just how representative of capitalist nations 
those few European studies - which have generally supported the Bourdieusian model - actually are, especially as most of them have been conducted in nations with very particular political economies and 'welfare regimes', to use Esping-Andersen's (1990) terms. Would the same conclusions be reached in starkly inegalitarian nations like the US, rapidly industrialised and culturally distinct East Asia, or the nations of Eastern Europe transitioning to capitalism only 30 years ago?

The intention in this book is to go some way towards providing a fuller picture by assessing, as best as possible with the data available, the broad generalisability of Bourdieu's image of social space, its homologies and its consequences for self-perception to capitalist nations while flagging potential sources of country-specific deviation. Just as advocates of previous images of class, once they had worked out an empirically verifiable proxy model in one nation, generally saw the next logical step to be comparison across a wider range of countries, so too it is now time to take Bourdieu global. Matching philosophical principles and operational procedures, the methodological foundation for all that follows will be the specific form of data analysis known as geometric data analysis, but it will be used - for the first time - for widescale comparative analysis. First, however, there is a need to unpack the context, concepts and outstanding questions at stake.

\section{From scales to classes}

Human thought tends to organise around all kinds of oppositions - this we know from Hegel and Durkheim to Bachelard - so it is no surprise that research on class and stratification, and the countless suggestions on how to depict them, has too. A double debate has, in fact, run through Western scholarship - and 'folk' thought too (Cannadine, 1998) - on these age-old concerns. On the one hand, are power and inequality best understood as being distributed between large, clearly defined classes or as being arranged in a scalar fashion, with no clear breaks? On the other hand, is there one overriding property that defines the great chain of social being, or a multiplicity of properties which either sit alongside or co-define class? For Marx the overall answer was simple: there are two classes defined by a single relation, namely, ownership or not of the means of production, and thus whether one is an exploiter or exploited. For Max Weber (1968) the distribution of power within a social order also ran between classes and groups, but he injected multidimensional thinking into the sociology of domination by distinguishing class, defined by property and market situations, from status, or esteem and prestige.

After the classics, into the mid-twentieth century, came the scales. Pioneered in the US, where talk of 'class' had too much of a ring of the Old World left behind to it and smacked of an unwelcome political radicalism, occupational prestige, as ranked by the general public, was the initial 
focal constituent. Income and education level were subsequently held to be efficient joint predictors, and thus indicators, of status, since they correlated so strongly with it, leading Otis Dudley Duncan (1961) to devise the first true index of socio-economic status usable across studies. Rolling prestige, education and income together in a single measure like this jarred with the calls from others, echoing Weber, to recognise the distinct existence of several scales in society - of income, authority and prestige, the latter being based on education as well as other factors - since occupying discrepant positions in each can generates all kinds of psychological effects manifest not least in deviant political attitudes (Lipset and Bendix, 1959; Lipset, 1960; Lenski, 1966). Updated socio-economic indexes constructed by Trieman (1977) and Ganzeboom et al. (1992) nevertheless continued the effort to collapse multiple facets of inequality into a single scalar measure, until Hauser and Warren (1997) concluded in their comprehensive appraisal of scales that the failure to decompose the effects of education and earnings renders them analytically deficient and thus, in their words, 'scientifically obsolete' (see also Bukodi et al., 2011).

Others, meanwhile, held fast to the principle that distinguishing bounded classes on the basis of set criteria revealed more than scales ever could. Some classifications were multidimensional, like Erik Olin Wright's (1997) Marxist categorisation of jobs on the basis of property ownership, skill and authority, and some tried not to over-homogenise by homing in on 'micro-classes', like David Grusky and his colleagues (see, e.g. Grusky and Galescu, 2005; Grusky and Weeden, 2001). The leading measure of class in sociology today, however, is the neo-Weberian Erikson-Goldthorpe-Portocarero (EGP) scheme. First devised by John Goldthorpe (1980), who had once flirted with prestige scales (Goldthorpe and Hope, 1974), and honed over the next 30 years of research into social mobility and educational inequality (Erikson and Goldthorpe, 1992; Goldthorpe, 2007a), the EGP schema distinguishes classes on the basis of property possession and employment relations, the latter of which are determined by the 'difficulty of monitoring' and the 'specificity of human capital' associated with different jobs. Effectively, however, the EGP scheme is unidimensional, since its whole premise is to produce a hierarchy of boxes stacked in order of life chances - whether they be in relation to health, educational attainment or social mobility. The explanatory limitations of this schema soon revealed themselves, therefore: in explaining educational inequalities, it transpired that parental education was a crucial factor, not just bare economic constraint or enablement (Bukodi and Goldthorpe, 2018); when it came to lifestyles, it was plain that differences in education level played a fundamental role - much more so than class (Chan and Goldthorpe, 2007a, 2007b, 2010a); and Goldthorpe's $(1982,1995)$ repeated prediction that the 'service class' or 'salariat' at the top of the stack should be conservative in political orientation was frequently belied by research that showed it to be fractured along educational lines, 
with the highly educated professions being more left-liberal in their outlook and the well-heeled but not so well-educated managers being somewhat more conservative (Evans, 1999; Houtman, 2003; see also debates in Clark and Lipset, 2001). On top of that it seems to jar disconcertingly with practical perceptions of social - and even occupational - difference (Filhon et al., 2016).

Some have suggested these limitations spring from the EGP scheme's ill-fit with post-industrial economies where the service sector and educational levels have mushroomed dramatically (Esping-Andersen, 1993; Oesch, 2006), and some have even tried to tweak the EGP scheme to make space for intra-class divisions (Güveli et al., 2007; Kriesi et al., 2008), watering down the original logic of construction in the process. Goldthorpe's response, however, has been to return to the prestige scales he had once rejected and put the differences down to status, defined by patterns of differential association between occupational groups, though in most cases the evidence suggested the key is actually education level (Chan and Goldthorpe, 2004, 2007a, 2007b, 2010a). The goal, it seems, was to defend what he dubbed a 'narrow' definition of class which could be played off of other apparently autonomous forms of stratification in multivariate analysis (cited in Lareau, 2008: 11-12). Perhaps the intention was to stay true to the Weberian spirit, but the definition of status is somewhat non-Weberian (see Flemmen et al., 2019). Why did Chan and Goldthorpe not just directly define it in terms of lifestyle practices, rather than try and find an underpinning causal mechanism (or predictive variable) in the occupational structure, since it is lifestyle that is the causal mechanism of life chances for Weber? And since they ultimately put the differences down to differential 'information processing capacity', best proxied by education and probably only bluntly captured by their occupation scale, why bother with their status measure at all? Still, it might be argued that there is nothing wrong with recognising other factors like education alongside a 'narrow' economistic definition of class, except that Goldthorpe and his allies falsely isolate them, treating them solely as distinct independent variables, and thus obscure the fact that it is their interplay - their variable combination and opposition - that generates tastes, outlooks, evaluations and the sense of one's place in the social order. Taking scholastic and economic indicators apart in multivariate analysis is all fine and good, but only if accompanied by sensitivity to their specific interrelation in constituting the whole, i.e. the system, of which they are elements.

\section{From classes to spaces}

When Bourdieu completed Distinction in 1979, the culmination of not only over a decade of empirical research but years of rethinking class 'from top to bottom' (Bourdieu and Wacquant, 1992: 160), it offered a radically different view of class. Selectively following the lessons of structuralism, class was 
depicted not as a series of parallel scales or a stack of boxes but as a 'field' or space. The properties defining the parameters of this 'social space' attached not to occupations, as they did for Duncan through to Goldthorpe, but to individuals - one does not need to have a job to be in the class structure, thus side-stepping the rancorous debates over the exclusion of women from class analysis, even if occupation often serves as an efficient proxy measure (see Atkinson, 2009). Small differences between individuals matter, moreover - rarely, if ever, do two people occupy exactly the same spot in this social space - but people do cluster together to greater or lesser degrees, meaning it can still make sense to talk of broad 'classes' of people within the social space, and 'fractions' of those classes, so long as one recognises this is merely an analytical shorthand rather than discovery of real social boundaries (Bourdieu, 1987a). Part of the reason for this is that the space is not gradational, structured into notches of income level, education or prestige score as scales are, but Euclidean, defined by the total variance of effective properties - analytically rendered by angle and distance - within the space. ${ }^{2}$ And those properties, or capitals, are broader than just income or education. Economic capital includes income, wealth (savings, shares, dividends, etc.) and property; social capital includes connections with others possessing capital but also membership of groups, organisations or families with some cachet; and then there is cultural capital. Often misunderstood (see Lamont and Lareau, 1988), this latter term refers to symbolic mastery, or ease and familiarity with valued systems of symbols and signs furnishing objects and events in the world with an abstract or transcendental - rather than practical - character, seeing them as examples of such-and-such concept, theme or 'school of thought' (artistic, philosophical, mathematical, etc.), for example (Bourdieu and Passeron, 1990). It manifests in the way one talks and holds oneself (its embodied form), it can be read off the objects and goods one possesses (its objectified form), and it is often proxied by educational level (its institutionalised form) (Bourdieu, 1997), though, since it is nourished in childhood, parental education or social position are also efficient indicators.

Being a space rather than a scale, Bourdieu's image of class is multidimensional, but in a very different manner to the classic Weberian model. ${ }^{3}$ The prime axis is total volume of capital, differentiating three classes - the dominant, intermediate and dominated - on the basis of how much people possess of all three forms. The second axis, often referred to as 'the capital composition principle', opposes those richer, in relative terms, in cultural capital (e.g. artists, intellectuals, teachers) and those richer in economic capital (e.g. industrialists, craftsmen, shopkeepers), splitting each of the classes into multiple fractions. These two axes are so important, argued Bourdieu, because they account for much of the variation in people's fundamental conditions of existence, setting the relative distance from necessity, the 'freedoms and facilities' (Bourdieu, 1984: 177), the possibilities and impossibilities, framing 
everyday experience. This is because, in capitalist social orders, economic capital and cultural capital are the prime forms of symbolic capital, that is to say, the prime forms of value, worth and legitimacy recognised - or rather, since they are ultimately arbitrary, misrecognised - among the populace.

The multidimensional model of class shatters common notions of a 'service class', 'elite' or 'ruling class' being a homogeneous bloc and replaces it with a conception of dominant agents struggling amongst themselves to define and impose which principle of misrecognition should be preeminent the 'dominant principle of domination', in other words (Bourdieu and Wacquant, 1993). Industrialists and private sector executives, on the one hand, and artists and intellectuals, on the other hand, may be united in their advantageous conditions of existence and claims to be 'successful' or worthy beings, but they are distinguished from one another by their mode of domination, distinction and reproduction - mastery of the economy, money and luxury or mastery of knowledge and culture - even if, paradoxically, they not only depend on one another for their self-definition (money/culture, hard/soft, selfish/snowflake, etc.) but together maintain a division of labour of domination in which education and money-making combine in various ways to reproduce and legitimise the structure of the misrecognition order. This is something obscured by the plurality of celebrated accounts of inequality focussing only on economic power and resources, the most famous of which is undoubtedly that offered by Thomas Piketty (2014; see also Atkinson, 2015; Sayer, 2015). Documenting only the properties and mutations of a small sector of the social space, the economically dominant, such accounts certainly have the virtue of making plain that the 'super-rich' or 'super-managers' constitute the dominant sector of the dominant class, and money the dominant principle of misrecognition in capitalist societies, but they obfuscate the full system of relations and differences complicit in the maintenance of domination and denigration.

There is, finally, a third dimension to the social space: trajectory, or shifts in capital stocks over time. Breaking with the static conceptions of class championed by Marxists and Weberians, long ago lambasted by the Cambridge School (Stewart et al., 1980), but also refusing the common practice among defenders of socio-economic scales (see, e.g. Ganzeboom et al., 1992) to control for age and eliminate 'cohort effects' so as to better bring out a correlation between income and education (which thus falsely separates out what are in fact mutually conditioning elements of social position determining condition of existence, sense of place and outlook), this notion builds time directly into the model of class. It incorporates the movements of whole sections of the social space as certain occupations or industries begin to become more or less populous, to pay more or less, and to demand higher or lower educational credentials for entry over time, but it also includes individual movements within the social space, in the form of social mobility and, for some at least, career progression. The relationship between class and age is complicated, 
though: while volume of capital may dovetail with age, or 'seniority within one's class', in certain instances, older age was, said Bourdieu (1984), associated with declining sections of the social space in France - the industries and jobs that were disappearing, becoming redundant and so on - while youth corresponded with the new, rising regions. Bourgeoning education systems in many capitalist societies to fit the swing towards a post- or deindustrialised economic field may mean that the emergent class fractions, and thus the ones disproportionately populated by the young, fall on the cultural side of the social space, though today's business leaders might also tend to rely on the educational system for their position (Bourdieu, 1996a).

\section{States of the space}

Indeed, the rise of cultural capital with the increasing turn towards a service-led, deindustrialised, consumer-oriented economy - and, it should be added, one increasingly incorporating women into the paid workforce - indicates that the structure of social spaces in Western territories was not always thus. Bourdieu himself traced the emergence of the opposition between cultural capital and economic capital back to the end of the nineteenth century, with the advent of a relatively autonomous intellectual field - artists, critics, university professors and so on freed from direct state patronage and religious control - opposed to the field of economic power - the industrialists and merchants - and with it the appearance of a secular cultural capital opposing economic capital (Bourdieu, 1971a, 1993a, 1996b). Only later did the division then creep down to set lower sections of the social space against one another too - the intermediate class for sure, but perhaps even the dominated class.

Before the fin de siècle, Bourdieu hints, the major 'horizontal' antagonism, at least within the dominant class or 'field of power', took different forms (see e.g. Bourdieu and Wacquant, 1993). ${ }^{4}$ The antecedent to cultural capital, later to become subsumed within it, was religious capital, opposing the leaders and the functionaries of the Church to 'temporal' or 'worldly' powers. The latter, for their part, have included economic capital in their midst ever since the commodification of land, labour and money begun centuries ago outlined by Polanyi (1944; see also Atkinson, 2020), but that was not always their dominant form. Feudal relations were, as Georges Duby (1978) showed, characterised by the opposition between the power of the oratores the holders of religious capital - and the bellatores - the families and houses that held dominion and extracted tribute or taxes on the basis of physical capital, or martial skill and numbers of fighters who could be mobilised. ${ }^{5}$ By the time economic capital came to pre-eminence at the temporal pole, however - at different speeds and via different processes in different nations - that physical capital had long since morphed, in a process painstakingly documented by Norbert Elias (2000), into the courtly symbolic capital of honour and reputation based on refined behaviour and titles of nobility. 
Even in the twentieth century, however, social spaces were not everywhere defined by the same principles. The Russian Revolution and the spread of communism, or state socialism, across Eastern Europe after the Second World War produced a series of spaces in which economic capital had been proscribed as a principle of misrecognition (Bourdieu, 1998a: 14-18). The bureaucratic field - that is to say, the field formed by state functionaries-crushed the relative autonomy of the economic field. Cultural capital continued to operate as an effective principle of difference, distinguishing intellectuals who were more or less dissident or complicit (or autonomous or heteronomous, as Bourdieu would say), but it came to be opposed to possession of political capital (cf. Konrad and Szelenyi, 1978; Eyal et al., 2001; Eyal, 2003). This particular species of misrecognition takes the form of connections and position within the ruling party and state machinery, or bureaucratic field, with all the favours and authority it conferred. The fall of communism in the late 1980s and early 1990s, however, re-introduced economic capital as a relatively autonomous differentiator and marked the decline (though not necessarily disappearance) of political capital, though many strove to convert the latter wherever they could. ${ }^{6}$ How far the twin forces of privatisation and democracy may have brought the post-socialist social spaces in line with long-standing capitalist ones, however, remains an open question. ${ }^{7}$

\section{Homologies}

With class reconceived as a multidimensional space, Bourdieu went on to demolish the Weberian opposition between class and status by showing lifestyles to be not a distinct system of stratification but the causal outcome - and thus so many symbols - of class positions. They have a measure of relative autonomy, for sure, since race, gender and other factors can feed into them, but the major explanatory root of styles of life is in the experiences associated with classed conditions of existence, since these furnish us with so many expectations, adapted desires and dispositions - our habitus, in short. Chan and Goldthorpe's causal fudge - of saying lifestyles are determined by status (though they are supposed to be the same thing) even though education and 'information processing capacity' (a rendering of symbolic mastery, perhaps) are the crux - is thus ironed out.

Yet this was not all. The multipolar vision of class also forced a rethink of the enduring question of the relationship between class and political outlooks. For decades hamstrung by binary substantialist thought, the scholarly assumption had long simply been that manual workers - not necessarily because they were the motor of revolutionary overthrow but simply because they wanted to improve their material standing - would homogenously vote for leftist parties offering programmes of economic redistribution and public ownership. Anyone falling into the capacious category of "nonmanual' work, being presumably better off, would - or at least should, from 
a 'rational' point of view - vote for right-leaning parties in order to protect their advantages. Deviation from this pattern, or 'dealignment' of class and political party, would thus demonstrate the weakening hold of class on political outlooks as new divisions and concerns opened up by a globalising world and affluent conditions took hold (see, e.g. Pakulski and Waters, 1996; Clark and Lipset, 2001).

The class/party nexus had long been complicated, however, by a clear link between education, or cultural capital, and degree of liberalism: the more highly educated one is, the more likely one is to hold liberal attitudes towards family values, sexuality, crime and punishment, migration and so on (Lipset, 1960). Even more specifically, it appears that level of education per se is cross-cut by the specific subject studied: arts, humanities and social sciences correspond sharply with liberal views, while business studies, law or medicine do so much less (Bourdieu, 1988; Surridge, 2016). An opposition homologous with the poles of the capitalist field of power, the result is the Nuffield quandary: sections of 'non-manual' workers, or the 'service class', vote for parties offering a more liberal agenda, and those parties may well also lean left on matters of welfare and redistribution. As more and more people attain higher levels of education and a divide between the qualified and the non-qualified creeps down the class structure, moreover, the cross-cutting political cleavage becomes more widespread.

Bourdieu (1984: 397-465) saw things differently. For one thing, voting for a party depends on the degree of fit between the ethos or habitus of the individual, as a practical sense of what is likely to improve their position in some way, and the specific 'line' offered by political parties. At the time Bourdieu was writing Distinction, the major theme was that while leftist parties offered the dominated a clear line on material issues, they stayed silent on 'moral' issues tapping into liberal or anti-liberal sentiments, leaving the dominated unconfident in expressing their ethos. Nevertheless, the relationship between cultural capital and liberal values, on the one hand, and economic capital and materialist issues, on the other hand, maps into the social space in a very particular way, and the tendency to vote left or right follows not a lower/high class binary but a rough curve through the social space (Bourdieu, 1998a: 5). Those lower in economic capital and higher in cultural capital vote for liberal-left parties - albeit for different reasons - while those lower in cultural capital and high in economic capital vote for right-wing conservative parties, the one largely for socially conservative reasons and the other out of economically conservative interests.

\section{After Bourdieu}

Bourdieu (1984: xi) himself acknowledged that the fruits of his labour represented only a 'particular case of the possible', and called for others to determine not only the signs and symbols expressing economic and social 
differences elsewhere but the varied 'scale and structure' of those very differences. Yet most researchers keen to mine Distinction for hypotheses to test in their own nations have concentrated on the relationship between class and lifestyles, the runaway train of scholarship generating the 'omnivore' thesis - i.e. the proposition that those rich in cultural capital are characterised by broad and varied tastes - probably being the most renowned result. The spatialisation of class underpinning Bourdieu's magnum opus was either ignored altogether or quickly dismissed, even by those apparently sympathetic to Bourdieu's vision. Some mobilised the old scales of education, income and prestige instead, for example (e.g. Bryson, 1996). Peterson and Simkus (1992), in the very paper giving birth to the omnivore thesis, deployed an a priori categorisation of occupations centred on position in the system of cultural production. Chan and Goldthorpe (2010a), unsurprisingly, stuck with the EGP scheme and their favoured status scale, though not before mistakenly claiming the capital composition principle to be essentially a concession to the Weberian separation of class and status (Chan and Goldthorpe, 2010b). Even those more well-disposed towards Bourdieu's conceptual tools and techniques, such as Bennett et al. (2009) in the UK, spurned it, opting instead to work with an adjusted version of the EGP scheme - the categories of which they called 'classes' - alongside education as if the latter was not part and parcel of class (see also Le Roux et al., 2008). Also creeping into this last study, but taken further by the team behind the later 'Great British Class Survey' (Savage et al., 2013, 2015), was the common mistake of taking lifestyles as directly constitutive of class, rendering impossible any causal analysis or empirical assessment of homology strength (see further Atkinson, 2017).

The neglect is not total, however. In select corners of Europe there have been some determined efforts to chart social spaces using appropriates methods, with Prieur et al. (2008) and Rosenlund (2009, 2015) leading the way (see also Schmitz et al., 2017; Flemmen et al., 2018, 2019). In both cases, dealing with Denmark and Norway respectively, Bourdieu's model was found to be in full effect, despite obvious political-cultural differences with France and the considerable time lag: volume of capital is certainly the primary dimension of social difference, but capital composition is also a crucial factor distinguishing places in the misrecognition order. Others have since followed suit, but with some added peculiarities. Melldahl and Borjesson (2015), for example, constructed the Swedish social space using data from the 1990 census for that country, though their decision to include gender as an active ingredient in their analysis subordinated capital composition to the division between men and women in the ranking of axes. More recently, de Keere (2018) generated a plot of the Flemish social space akin to that found in France, Denmark and Norway, though his decision to include indicators of consumption risked conflating it with the lifestyle space and the insertion as an active variable of a pre-existing class scheme modified to distinguish capital composition risked tautology (cf. Flemmen et al., 2019; 
Jarness et al., 2019). Similarly, Jodkha et al. (2018) seemed - technical details were rather sketchy in this case - to include indicators of attitudes and orientations alongside measures of capital in their construction of the German and Laotian social spaces, entangling the class structure with the dispositions and schemes of perception - the space of habitus or of dispositions, as Bourdieu (1984: 126; 1998a: 7) put it - it generates, thereby potentially undermining the causal model of class and practice set out in Distinction (Bourdieu, 1984: 172) and, on a technical level, perhaps distorting the map of classes by introducing variables of a different species with a disproportionate differentiating power. ${ }^{8}$ Cvetičanin et al. (2012), finally, built a map of the social space in Serbia, though following their suspicion that social connections and party membership are more significant in post-socialist social orders than elsewhere they included extra indicators of social and political capital for good measure (see also Cvetičanin and Popescu, 2011). This had the effect of complicating the capital composition axis by opposing those rich in cultural capital and with high incomes to those possessing both extensive social capital and considerable amounts of wealth and property.

Needless to say, with social spaces charted, the homology between capital holdings and lifestyles was thrown into sharp relief, revealing differences by capital volume and capital composition where others would only see an omnivore-univore divide (esp. in Prieur et al., 2008; Rosenlund, 2009; Flemmen et al., 2017a, 2018, 2019; see also Lebaron and Le Roux, 2015). The move also, however, poured further light on the puzzle of political attitudes, lucidly confirming that the tendency to incline rightwards on materialist politics (taxation, property ownership, industrial disputes) increases with possession of economic capital at the same time as degree of liberalism on moral matters (sexuality, family values, etc.), as well as on so-called postmaterialist issues (environmentalism, nuclear weapons, national identity, etc.), which often pushes one leftwards in a two-party political system, increases with possession of cultural capital (Rosenlund, 2009; Harrits et al., 2010; Flemmen, 2014; Flemmen and Haakestad, 2018; though cf. Jarness et al., 2019; see also Chiche et al., 2000; de Keere, 2018). It really is not a question of class versus education, or status, in other words, but of a homology of political stances with capital volume and capital composition - i.e. class in both cases. The mediating factor is the habitus, or the sense of desirable and possible means to conserve or improve one's position in the social space, with the relationship between cultural capital and family values, for example, implicating the different familial reproduction strategies between classes.

\section{Unresolved questions}

Encouraged by these endeavours, a project was recently undertaken to construct models of the social space, lifestyle space and space of political position-takings in the UK (Atkinson and Rosenlund, 2014; Atkinson, 2017). 
Exploiting a wide range of existing surveys and reanalysing Bennett et al.'s (2009) data, it unearthed more or less the same key axes of the social space as in 1970s France and contemporary Denmark and Norway and discovered the familiar homologies with lifestyles and political attitudes, though on the latter the recent liberal turn of the once leftist UK Labour Party had generated significant disconnect between the dominated class and party politics. As in Denmark and Norway, something Bourdieu himself somewhat overlooked (see Saint-Martin, 2015) also transpired: the social space was found to be profoundly gendered, even without sex being mobilised as an active variable in the statistical analyses. Women tend to be richer in cultural than economic capital, from top to bottom of the social space, while men are the opposite.

Yet there was also a difference. The capital volume axis was much more pronounced in the UK than in Denmark or Norway, and the capital composition principle less so. When the positioning of individuals was examined on the axes, the dominated appeared to be more homogenous (i.e. less dispersed) in terms of capital composition than the intermediate or dominant zones of the social space, lending a rough inverted-triangle shape to the class structure. There was dispersion enough to differentiate class fractions at the bottom, for sure - there was more spread than Bourdieu (1984) seemed to find in France - but it was nothing like as even as in the Nordic countries. The question is then raised of whether this reflects structural differences between nations which might have wider significance - could it be to do with degrees of economic inequality, of accessibility of education, of rates of post-industrialisation, of contrasting welfare regimes, and so on? What might be the consequences for habitus and homologies if so? Or could it be down to something else, such as methodological differences - the fact that the original Norway and Denmark studies were based on samples drawn from single cities, for example, rather than across the respective nations, or differences in variables used, such as their reliance on ownership of cars, boats and summer houses as measures of economic capital? ${ }^{9}$

Cécile Brousse (2017) has recently tackled some of these questions via large-scale comparative statistical analysis and suggested, on the basis of her results, that the capital composition principle is indeed more prominent in some countries, particularly Nordic ones, than others, especially post-socialist ones. As useful a starting point as this is, however, the findings are confined to Europe alone, leaving the transposability of Bourdieu's model to some of the most powerful economies of the world, like the US or Japan, a mystery. They are, moreover, the product of a manipulation of a limited range of rudimentary variables - a pre-existing occupational measure, household income and years of schooling - which may hide as much as it uncovers. It could be, for example, that income and years of schooling are highly correlated, giving the impression that capital composition matters little, when other elements of the capitals in question - inherited cultural 
capital, economic wealth, etc. - would be more starkly opposed. ${ }^{10}$ Finally, having already achieved a considerable feat for a single article, Brousse opts not to check the homology of positions and position-takings and thus adjudicate whether the presence and strength of the capital composition principle actually matters.

All this leaves us with three outstanding queries. First, is the general structure of social space as charted in Distinction, as Bourdieu postulated and as the Nordic and UK studies suggest, a universal feature of capitalist nations old and new (cf. Flemmen, 2013)? It may well be reasonably conjectured that volume of capital will inevitably emerge from any statistical analysis as a differentiator or conditions of existence, but the supporting role of capital composition - of the opposition of economic capital and cultural capital, that is - is by no means given. It could be, for example, that volume of capital is effectively exhaustive of differentiation in some instances, or that it is cross-cut by a polarity of high-low economic capital that is not inversely related to cultural capital (or vice versa). If capital composition is consistently confirmed as a major principle of difference alongside capital volume, then the second question is this: are there any systematic variations within that template which might be linked to differences in economic policy - whether related to redistribution, training or industry - between countries, forged as it is in divergent national fields of power? Does capital composition set sections of the social space off against one another from top to bottom of the social space, or is it more localised to certain regions? Additionally, however, there may be discrepancies in the relationship between capital composition and occupational structures, regions, gender, age and social mobility, the last two of these inevitably broaching the matter of whether capitalist social spaces have been following similar trajectories or going in their own directions. And finally, does the principle of correspondence between social positions and position-takings hold across social orders, whatever the national variations in social spaces?

Evidently the only way to begin to answer these questions is to engage in systematic cross-national comparative analysis, situating the existing studies in a wider context by constructing models of social spaces for a range of nations using as similar variables as possible and examining their respective homologies and effects. This, then, is precisely what I aim to do in what follows. The orientation is, in line with the applied rationalist epistemology advocated by Bourdieu et al. (1991), largely deductive, starting with a logical construction of the object generating hypotheses, or questions, to be explored. In this case, as in the research on Britain, we operate with the well-founded premise that the major principles of misrecognition in capitalist social orders with relatively expansive multi-tier education systems will be broadly the same and proxied in a consistent manner by standardised indicators, even if the histories and substance of those principles - relating to different national canons, languages, economies, etc. - vary from country 
to country. The major hypotheses springing from this construction, as we have seen, relate to the nature, localisation and causal effects of the capital composition principle across capitalist nations old and new, big and small, rich and poor.

\section{The path ahead}

The process by which the guiding hypotheses of the research are to be investigated is laid out in the next chapter. There the reader is introduced to the data source, the nations studied, the variables used and their manipulation and, finally, the specific technique deployed. As in other studies of national social spaces the tools of geometric data analysis have been mobilised, but I also break with convention by using categorical principal components analysis as the foundation stone rather than multiple correspondence analysis - a move that will require some elaboration and justification. Some readers uninterested in technical details and debates might want to skim or skip parts of this chapter, though I do endeavour to provide an accessible overview of the methods so as to facilitate interpretation of the results. Once these preliminaries have been laid out, Chapter 3 provides the basis for all else by detailing the models of social spaces for 23 nations. Here we will see their major axes, the distributions of individuals and the extent to which they confirm or confute the starting conjectures.

In the first of the chapters examining homologies, Chapter 4 looks at the correspondence between the axes of the social space, as derived from the statistical models, and occupational groupings. The purpose is to examine the degree to which the oppositions within the division of labour of domination resemble those discovered elsewhere, and in particular whether the opposition within the field of power between contemporary 'spiritual' and 'temporal' powers takes similar forms across nations. Chapter 5 then examines the intersections and homologies of the social space with other principles of vision and division that Bourdieu either misleadingly described as 'secondary' in Distinction or side-lined altogether. These are gender, religious creed and geographical space, the latter covering both the urban/rural opposition and the capital/provinces polarity. Chapter 6 tackles the question of trajectory, partly by examining the stark distribution of the generations across social space models but also by taking a closer look at specific patterns of social mobility emerging from the spaces.

Chapter 7 begins to determine the relationship between positions and position-takings and, with that, broach the nature of different ethos or habitus attached to different locations. The specificity of the data source means there are limitations on what can be examined in this regard - we cannot, for example, delve into the relationship between the social space and the space of lifestyles. We can, however, investigate something fundamental to not only the Bourdieusian model of class but every tradition of class analysis 
down the ages: political position-takings. Specifically, and with the contemporary rise of the populist far-right supplying the major context, the chapter will map the correspondence between the social space and political parties but also, taking up a specific thesis from Bourdieu's work, the old left/ right opposition on matters of economic redistribution and social welfare. Chapter 8, finally, explores what Bourdieu called 'class sense' and 'symbolic violence' by charting the regularities in people's perceptions of their place in the whole, their views on the underlying reasons for people's social position and their sense of in/justice. The Conclusion brings together the findings to adjudicate, with appropriate caveats, the degree to which the class structures of capitalist societies appear to vary, but also discusses what remains to be done in the quest to document the features, effects and experience of class across the globe.

\section{Notes}

1 See Saint-Martin (2015) and Bourdieu and Delsaut (2002).

2 It is, at the same time, Leibnizian, insofar as Leibniz - a figure looming large in Bourdieu's corpus - postulated that space exists only as a relation between actual objects (see Pinto, 2015). Without objects - in this case members of a social order - there is no space.

3 It should also be distinguished from Pitirim Sorokin's (1927) early spatial vision of stratification, in which horizontal difference is defined by membership of different groups (organisations, nations, religions) and vertical difference defined by function or location on scales of prestige and economic standing.

4 I put 'amongst the dominant' because while there must have been a degree of mutual orientation and struggle within territorial fields of power for centuries, growing and shrinking with different conquests and defeats, for most people those working the land or populating the small urban centres - social differences and struggles were much more localised, albeit shaped by the trans-regional struggles of the dominant class. The integration of local misrecognition orders into national social spaces only took place with processes of state building and the unification of economic and cultural markets they brought (Bourdieu, 2004, 2014).

5 As Emile Benveniste made clear, the opposition of religious/spiritual authority and physical/martial authority, being rooted in the most basic features of human beings (symbol use and corporeality), can be traced back to the earliest civilisations and underpinned not only feudal relations but also the Indian caste system, with its opposition between Brahmin (the dominant dominant) and the Kshatriyas (the dominated dominant) and tightly controlled system of reproduction.

6 See the special issue of Theory and Society on 'Circulation vs. Reproduction of Elites during the Postcommunist Transformation of Eastern Europe', Vol. 24, No. 5, with a lead paper by Szelenyi and Szelenyi (1995), and Pop (2018).

7 The Nuffield school, for their part, have simply assumed that the EGP scheme can be applied to post-socialist states with only a slight modification: separation of an agricultural fraction within the working class to capture the swathes of the workforce still involved in farming (see Breen, 2004; also Domanski, 2000).

8 This is further complicated by the fact that Jodhka et al. (2018) do go on to map a specific space of habitus in Germany. 
9 That variable choice can make a substantial difference is suggested by the fact that the models of Norway's social space presented by Flemmen et al. (2018) and Flemmen et al. (2019) appear to differ by only one variable (an occupation-based one), but the capital composition principle is much more pronounced, statistically speaking, in one than it is in the other.

10 This problem also characterises Hugrée et al.'s (2011) effort to construct a social space and scheme of classes at the European level. Lacking anything in their chosen datasets other than the basic measures of economic and cultural capital, which are closely correlated, they depend on indicators of working conditions to flesh out the model. Unsurprisingly, capital composition is absent and replaced by a secondary principle of difference based on the degree of independence and autonomy in employment - an interesting finding in itself but not actually a model of the social space sensu stricto. 


\section{Chapter 2}

\section{Constructing the spaces}

There is no direct access to reality or Archimedean point from which to view the workings of the social world. As Bourdieu had it, the notion of social space is nothing more than a heuristic model, that is to say, a construct of the object under investigation, mediated by language and symbols and devised for analytical purposes. Hard won against the illusions of common sense focussing on the substance of things - with this or that property said to assign someone to a fixed class definitively - its purpose is to render the relations of difference, of direction and distance, that differentiate observed conditions of life and perceptions of place. Yet it is only ever an approximation of reality, open to the possibility of revision in light of evidence and reasoned argumentation. Scientific endeavour is, as Bachelard demonstrated and Bourdieu elaborated, progressive in the sense that its particular conditions of practice operate to not only confirm constructions of the world, when they fit empirical observation and logical analysis, but also identify and eliminate intellectual errors and make our models 'less wrong', even if it typically unfolds via the accumulation of anomalies and limitations forcing a radical rethinking of conceptual tools. Pristine truth, however, is a telos that will never be reached, an unattainable goal or ideal the pursuit of which nevertheless encourages and allows us to get closer to it.

The construction of the object is an approximation of reality that can itself be approximated to varying degrees by available instruments of measurement and methods. A statistical map of a specific social structure like the social space is, in other words, a second-order approximation. The size and quality of a sample, but also the specific number and combination of variables, with their own inner logic (e.g. number and spread of categories), will yield a model situated along a continuum structured by the polarity of loose/broad/vague and firm/refined/detailed. The former pole is not to be discounted altogether - models towards this end can still reveal something of the social structure studied so long as one is fully aware and open about the gaps and possibilities - and the opposition is cross-cut by a second continuum of degree of distortion based on the (un)suitability or (in)appropriateness of specific variables and techniques to the model of reality in 
question (e.g. the use of lifestyle variables to define the model of social space or dependence on linear statistical techniques). It is imperative, therefore, that we make clear in what way and to what extent we expect the following analyses to render, and thus confirm or modify, the guiding heuristic model of the typical capitalist social space by outlining the data sources, the variables, the specific techniques and the orientations and procedural operations in play.

\section{Data source and nations studied}

The data derives from the 2009 'Social Inequality IV' module of the International Social Survey Programme (ISSP), a suite of questions embedded in various national surveys. This was an auspicious time to conduct a survey on social inequality given that the imprint of the global economic crisis of the first decade of the millennium was being firmly stamped on many social orders (see, e.g. Sánchez-Mira and O’Reilly, 2019). Capitalist social spaces are, however, systems of considerable institutionalisation, which is to say that the mechanisms involved in defining and maintaining the value of the core capitals over time, most of them controlled or overseen by the state, are highly codified and regulated by a large body of agents (Bourdieu, 1990). They operate, therefore, to ensure that the general structure of the social space remains relatively stable through recession, and there is, in fact, everything to suggest that the effects of economic crisis - unemployment, pay cuts, inflation and so on - are filtered through the existing topology of the social space such that contrasting segments are typically impacted at different rates and in different ways (Atkinson, 2012, 2013). Crisis may well alter the substance attached to social positions and even modify some of the distances between them, but there is every reason to suppose that the overall relational configuration of difference remained steady through the financial cataclysm that defined the start of the twenty-first century. Similarly, it is posited that the structures mapped out in the analyses to come can still act as a rough guide to social topology ten years later, though of course it may vary by country depending on their specific political response and trajectory of economic mutation. A fresh round of the Social Inequality module is due to appear imminently at the time of writing, so it would be a worthwhile hypothesis to explore.

All the national samples within the ISSP are designed to be representative of the adult population, though variation in sample size means that some results require greater caution in their interpretation than others. ${ }^{1}$ Thirty-nine countries are included in the module, but not all of them delivered the relevant questions. Some have had to be omitted from analysis, therefore, among them several South American nations and the one African country taking part in the survey. There is, as a consequence, a regrettable bias towards the global North in what follows. China has also been excluded as a case apart, 
while several samples for European nations have been set aside on technical grounds, leaving a total of 23 countries under the sociological microscope. ${ }^{2}$ The Belgian sample, however, covers only Flanders and a small contingent from (majority French) Brussels, so it will be more accurately described as the Flemish case. This does, of course, mean that the results of all analyses for this sample have to be handled with extra care - the model produced will be an even more partial and distorted approximation than others, bearing on only the densely populated and highly urbanised and industrialised North of the country and thus missing the structuring of the national social space by the Flemish/Walloon opposition, but the appearance or not of the expected dimensions in the space will still be informative.

Unlike traditional class theory, in which variations in class structures are reducible to the numbers of people in, and the rise and fall of, different types of occupations and industries (see Myles and Turegun, 1994), what really matter in cross-national comparison of capitalist social spaces are the mechanisms broadly defining economic and educational disparities, of which occupational shifts and sectorial change are simply elements. When it comes, therefore, to anticipating the possible principles of variation between the nations investigated - what factors may intensify or augment specific oppositions, that is - a broad guiding hypothesis is that degree of economic inequality, measured however partially by such indices as the Gini coefficient, and exclusivity of education, especially tertiary education, are likely to play a part. Some indicators of these, alongside general gauges of global standing like gross domestic product (GDP) and sectorial composition, are provided in Table 2.1 for the 23 analysed countries. Among the longstanding capitalist social orders there is an opposition on economic inequality between the egalitarian Nordic nations and rather more polarised Israel and the US, ${ }^{3}$ and an opposition regarding average years of education - modest as it might generally be - between the Nordic nations, France, the US and Australia, on the one hand, and Germany (where technical vocational education is highly prized), Italy and Austria, on the other hand. The Nordic nations and the US also tend to have the largest workforces in the service sector and in professional-managerial roles, and Austria, Italy and the East Asian social orders - the last of these, especially in the cases of South Korea and Taiwan, transforming rapidly from relatively penurious agrarian societies into manufacturing powerhouses through the second half of the twentieth century - the smallest.

The post-socialist nations include the Western-facing Visegrád countries of Poland, the Czech Republic and the Slovak Republic; the Baltic states of Estonia and Latvia; and Russia. Each has travelled its own path since subjection to 'the strong blast of modern capitalistic competition', to borrow a phrase from Weber (1991: 366), resulting in divergent industrial compositions, income disparities and educational provision in the survey year. The once-united Czech and Slovak Republics, for example, are, on the surface, 
Table 2.I Some features of the countries studied

\begin{tabular}{|c|c|c|c|c|c|c|}
\hline Country (Code) & $\begin{array}{l}\text { Gini } \\
\text { coefficient } \\
(2008 / 9)^{a}\end{array}$ & $\begin{array}{l}\text { Service } \\
\text { sector } \\
\text { employment } \\
(\%)(2009)^{a}\end{array}$ & $\begin{array}{l}\text { Average } \\
\text { years of } \\
\text { education }^{b}\end{array}$ & $\begin{array}{l}\text { GDP } \\
\text { world } \\
\text { rank } \\
(2009)^{a}\end{array}$ & $\begin{array}{l}\text { Share of } \\
\text { workforce in } \\
\text { professional/ } \\
\text { managerial } \\
\text { positions (\%)c }\end{array}$ & $\begin{array}{l}\text { Rate of } \\
\text { urbanisation } \\
(\%)^{a}\end{array}$ \\
\hline Australia (AU) & 0.36 & 68 & 12.9 & 13 & 16 & 85 \\
\hline Austria (AT) & 0.32 & 70 & 11.3 & 24 & II & 58 \\
\hline Belgium (BE-FL) & 0.29 & 75 & 12.3 & 19 & 19 & 98 \\
\hline Czech Republic (CZ) & 0.26 & 58 & 12.4 & 39 & 10 & 73 \\
\hline Denmark (DK) & 0.29 & 77 & 12.9 & 29 & 23 & 87 \\
\hline Estonia (EE) & 0.32 & 64 & 12.8 & 99 & 28 & 68 \\
\hline France (FR) & 0.33 & 74 & 13.8 & 5 & 18 & 78 \\
\hline Germany (DE) & 0.32 & 70 & 11.0 & 4 & 14 & 77 \\
\hline Iceland (IS) & 0.29 & 75 & 14.2 & 108 & 26 & 94 \\
\hline Israel (IL) & 0.36 & 77 & 12.9 & 38 & 20 & 92 \\
\hline Italy (IT) & 0.34 & 67 & II.I & 7 & II & 68 \\
\hline Japan (JP) & 0.32 & 69 & 12.8 & 3 & 6 & 90 \\
\hline Latvia (LV) & 0.35 & 67 & 12.5 & 89 & 16 & 68 \\
\hline New Zealand (NZ) & 0.35 & 72 & 14.2 & 50 & 24 & 86 \\
\hline Norway (NO) & 0.26 & 77 & 14.6 & 25 & 28 & 79 \\
\hline Poland (PL) & 0.34 & 56 & 11.9 & 20 & 16 & 61 \\
\hline Russia (RÚ) & 0.40 & 64 & 11.9 & 12 & 20 & 74 \\
\hline Slovak Republic (SK) & 0.26 & 58 & 12.3 & 61 & 7 & 55 \\
\hline South Korea (KR) & 0.31 & 69 & 12.7 & 14 & 6 & 82 \\
\hline Sweden (SE) & 0.27 & 78 & 12.6 & 21 & 20 & 85 \\
\hline Switzerland $(\mathrm{CH})$ & 0.33 & 7I & 11.6 & 18 & 17 & 74 \\
\hline Taiwan $(T W)^{d}$ & 0.34 & 59 & 11.6 & 22 & 8 & 79 \\
\hline US (US) & 0.41 & 81 & 13.6 & I & 26 & 81 \\
\hline
\end{tabular}

a Source: World Bank database (http://data.worldbank.org).

b Source: ISSP 2009.

c Source: World Bank database (http://data.worldbank.org). Refers to the share of the working population.

d Data on Gini, GDP, the service sector and urbanisation for Taiwan are not available from the World Bank and are instead drawn from the CIA World Factbook (https://www.cia.gov/library/publications/ the-world-factbook/geos/tw.html) in the case of the Gini coefficient, GDP rank (for 20/4) and urbanisation and the Taiwan Statistical Bureau for the size of the service sector (http://eng.stat.gov. $\mathrm{tw} / \mathrm{ct}$.asp? $\mathrm{xltem}=|2683 \& \mathrm{ctNode}=| 609 \& \mathrm{mp}=5)$.

the least unequal, at least in terms of conventional measures of income distribution, while Russia scores a high Gini coefficient compared to the global trend, yet the GDP of Russia outstrips its former satellites by some margin. All the Eastern European nations, however, tend to have smaller service sectors than mature capitalist countries, even if they comprise the bulk of economic activity, on account of not only large manufacturing sectors but also (especially in Poland) relatively large agricultural sectors. Hence the relatively low rates of urbanisation in these samples. This is in the process of change, for sure: data from the World Bank clearly indicate that employment in manufacturing and agriculture declined and employment in services 
increased across Eastern Europe by between 10 and 20 percentage points for both men and women from 1991 up to and after 2009, with the 1990s being the main period of change, and this has gone hand-in-hand with expansion and diversification of the higher education system (on Russia, Latvia and Estonia, see contributions to Huisman et al., 2018). Nevertheless, sectorial composition is still notably different from the other nations in the study.

Without entering into the details of competing typologies of social orders - as representing different 'welfare regimes' or 'varieties of capitalism' - or pretending to put forward a new one, the patterns can be attributed to several core principles of difference. The first is degree of state regulation of the market, which is equivalent to the degree of autonomy accorded to the economic field, in the form of remuneration policy (minimum wages, salary caps, etc.) and corporation and capital taxes, and the scale of welfare provision, or the size of the 'left hand of the state' in Bourdieu's (1998b) terms, particularly in the form of social assistance payments (tax credits, income support, etc.). The polarity here is between liberal social orders and more socialistic, or social democratic, ones. The second, crosscutting principle is the relative size and differentiation of the national educational field (cf. Bourdieu and Wacquant, 1993: 24), which goes hand-in-hand with the occupational and industrial constitution of the social order. Both factors implicate the size and power of the state, or bureaucratic field, within the national field of power, as well as the internal struggles of those two spaces, but both are also linked to positioning within the global division of labour. More accurately, since national specialisations (knowledge production, technical prowess, manufacturing or agriculture) and the occupational structures and skill distributions they involve are rooted in differential tax bases and power imbalances in trade relations, we would say that they are shaped by (and shape) location within a global field or, more precisely, a 'space of states'- a field in which nation states are situated and struggle for position depending on their possession of economic, cultural and military capitals recognised by all players (Go, 2008; Schmitz and Witte, 2020; Atkinson, 2020).

Comparative sociology, like all domains of social life, has long been riven by an internal opposition. In this instance the antagonism is between advocates of 'variable-oriented' approaches, tracing their lineage from Durkheim to structuralism, and 'case-oriented' approaches rooted in Weberian principles (for discussions see Ragin and Zaret, 1983; Ragin, 1991, 2014; Crompton, 2006: 24-6; Goldthorpe, 2007b: chap. 3). If the former seek to replace country names with variable names (e.g. GDP) so as to abstract from national specificities, test the extrapolation of theories, identify similarities or regularities across social orders and maximise the number of analysed cases to that end, then the latter focus on the specific histories and structures of a small number of purposively selected nations to discover principles of difference and build explanations inductively. From the perspective outlined above, however, it becomes clear that the polarisation 
is overdrawn, and potentially operates as an epistemological obstacle to analysis. For while national social orders can logically be taken as specific 'cases' on the basis of their relatively autonomous fields of power, we cannot dismiss recourse to variables such as GDP, Gini coefficients and sectorial composition as general indicators of the broad classes of conditions of possibility for action within fields of power vis-à-vis the structure of social space given by location within the global field. Nor, for that matter, can we do away with the nation state - or more precisely, the national field of power and its attendant social space - as a unit of analysis, as those advocating 'methodological cosmopolitanism' would urge (Beck and Sznaider, 2006), even if we do have to acknowledge its position within the global field and the internal or border-spanning practices and processes that might spur (cf. Breen and Rottman, 1998).

All in all, therefore, the two approaches - focussing on specific case studies or systematic regularities based on indicators of states' capital - are complementary once situated within a unifying framework and might even form a continuum along which specific studies can situate themselves depending on their task at hand. The current enquiry sits at neither extremity of the scale but is undoubtedly closer in orientation to the so-called variable-oriented approach. It does not banish county names in favour of generic indicators, true enough, but it endeavours to test the applicability of Bourdieu's model beyond the Gallic site of origin across a variety of nations, to be concerned primarily with systematic tendencies and differences linked to broad socio-political divergences and to avoid getting too hung up on the aberrant deviations of individual country samples on this or that theme.

There is one more corollary of the existence of a space of nation states defined by differences in holdings of economic, cultural and other resources to make plain: the global hierarchy of social spaces. Even if social spaces across the world are found to be structured according to the same principles as 1970s France, i.e. by volume and composition of capital, that does not mean that those occupying homologous positions enjoy the same absolute conditions of existence. The dominant in one country, for example, are defined as dominant relative to others within the same national social order, but their pay, assets and level of education may typically be substantially lower than those in equivalent positions in other countries. As Hugrée et al. (2011) have documented, the dominant classes - as they define them in Eastern and Southern Europe experience conditions of existence setting them apart from the intermediate and dominated classes in their respective countries, but looking across the continent it becomes clear that those conditions are comparable with or worse than the conditions of existence enjoyed by the intermediate and even, in some respects, dominated classes in the richer countries of the West and North. Insofar as the agents in the different social spaces are mutually aware of these cross-national differences which, given the integrative project of the European Union, is perhaps more 
likely across the Old Continent than in other regions - that can have specific effects on their sense of place and their strategies. Since our data source does not contain appropriate measures for equivalating economic capital across nations we cannot directly construct a model of the global hierarchy of social spaces, but we can infer from the data in Table 2.1 and comparison of some capital indicators just how the nations differ from one another and perhaps, therefore, the different meanings attached to the corresponding positions across social orders.

\section{The indicators of capital}

The ISSP module harvested information on, inter alia, household income, savings and home ownership/value, individual education level, mother's and father's occupations and number of books in the parental household when the respondent was in their mid-teens. These are, without a doubt, major indicators of economic, cultural and social capital, and thus determinants of conditions of existence, within contemporary capitalist social orders and offer the opportunity for constructing relatively balanced - i.e. less distorted - models of social spaces (see Rosenlund, 2015). Further measures - of institution or discipline of academic study, of parental and partner's education, of possession of stocks and shares or current book ownership and so on - would have been desirable, undoubtedly, as they would produce more detailed and nuanced results. What we have is certainly sufficient, however, being comparable with existing studies of social spaces once stripped of questionable variables, and compensated by its availability across an extensive selection of nations. ${ }^{4}$ It might even be argued that since the variables are core and comparable measures of capital possession rather than indicators of nation-specific modulations, facilitating comparison on a like-for-like basis, the resultant solutions will give a clearer view of shared baseline structural features. Yet we have to content ourselves with 'skeletal' models, towards the broader/looser end of the spectrum of second-order approximations, much as the palaeontologist conjectures the anatomy and physiology of dinosaurs from ossified remains aware that further analyses of skin and feather imprints, for example - may confirm or revise them.

The measures of economic capital - home ownership and value, value of savings and household income (monthly or yearly depending on the country) - are all recorded in domestic currencies. They are dogged by missing data: frequently between 20 and 30 percent of the samples give no response to one or more of the questions, the figure generally being higher in Southern and Eastern European samples and lower in East Asian and Nordic ones. Inspection of the characteristics of individuals with missing data indicates that it is not entirely random, but more likely to be attached to lower-educated older and younger manual workers. In any case, missing data is treated as passive in the models produced, but individuals with 
missing data across all indicators of economic capital - generally rare - have been excluded from analysis altogether.

In relation to cultural capital, the most direct measure - though not necessarily the most distinguishing - is highest educational qualification attained. This was initially recorded using each nation's system of qualifications, but a standardised cross-national measure of education has also been computed by the ISSP team. After comparison of the two measures, the standardised variable was deemed more satisfactory in terms of parity of sample distribution across categories and is certainly more expedient for model construction and comparative analysis. ${ }^{5}$ It distinguishes those with no qualifications, those with the lowest national qualifications, those with qualifications above the lowest but not equivalent to having completed higher secondary schooling, those having completed higher secondary schooling, those with non-university qualifications above secondary level (such as various diplomas and college-level credentials) and those with university degrees. A second measure of cultural capital, tapping specifically into inherited cultural capital, is the number of books in the family home when the respondent was in their mid-teens. Of course this is a very rough measure - we do not know what kind of books they were or how they were displayed and used - but it still gives at least some indication of the kind of milieu in which the respondents were immersed and the likelihood of building symbolic mastery.

Indicators of parental (both father's and mother's) occupations when the respondent was $13-15$ years old are also available at a highly disaggregated level. These were first coded into a slightly modified two-digit version of the International Labour Organization's (ILO) 1988 edition of the International Standard Classification of Occupations (ISCO), which was then aggregated into three categories: professionals and corporate managers, presumed to have been relatively rich in capital; various technical, administrative and associate-professional occupations, as well as managers of small enterprises, treated as intermediate in their capital possession; and manual, skilled and personal service workers typically associated with low levels. ${ }^{6}$ There is also a category in each case for those who did not work when the respondent was a teenager.

Examination of the composition of the categories revealed that, no matter the nation, mothers in the dominant class tended to work most often as teachers, i.e. occupations requiring higher levels of education, such that this measure is likely to function as another rough indicator of inherited cultural capital (parental education was not recorded). In some nations, however, particularly where female employment is not particularly high, there were very few mothers in the dominant class at all. Fathers in the dominant class were more likely to be found in corporate management than mothers, suggesting some degree of inherited economic capital, or perhaps social capital in the form of mediated access to economic resources, though fathers were 
frequently to be found in cultural-capital-rich positions too, and so the category might also be taken to signal inherited and proxy cultural capital. Nevertheless, the distributions of mothers and fathers across occupations and classes are dissimilar enough to indicate that they are not measuring the same thing and are worth keeping as distinct variables. There is no escaping the fact, however, that having three variables of inherited cultural capital and only one of acquired cultural capital is likely to boost the relative importance of the former and push the conjoined issues of trajectory and reproduction to the forefront. The degree to which that matters is for future research with alternative datasets to tell.

\section{Geometric data analysis}

The movement of scientific thought is, as Bachelard established, intimately bound up with the development of specific instruments and techniques of observation and measurement. Theory and method, or construct and practice, are not, in other words, distinct and unrelated elements of the scientific process but always and inevitably mutually constitutive. Without going as far as the radical postmodern or actor-network reading of Bachelard which posits that certain core ideas are only possible with the invention of specific apparatuses, certain tools and operations - from microscopes and telescopes to specific statistical manipulations - undoubtedly facilitate and sharpen conceptualisations of the world and establish the faults of others. Bachelard thus called them 'phenomeno-techniques' as a means of rendering the inescapable reciprocal conditioning of perception and method.

The history of sociological research on class is no different. To put it bluntly, transformations and revolutions in the definition and operationalisation of the very concept of class have gone hand-in-hand with adoption of specific methodologies and techniques of observation. The qualitative/ quantitative split is germane here, especially as it manifests in the opposition between the early ethnographic 'community studies' working with loose anthropological understandings of class based on shared culture and ways of life, like those of W. Lloyd Warner in the US or Young and Wilmott (1962) in the UK, and the pioneering statistical analyses, like those of Lipset or Otis Dudley Duncan, looking for hard-and-fast ways to determine people's place in the world and its effects. More than that, however, the prevailing conceptualisations of class and stratification at various points over the last century have been manifestly constrained and facilitated by the development and dissemination of specific operations in the field of statistics. The fashion for one-dimensional scales of prestige or socio-economic standing, for example, was inextricably tied to the invention of simple linear regression, where changes in one independent continuous variable are systematically compared against changes in a dependent variable (Goldthorpe, cited in Lareau, 2011). In order to conduct that kind of analysis, stratification had to 
be boiled down to a single dimension. The development of multivariate regression facilitated the postulation of multiple scales, but, more importantly, the subsequent emergence and dominance of the categorical EGP scheme is unmistakably associated with the move towards logistic regression, where the relative odds of a specific outcome are calculated in order to compare specifically between classes, and its extension into log-modelling. The brevity and nature of the discussion of its original construction (Goldthorpe, 1980), in which the chopping-up of Goldthorpe's previously constructed scale into categories comes across as largely a practical means to the statistical end, suggest a subordination of construct-building to method, no matter how much Goldthorpe (e.g. 2007a) subsequently went on to provide post-hoc theorisation of the scheme.

The broadly relational construction of the social world developed by Bourdieu, and his vision of class in particular, was largely based on a series of conceptual syntheses - an effort to overcome the opposition between subjectivism and objectivism, phenomenology and structuralism - though this was surely informed by his mobilisation of both qualitative and quantitative methods from the very start of his research career. There is no doubt, however, that the refinement of his model into a fully multidimensional, topological definition of class relations by the time of Distinction was coupled with his discovery of a subversive branch of statistics developed in France by Jean-Paul Benzécri. Subsequently dubbed 'geometric data analysis' (GDA), Benzécri's approach was opposed to popular linear techniques like regression which distinguish 'dependent' and 'independent' variables and examine variation in one according to variation in the other. Instead, his interest was in producing a series of techniques that could map out spaces of difference - which could, in other words, array variables and their categories, or individual cases, within a multi-axis Euclidean space defined by distance and direction. Which variables or categories are associated with which other variables or categories, and to what degree and in what ways, given how close to or far away they are from one another and their relative location (above, below, to the left or right, etc.)?

More concretely, GDA operates by distinguishing the different, independent ways in which the variables or variable categories relate to, or rather vary from, one another, each way becoming a dimension or axis of the space. Yet these dimensions are of varying weight or importance, with one occupying prime position and others being important to decreasing degrees. This is based on the total variance or inertia between variables or categories: each axis accounts for, or 'explains', a proportion of the total inertia. In turn, each variable or category contributes its own proportion to the inertia of the axis, allowing us to determine which variables or categories are the most important in shaping each dimension.

Although GDA has developed over time into a family of techniques, Benzécri's initial innovation was correspondence analysis (CA). ${ }^{7} \mathrm{CA}$ works 
on a two-way data table - for example, income categories crossed against highest educational qualification. It transforms the differences recorded numerically in the cells into a multidimensional graphical representation of dispersion with the units of distance being standard deviations. Each axis of the space bears an associated 'eigenvalue' $(\lambda)$, which denotes the variance of the cases along the axis, and when divided by the sum of eigenvalues for all axes, we determine the proportion of the total variance accounted for by that axis. We can also see which categories (or 'modalities') of the column variable are more or less like which other categories of the column variable, and which categories of the row variable are more or less like other categories of the row variable, on each axis, but also the degree of correspondence between the categories of the column variable and the categories of the row variable.

CA certainly fits a relational orientation towards the social world and has its uses, but it was not the technique that interested Bourdieu and his collaborators. Their focus was instead on multiple correspondence analysis (MCA), a later extension of CA to tables crossing individuals on the rows with categories from multiple variables in the columns (an 'indicator matrix'). This is done using 'disjunctive coding', i.e. according a 1 to an individual for each category of a variable that characterises them (x amount of income p/a, holds a degree, mother dominant, etc.) and a 0 for all others. The logic is otherwise more or less the same as with CA - multiple polarising dimensions together accounting for all the variance between categories and individuals - but we can explore the distribution of individuals as well as categories in the resulting map. Additionally, one can project 'supplementary' variables into the space - variables whose categories do not contribute to the calculation of inertia but whose spatial association with individuals and 'active' modalities can be examined. A prime example being projection of indicators of taste into a model of the social space (or vice versa, as was Distinction's tactic), this facilitates the empirical examination of homologies and provides 'external validation' for the space. The affinities of the method with Bourdieu's perspective are thus evident: it 'thinks in terms of relations', as he put it himself (in Bourdieu et al., 1991: 254), unearthing hidden structures of opposition and correspondence between agents (people) and characteristics (capitals, position-takings).

MCA is now the most widely used GDA technique amongst those inspired by Bourdieu and, though he and colleagues used it in Distinction to chart the structures of the lifestyle space rather than the axes of the class structure (which were instead based on a geometric reading of tabular data), it underpins most of the studies mapping social spaces discussed in the Introduction. It and CA are not, however, exhaustive of GDA, and neither are they the most widely used GDA methods in social science, although most people would not think of it this way. The fact is, CA and MCA are part of a wider collection of techniques, usually described as 'factorial' or 'data 
reduction' techniques, geared towards reducing variance between variables down to a small number of underlying dimensions. Both require categorical variables - variables split into discrete chunks - and both are particularly effective when the variables are nominal, that is to say, when there is no obvious order or hierarchy to the categories. An alternative factorial technique that deals with continuous variables instead - variables measured on a scale, like height or age - is principal components analysis (PCA). A variety of PCA also exists that can handle any and all types of variable, i.e. continuous, nominal and (when the categories of a variable follow a defined order) ordinal. This is called 'non-linear' or 'categorical' PCA (CatPCA).

A major difference between CA and MCA, on the one hand, and PCA and CatPCA, on the other hand, is that the latter work with whole variables, no matter their type, rather than categories, though one can certainly examine features of constituent categories of nominal and ordinal variables in CatPCA models. The numerical base is not a cross-table or indicator matrix but a correlation matrix, and though one can and should still calculate the contribution of a variable to the inertia of an axis specific interest is placed on the 'factor loading', or the correlation of the variable with the dimension, which also functions as its coordinate. ${ }^{8}$ When dealing with continuous and ordinal data, PCA thus tends to focus on and document vectors, that is to say, the direction and distance of travel of the variable as a whole from the origin of the space (called the barycentre) relative to all others, rather than the location (or 'centroid') of specific constitutive categories.

However, the development of PCA and CatPCA has been associated not with Benzécri and his students, nor its application pursued by those interested in specifically Bourdieusian themes within sociology. Their core proponents typically think of them not as species of GDA at all but as means of producing reliable composite scales. Instead of looking at the relationship between an independent variable and a whole series of dependent variables, in other words, one can reduce the dependent variables down to fewer, more basic underlying 'factors' or 'components' and use them as the dependant variables instead. Although there is some use of the techniques to that end in political science and political sociology, where scales of political orientation are the focus (left/right, liberal/authoritarian, etc.), the major figureheads in the development and application of CatPCA over the last few decades have been members of the Leiden School, a collection of psychologists whose interests lie in using the techniques to produce reliable composite measures of personality (see especially Gifi, 1990; Meulman et al., 2004; Linting et al., 2007a, 2007b; Linting and van der Kooij, 2012). Much of their specific mathematical and statistical work has been aimed, therefore, at measuring and manipulating scale reliability, deploying, for example, Cronbach's alpha to gauge the purity of factors and championing the principle of axis rotation wherein individuals and variables are artificially re-oriented in the space so that they better 'line up' along different dimensions. 
For all this, however, PCA and CatPCA share the same basic procedural principles as CA and MCA and can, as many have indicated, be recast as members of the GDA family and harmonised with Bourdieu's relational philosophy (Jambu, 1991; Lebart et al., 1995; Le Roux and Rouanet, 2004; Greenacre and Blasius, 2006; Blasius and Greenacre, 2014; Le Roux, 2014). After all, PCA and CatPCA both produce Euclidean spaces of individuals and variables defined by distance and direction, and both are based on the inertia and eigenvalues of multiple axes. In fact, so close are MCA and CatPCA in their logic and operation that a CatPCA of multiple nominal variables alone is an MCA (DiFranco, 2016). Cronbach's alpha is no longer important and axis rotation treated warily -if we are using PCA to construct a model of a hypothesised space then rotating the axes might be a distortion (Jambu, 1991; Rosenlund, 2009). With PCA and CatPCA as with CA and MCA, we are interested in the structure and constitution of the space as an approximation of a modelled system of oppositions and the projection of supplementary variables into it to investigate homologies.

On the latter point, in both MCA and CatPCA supplementary nominal variables can be cast into the models in order to progress to structured data analysis (Le Roux and Rouanet, 2004: Chapter 6; Hjellbrekke, 2019: Chapter 4). The positioning of variable categories along the different axes suggests correspondence between active and supplementary modalities in the case of MCA and, in the case of CatPCA, between vectors and characteristics - the degree to which certain characteristics are associated with certain directions and distances in the space, that is. Eyeballing the coordinates and correspondences of categories can sometimes seem enough to draw sociological conclusions, but there are in fact a series of tests that can be applied to establish whether the positioning of a supplementary characteristic is statistically significant. These have mostly been developed for and applied to models produced by MCA, but since CatPCA is based on exactly the same operational principles, the same tests can be employed. One that we shall have recourse to in the analyses to come is the typicality test, which operates to determine whether the distance between the mean point of a variable category and the axis origin is significant (Le Roux and Rouanet, 2010: 82ff). The higher the test statistic, the more notable the deviation, or the more 'atypical' the positioning of the category is on the axis compared to the sample as a whole, with anything higher than 2.58 being significant at the 1 percent level (two-tailed) and anything higher than 1.96 being significant at the 5 percent level, though the test statistic can be inflated where the number of individuals in the category is high (Hjellbrekke, 2019: 68). Another test is the comparison of standardised deviations, which enables us to adjudicate whether the distance between two categories on an axis of a space is notable ( $\geq 0.4$ ) or substantial ( $\geq 1)$ (Le Roux and Rouanet, 2010: 58; Hjellbrekke, 2019: 64; Le Roux et al., 2020: 22). ${ }^{9}$ Both can be supplemented by analysis of variance (ANOVA), which in this case determines whether the differences 
between the mean coordinates of a variable's categories on an axis are significant or not given inter- and intra-category variance and, when the Eta ${ }^{2}$ figure is calculated, the strength of the association between the axis and the variable in the form of the proportion of the variability in the axis (from 0 to 1) that can be 'explained' by the variable (Hjellbrekke, 2019: 73-6). ${ }^{10}$

\section{MCA or CatPCA?}

Given all that has been argued so far, the question inevitably emerges as to which method is optimal for investigating the hypotheses at hand. In fact, despite the considerable time and labour involved, which were not anticipated at the outset, models were constructed for each of the 23 nations studied using both MCA and CatPCA, deploying the variables outlined above in slightly different ways, and the corresponding output compared. The chief conclusion was that their findings essentially indicated the same fundamental structures of difference, but the decision has been taken to report the CatPCA models for several reasons.

First, treating most of the variables analysed as strictly nominal rather than ordinal is potentially inapt since there is an obvious low-to-high ordering of categories. This is confirmed by inspection of transformation plots in the CatPCA analysis. These diagrams plot the nature of the relationship between a specific variable and all other variables within the model, and where the variables are categorical an ascending line (no matter its slope from category to category) indicates the variable follows an ordinal pattern whereas a line that rises and falls between categories indicates the variable should be treated as nominal (Figure 2.1). ${ }^{11}$ In our case, every variable in all the models followed an ordinal pattern of varying manifestation bar one. In some (though not all) models, the transformation plots indicated that mother's occupation should be treated as nominal, largely because having a mother who did not work, in these instances, occupies a place in the social hierarchy at odds with its coded placement in the order of categories (i.e. it can be 'higher' on an axis than having a mother in the dominated class yet is 'lower' than it in the ordinal structure). ${ }^{12}$

Another stark indication of the ordinal nature of the variables was the appearance of a 'Guttman effect' on the plane of axes 1 and 2 in many of the MCA models. This effect takes the form of the prime axis being defined by high/low categories and the secondary axis being defined by middle/end point categories, thus lending a parabolic U-shape to the distribution of individuals and modalities. It suggests the existence of a hierarchical, ordinal organisation of the data (Le Roux and Rouanet, 2004: 220-1). In itself that can be a useful finding, of course, but there are a number of strategies for dealing with the Guttman effect so as to uncover more interesting sociological oppositions it might obscure (Hjellbrekke, 2019: 96). One of these is systematic recoding, especially in the form of collapsing together extreme 

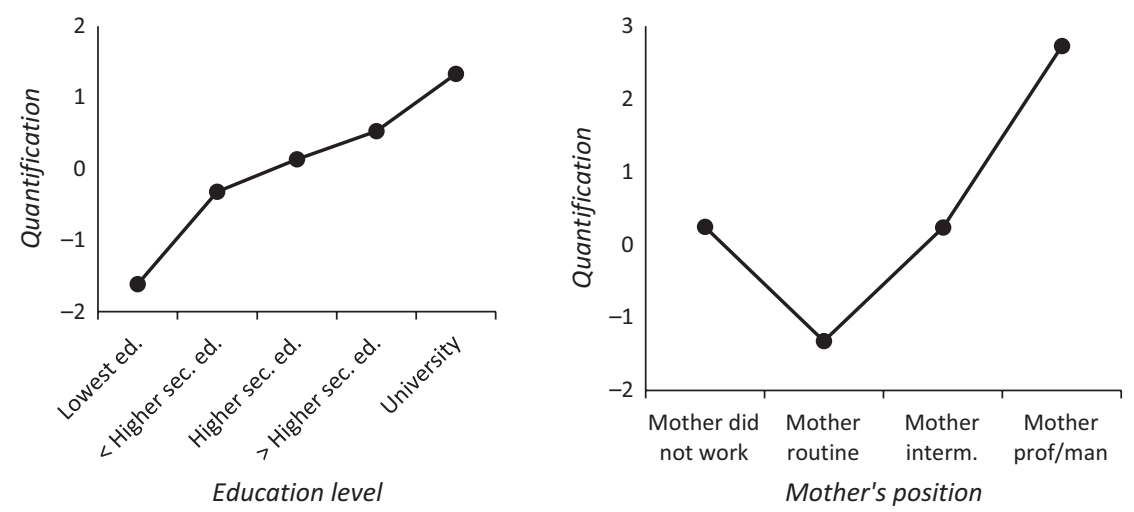

Figure 2.l Two transformation plots.

Note: The figure on the left shows a transformation plot for an ordinally structured variable (education level). The figure on the right shows a transformation plot for a variable treated as nominal (mother's position). Based on data for France.

categories so as to lessen their effect relative to the middle. This was trialled for all models, with some samples and variables requiring extensive recoding while others required little or none at all. The result was a series of solutions that bore a number of disadvantageous features. First, they differed markedly in number and distribution of individuals across categories, reducing their comparability. Second, binary variables were sometimes necessary to escape the Guttman effect, especially for parental occupations, and these, when put alongside multicategory variables, can have an effect of artificially strengthening oppositions. Third, and following from this, the outcome of the recoding operation was usually an extremely strong first axis and a fairly weak second axis, almost to the point of rendering the models effectively unidimensional according to standard principles of axis retention. Finally, some aggregated modalities ended up having a disproportionate weight in the model, sometimes grossly so, and when subject to specific tests it transpired that the models were not as internally stable as one would desire (Le Roux and Rouanet, 2004: Chapter 7; Hjellbrekke, 2019: 76).

The above problems did not affect all MCA models, it should be stressed, and with a greater number of appropriate nominal variables the Guttman effect would probably be avoided or reduced - as suggested by the number of MCA models of social spaces produced by others and which, as discussed, include a number of variables (e.g. occupational schemes) that might be debatable on theoretical grounds but which may well have a very practical effect. Still, a lot of work was necessary - which always risks accusations of arbitrariness and artificiality of results - to produce models that were not as comparable or robust as they could have been. CatPCA, however, assuming most of the variables to be ordinal from the outset and running all vectors 
through the barycentre, avoids the Guttman effect altogether. Recoding was still necessary, however, to bring some degree of uniformity to the variable categories, especially the variables of economic capital since these were measured with widely contrasting numbers of categories from nation to nation. The coding operation was more 'light-touch' than for the MCA models, though, simply aiming as far as possible to achieve a roughly even distribution of individuals across a similar number of categories from sample to sample. It was also necessary, as it is with MCA, to combine low-response categories with adjacent ones so as to avoid overpowered categories. ${ }^{13}$ This was most pertinent with the measures of inherited cultural capital. Table 2.2 presents the overall distribution of categories across variables and models.

Overall, the final CatPCA models exhibited greater stability and interpretability, or internal validity, than the MCA models, but they were also more revealing when it came to structured data analysis - a capacity usually considered demonstrative of a model's external validity (Hjellbrekke, 2019). Not only that, but they are far more parsimonious. There is, quite simply,

Table 2.2 Sample size and number of variable categories in the models

\begin{tabular}{|c|c|c|c|c|c|c|c|c|c|}
\hline Country & $n^{a}$ & $\begin{array}{l}\text { Education } \\
\text { level }\end{array}$ & Books & $\begin{array}{l}\text { Mother's } \\
\text { position }\end{array}$ & $\begin{array}{l}\text { Father's } \\
\text { position }\end{array}$ & Income & $\begin{array}{l}\text { Savings } \\
\text { value }\end{array}$ & $\begin{array}{l}\text { Home } \\
\text { value }\end{array}$ & Total \\
\hline Australia & 1362 & 5 & 7 & 4 & 4 & 7 & 5 & 5 & 37 \\
\hline Austria & 929 & 4 & 7 & 3 & 4 & 6 & 5 & 5 & 34 \\
\hline $\begin{array}{l}\text { Belgium- } \\
\text { Flanders }\end{array}$ & 999 & 5 & 7 & 4 & 4 & 5 & 6 & 5 & 36 \\
\hline Czech Republic & 1060 & 4 & 6 & 3 & 4 & 7 & 5 & 5 & 34 \\
\hline Denmark & 1369 & 4 & 6 & 4 & 4 & 5 & 5 & 5 & 33 \\
\hline Estonia & 846 & 4 & 6 & 3 & 4 & 6 & 6 & 7 & 36 \\
\hline France & 2655 & 5 & 7 & 4 & 4 & 7 & 5 & 6 & 38 \\
\hline Germany & 1283 & 4 & 6 & 3 & 4 & 7 & 5 & 5 & 34 \\
\hline Iceland & 947 & 5 & 5 & 4 & 4 & 8 & 6 & 6 & 38 \\
\hline Israel & 1067 & 5 & 6 & 4 & 4 & 8 & 6 & 5 & 38 \\
\hline Italy & 819 & 4 & 7 & 4 & 4 & 8 & 5 & 5 & 37 \\
\hline Japan & 1145 & 4 & 6 & 3 & 4 & 7 & 7 & 6 & 37 \\
\hline Latvia & 838 & 5 & 6 & 3 & 4 & 7 & 5 & 5 & 35 \\
\hline New Zealand & 916 & 5 & 7 & 4 & 3 & 6 & 6 & 6 & 37 \\
\hline Norway & 1423 & 5 & 6 & 4 & 4 & 8 & 7 & 6 & 40 \\
\hline Poland & 1152 & 5 & 7 & 3 & 4 & 7 & 4 & 5 & 35 \\
\hline Russia & 1438 & 5 & 6 & 4 & 4 & 7 & 4 & 5 & 35 \\
\hline Slovakia & 975 & 4 & 7 & 4 & 3 & 7 & 5 & 7 & 37 \\
\hline South Korea & $|4| 4$ & 5 & 7 & 3 & 4 & 7 & 5 & 6 & 37 \\
\hline Sweden & 1137 & 5 & 6 & 4 & 4 & 7 & 5 & 6 & 37 \\
\hline Switzerland & 1055 & 5 & 6 & 3 & 4 & 5 & 6 & 4 & 33 \\
\hline Taiwan & 1867 & 5 & 7 & 3 & 4 & 6 & 7 & 5 & 37 \\
\hline US & $|5| \mid$ & 4 & 7 & 4 & 4 & 7 & 5 & 6 & 37 \\
\hline Average & 1226 & 4.6 & 6.4 & 3.6 & 3.9 & 6.7 & 5.4 & 5.5 & 36.2 \\
\hline
\end{tabular}

a Active individuals, weighted. 
far less output to report to the same end - a feature particularly relevant for comparative research requiring the construction of multiple models. With MCA, one should report not just axis eigenvalues and inertia but the contributions of each modality to each interpretable axis. With CatPCA, on the other hand, focussing on whole variables rather than modalities lightens the data load. This does not mean that MCA is unsuited to comparative research, and had the results of the two methods differed substantially then the manner of proceeding would have to be different, but for large-scale cross-national research like this, with 23 nations under investigation rather than just several and with the different methods producing convergent conclusions, it makes sense to avoid unnecessarily over-complicating things.

There are, of course, downsides to reporting the CatPCA models rather than the MCA solutions. MCA allows one to break down the effect of variables into their constituent categories, which can be useful for deconstructing the strong contribution of a variable in the model or highlighting that a variable, while contributing weakly to an axis overall, might still contain a single modality that contributes above average to the axis. Of course that has to be balanced against the problem of creating over-strong modalities mentioned above, and the benefit of having done both methods is that variable/modality divergences in contribution can be noted where they were consistent. Another shortcoming of detailing the CatPCA models is that the output is not directly comparable with previous research producing social spaces through MCA. Eigenvalues and inertia rates of axes and coordinates of specific modalities simply cannot be equated. Since the analyses to be presented in the chapters to come include most of the nations already studied by others, however, thus generating a common baseline for comparison, the problem is largely dissolved.

\section{Conclusion}

The concordance of GDA with the relational philosophy inherent in the notion of social space is indisputable, but the geometric planes produced by analyses of correspondence or principal components are not unmediated reflections of social reality, and the temptation to directly, and erroneously, refer to zones of the models as zones of social space, or to categorically assert that the selected indicators are definitive of structures of difference, will have to be guarded against. A GDA solution is not just a model, but a model of a model, that it to say, an approximation of a certain conceptual construction of the world, albeit one worked out via logic and in dialogue with robust evidence. It is to the sense of social distance and practice of everyday life what the cartographer's map is to the quotidian sense of geographical space and physical distance: an abstract, reductive representation of the major directions, expanses and fault lines providing the conditions of possibility for certain experiences and movements, dependent on the tools of measurement and symbolisation available. 
Although MCA is the most widely used species of GDA among the Bourdieu-inspired, in line with the Frenchman's own practice, it is not the only GDA tool out there and, ultimately, the precise choice of method must suit both the question and the nature of the data at hand. MCA is designed for nominal data, making it perfect for analysing lifestyle spaces with variables relating to favourite sport, artform or whatever, and it can be useful for Likert-scale data under certain conditions, as with spaces of political position-taking (see, e.g. Atkinson, 2017). It certainly can be used for mapping social spaces, especially when there are unambiguously nominal indicators available, but when the variables are clearly all or mostly ordinal in nature, it may be better not to falsely treat them as nominal and instead look to other methods. CatPCA fits the bill, but has been overlooked by many of those inspired by Bourdieu because of its association with thoroughly alien traditions of social science. Yet it is a variant of GDA, it does produce multidimensional spaces of dispersion and it can be used to examine homologies through structured data analysis. In mathematical foundation and practical operation MCA and CatPCA are extremely close siblings, so there is no reason why CatPCA cannot be considered a fitting technique for approximating the relational structures of social domination across contemporary capitalist societies.

\section{Notes}

1 For details on the sampling procedures, which differed for each nation, see the monitoring report available at http://www.gesis.org/issp/modules/issp-modulesby-topic/social-inequality/2009/. Full-time students are excluded from analysis. All analyses use weighted data where a weighting variable is available, including in the case of Germany where a design weight countering an imbalance in the sample between East and West Germany has been constructed.

2 In the cases of Portugal and Spain the level of missing data on some of the key variables (sometimes as high as 70 percent) was deemed too high. The Finnish sample was unsatisfactorily small once the disproportionate number of students was removed from it, while the data for Great Britain was invalidated by an apparent coding error on a key variable (home value). For Turkey, the extreme skew of responses on one variable (mother's occupation) meant that a comparable model could not be adequately constructed. Regarding those countries remaining in the study, it should be acknowledged that previous research has determined that some nations provide more reliable survey data than others, even on widely used survey programmes, and that this is linked to the level of corruption in the country (Blasius and Thiessen, 2018). The polarisation is between some Eastern European nations (more corrupt, less reliable data) and Nordic nations (least corrupt, most reliable data), with others in between.

3 At least in terms of income - wealth disparities may reveal a slightly different picture (Skopek et al., 2014).

4 While the ISSP is not without issues in relation to consistency of variable definition across nations, encouraging caution in interpreting the results, it is among the best surveys in this regard and what problems there are relate more to topical questions than demographic indicators (Jowell, 1998). 
5 Age of leaving education is also available in the ISSP dataset as a continuous variable and was compared against education level. It yielded almost identical results, with the disadvantage of giving a more ambiguous measure of acquired cultural capital than educational qualification (cf. the discussion in Bourdieu, 2019: 26).

6 The full rationale and justification for this classification will become clear in Chapter 4.

7 The foundations of GDA, for those who want to know more, are laid out in Benzécri (1992) and Le Roux and Rouanet (2004, 2010). Rosenlund (2009) and Hjellbrekke (2019) also contain excellent overviews.

8 The factor loading is calculated by multiplying the variable's eigenvector by the square root of the axis eigenvalue. The contribution of a variable to an axis is calculated by dividing its squared factor loading by the eigenvalue.

9 The threshold for notability is a rule of thumb and some argue it should be as low as 0.3 .

10 Given the sensitivity of ANOVA to disparities in size between variable categories, which in some cases will be pronounced, it should be treated as only a guide rather than a definitive assessment. The same is true, in fact, of any test of statistical significance in GDA (Hjellbrekke, 2019: 69).

11 Transformation plots were run for each variable twice, one defining the variable as nominal and another as ordinal, since the ordinal option automatically constrains the shape of the plot. The conclusion that a variable is ordinal is thus based on the pattern that emerges when assuming the variable to be nominal.

12 Nominal variables can be defined as single nominal or multiple nominal. They are defined as single nominal in cases where an order of categories is unknown but it is desirable to determine one across axes in the analysis, generating vectors and factor loadings, and as multiple nominal when ordering is considered logically impossible or undesirable, thus working on the centroid model underpinning MCA and producing no factor loading (DiFranco, 2016). In the case of mother's occupation, setting it as single or multiple nominal made little difference to the overall structure and interpretation of the resultant spaces, but for the sake of parsimony and consistency within and across models it has been defined as single nominal in all cases.

13 Recoding for CatPCA is done with reference to transformation plots. If the line between two or more adjacent categories is flat, it indicates that the categories do not differ from one another in their relationship to other variables and can be taken together. Where there is a noticeable gradient, however, recoding has to be more carefully considered. 


\section{Chapter 3}

\section{Social spaces}

The immediate task before us is to map out the targeted social spaces, in rare cases re-tracing contours previously sketched by others but in most instances charting entirely new territories. Will capital volume and capital composition emerge as the primary and secondary axes of difference? Will there be other, additional axes of importance, perhaps tapping into trajectory effects? Might volume of capital be effectively exhaustive of social differentiation, as older traditions of thought championing composite socio-economic scales assumed, pushing capital composition into marginality or irrelevance? It could well be, after all, that all seven variables in the CatPCA models load substantially onto a prime axis that accounts for almost all variance. Though the statistical strength of a principle of difference evidently cannot and should not be taken as a direct reflection of its social and sociological pertinence (examination of homologies with positiontakings would be needed to confirm or confute that), an overwhelmingly unidimensional solution, with all vectors clinging tightly to the axis of the premier component like a multi-handed clock indicating midnight, would be very telling. Or might there be alternative axes in place of capital composition, or even capital volume, constituted by specific combinations of capital indicators, and what would the bearing of that statistical finding be on the constructed conceptual model of the social space? Finally, and crucially, are there any consistent patterns or regularities across the country models that indicate common structures of difference and domination, explicable political-economic variations or, perhaps, a world of national idiosyncrasy?

\section{The prime dimension}

Analysis reveals, first of all, that in each and every case the space of social difference can be effectively modelled as a three-dimensional system of oppositions and, additionally, that those oppositions bear striking resemblances across national samples (Table 3.1). ${ }^{1}$ The prime axis of differentiation, to start with, has, judging from factor loadings (those above 0.4 being definitive), a common character (Table 3.2). The most consistently powerful 
correlation is with the respondent's education level, followed by number of books in the family home. There seems to be a clear relationship, then, between acquired and inherited cultural capital, an inference seemingly confirmed by the vectors of parental class position along the axis. Father's occupation, which is, as we know, better understood as a broad indicator of social capital (past and/or present) than inherited cultural capital per se given its internal structure, has a substantial factor loading on Axis 1 in all national models, most notably those for Austria and Italy, though the association is weakest (though still notable) in Slovakia and at the weaker end of the spectrum in several other Eastern European states (Estonia, Latvia, the Czech Republic), the Far East and the US. In the case of the Far East, especially Taiwan and South Korea, this might reflect the rapid economic development, industrial change and educational expansion of the later twentieth century, creating starkly different fields of possibilities for successive generations, though it must also be borne in mind that doxic notions of honour have long compelled even the poor to invest what meagre resources they have, at great sacrifice, in the schooling of their children (see Seth, 2002; Oh, 2010; Jung and Gil, 2019). In the case of the US and Eastern Europe, it perhaps fits with the general image of greater social fluidity in these nations (Breen, 2004; Bukodi and Goldthorpe, 2018), though educational expansion and, in the case of Eastern Europe, economic restructuring and the new possibilities they entail must be borne in mind too.

Mother's occupation - which is, as previously mentioned, more indicative of inherited cultural capital than father's class is - is slightly more variable. In the majority of samples it does have a positive correlation with the principal axis above 0.4. Only in the Russian model is it greater than 0.7 , but it registers a relatively large factor loading in most of the other post-socialist nations (Latvia, Poland, Estonia, Slovakia), as well as Israel and Australia. In most of these cases, in fact (Poland is the exception, but only just), mother's class is more important than father's class on the axis. It could well be, for the post-socialist cases, that this effect is the consequence of traditionally high rates of female workforce participation in these countries. In a minority of samples, however, mother's occupation plays a lesser, or different, role. In four nations - Switzerland, Germany, Japan and the US - it bears only a minor factor loading, and in two more - South Korea and, especially, Taiwan - it has a notable negative relationship with the axis. The peculiar relationship in the latter two cases would seem to be linked to the atypical positioning of having a mother who did not work when the respondent was a teen. While it is not uncommon for this category to sit above having a mother in routine manual work in the space, and/or just above the axis origin, in these two models the coordinates for having a non-working mother, a populous category, are substantially higher on the positive side of the axis ( 0.2 in both cases) and considerably higher than the category for routine work ( -0.38 and -0.36 in South Korea and Taiwan respectively) than 
Table 3.I Eigenvalues and inertia in the models

\begin{tabular}{|c|c|c|c|c|c|c|c|}
\hline \multirow[b]{2}{*}{ Country } & \multicolumn{2}{|c|}{ Axis I } & \multicolumn{2}{|c|}{ Axis 2} & \multicolumn{2}{|c|}{ Axis 3} & \multirow[b]{2}{*}{$\begin{array}{l}\text { Cumulative } \\
\text { inertia }\end{array}$} \\
\hline & Eigenvalue & $\begin{array}{l}\text { Inertia } \\
\text { (\%) }\end{array}$ & Eigenvalue & $\begin{array}{l}\text { Inertia } \\
(\%)\end{array}$ & Eigenvalue & $\begin{array}{l}\text { Inertia } \\
(\%)\end{array}$ & \\
\hline Australia & 2.54 & 36.3 & 1.64 & 23.4 & 0.88 & 12.6 & 72.2 \\
\hline Austria & 2.67 & 38.2 & 1.71 & 24.4 & 0.87 & 12.4 & 75.0 \\
\hline $\begin{array}{l}\text { Belgium- } \\
\text { Flanders }\end{array}$ & 2.92 & 41.7 & 1.52 & 21.7 & 1.02 & 14.6 & 78.0 \\
\hline Czech & 2.55 & 36.4 & 1.28 & 18.3 & 0.89 & 12.7 & 67.4 \\
\hline Denmark & 2.43 & 34.7 & 1.74 & 24.8 & 0.89 & 12.8 & 72.3 \\
\hline Estonia & 2.59 & 36.9 & 1.40 & 20.0 & 1.01 & 14.4 & 71.4 \\
\hline France & 2.60 & 37.1 & 1.52 & 21.7 & 1.05 & 14.9 & 73.7 \\
\hline Germany & 2.63 & 37.5 & 1.45 & 20.6 & 1.09 & 15.6 & 73.8 \\
\hline Iceland & 2.01 & 28.8 & 1.71 & 24.5 & 1.03 & 14.7 & 67.9 \\
\hline Israel & 2.62 & 37.5 & 1.76 & 25.1 & 1.03 & 14.7 & 77.3 \\
\hline Italy & 2.76 & 39.4 & 1.63 & 23.2 & 0.92 & 13.2 & 75.8 \\
\hline Japan & 2.40 & 34.3 & 1.66 & 23.7 & 1.29 & 18.4 & 76.4 \\
\hline Latvia & 2.45 & 35.0 & 1.52 & 21.7 & 0.99 & 14.1 & 70.9 \\
\hline New Zealand & 2.42 & 34.6 & 1.55 & 22.1 & 1.06 & 15.2 & 71.9 \\
\hline Norway & 2.09 & 29.8 & 1.82 & 26.0 & 0.95 & 13.6 & 69.5 \\
\hline Poland & 2.99 & 42.7 & 1.19 & 17.0 & 0.96 & 13.8 & 73.5 \\
\hline Russia & 2.45 & 35.1 & 1.37 & 19.5 & 1.10 & 15.7 & 70.2 \\
\hline Slovakia & 2.80 & 40.0 & 1.43 & 20.5 & 0.98 & 14.0 & 74.6 \\
\hline South Korea & 2.65 & 37.8 & 1.38 & 19.8 & 0.97 & 13.8 & 71.4 \\
\hline Sweden & 2.53 & 36.1 & 1.55 & 22.1 & 1.01 & 14.4 & 72.6 \\
\hline Switzerland & 2.36 & 33.6 & 1.56 & 22.3 & 1.03 & 14.7 & 70.6 \\
\hline Taiwan & 2.81 & 40.2 & 1.25 & 17.8 & 1.04 & 14.9 & 72.9 \\
\hline US & 2.59 & 37.0 & 1.54 & 21.9 & 0.94 & 13.4 & 72.4 \\
\hline Average & 2.56 & 36.6 & 1.53 & 21.8 & 1.00 & 14.3 & 72.7 \\
\hline
\end{tabular}

elsewhere. Whatever the possible social factors that might coincide with this cultural expectations over gender roles and the degree of familial distance from necessity required for mothers to take time out of work - or its specific relationship to the positioning of the categories across other axes, to be explored later, the important point is that having a mother in routine manual work still corresponds with the lower end of the dimension and a mother in non-manual employment - professional-managerial employment is exceedingly rare in both samples - with the top end (for South Korea and Taiwan, the category coordinates are 0.59 and 0.91 respectively).

All in all, looking at the relationship between the variables so far discussed, the typical order of importance is education $\rightarrow$ books $\rightarrow$ father's class $\rightarrow$ mother's class, though there are some minor deviations. In other words, the most important elements are acquired cultural capital, in the form of education level, and probably the most effective measure of inherited cultural capital in the form of books in the childhood home. Parental 


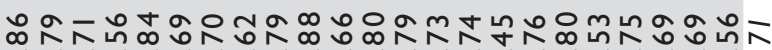
000000000000000000000000

$\infty N$ ONaN $\infty$ N ó 00000000000000000000

윰ำ

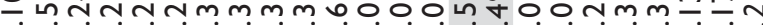
ó ó

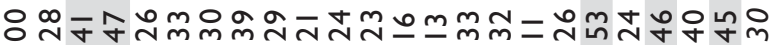

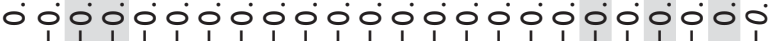

ฟ กตร t. t $0_{1}^{\circ} 0_{1} 0_{1} 0_{1} 0_{1} 0_{1} 0_{1} 0_{1} 0_{1} 0_{1} 0_{1} 0_{1} 0^{\circ} 0^{\circ} 0_{1}^{\circ} 0^{\circ} 0_{1}$

그ำ

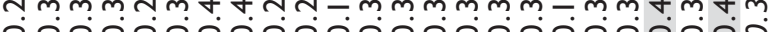

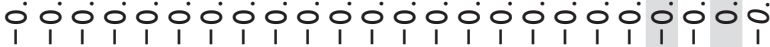

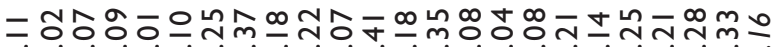

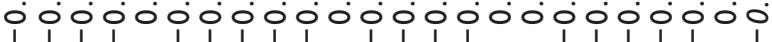

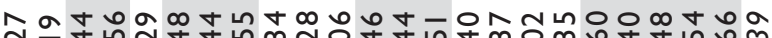

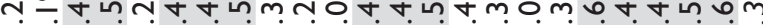

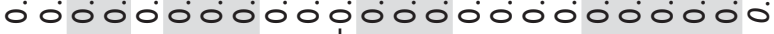

二 б.

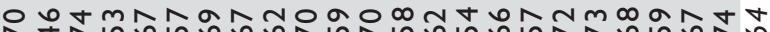

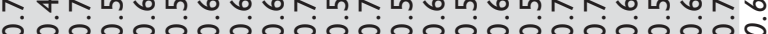

นูำ

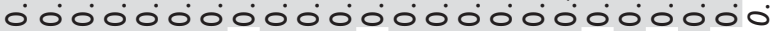

ช้ 0 000000000000000000000

ֻ $00^{\circ} 00^{\circ} 00^{\circ} 0^{\circ} 0^{\circ} 0^{\circ} 0^{\circ} 0^{\circ} 0^{\circ}$

웅

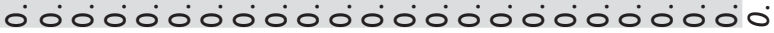

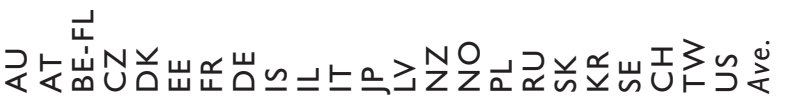


class positions, with all their ambiguities and homogenisations at this level of aggregation, are secondary. Nevertheless, they consolidate the interpretation that inherited capital is important to this axis, cultural capital in particular but not necessarily exclusively.

Yet there is more. Indicators of economic capital also load on to the first axis above the threshold of 0.4 , and the most notable in this regard is household income. It is, in fact, more important to the axis than parental class when looking at the cross-national aggregate pattern, though its order of importance differs from nation to nation. Its highest loadings are in the models for the US, South Korea, Slovakia, Flanders and Australia, but its importance is less pronounced - though still substantial - in Austria, the Czech Republic, Estonia, Italy, Latvia, Norway, Russia and Switzerland. In only three models (Australia, South Korea and the US) does its loading surpass that of books in the family home, and in the US model alone does it exceed that of even education level, making it the single most important variable to the dimension. Nevertheless, the take-home finding is the strong interrelationship, or correspondence, between acquired and inherited cultural capital, on the one hand, and household income, on the other hand. This indicates not only a causal relationship between social origin and success within the education system - social reproduction, in other words but a consistent nexus, perhaps mediated by the inherited/acquired cultural capital link, between social origin and earnings (one's own and/or those of a cohabitating partner).

Indicators of wealth - value of savings and domestic property - are less consistent features of the prime axis of differentiation. They correlate positively with the axis in all cases but one, Italy, where the coordinate for home ownership sits almost in the centre. Savings are important to the dimension in 14 cases, but while they yield a particularly high factor loading in Taiwan and the US they typically have a correlation of between 0.4 and 0.5 and, in many cases, 95 percent confidence intervals extend below the 0.4 threshold. Home value follows a very similar pattern, having a factor loading above 0.4 in 13 cases (not necessarily the same cases where value of savings was important) and even then it is usually fairly low compared to the other indicators of capital. Overall, therefore, there is a case to say that the prime axis indicates differentiation by capital volume in just over half the cases, with wealth playing a secondary role, but that in all others the axis is perhaps more properly characterised as cultural capital plus income.

The picture becomes somewhat clearer, however, if we move beyond factor loadings to examine the relative contributions of variables to the axis, thus distinguishing major ('explicative') indicators from minor ('explained') ones (Table 3.3). Looking for those indicators bearing an above-average contribution, it quickly transpires that education typically remains the most important piece of the puzzle, explaining between a fifth and a quarter of the inertia, followed by books in the family home. Only in the US is the 
$\lambda$ L

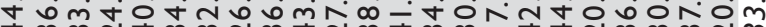

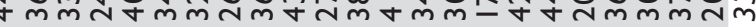

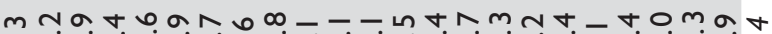
ㅇํำ

on ○ İm

0.7 .

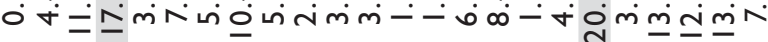

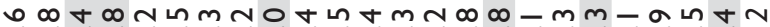

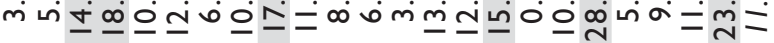

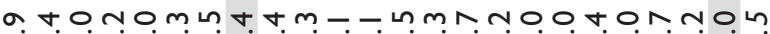

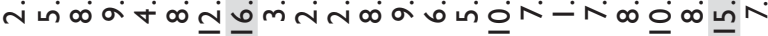

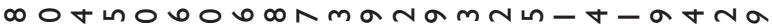
Ó00்

am $m-$ แn $\infty$ t N-

น + ด เก

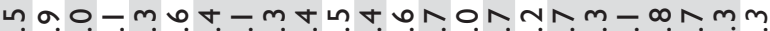

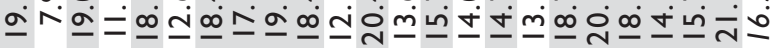
t m人

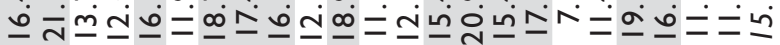

-

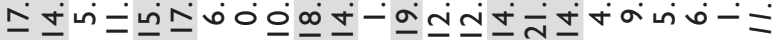

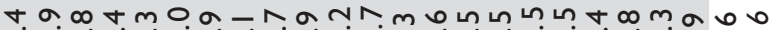

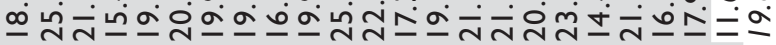

m

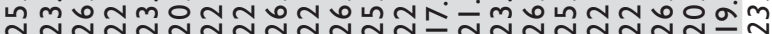

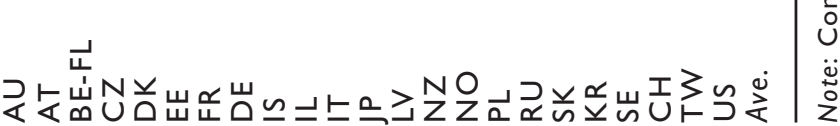


latter not an explicative variable. Parental class, however, is more inconstant. Mother's class contributes above average to the axis in only ten cases, usually at a lower level than books and acquired cultural capital (Latvia and Russia are exceptions), while father's class is explicative in 13 cases and, again, usually to a lesser extent than education level and books in the family home (Switzerland is a marginal exception), though in some cases there is more parity.

Examining the relative contribution of household income to Axis 1 reveals that it remains important in 16 cases, though to varying extents. It is typically, though not always, a little less important than education and books in the family home to the axis. Indicators of wealth, however, are now disclosed to be almost universally explained variables on the axis, with a characteristic contribution of around 7 percent. In only three models (for the Czech Republic, Taiwan and the US) are savings explicative and in only the US space is home value key (and more so than inherited cultural capital). What this means, therefore, is that the prime axis of differentiation can only reasonably be characterised as proxying capital volume in three cases. These are (i) the Czech Republic, where acquired cultural capital (education), inherited cultural capital (books) and economic capital (savings) all play an active role; (ii) Taiwan, where education, books, income and savings are explicative; and (iii) the US, where education, income, savings and home ownership are key. Education plays the lead role in the first two cases, while in the US the axis is really defined by economic capital and acquired cultural capital.

Six of the models, it transpires, now have a prime axis defined exclusively by cultural capital, both acquired and inherited, even if the contribution of father's class to the axis may indicate something else too (and it should be borne in mind that income is often very close to being explicative). These are Austria, Estonia, Italy, Latvia, Norway and Russia. The remainder of the models possess a prime axis that can be characterised as cultural capital plus income, with income typically being of lesser importance than education and books in the family home but as important as or more important than parental class.

\section{The second dimension}

What, then, of the second dimension of difference? The most striking feature, revealed by even a quick glance over the factor loadings, is the predominance of precisely those variables least important to the first axis: savings and property value. There is some variation across samples, with factor loadings for both indicators being higher in some models than others, but their association with the axis is nonetheless clear and uniform. The relationship with income, however, is less powerful or consistent. It is usually correlated positively with the dimension - the exceptions are 
the US, where the whole axis is flipped, and Latvia, where the coordinate sits close to the origin - but only fairly weakly. In only four cases does it breach the threshold of 0.4 , and in only one (Poland) is its factor loading greater than that of either savings or property value. ${ }^{2}$ For most samples, therefore, the 'positive' character of this dimension is defined by higher holdings of wealth.

Looking across the indicators of social and cultural capital, on the other hand, the first finding is that these are almost all negatively correlated with the axis, indicating, perhaps, an opposition according to capital composition. There are exceptions: in the models for Denmark, Italy, Poland and Russia the correlation of education level with the axis is positive, but so close to the origin as to render it effectively neutral on the axis. Taiwan and South Korea also continue their particularity vis-à-vis mother's class by seeing it load positively on the axis, contrariwise to father's class, and substantially so in the case of South Korea. Again, however, this is related to the ordering of the categories, with having a mother who did not work falling in the middle, and in both cases, as might be expected, having a mother in non-manual work corresponds with the low-wealth/high cultural capital pole of the axis (vector coordinates for this category are -1.1 and -0.8 for the Korean and Taiwanese models, respectively) and having a mother in routine manual work corresponds with the high wealth/low cultural capital end (coordinates 0.7 and 0.3 ).

Otherwise, however, education level, books in the family home and class of both parents follow vectors proceeding in the opposite direction from those of wealth possession. That said, the correlations are not usually strong. Only in Japan does the loading of education level on the axis exceed -0.4 , and in most cases it is relatively close to the origin. Number of books has a

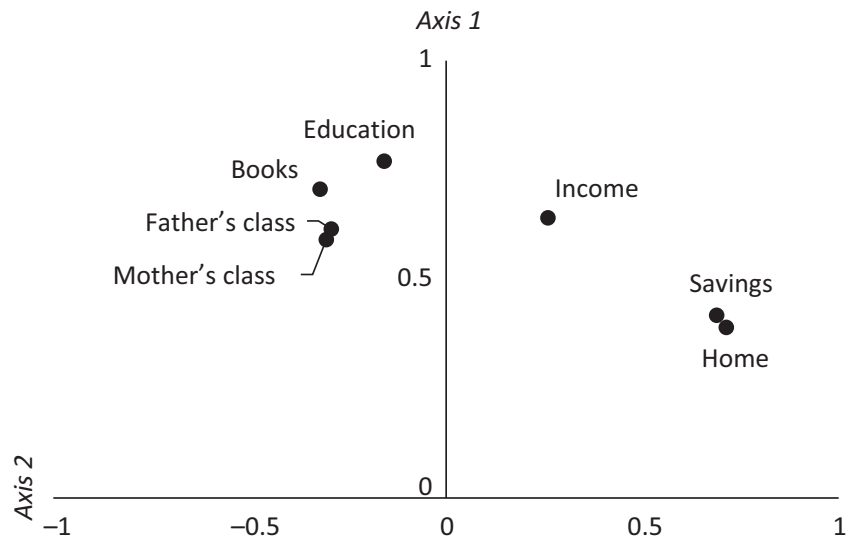

Figure 3.I Average factor loadings on Axes I and 2. 
higher average negative loading, but only becomes notable in four samples those for France, Germany, Switzerland and the US - and in no model does the figure go below -0.5 . The pattern is similar for father's class, where the variable correlates negatively with the axis to a substantial degree only in the models for Flanders, the Czech Republic, South Korea, Switzerland and (once flipped) the US, and only below -0.5 in South Korea. Mother's class position plays a more active role, however, being a key element in 11 models, though again the loading is only below -0.5 in two models. All in all, then, there are 15 instances where the case could reasonably be made that the second axis of differentiation taps specifically into capital composition, though mainly via inherited cultural capital. In only four of those, however, does more than one indicator of cultural capital play an important part in codefining the axis alongside economic capital: Flanders, the Czech Republic, Switzerland and the US. In the remaining models the second axis is most accurately characterised as one of low/high wealth, though the tendency for negative correlation with indicators of cultural capital, particularly inherited cultural capital, cannot be ignored.

Examination of relative contributions of variables to the axis inertia once again sharpens our view of what is going on. First, as might be expected, value of saving and property are by far the strongest contributors across almost all models. Both typically account for between 20 and 40 percent of the variance, with the figures being particularly high in the model for Australia, Latvia and Russia. There is usually parity between the two, moreover. In the cases of Germany, Israel, Slovakia and Taiwan the value of property becomes noticeably more explicative than savings value, and in Italy and Poland the reverse relationship emerges, but otherwise the two indicators of wealth can be said to be almost equal partners in defining the second axis across most models. Second, continuing the theme that transpired when examining the factor loadings, household income is generally far less important to defining the axis than the other indicators of economic capital. In the same four models where it loaded above 0.4 - Austria, Italy, Norway and Poland - it can be considered explicative, though only in Poland is it more important than an indicator of wealth. Elsewhere it is most certainly an explained variable.

Third, the importance of economic capital to the axis is so great that wealth becomes exclusively explicative, or explicative in conjunction with income alone, in 16 cases. In the remainder, one or more indicator of cultural capital also becomes explicative. In no cases does education contribute above average to the axis, and in only two does the variable for books in the family home. Father's class plays a role in the Czech space and the Korean space, but a more frequently explicative indicator of inherited cultural capital is mother's class, which contributes above the average in six models, including the Czech and US spaces again but also South Korea, where we have seen the negative loading hides the same patterning of mothers in manual 
and non-manual work as observed elsewhere. In sum, the second axis can be argued to approximate capital composition in only seven cases, and in only the US, the Czech Republic and South Korea (arguably Germany too) is it not heavily weighted by wealth. In all other instances the axis is confirmed to be one distinguishing high/low wealth, even if this tends to coincide with, and 'explain', inverse vectors for (inherited) cultural capital. ${ }^{3}$

\section{The statistical model and the constructed model}

In only a handful of cases, then, is the classic structure of capital volume and capital composition proxied by the first two dimensions of the statistical models. The typical space is, instead, characterised by a prime axis distinguishing those with high cultural capital and income from those with low cultural capital and income and a secondary axis polarising those with high wealth holdings and those with low wealth holdings. If we plot the average factor loadings in a two-dimensional space we can see the importance of education to the first axis and wealth to the second axis (Figure 3.1). We also see the weak - but still positive - correlation of the wealth variables with the first axis. The close correspondence of indicators of inherited cultural capital, furthest to the left, and their opposition to indicators of wealth become visible too. Finally, it becomes clear that household income, while strongly associated with the first axis and only weakly related to the second axis, still, on average, sits between the indicators of wealth and cultural capital, following a vector in what might be described as a roughly north-north-easterly direction.

Are we to infer from this arrangement of vectors that the major principle of difference and domination in the societies studied is not, strictly speaking, volume of capital but cultural capital plus income? Is the secondary principle of difference not really capital composition but high and low personal wealth, which only modestly runs counter to holdings of cultural capital? Could the latter be indicative of the increased prominence across capitalist societies of the 'super rich' or 'super privileged' of the kind recently spotlighted by several analysts (Dorling, 2014; Keister, 2014; Picketty, 2014; Sayer, 2015; Hay and Beaverstock, 2016)? Possibly, though the fact that capital composition does emerge on the second axis in the model for the US, a social order particularly polarised by income and wealth holdings, gives grounds for caution. Indeed, it would be foolhardy to jump too quickly from the statistical model to the constructed model generally, since the former is beholden to specific technical features like the number and nature of variables and variable categories - with indicators of subject studied, parental education, share ownership and so on, and with different pre-given cut points for the indicators of economic capital, the models could have come out 
differently - not to mention the modest sample sizes. There is also the little matter of logic. Those with higher inherited cultural capital and income and higher wealth are still surely the most advantaged in a social order - the furthest from necessity, one might suppose, facing specific experiences and opportunities and acquiring certain interests and dispositions in adaptation while those with neither are the least advantaged, forming the major principle of social difference, and those with a high stock of one type of capital but not the other are advantaged to a lesser degree than those who hold both and in different ways.

There is, however, another reading of the spaces produced by the statistical analyses - one that does not directly equate quantitatively deduced axes with salient social principles of difference, that does not mistake the model of reality for reality itself and which recognises that empirically derived representations based on specific techniques and measures can produce approximations of greater and lesser detail and distortion. For ultimately, if it can be said that in most cases the first axis of the models tends to distinguish primarily high/low cultural capital and the second primarily high/low wealth, with income cleaving somewhere between, then ipso facto there is, running through the middle of those axes, a hypothesised vector for capital volume and, orthogonal to that, one for capital composition. In other words, the clouds of individuals underpinning the detected axes are logically still structured according to capital volume and capital composition, even if that fact is hidden or obscured by the operations of the chosen statistical technique. ${ }^{4}$

The gap between statistical axes and hypothesised axes is a question of degree, however, since the patterning of variables along the principal components and the extent to which they deviate from the classic volume/composition dichotomy vary. A simple operation can, in fact, give us some handle on this. By taking the mid-point on both axes between the mean loading of the indicators of cultural capital, on the one hand (disregarding mother's occupation in Taiwan and South Korea), and the mean loading of indicators of economic capital, on the other hand, we can approximate the vectors for capital volume and (positing a perpendicular relation) capital composition. With the help of some basic geometry and trigonometry we can thus calculate the degree of clockwise rotation required to move from the statistical axes to the hypothesised axes of capital volume and composition, or the extent of 'tilt' within each of the statistical models. Thus it transpires that the average tilt is 13.5 degrees in the space, but that it varies considerably from model to model (Figures 3.2 and 3.3). As might be expected from what we have seen so far, the rotation is smallest in the US and the Czech Republic, but also South Korea and Taiwan as well as Germany. The tilt is most pronounced, meanwhile, in Italy, Russia, Australia, Austria, Israel and many of the Nordic countries. 


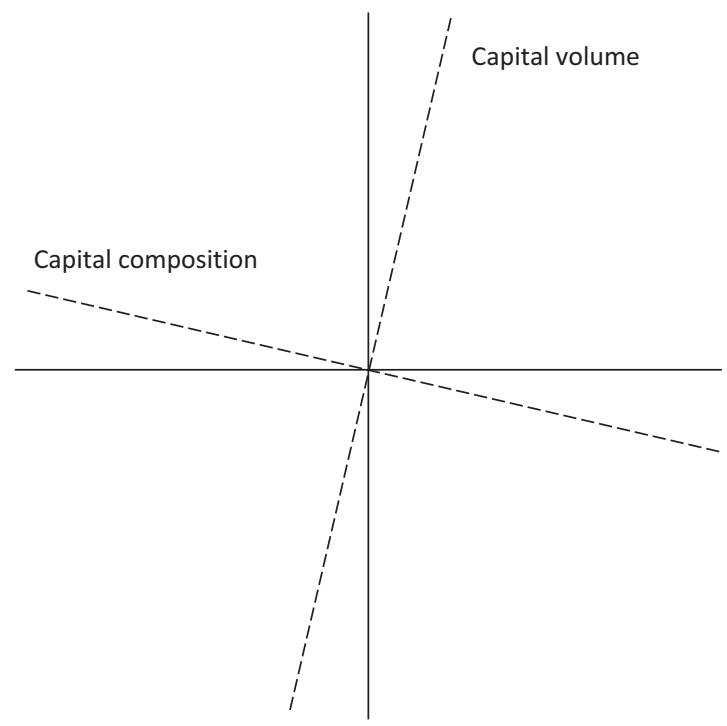

Figure 3.2 Average modelled vectors for capital volume and capital composition.

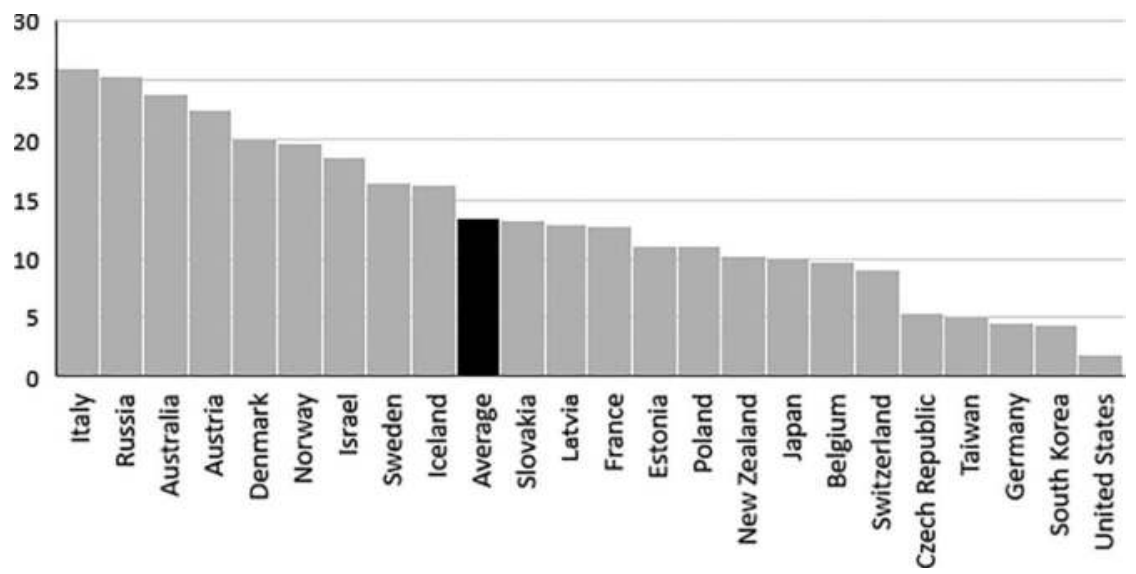

Figure 3.3 Degrees of rotation between CatPCA axes and modelled vectors for capital volume and composition.

\section{The shape of class}

Now that we have explored the basic structural relationship between indicators of capital across social orders, and detected within it the universal existence of vectors for capital volume and capital composition, we need to examine the apparent 'shape' of the class structure by investigating the distribution of individuals in the resultant spaces. Is there an even spread, 
as found in many Nordic studies, or are there regular sites of concentration and dispersion indicating areas of greater and lesser differentiation? Are there, moreover, any skews in the distribution of individuals following, for example, the hypothesised vectors for capital volume or composition? Initial inspection of the spaces of individuals reveals that many, like Australia, appear to be characterised by fairly even dispersion while others, like Austria, clearly display zones of greater and lesser homogeneity - specifically, in this case, a homogenisation of those with low cultural capital in terms of their economic capital (Figure 3.4). A more systematic yet straightforward method to assess the general tendency, however, is to cut each axis into three categories - low, middle and high - based on frequency terciles and determine their respective means (i.e. the coordinates for their central tendency) and standard deviations in both dimensions (Tables 3.4 and 3.5). The segments will have slightly different meanings depending on the degree of divergence between statistical axes and conceptual axes, which must be taken into account in interpreting the results, but this will nevertheless unveil any regularities of slope and span across the models.

Focussing on the aggregate level patterns, and beginning with the segments on Axis 1 - i.e. those high, middling and low in terms of cultural capital and income - the first finding to note is the lack of any obvious skew of their respective mean positioning on Axis 2 of the kind that might indicate a relationship with the posited vector for capital volume (Figure 3.5). The average central point of each sector sits astride the line of Axis 1. Next, the standard deviations for the three categories along Axis 1 indicate greater vertical dispersion at the bottom and the top than in the middle, with the upper region being most dispersed of all. In other words, the middle tercile is typically relatively homogenous in terms of its holdings of cultural capital and income, whereas the bottom and the top are a little more heterogenous. This
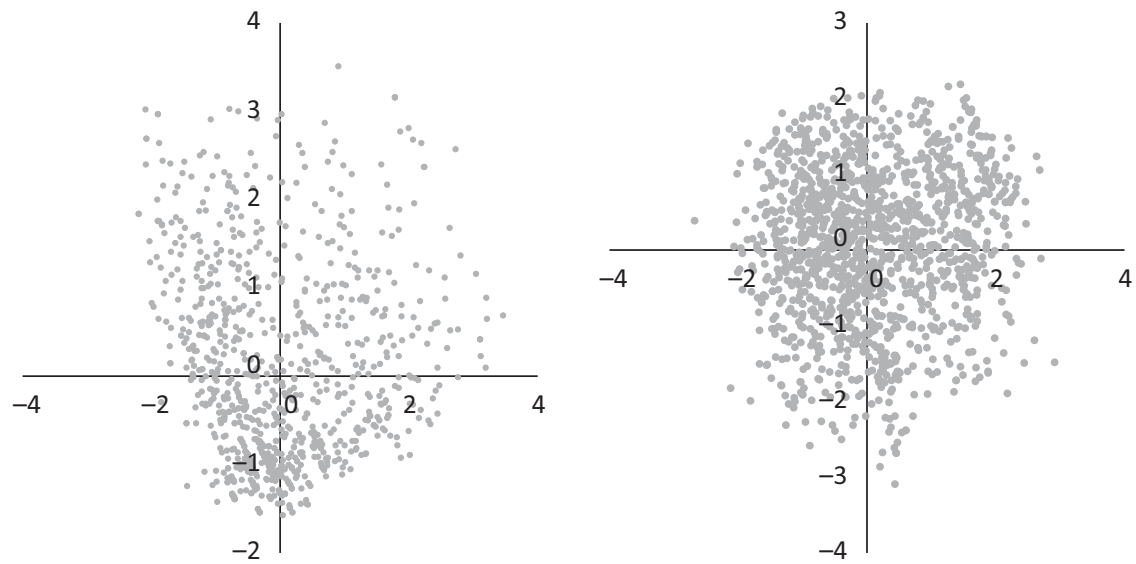

Figure 3.4 Two spaces of individuals: Austria (left) and Australia (right). 


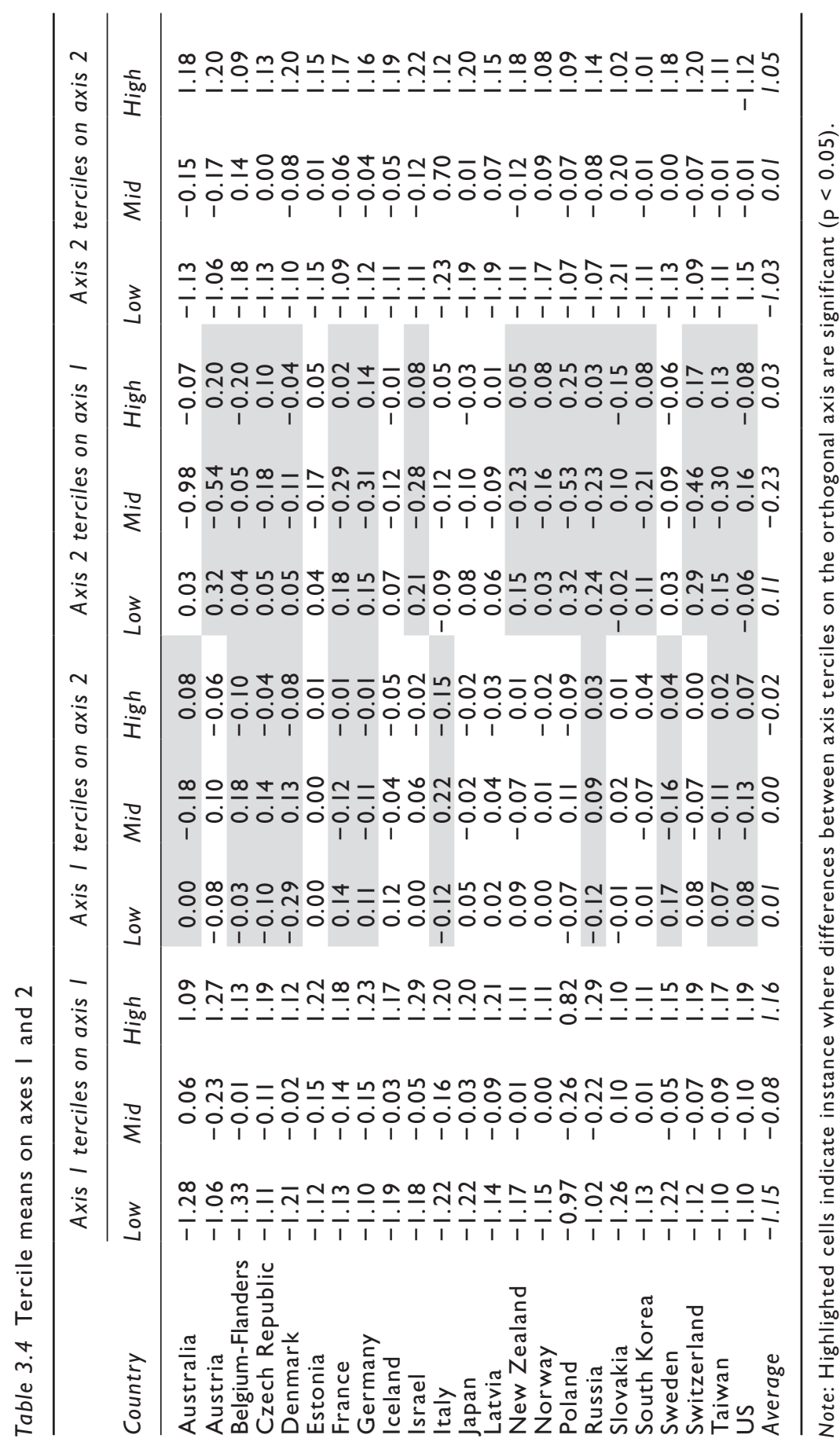




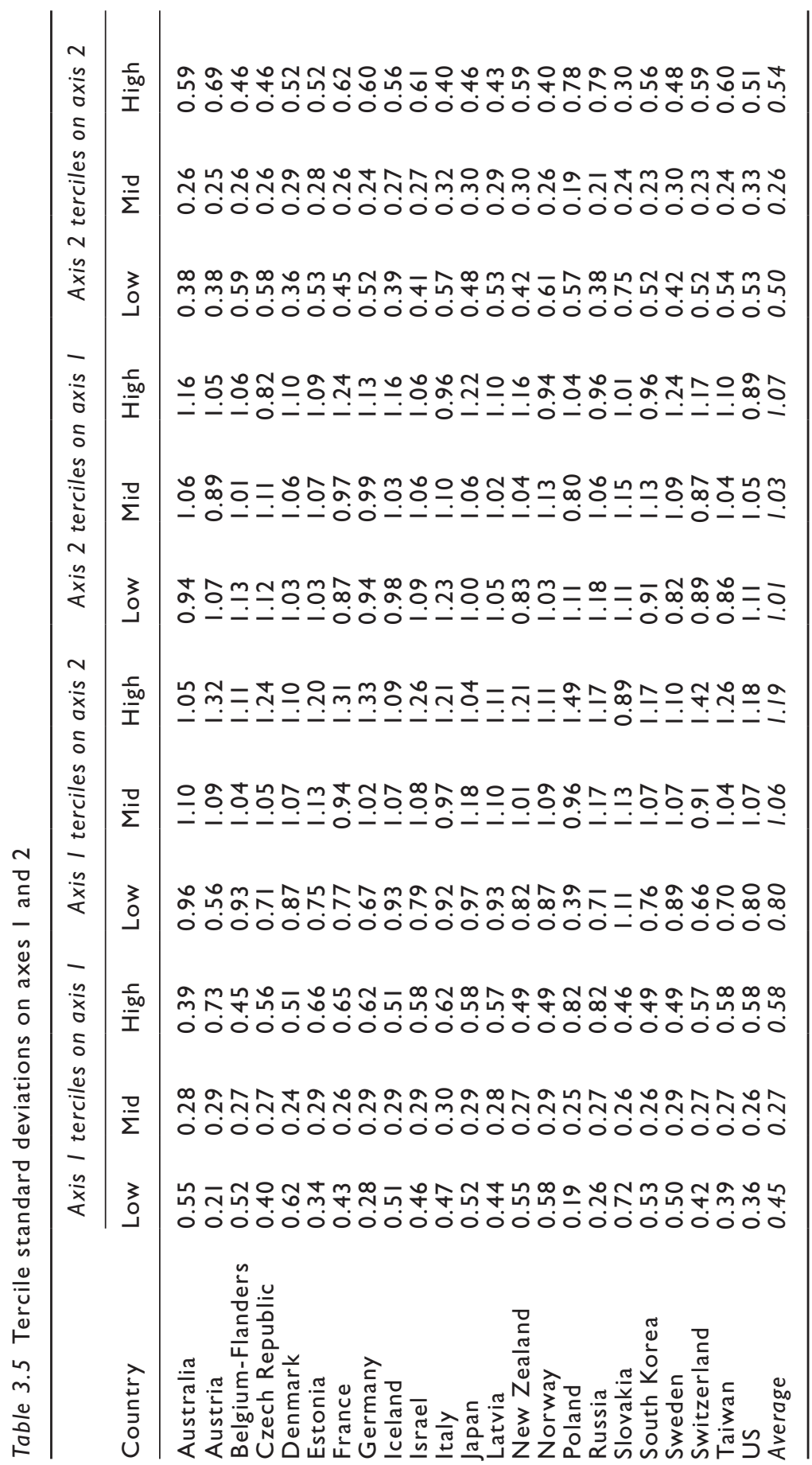


would seem to suggest the scatter of individuals along the axis approximates a bell curve and that, therefore, if diagrammed purely in terms of frequency distribution it would fall into some sort of diamond formation. As popular as that polygonal image might generally be for rendering contemporary class structures, however, it is misleading: the class structure is multidimensional, and the distribution of individuals determined by more than one principle, as the third discovery makes clear: there is a pronounced tendency for the regions on Axis 1 to become progressively more dispersed along Axis 2, i.e. in terms of their wealth (and inherited cultural capital), as they rise up the model. The bottom segment, poorest in cultural capital and income, is thus the least dispersed laterally, and its constituents thus tend to hold similar stocks of wealth, whereas those at the top are clearly most scattered according to wealth and, secondarily, inherited cultural capital, with the middle category, on average, in between. This is reminiscent of the inverted triangle distribution of individuals in the UK space along the capital volume axis.

Turning to the three sectors of the wealth axis, it can be seen that, unlike the groups on Axis 1, there is some separation from the axis line. There is, to be more precise, a slight tendency for those higher and lower in wealth to be above the axis line and a moderately more pronounced downwards drag of the middle wealth group. In other words, there is a correspondence modest as it may be - between lower stocks of cultural capital and income, on the one hand, and middling stocks of wealth, on the other hand. When it comes to dispersion along the axes, the same pattern revealed along Axis 1 reappears: the middle sector is much more compressed on Axis 2 than the bottom and top sectors, indicating homogeneity, though the difference between the top and bottom is trifling. However, there is a clear divergence
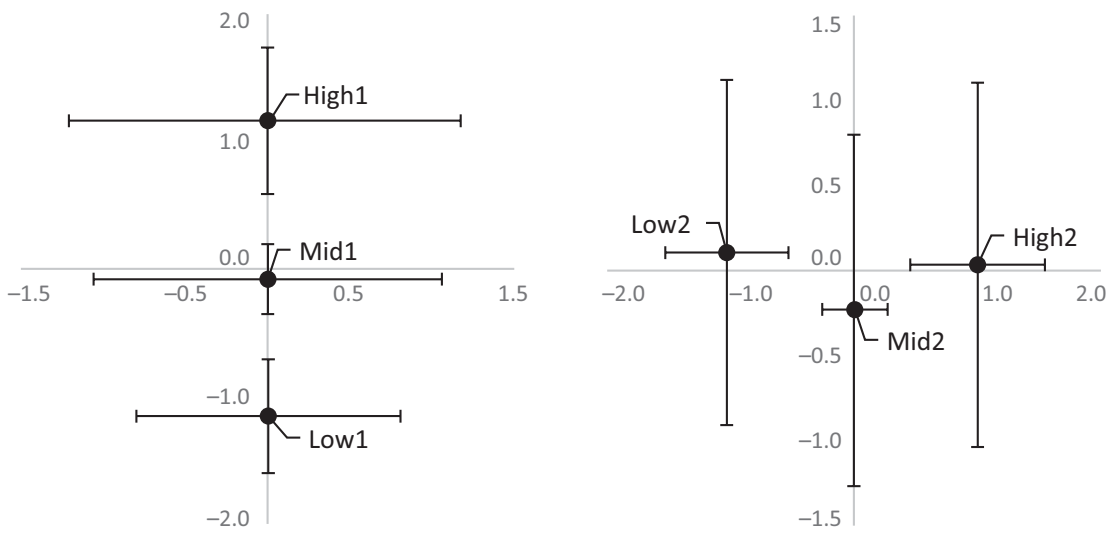

Figure 3.5 Average means and standard deviations of axis terciles on Axes I and 2 .

Note: The figure on the left displays data for terciles on Axis I, and the figure on the right displays data for terciles on Axis 2 . 
in the distribution of individuals across the perpendicular axis. Unlike the terciles of Axis 1, the internal dispersion of those high, middling and low in wealth and inherited cultural capital along the axis of cultural capital and income emerges as both wide and fairly equal from group to group, though the mean positioning of the middle group means more of its constituent members sink towards the bottom of the space and fewer are at the top. This finding perhaps needs to be taken in conjunction with the aggregate trend on Axis 1, though. A more accurate rendering of spread within the space would have the lower whiskers of the high- and low-wealth categories pulled in towards the low cultural capital sector on Axis 1 and the respective upper whiskers turned outward from the axis, indicating the inverse slopes of an upturned triangle. ${ }^{5}$

It should be reiterated that if individuals are, on aggregate, distributed along a roughly triangular formation it is not, strictly speaking, in relation to capital volume and composition, since the posited vectors for these principles if division usually run at distinct tangents to the statistically derived axes, but vis-à-vis cultural capital/income and wealth. When thinking about the patterning of individuals relative to the theoretically posited (and so far confirmed) axes, then, some very specific conclusions emerge. One of these is the relatively large and dispersed zone of individuals higher in cultural capital and lower in wealth and, in contrast, the smaller spread of those with the opposite holdings. Everything would seem to indicate that those who are poor in both cultural and economic terms are relatively sparse compared to those with little cultural capital but a modicum of wealth in the form of savings and home ownership. This could well be an effect of the variables and their categories, but it could also be that it indicates something of the changing shapes of social spaces across deindustrialising capitalist nations with expansive education systems. On the one hand, and continuing trends first spotted in Distinction but also resonating with later work by others (e.g. Bukodi and Goldthorpe, 2018), it could well signal the growing number of those who are relatively highly educated, and who have grown up with parents in an expanding professional-managerial bloc, but who have not (yet) managed to accumulate substantial savings or a home of their own. On the other hand, the enlarged education system might well have diminished the numbers of those with little economic and cultural capital, and instead those with little in the way of cultural capital (but also lower incomes) are likely to have accumulated a modicum of savings and home property because they are disproportionately of an older generation. These axes, as defined by these variables, may well, therefore, be tied up with trajectory effects, with the patterning of cultural capital and economic capital, both acquired and inherited, being intimately and inescapably bound to generational shifts, and the associated opposition of the old and the new, and reflect successive states of the system of reproduction in a single structure - a possibility that will be explored further in a later chapter. 
There are, of course, variations on and deviations from the aggregate patterns across the national samples. Some spaces of individuals, for example, are more dispersed along the cultural capital/income axis than others, with the models for Israel, Flanders, Italy and Japan being the most stretched while those for Poland and South Korea are the most compressed. Similarly, some spaces are dispersed along the wealth axis to a greater degree than others, with Japan and Italy once again evincing considerable spread and Poland and South Korea being most compact. There are also differences in the degree of 'dip' displayed by the middle zone on the second axis, in the degree and nature of the divergence between the top and bottom categories of Axis 1 on the wealth axis, and in whether or not the deviations between segment means on the cross-cutting axis are statistically significant or not. The standard deviations also reveal sectors to be more or less spread vertically and horizontally across different models, making it possible to see which are more like Australia (e.g. Iceland and Sweden) and which are more like Austria (e.g. Poland and Switzerland) in the general shape of the space of individuals as well as which display their own distinctive patterns (e.g. the diamond model of Japan).

Not too much should be read into the specific discrepancies between national samples, however, since the precise distribution of individuals is linked to the constitution of the component variables, that is to say, their numbers of categories and the distribution of respondents across them. This is, arguably, less problematic for Axis 1, where the major relevant measures are mostly uniform in their internal composition and the distribution of respondents across them sociologically telling, but more troubling for Axis 2, where the number and spread of individuals across salient categories are more variable even if efforts were undertaken to achieve a degree of cross-model parity. Ultimately, the sample variations may be useful to bear in mind as context for analyses that follow, but they should not be taken to mean anything substantial about how the shape of the class structure actually varies from one nation to another. That would be to move too hastily from the model of reality to reality itself. The core finding has to be, instead, the general tendency, for all the minor differences between samples, for the space of individuals to bear a skew towards the high cultural capital/low economic capital pole.

\section{Principles of variance in axis strength}

If sample specificities regarding the spread and pattern of individuals within the derived spaces cannot be readily taken as indicators of national divergences, might the same be said for discrepancies in the relative strength of the two major axes of difference? There are, after all, substantial differences in the amount of inertia explained by the primary and secondary dimensions across the models. The first axis is particularly forceful, for example, in Poland, Flanders, Slovakia and Taiwan but more modest in Iceland, Norway, Switzerland and Denmark, while the second axis is relatively pronounced in Norway and Israel but weaker in Poland, Taiwan and the Czech Republic. 
The difference in strength between the two dimensions is widest in Taiwan and Flanders, but there is greater parity in the models for Iceland, Norway and Denmark. Could this be due to the number of categories in the variables and any imbalance between the cultural and economic indicators? An initial examination of the relationship between axis strength and the space of individuals reveals no obvious connection between the two - strong primary axes can characterise spaces that are compressed or stretched (e.g. Flanders and Poland), while spaces that were markedly different in their dispersion of individuals can have similar axis profiles (like Austria and Australia). It also seems telling that weaker primary axes, and greater axis balance, characterise the egalitarian and more highly educated Nordic societies, raising the question of whether differences may follow cross-national tendencies in the accessibility and distribution of specific manifestations of capital.

A simple way to test whether axis strength is related to political economy is to examine the bivariate correlations between explained inertia on each axis and a range of indicators bearing on the institutionalised distribution of capital within nations. In the case of economic capital we can use the Gini coefficients for both income and wealth at the time of the ISSP survey. In the case of cultural/social capital we can examine the relationship with the average age of leaving education, the proportion of individuals who had a parent in a professional/managerial role when they were growing up and, to balance that, the proportion having parents in routine manual work. These factors are, however, indissociable from broader structural tendencies, specifically the industrial and occupational constitution of social orders in the present and recent past. The more highly educated the sample, and the more the respondents and their parents are/were in professional-managerial, or at least non-manual, jobs, the more likely it is, one might assume, that they derive from a social order (long) oriented towards knowledge production, service provision and/or specialist technical skill rather than heavy industry and mass production. To add further context and confirmation, therefore, we can add other related indicators bearing on these which might be taken to measure the degree of deindustrialisation of a social order: the proportion of the workforce in the service sector, the proportion of respondents in professional or managerial positions, the proportion of respondents working in the public sector and the proportion of GDP expenditure on education.

The relationship with the share of women in employment is also explored on the grounds that greater workforce participation among women may generate a greater uptake of higher education, and, given its prominence in some models, the correlations with the proportion of respondents with a mother who did not work when they were young are also investigated. Both relate, ultimately, to the present and past state of the gender regime of nations, that is to say, the degree to which women's employment is encouraged or discouraged by national doxa regarding men's and women's roles and specific policy programmes (parental leave, childcare subsidies, family wage policies, etc.). Sample size calculations indicate that only correlations above 0.56 , assuming 
a p value of 0.05 (two-tailed), should be taken seriously, and even then the small number of cases demands caution in interpreting the results, but they may nevertheless signal something systematic. Moreover, given the specificity of the axes in the Czech, German, South Korean and US models correlations have been run both including them and excluding them (in which case correlations need to exceed 0.598 ) to see if they make any difference. ${ }^{6}$

The statistical relationships between the axes and a discrete series of interconnected indicators suggest that differences in the degree to which cultural capital (and income) differentiate people compared to wealth may indeed be related to specific features of industrial composition (Table 3.6). It transpires that the strength of Axis 1 is negatively correlated with education and specific features of occupational/industrial structure. Some of these like the proportion of respondents in professional-managerial positions or the proportion of the workforce employed in services - are below the threshold of interpretability, but it can be more confidently inferred that the higher the average years of education, the higher the rate of female employment and the lower the number of people with parents in routine jobs, the weaker the differentiating power of inherited and acquired cultural capital. The tendencies are marginally more pronounced when the divergent models are excluded. Axis 2, meanwhile, displays reverse tendencies, though the relationship with years of schooling and the rate of female employment are not quite strong enough to be taken too seriously. It can be more securely argued that the higher the proportion working in the service sector and the lower the proportion with parents who were in routine work, the greater the differentiating power of wealth (and inherited cultural capital). The patterns are similar whether the American, German, Korean and Czech models are included or not, though most of the key relationships become a touch stronger, and the relationship between social origins and Axis 2 a little weaker, if they are excluded. ${ }^{7}$

Whatever the limitations of this analysis, and there are many, it is enough to firm up the hardly outlandish notion that the differentiating power of education and social origins may well lessen when more people - including women entering the workforce - are highly educated and have parents in non-manual (if not necessarily professional) roles. This might even play out in the everyday sense of difference, as people with university degrees or white-collar parents are simply more common. At the same time, however, it could be that with more refined indicators of cultural capital the inertia of Axis 1 would increase in those cases where it is currently weaker. In some social orders, having a degree or a white-collar parent might be crucial for differentiating conditions of existence and the feel for the game, but where they are more ubiquitous it may well be that holding a degree from a specific institution or in a specific subject, or having a parent in a specific (higher) profession, become more important both structurally and perceptually. Such is the relational nature of the social world. 


\begin{tabular}{|c|c|c|c|c|}
\hline & \multicolumn{2}{|c|}{ All models } & \multicolumn{2}{|c|}{ Adjusted } \\
\hline & Axis I & Axis 2 & Axis I & Axis 2 \\
\hline Average years of education ${ }^{a}$ & $-0.659 * *$ & $0.478 *$ & $-0.709 * *$ & $0.53 I^{*}$ \\
\hline $\begin{array}{l}\text { Prop. of GDP on education }{ }^{b} \\
\text { Proportion in professional/ } \\
\text { managerial jobs }\end{array}$ & $\begin{array}{l}-0.392 \\
-0.497 *\end{array}$ & $\begin{array}{l}0.504^{*} \\
0.400\end{array}$ & $\begin{array}{l}-0.380 \\
-0.543^{*}\end{array}$ & $\begin{array}{l}0.438 \\
0.326\end{array}$ \\
\hline $\begin{array}{l}\text { Proportion with parents in } \\
\text { professional/managerial jobs }{ }^{a}\end{array}$ & -0.343 & $.0480 *$ & -0.360 & 0.392 \\
\hline $\begin{array}{l}\text { Proportion with parents in } \\
\text { routine work }\end{array}$ & $0.610 * *$ & $-.0611 * *$ & $0.636 * *$ & $-0.591 * *$ \\
\hline $\begin{array}{l}\text { Proportion with a mother who } \\
\text { did not work }\end{array}$ & 0.281 & 0.194 & 0.264 & 0.252 \\
\hline Rate of female employment ${ }^{\mathrm{a}}$ & $-0.632 * *$ & $0.422 *$ & $-0.657 * *$ & 0.348 \\
\hline $\begin{array}{l}\text { Proportion in service sector } \\
\text { employment }{ }^{c}\end{array}$ & $-0.457 *$ & $0.746 * *$ & $-0.540 *$ & $0.795^{* *}$ \\
\hline $\begin{array}{l}\text { Size of public sector } \\
\text { Income Ginic } \\
\text { Wealth Ginic } \\
\text { GDP rank }{ }^{c}\end{array}$ & $\begin{array}{r}-0.360 \\
0.072 \\
-0.142 \\
-0.342\end{array}$ & $\begin{array}{l}0.163 \\
-0.052 \\
0.07 \\
0.072\end{array}$ & $\begin{array}{r}-0.344 \\
0.074 \\
-0.156 \\
-0.325\end{array}$ & $\begin{array}{r}0.049 \\
-0.200 \\
-0.030 \\
0.042\end{array}$ \\
\hline
\end{tabular}

Notes: Shaded cells indicate correlations meeting the sample size criterion.

Sources: ${ }^{a}$ ISSP; ${ }^{b}$ UNDP (http://hdr.undp.org/en/content/expenditure-educationpublic-gdp); ${ }^{c}$ World Bank (2009 data).

* Correlation is significant at $p=0.05$ (2-tailed).

$* *$ Correlation is significant at $\mathrm{p}=0.01$ (2-tailed).

A large service sector and lesser probability of having parents in routine manual work - and ipso facto a greater probability of having parents in non-manual work, indicative of deindustrialisation - go hand-in-hand with polarisation according to wealth and inherited cultural capital, that is to say, it augments the opposition between those who are educated and originate from higher echelons of the social space but have fewer economic resources and those with lower inherited cultural capital but substantial wealth. Perhaps the superabundance of individuals in the spaces rich in cultural capital but poor economically are disproportionately working in newer, lower-paid service-sector jobs - a possibility to be explored later.

If indeed it can be said, on the basis of what we have seen, that the constitution of the social space - i.e. what matters and how for defining difference - is linked in some way to the degree of deindustrialisation and governmental action to expand access to higher levels of education, and if deindustrialisation and educational expansion can be said to be - at least in part, as other factors will be involved - strategies pursued by state actors in the space of states, as means to improve economic standing and political voice on the world stage, then it becomes clear that the shape of the class structure, and all the everyday practices and perceptions it spawns, is irrevocably yoked to the position 
occupied and trajectory travelled by its home nation state in the global order. Given that the correlations are often modest and contain specific deviant models, however, it is worth emphasising that no iron law or universal determinism is posited here, only regularities across diverse spaces of difference in which myriad factors interact and intervene. Each nation's social space, ultimately, is the product of struggles and strategies within its own relatively autonomous field of power, with its own unique history (or 'path'), even if general principles of variation between fields of power given by position in the global field also delimit the space of possibilities for action.

\section{Conclusion}

There is, it would seem, a remarkable cross-national consistency to the structure of the relationship between fundamental components of capital in contemporary capitalist misrecognition orders. In all but a few cases, the first two dimensions of difference, using our chosen statistical procedure, were immediately discernible. The more substantial of these took the form of a high/low polarity based on cultural capital plus household income, demonstrating a close connection between inherited cultural capital and acquired cultural capital - social reproduction, in other words - as well as earning capacity. The other opposed those with low and high wealth holdings, which tended to have a negative, but not always strong, correlation with inherited cultural capital. Having a degree of personal wealth, therefore, is irreducible to cultural capital or income, effectively, in conjunction with the first axis, differentiating those with a high volume of capital in toto and those with low cultural capital, and even relatively low income, but ample savings and considerable home value.

In a few analyses the axes came out differently, distinguishing capital volume and capital composition in the manner posited at the outset. Yet even the remaining spaces do not refute the classical model of social space as defined by these two principles but, in their own way, confirm it instead. The spaces are structured in such a way that vectors for capital volume and capital composition unambiguously cut through them, with the 'tilt' between statistical model and conceptual model being a question of degree. The statistical procedure is not designed to bring out the social salience of sources of advantage and disadvantage or the fault lines of people's sense of difference, only the correlative relationships between variables, and so it is perhaps no surprise that it highlights the close connection between species of the same capital and their differentiation from species of other forms of capital. The fact that it does so means it approximates the heuristic model only in a specific way.

Inherited cultural capital and wealth play a significant role in differentiating people according to capital composition - more significant than either education or income, though they play their part too. It may well 
be, as already stated, that aspects of acquired, institutionalised cultural capital (subject, institution, etc.) would come out prominently if there were measures of them available, but it might also just be that, with social change - educational expansion, industrial transformation, growing wealth disparities and generational gaps - inherited cultural capital and the capacity to save and own a home have assumed greater importance than in the past. Only future research with a fuller range of capital indicators at its disposal will be able to adjudicate that for sure.

We saw that the spaces tend, on aggregate, towards a broadly triangular configuration and made the case that, when considered relative to the vectors for capital volume and capital composition, this indicates a greater or lesser - depending on the tilt of the model and the dispersion of individuals profusion of those with high stocks of cultural capital but lower stocks of economic capital and a relatively diminutive section of those equally poor in all forms of capital. This, we broached, may be linked to generational change. It also became clear that differences in axis strength may be rooted in the industrial-occupational constitution of nations, and possibly the gender regimes underlying female participation in the workforce, which are themselves indicative of a relationship between social spaces and positions in the space of states.

It might reasonably be claimed, in sum, that the first and most basic outcome of all that we have seen so far is solid confirmation that capital volume and capital composition appear to be universal principles of difference across capitalist nations old and new, with variations in axis strength indicating the relative importance of the elements of capital measured here. Along the way, however, myriad follow-on questions have inexorably presented themselves. Some of these relate to the yet-to-be analysed third dimension of difference in the models. What is its structure in each case, and is it the same across models or are there systematic variations? Does it relate to the third axis of the social space as posited by Bourdieu, i.e. trajectory? Others bear on the social characterisation of the two core axes of difference. What is the relationship between the spaces and gender, generation and occupation, and other factors for that matter? To what extent and in what ways do the spaces correspond with outlooks and practices indicating differences of ethos, or habitus, grounded in different conditions of existence, and with divergent perceptions and evaluations of one's place in the world? Do the correspondences fit with the detection of capital volume and composition in the spaces or follow alternative lines of division and opposition? Are they even arrayed multidimensionally at all, justifying the spatialisation of class, or are they, as those advocating one-dimensional visions of class and stratification might suppose, differentiated by capital volume (or cultural capital plus income) alone? The only way to answer these latter queries is to embark on a systematic examination of homologies, beginning first of all with the relationship between class and the occupational division of labour. 


\section{Notes}

1 Axis retention is based on several standard principles (see, e.g. Le Roux and Rouanet, 2004: 162; Linting and van der Kooij, 2012; DiFranco, 2016): (i) retention of all axes with an eigenvalue larger than 1 (the so-called 'Kaiser criterion'); (ii) retention of axes together accounting for a substantial proportion of the total inertia, here set at 70 percent; (iii) retention of axes explaining a substantial quantum of inertia for each variable (in this case a minimum absolute contribution to the sum of retained eigenvalues of 0.4 , though it was usually much higher); and finally, (iv) sociological interpretability. To aid selection the models were bootstrapped, generating 95 percent confidence intervals for each pertinent figure (Linting et al., 2007b). This allowed in some cases for retention of axes where critical values fell below the stated thresholds (e.g. eigenvalue $<1$, inertia $<70$ percent) but included the latter in their confidence intervals. The process is complicated by the peculiarity of the CatPCA procedure: one has to specify how many axes are to be retained before the analysis, and the results for a two-dimensional model will not, for example, be the same as those for a three-dimensional model. This means one has to experiment with different numbers of axes to determine the optimal results. In our case, operating with relatively few variables, the starting point was a two-dimensional solution, which was then extended to a three-dimensional solution, while further analyses of four-dimensional solutions revealed little extra insight but less adequate results (e.g. reduction of axes to single variables).

2 The Polish model is complicated by the existence of a third dimension polarising those with high savings but low property value and those with low savings but high property value.

3 Here the MCA models diverged slightly from the CatPCA models insofar as the former often contained certain modalities of inherited cultural capital especially a mother in professional/managerial position or having a large number of books in the family home - and, more rarely, acquired cultural capital contributing above average to the second axis. They were nearly always, however, so heavily outweighed by modalities of high and low savings and property value that interpreting the axis as anything other than primarily a wealth one was a stretch.

4 Rotating the axes using standard algorithms, experimented with despite the suspicion a GDA approach encourages, only exacerbates the issue by more firmly and universally distinguishing high/low cultural capital and high/low wealth on the two axes respectively.

5 This is, in all probability, what concentration ellipses would depict could they be calculated and diagrammed for the aggregate patterns.

6 That the Belgian sample represents Flanders alone should also be borne in mind when considering correlations of axis strength with variables not drawn from the ISSP sample.

7 Additional tests were undertaken to examine the possibility that axis strength is linked instead to operational procedure and, therefore, artefactual. Thus explored were correlations of inertia rates with: (i) the total number of categories in the model; (ii) the number of categories for the variables measuring cultural capital; (iii) the number of categories measuring economic capital; (iv) the discrepancy between categories for cultural capital and categories for economic capital; (v) and - to test whether axis strength is related to axis 'purity' - the proportion of inertia on each axis explained by variables of cultural or economic capital. No results were significant at the 5 percent level and coefficients were low $(<+/-0.4)$. 


\section{The division of labour of domination}

Class, as we know, is neither defined by nor reducible to occupation, but the two nevertheless entwine in myriad ways (Atkinson, 2009). Jobs and industries demand and repay certain species and quantities of capital, generating broad correspondences with sections of social space. These correspondences, in turn, nourish schemes of perception and evaluation, that is to say, practical association of certain occupational titles or domains with having or lacking money, education or connections, such that when we learn what somebody does for a living we intuit, however vaguely, the kind of person they may be - their likely tastes, outlook, and so on - and their social distance or proximity to ourselves. We may seek to present or designate our own jobs in certain ways to give off a particular impression, perhaps in a bid to 'claim the things normally associated with those words', i.e. 'the corresponding material and symbolic profits' (Bourdieu and Boltanski, 1975: 14120), or even, as Goffman (1951: 296) had it, as an attempt to 'signify a status the claimant does not in fact possess'. In this sense, like lifestyle practices, the homology between social space and occupations furnishes a system of signposts for recognising and asserting one's place and the place of others.

On top of that, however, the nexus between social position and occupation reveals the typical 'occupation effects' attached to zones of the social space and compounding the class habitus: kinds of physical spaces inhabited, characteristic working rhythms, workplace values and struggles and so on. Some of these are more or less imposed by others via circuits of symbolic power, but others shade into being field effects, that is to say, solicitations or demands to act in certain ways given the state of play in a struggle over a specific sub-species of capital, whether it be that at stake in an employing firm or organisation or that orienting players within a field of cultural or ideological production (art, science, politics, law, religion, etc.) nested within the field of power. In short, the nature of the correspondence between a social space and the occupational division of labour reveals something about the institutionalised reproduction of the social space, the everyday symbols and signifiers of location in social space and the patterned interplay of the forces of the social space with forces emanating from other, relatively autonomous, arenas of struggle. 


\section{Principles of classification}

In setting out to investigate the correspondence between the structure of capital and the distribution of occupations, however, the social scientist is immediately faced with the problem of classification. As Bourdieu (2019) stressed, the impulse to divide social reality into categories and endow them with specific names - including in relation to occupational clusters - is no self-evident or neutral operation. It is, instead, intimately entangled in the very processes of the social reality being categorised in at least two ways. First, the scholar's classifications are not divorced from the specific vision and interests attached to his or her position both in the social space and in the intellectual field - claiming such-and-such an occupation is equivalent to another and opposed to something else depends on what one takes the fundamental principles of difference and similarity to be, which can be as much a product of non-scientific investments as scientific principles and generate clashing perspectives on what counts as 'objective evidence' for classification and the processes it claims to illuminate. The classic case is Marxism, reaching its peak in the efforts of Poulantzas (1975) and Wright $(1985,1997)$ to construct typologies and grids of classes and class fractions in service, ultimately, of an overriding political cause, and the resulting conflict with the defenders of the EGP scheme who claimed, among other things, that whether or not class polarisation and proletarianisation could be found to be occurring, with all its postulated consequences for political mobilisation, depends entirely on how people are categorised (Marshall et al., 1988).

Here, with Bourdieu (1991, 2019), the overriding logic of occupational classification follows from the baseline premise that what matters are the objective relations of distance and direction regarding the major principles of misrecognition in capitalist social orders proxied by the models of social spaces constructed in the last chapter using indicators of core capital variants. Like the botanist or zoologist building taxonomies on the basis of a system of correlations between an ensemble of criteria, similarities and differences between occupations are, in short, posited according to associated capital profiles rather than productive function or employment relations. They are not, like Marxist schemas, infused with the desire to document (or encourage) possibilities for the emergence of real, mobilised social groups effecting social change, and unlike in the EGP scheme the resultant boundaries are acknowledged to be purely sociological constructs based on relational principles rather than grounded in substantial properties (Bourdieu, 1987a). The task here is not, however, to establish a universal proxy measure for social position that can then be applied going forward an endeavour which is neither necessary, given our capacity to inspect homologies using the geometric models already assembled, nor possible, since it would require bottom-up construction of categories using multiple indigenous datasets for each nation with much larger sample sizes than 
we have available in the ISSP (cf. Hansen et al., 2009; Atkinson, 2017). Instead, the charge is simply to test the hypothesis, derived from the work of Bourdieu (1984) and those after him, that the correspondence between capital holdings and occupations - and their associated fields - takes a similar, familiar form across capitalist social orders.

One part of this hypothesis holds that volume of capital, being a continuum defined by polarities and a middle, will correspond to a tripartite split. At the top will be the dominant class, so named not simply because its constituents experience the opportunities and advantages that come from relative distance from necessity but because they correspond with jobs and roles associated with authority and legitimacy to define some aspect of the world, including the value and exchangeability of capital, manifest in control over the production and dissemination of ideas and goods. Populating the field of power, they are the holders of symbolic power and the suppliers of the market of symbolic goods. Below them, the intermediate class is conjectured to correspond with jobs and roles demanding and perpetuating middling levels of capital and which are, in many cases, auxiliaries and functionaries of the field of power, i.e. nodes in the interweaving chains of symbolic power facilitating the delivery of its goods or decrees to the populace - clerical workers, lower-level socio-medical workers (e.g. nurses, counsellors, youth workers, entertainers) and technicians. The last of these, as 'masters of technique', include not just operators of specialised equipment (machines, robots, etc.), with a certain level of higher-level training, but implementers of specific practical procedures and operations allied to the field of power (brokers, bookkeepers, inspectors, police officers, etc.). At the bottom, the dominated zone of the social space is likely to be populated by those in jobs demanding little cultural capital and returning little economic capital, and thus furnishing relative proximity to necessity as well as scant symbolic power.

The other aspect of the hypothesis, however, concerns the internal fracturing of classes along the lines of capital composition. The supposition is that the contemporary manifestation in secular capitalist societies, including new ones, of the age-old opposition between the bellatores and oratores, or the powers temporal and spiritual, each pole struggling to impose its own principle of dominance as the dominant principle, is the opposition between the agents and allies of the economic field (employers, managers, business-oriented professionals), where economic capital rules, and the agents and allies of the intellectual field (encompassing cultural production and pedagogy as well as intellectual production narrowly defined), where cultural capital of various species holds sway. This division is likely to cascade into the intermediate zone of the social space, while at the bottom, among the laboratores, prior research suggests there may well be a division between skilled workers (plasterers, metal workers, electricians, farmers, etc.) and personal service workers (carers, attendants, hairdressers, etc.), the 
one being associated more with economic capital than cultural capital and the other with the reverse profile, with routine manual workers (machinists, labourers, cleaners, etc.) sitting in between (Hansen et al., 2009; Atkinson, 2017). Like the oppositions above them in the social space, any detected division between personal service workers and skilled workers, insofar as it entwines with educational expansion and industrial transformation over the preceding decades, and thus the struggles, mutations and practices of the bureaucratic and economic fields, may well be bound up with an opposition between the new and the old.

\section{A taxonomy}

The second entanglement of sociological classification in the social reality it classifies, not unconnected to the first, is its dependence on existing classifications produced by others. In this case, the construction of occupational categories takes as its raw material the categorisations generated via a whole system of prior, interest-laden decisions and interpretations. Where only a basic set of boxes founded upon an alien logic is available in a dataset - like the EGP scheme, for example - using this can lead to severe inconsistencies and blind spots, particularly regarding the role of capital composition. Even the most detailed and refined categorisation of occupations and the distribution of respondents within it, however, are the outcome of a multitude of social forces that must be laid bare in the name of epistemological vigilance. In our case, the ISSP dataset includes the International Labour Organisation's (ILO) International Standard Classification of Occupations (ISCO) at its most disaggregated (unit) level, with hundreds of precise occupational titles ranging from senior government officials and chief executives to forestry labourers and freight handlers. Being the creation of a body self-tasked with the international representation and defence of 'labour', thus bearing the sanitised traces of a Marxist worldview, its chief criteria for adjudicating classification are differences of skill and function in the production process. At the higher levels of aggregation suggested by the ILO - wherein, for example, all 'professionals', including 'business professionals', teachers and artists, are collapsed into one category - this undermines any effort to detect correspondences with the multidimensional structure of capital. At the unit level, however, there is greater scope for re-combination in line with the hypotheses deriving from our specific model of class and its relation to employment. 1

Thus, as a means to pursue an initial test of the homology between the social space and the occupational division of labour - or the division of labour of domination - a revised aggregation of the unit-level ISCO codes has been constructed. Following the discussion above, there are nine categories designed to capture three layers of capital volume as well as possible internal fissures by capital composition and, allied to that, position relative 
to the field of power. The postulated top tier comprises three categories. Running from the cultural side of the space to the economic side, these are: intellectuals (teachers, scientists, cultural producers), professionals (medical and legal professionals, engineers) and business executives (managers and 'business professionals' such as accountants). The three categories of the intermediate class, following the same sequence, are socio-medical services (as described above), clerical workers and technicians. The inner divisions of the dominated class, finally, are held to correspond with personal service work, manual work and skilled work. ${ }^{2}$ The schema is complemented by a second variable distinguishing employers and the self-employed.

Even the unit-level classification of occupations underpinning the taxonomy has limitations affecting its accuracy and adequacy. There is still, for one thing, a certain degree of homogenisation: those classified as 'medical doctors', for example, are in all likelihood - as a detailed analysis of any medical field would no doubt reveal - dispersed along multiple dimensions, with, for instance, seniority and specialism bearing some correspondence with the first two axes of the social space as well as differences of social origin. ${ }^{3}$ We certainly know from Bourdieu's (1993a, 1996b) work that this applies to the artists and writers populating fields of cultural production, riven by the antagonism between autonomous (artistic) and heteronomous (economic) forms of capital, and given the low numbers of respondents in each category there is always the risk of conflating the category, or field (or even multiple fields, as in the case of the category for 'authors, journalists and other writers'), with the specific position of a few individuals.

On top of the issue of homogenisation, there is the peculiar chain of social situations involved in the recording of someone's occupation in a survey ensuring that there is always a loose and variable relation between the nominal and the real (cf. Bourdieu and Boltanski, 1975). Being asked one's occupation, even briefly or remotely in a questionnaire, is not a neutral act but, assuming there $i$ a generally intuited correspondence between occupation and position in social space, and thus one's place in the misrecognition order, no matter what form it may take, a solicitation for articulation of one's relative authority and worth in the world. Respondents may offer their 'officially' designated job title - a label either imposed on them by others (bosses, managers, etc.) invested with the authority to nominate and with their own interests in nominating thus (perhaps offering specific titles in a bid to mask, to rival companies and workers themselves, the actual skill levels demanded and working conditions offered), or self-chosen. Either way the job title is inextricably lodged within relations of symbolic power and struggle. Or the respondent may opt - since they are not bound to give their official title in the survey situation, if they even remember it - to give a different designation, potentially very vague, which may function as a strategy of self-presentation insofar as she proffers a label designed to elevate her place in the eyes of others (and herself). The ‘technician' so titled by his employer may well believe 
himself to be nothing more than a 'glorified plumber' (Atkinson, 2010: 5.5), but equally a plumber may spontaneously describe himself as a technician so as to give off a specific impression to the interviewer and whoever they think may read the research findings. And then, of course, there is the final filter of the survey coder - the individual, with his or her own scheme of perception honed by specific training (perhaps in the logic of ISCO) and all the quotidian pressures on time and decision-making stemming from their lifeworld (language proficiency, deadlines, illness, family commitment and so on), tasked with translating the given job titles into the pre-set categories of the chosen scheme (not to mention the individual charged with translating indigenous labels into English for archiving).

All this is enough to remind us that when describing the properties of specific occupational categories one must always think in terms of 'those categorised as' rather than assume a ready congruence between the nominal and the real. It also encourages - as do the modest sample sizes at hand caution in interpreting the data, though greater confidence in the conclusions will come if examination of the aggregate pattern discloses evident cross-national regularities. Severe and constant discrepancies of correspondence from one model to another, on the other hand, may well signify national specificity, but they could also raise the possibility that the gap between the objective-structural and subjective-linguistic principles of division is generally too great to draw firm conclusions on the relationship between the social space, on the one hand, and occupations and fields, on the other hand - an interesting finding in itself, of course, but one which leaves the starting hypothesis untested.

\section{The distribution of individuals}

The distribution of respondents across the nine categories yields a first indicator of the imbalances inhering in the division of labour of domination (Table 4.1). As might be expected, the aggregate tendency is for the occupations postulated to carry little symbolic power to be the most numerous, comprising, on average, 46 percent of the samples, while the other two layers are more or less equivalent in size. Within each tier, moreover, there are some recurrent disparities: business executives tend to outnumber those categorised as intellectuals and professionals, for example; technicians tend to outweigh those in the socio-medical services; and manual workers tend to be more numerous than those in skilled work or personal services. If the homologies with capital possession are as expected, this would mean that the flank of the social space characterised by higher economic capital tends to outstrip the cultural side, at least in terms of paid employment.

Some differences between national samples are, however, systematic and comprehensible enough to infer that the specific structure of the division of labour of domination is attached to tendencies of industrial composition and political economy and, with that, location and strategy in the global space of nation states. We already know from Chapter 2 that the Nordic 


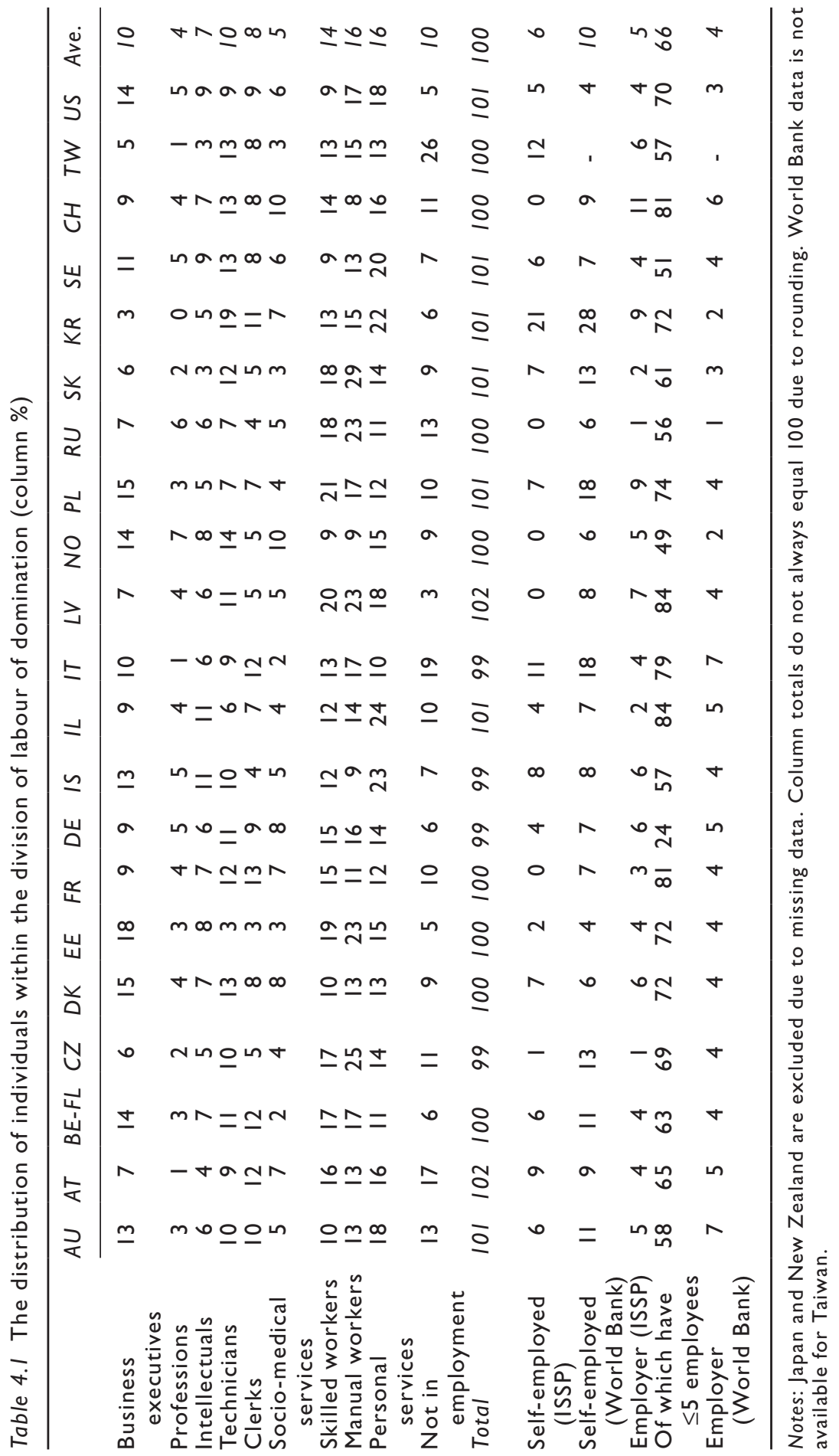


countries and the US have the largest proportions of workers in professional and managerial roles and that the rapidly developed East Asian countries have the smallest, but now, when set against the size of other layers of the occupational structure and intra-tier divisions, further and more nuanced patterns emerge. It transpires, for example, that the size of the professional-managerial blocs in the Nordic samples and the US derives principally from the considerable number of business executives there, though intellectuals have greater weight in Iceland than elsewhere. It also emerges that the diminutive size of the professional-managerial sector (and perhaps the field of power) in South Korea and, to a lesser extent, Taiwan is balanced against a relatively large proportion of people working in technical jobs - which is perhaps not surprising since the economy in these nations foregrounds electronics and hi-tech manufacturing. The post-socialist nations, meanwhile, tend to have the largest proportions of people working in manual and skilled work - but not necessarily personal service work, which is most sizeable in Iceland, Israel, South Korea and Sweden - as well as the smallest percentage working in the intermediate occupations. In Estonia and Poland this is paired with a noticeable skew within the posited top tier of the occupational structure towards business executives, which may well be an effect of a relative underdevelopment of the public and service sectors in those nations and reflect the stark polarisation between 'winners' and 'losers' of economic transformation and liberalisation postulated by others (Hugrée et al., 2011).

As for the self-employed and employers, who overlap with the nine categories, these each tend to account for around 5 percent of the samples. Self-employment is particularly high, however, in South Korea, Taiwan, Italy, Austria and Iceland and low - or absent from the sample - in the Czech Republic, France, Latvia, Norway, Russia and Switzerland. Employers, for their part, are particularly well represented in the samples for Switzerland and, again, South Korea, but few in the samples from Russia, the Czech Republic and Israel. The vast majority of these employers across all samples, it should be stressed, are small employers, i.e. they employ only five or fewer people. ${ }^{4}$ Large employers are present but only in tiny numbers. Comparison with figures from the World Bank, based on modelled estimates from the ILO for 2009, indicates there is a systematic tendency for the self-employed and employers to be underrepresented in the samples (Denmark and Iceland are exceptions), with the discrepancies being large in the Czech Republic, Italy and Poland. ${ }^{5}$ On the whole, however, the two patterns are not hugely out of step with one another and the specificity of the South Korean sample certainly accords with the ILO estimates.

\section{Correspondences}

The nine categories of the occupational schema, alongside the categories of the variable distinguishing employers and the self-employed, have been projected 
in to the statistical models as supplementary multiple nominal variables and subjected to tests of axis (a)typicality. The axes of the models, of course, are defined in slightly different ways. Axis 1 is sometimes a cultural capital axis, most often an axis of cultural capital plus income, and in a few cases a capital volume axis, while Axis 2 is generally a wealth axis, with a moderate negative relationship with cultural capital, and only in a few cases is it a more straightforward capital composition axis. As previously discussed, the result is a set of models with varying degrees of tilt between posited vectors for capital volume/composition and the statistically derived axes. To bring some uniformity to the analysis, therefore, and place the occupations relative to capital volume/composition consistently, coordinates for the supplementary categories have been re-calculated according to the computed degree of model tilt. ${ }^{6} \mathrm{We}$ cannot, however, run typicality tests on the new coordinates, so we will begin by discussing the findings for the raw solutions before comparing against coordinates in what might be labelled the 'rotated' models.

Starting with Axis 1, cultural capital (plus income), the aggregate pattern is clear (Table 4.2). Professions, intellectuals and business executives, rich in the forms of misrecognition in question, stand opposed to manual workers, skilled workers and personal service workers - in other words, the three categories held to be homologous with the dominant class gather at one end and the three groupings associated with the dominated class at the other. Of the dominant categories, professions tend to be the furthest towards the positive pole, followed by intellectuals and then business executives, and in every single case the placement of all three is statistically significant - that is to say, the mean positions of the categories along the axis are atypical when compared against the samples as wholes. The distances between the three categories vary from model to model, however, and in some cases the gap between intellectuals and professions (as in Poland or the US) or between intellectuals and business executives (as in Slovakia and South Korea) is negligible, but in only a couple of cases (e.g. Estonia and Iceland) does the order of categories actually shift and even then only by fairly slender margins.

Of the dominated categories, manual workers are the most deprived of cultural capital (and income), followed by the skilled workers. Personal service workers are higher up the axis - they tend, in other words, to be associated with higher education levels and inherited capital, and possibly income, than the other fractions of the dominated class. They sit very close to the centre of the axis in the models for Russia and Taiwan, and even fall just on the positive side of the dimension, in the intermediate zone, in the Italian, Latvian and Slovakian spaces. In all these divergent cases the central position of the personal service workers fails to render them atypical, i.e. strongly associated with either pole of the dimension. Iceland and the US - the latter of these bearing a capital volume dimension, of course provide exceptions to the pattern insofar as personal service workers fall lower than skilled workers. 


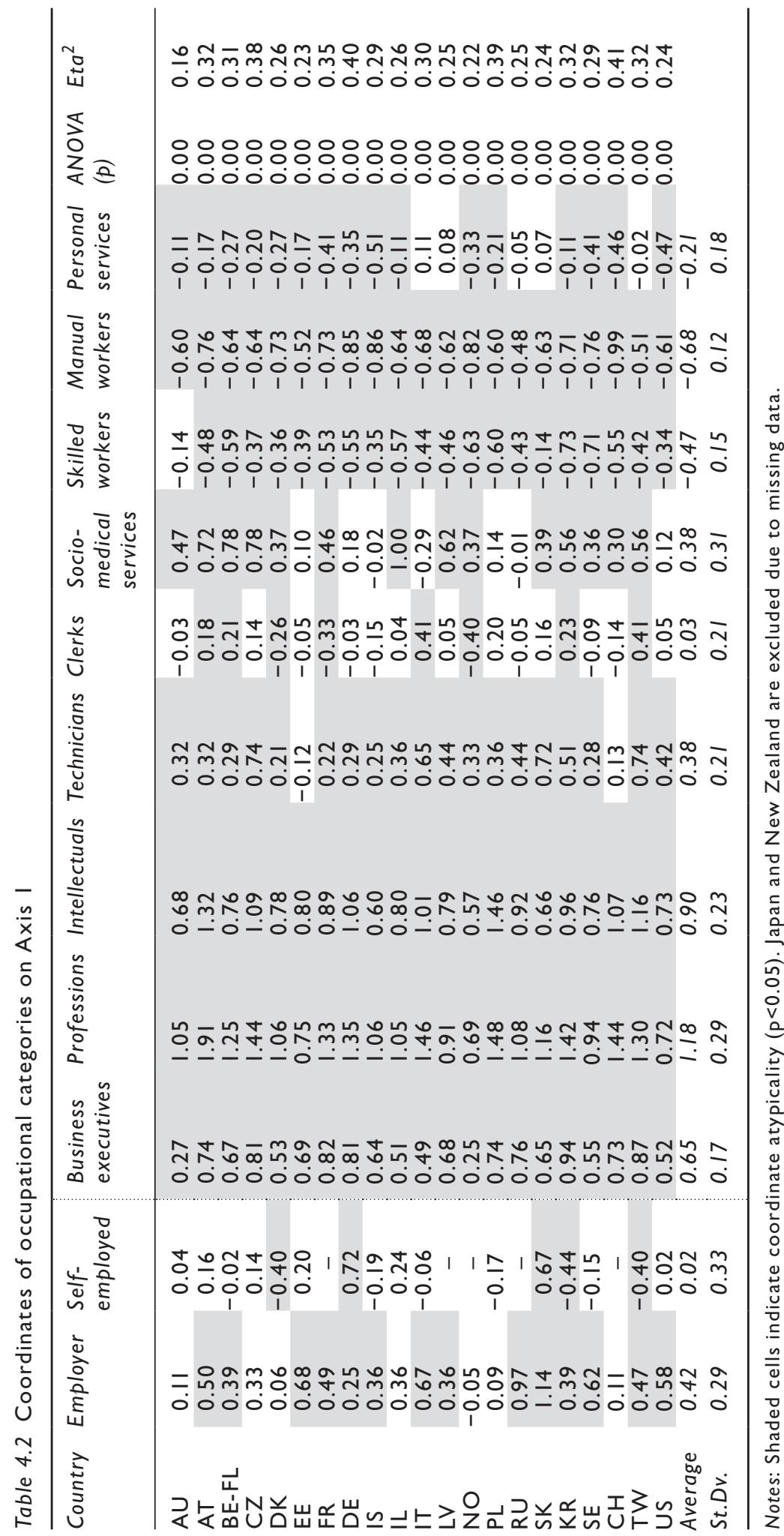


The middle zone of the axis appears, on aggregate, to be populated by technicians, clerks and socio-medical workers, though this hides a good deal of variation across the models. Both the technicians and the socio-medical workers tend, on average, to be toward the higher end of the middle region. In fact the association of the technicians with the high-capital pole is statistically significant in all but two cases (Estonia and Switzerland) and their typical location is higher than that of the business executives in the models for Australia, Italy and Norway and higher than that of both the business executives and intellectuals in the Slovakian space. The pull of the sociomedical workers towards the high-capital end of the axis is also significant in 14 cases and their typical location higher than that of one or more category of the posited dominant class (though never the professions) in the models for Australia, Flanders, Israel and Norway. They are lower down the axis in the Estonian space and even fall below the origin in the models for Iceland, Italy and Russia, but never significantly so - here, in other words, they are more obviously nestled within the intermediate region of the dimension. Clerks, finally, are a little more varied yet more consistently intermediate in their location. They are associated with the high-capital end of the axis to a statistically significant extent in the models for Austria, Flanders, Italy, South Korea and Taiwan, though they never overtake a dominant category, and are associated with the low-capital end to a statistically significant extent in the models for Denmark, France and Norway. Elsewhere, however, their central position is not atypical of the sample, meaning their average position is more evidently intermediate in character.

The central region of Axis 1 is also where the self-employed and employers tend to be found, suggesting they may not to be especially rich in cultural capital overall. Again, however, there is some variety from nation to nation, which may in part be attributable to low numbers in each category. The self-employed are atypically low on the axis in the models for Denmark, South Korea (where Axis 1 is a volume axis) and Taiwan, but atypically high in those for Germany and Slovakia - elsewhere they are more middling, giving them a location very similar, on the whole, to clerks on the axis. Employers, whose aggregate position is akin to that of technicians and socio-medicals workers, i.e. at the higher end of the intermediate region, are in fact associated with the higher-capital end of the axis to a statistically significant degree in 14 cases, and are located above the business executives in the models for Italy, Sweden and the US and above business executives and intellectuals in those for Russia and Slovakia, suggesting a particularly close relationship between inherited capital and business ownership in these samples. Otherwise, however, they do fall into a more central location on the axis.

If Axis 1 arrays the categories roughly according to their hypothesised class associations, i.e. following a dominant/dominated split, with a systematic skew placing those categories higher in cultural/inherited capital above those lower in cultural/inherited capital, then Axis 2 - distinguishing those high and low in wealth, with a varying degree of negative correlation with 
cultural capital - introduces a cross-cutting principle of intra-class difference (Table 4.3). A range of oppositions emerge at the different layers of Axis 1 , though they are clearly more pronounced at the higher end. ${ }^{7}$ Thus we now see, on aggregate, an opposition between employers and business executives, on the one hand, at the wealthy pole of Axis 2 , and intellectuals and socio-medical workers, on the other hand, towards the low-wealth/ high-inherited capital pole or, at the very least, more centrally located. Skilled workers also tend to be pulled towards the high-wealth pole, but the distance between them and other fractions of the dominated class is smaller than between categories higher up the principal axis.

The key oppositions manifest differently across models. In the Flemish space, for example, only the placements of the business executives, employers and intellectuals is statistically pronounced, even if the other categories fall into expected locations, whereas in the Czech space the chief opposition is between low-wealth/high-inherited capital intellectuals and socio-medical services, on the one hand, and high-wealth/low-inherited capital employers and skilled workers, on the other hand. Looking globally, however, business executives and employers come out as significantly atypical in most cases, even if intellectuals and socio-medical workers do not, and where they do not come out as significantly atypical they are often balanced by intellectuals, professionals, socio-medical workers and/or personal service workers being significantly atypical in the opposite direction. ${ }^{8}$ Skilled workers occupy an atypically wealthy position in 12 cases (the only category to do so in the Latvia space, where differences between modalities are otherwise non-significant), and personal service workers an atypically non-wealthy, and perhaps cultural-capital-rich, location in seven.

There are three cases displaying slightly more idiosyncratic correspondences of capital and occupational category, even if many of the categories otherwise fall roughly into anticipated locations. The wealthy/less wealthy opposition corresponds with divisions between clerks/socio-medical services and the self-employed in the Italian space, between intellectuals/personal service workers and manual workers in the model for Russia and between manual workers and professions in the Slovakian model. Whatever the reasons for these anomalies - and subsequent analyses may provide some answers they do not detract from the overriding cross-national propensity for occupational categories to fall more or less as would be expected, i.e. with those occupations allied more with the economic field, as well as skilled workers, to be associated with higher stocks of economic capital than cultural capital and those occupations allied with the fields of cultural/intellectual production, as well as the expanding service sector, to have the reverse profile.

If, when looking at the aggregate coordinates for the categories across both axes, there appears to be greater dispersion on the economic side than the cultural side of the space, particularly relating to the location of employers, this may be attributable to the skew in the CatPCA models and fruitfully compared against the aggregate coordinates of the rotated models, where the vertical axis is capital volume and the horizontal axis capital composition (Figure 4.1). The difference is not, in fact, particularly substantial. 


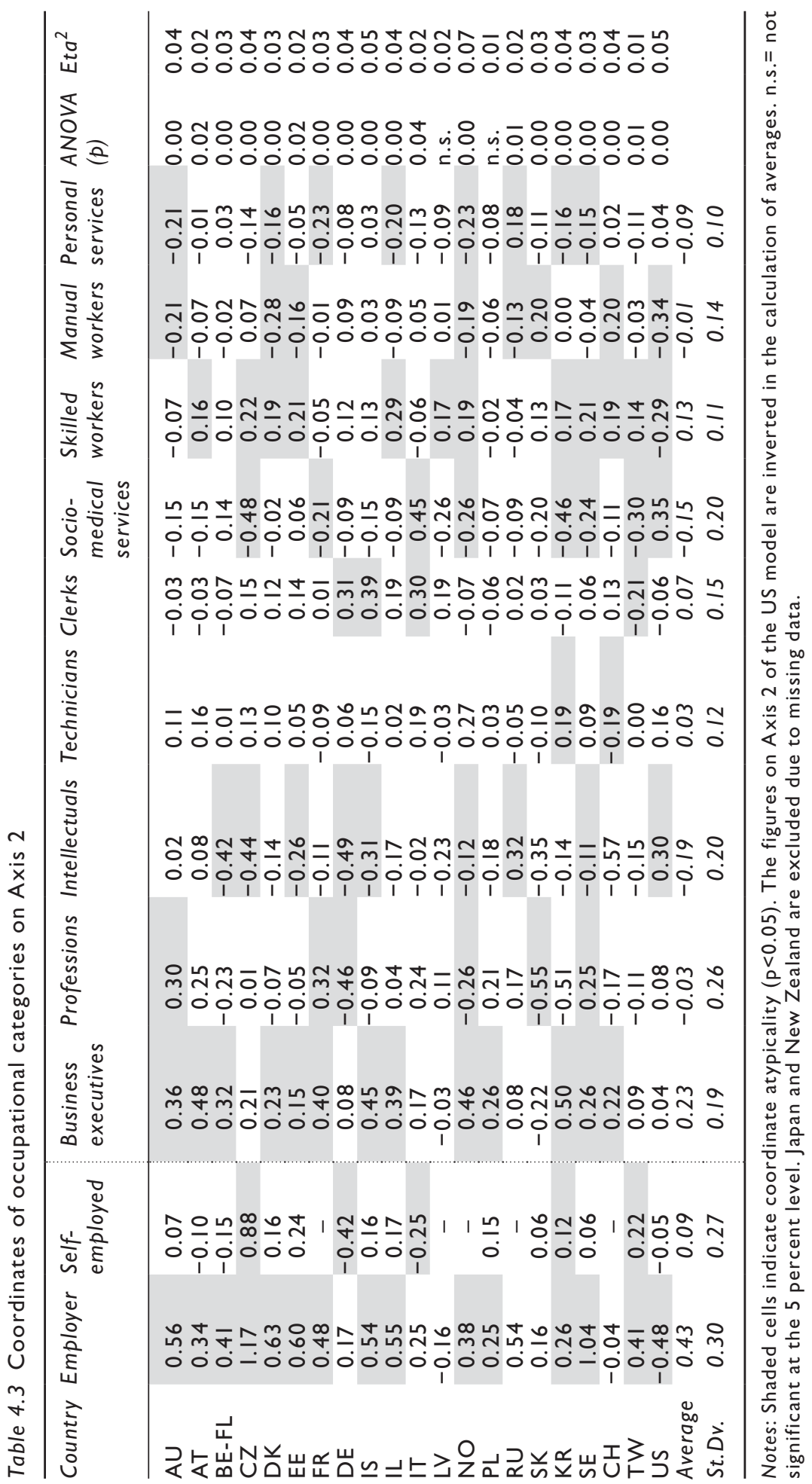




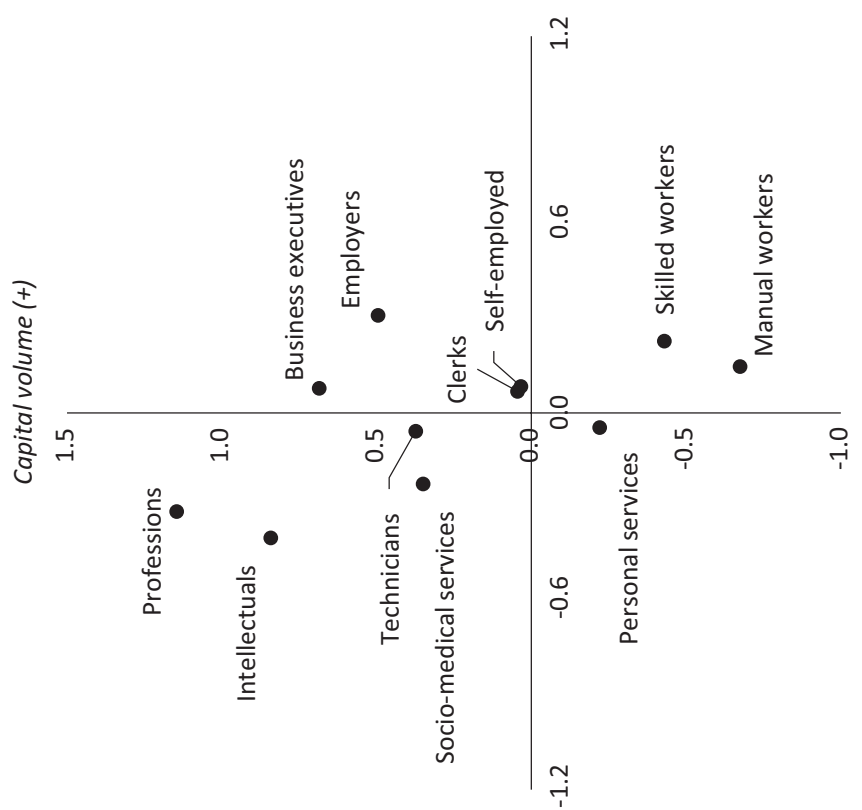

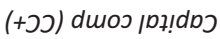
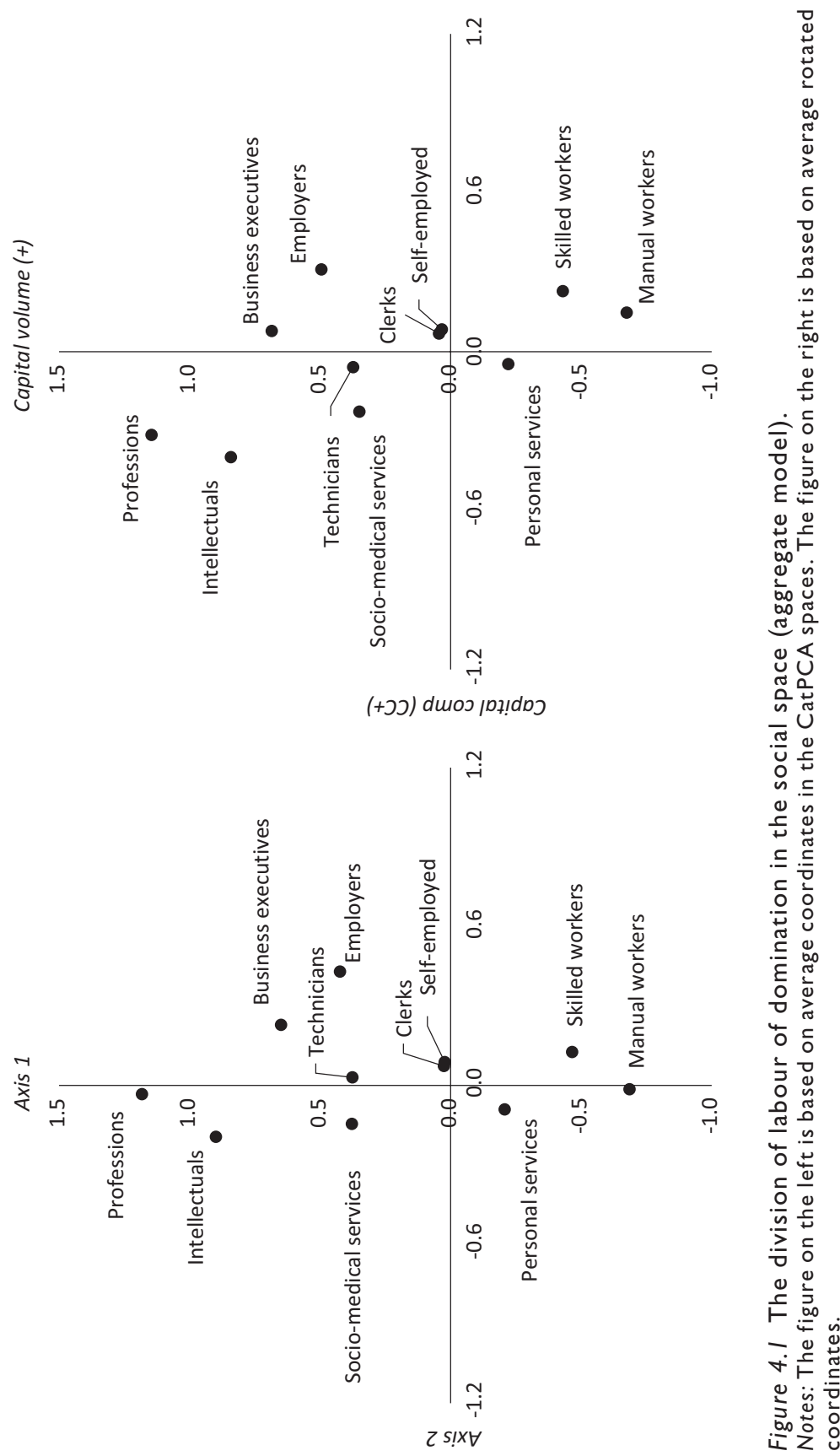
Intellectuals, socio-medical services and, especially, professions now appear further towards the left-hand side of the model, while business executives have been pulled upwards and towards the centre line of the volume axis. Employers have followed suit, but still define the extremity of the economic pole of the composition dimension, closely ahead of skilled workers and, now, manual workers. It might be thought that employers would figure higher up the volume axis than they do, but it must be remembered that most of those falling into this category are small employers, so their more intermediate position is not so surprising - larger employers, with greater profits and investment portfolios and, perhaps, the tokens of businessrelated higher cultural capital, such as the MBA, would likely be placed much higher along the volume axis (their lateral position would depend on the weight of economic capital in their stocks).

\section{Field specificity}

The initial taxonomy of occupations has facilitated confirmation of the posited two-dimensional homology between capital and the division of labour in capitalist societies: there is a hierarchy of jobs, and associated relationships with the field of power, corresponding with capital volume, but also a secondary opposition, corresponding with capital composition, pitting the modern-day oratores and bellatores - intellectuals and masters of the economy - against one another within the field of power as well as dividing those below them. The question now arises, however, of internal variation according to field membership. As revealing as the nine-part schema has been, its construction via theory-led aggregation involved a degree of homogenisation - i.e. the combination of multiple relatively autonomous (sub)fields of struggle into single categories for purposes of detecting the major fault-lines. Cultural producers, scientists and other constituents of the 'intellectual' category, for example, are alike enough in their capital profiles to all be considered social opposites of the captains and crew of industry, and to have variants of the same class habitus, but these sub-groups, entangled in their own fields, are likely to occupy, on average, slightly different positions in the social space from one another - one being further to the cultural pole in the space than others, for instance and to have their class habitus modulated accordingly (as well as by virtue of their field membership). ${ }^{9}$ If the 'micro-class' critique of traditional class analysis has any virtue, it is in highlighting that there are lower-level differences, processes and boundaries - distinguishing medical doctors from lawyers, for example - that matter, even if it frequently goes too far in downplaying the existence and importance of overarching similarities and differences. The benefit of a relational model of class, fields and classification is that it avoids getting trapped in either/or logic by permitting movement between different levels of analysis: it is not that there simply are either micro-classes (however defined) or macro-classes - an ontological 
claim premised on a substantialist worldview. Instead there are different layers of similarity and difference, mutual orientation and struggle that the sociologist can, perhaps like the astrophysicist alternately examining a solar system and parent galaxy, bring into focus and shuttle between depending on the task at hand. There is the layer of broad differences by position in the social space, proxied by relatively large categories; the layer of inter-field difference (e.g. cultural production versus scientific production); the layer of intra-field differences (e.g. the dominant and dominated in the economic field); and so on. In their fine-grained analysis of social mobility in Britain, for example, Friedman and Laurison (2019) demonstrated both the general class-based capitals and habitus facilitating and impeding access to the field of power and their inflection by the specific culture and recruitment practices of constituent fields.

The next task, therefore, is to explode the top-tier categories of the schema deployed so far and map the structure of the field of power a little more closely, at least insofar as it corresponds with the social space. This should nuance the picture painted of the division of labour of domination, and perhaps illuminate the discrepancies and idiosyncrasies of specific national models by revealing the inner composition of the original categories. The problems of unit-level homogenisation in the ISCO scheme are still there, of course, and using more specific categories, especially where sample sizes are modest and/or the numbers of people in professional-managerial work limited, inevitably means dealing with small-n modalities (sometimes containing fewer than ten respondents). This is not a problem for GDA in the way it is for linear statistical techniques - the tests of coordinate atypicality can be applied to categories of any size without difficulty (category $\mathrm{n}$ and sample $\mathrm{N}$ are, in fact, built into the formula) - but it does mean the risk of erroneously conflating overall field position with the position of just a few individuals is heightened considerably. The consistency of category positions across models will be paramount, therefore, but the results must still be treated with the utmost caution whatever the pattern.

The three professional-managerial categories of the initial taxonomy have been disaggregated into a number of sub-categories roughly proxying fields and groups relevant to the field of power. ${ }^{10}$ There are the representatives of the political field (legislators and officials), the juridical field (legal professionals), the medical field, the scientific field (with natural and social scientific sub-fields) ${ }^{11}$ and the field of cultural production (authors, artists, musicians), all relatively rare within the samples (Table 4.4), as well as university and school teachers (the major inculcators of the ideas produced in the field of power even if they are not all strictly agents within it) and engineers (who may not form a well-defined field but who are perhaps, as a collective, characterised by an opposition between the logic of the economic field and the logic of the intellectual field). The 'business executives' classification has been split into three categories posited to have different relations to the economic field: corporate managers, representing more dominant players 


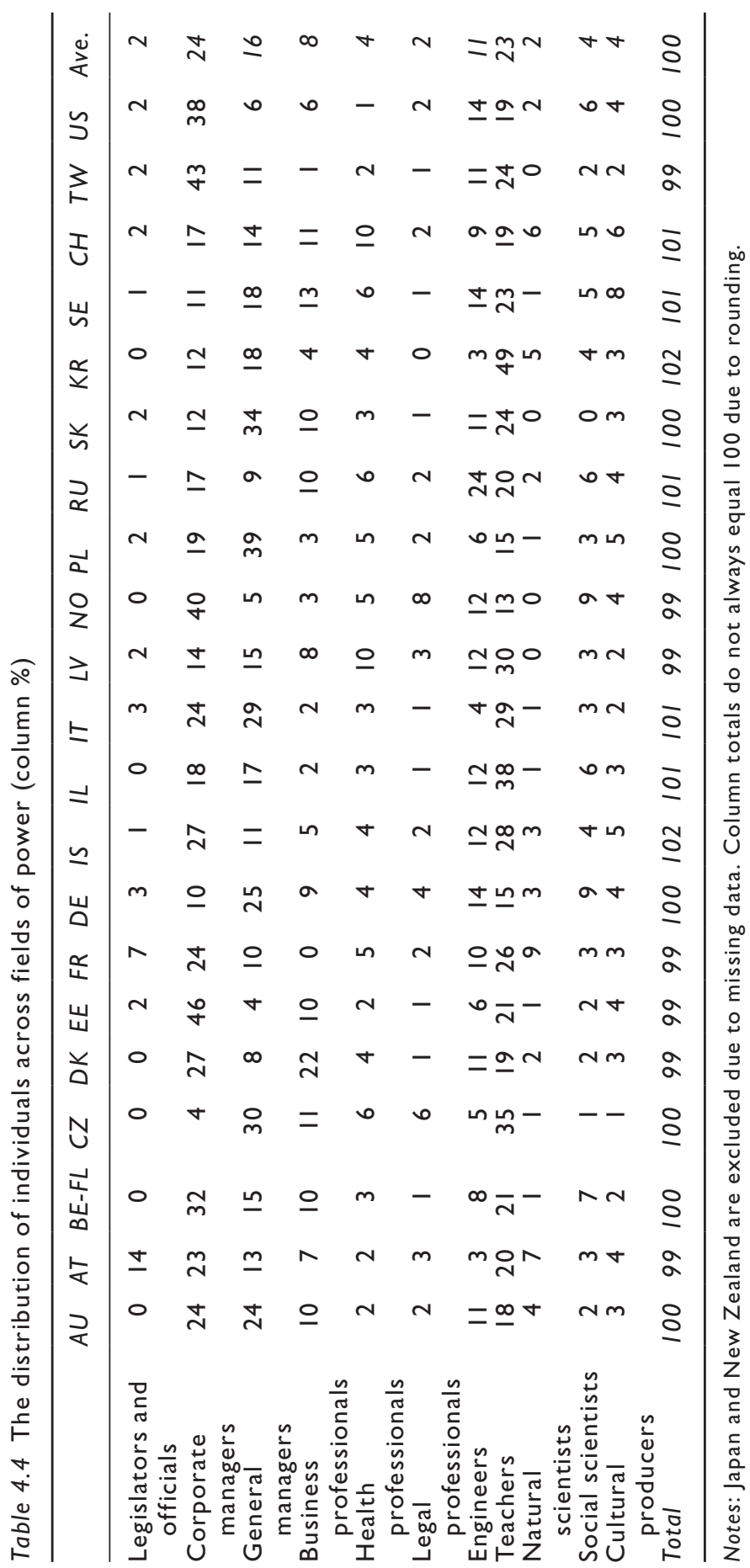



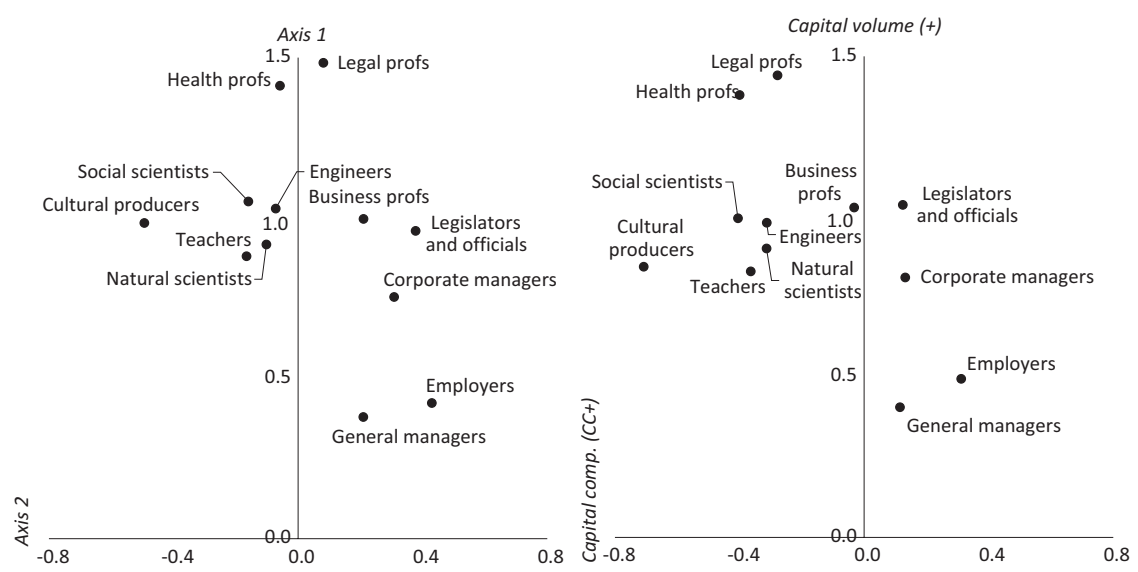

Figure 4.2 The field of power and the social space (aggregate model).

Notes: The figure on the left is based on average coordinates in the CatPCA spaces. The figure on the right is based on average rotated coordinates.

in the field; 'general managers', or managers of small enterprises, who represent more dominated players within the field, and 'business professionals' (accountants, personnel professionals, etc.), who, while not necessarily being agents within the field per se, are to some degree oriented towards the principles and/or struggles of the field in their employment-related practice.

Examination of the aggregate correspondence of the categories with the model axes reveals several specifications to the homology traced earlier (Figure 4.2). Beginning with the left-hand side of the model - the lowwealth/high-cultural capital pole of the horizontal axis - it now becomes evident that the cultural producers are noticeably further to the left of the agents and mediators of the intellectual field (including engineers), who are otherwise very close together in terms of their capital profiles on the negative side of the dimension. They may all be characterised by lesser holdings of wealth than others, therefore, which automatically increases the weight of acquired and inherited cultural capital in their stocks, but the imbalance is most marked for authors, artists and musicians, who are no doubt less likely to enjoy stable and well-paid employment, facilitating the accumulation of economic capital, than the scientists and teachers.

Health professionals and legal professionals are furthest along the primary axis, on average - i.e. they are most closely associated with advantaged social origins and acquired cultural capital, as well as high income - with only a slight margin of horizontal difference between them. Meanwhile, on the right-hand side of the model - stretching towards the high-wealth pole the players of the economic field tend, in fact, to be separated by a fair margin: the managers of smaller enterprises are lower down the primary axis 
than the corporate managers, and indeed any other category, and ultimately placed within the intermediate zone of the space, with a mean coordinate on the first axis equivalent to the socio-medical workers or technicians. ${ }^{12}$ They appear, then, to be much less likely to be characterised by higher education levels, advantaged social origins or high incomes than the rest, but since they are closer towards the origin of the wealth axis than the corporate managers it can also be inferred that they tend to have more modest savings and property holdings too. The business professionals, meanwhile, have similar stocks of wealth to the managers of small enterprises but are much more likely to be characterised by higher levels of cultural capital and, perhaps, income. Perhaps the most surprising feature of the high-wealth pole of the space, however, is the positioning here of those categorised as legislators and officials - the players within the political field, that is. Being a policy maker or political representative may well, on the whole, be associated with higher social origins and acquired cultural capital, but it also seems to be associated, on average, with higher holdings of wealth than any other category.

Systematically shifting all categories counter-clockwise to adjust for the posited tilt built in to each model seems at first to yield a less balanced composite model, but this must be set against the finding from Chapter 3 that there is a recurrent skew of individuals towards the cultural pole of the capital composition axis. Categories that were more centrally located, including the health professionals and legal professionals, are now located further to the left of the space, suggesting a greater weight of acquired and, especially, inherited cultural capital to economic capital. The specificity of the cultural producers becomes even more pronounced, but there is also a clearer association of occupations linked to the intellectual field with higher education and advantaged social origins but lower economic capital, either because they have not (yet) been able to accumulate substantial savings and buy a house or because their habitus inclines them to actively reject accumulation of economic capital (preferring to rent their home, for example). On the other hand, the business professionals become more centrally located, signifying a balanced stock of capital, and the managers and officials are pulled more towards the middle of Axis 2 as well - closer, on average, to the origin than the skilled workers and manual workers, though not the employers. This suggests that managers may, typically, have relatively even stocks of capital, albeit still tipped towards a higher ratio of economic to cultural capital relative to others - a profile not out of step with Bourdieu's (1984: 128-9) model of the French social space and perhaps unsurprising given the premium put on educational credentials for securing employment in any sector of the field of power in contemporary capitalist societies (Bourdieu, 1996a).

There is the crucial question, however, of whether these aggregate patterns reflect consistency across national models or mask wild variation from sample to sample. Inspection of individual coordinates confirms that 


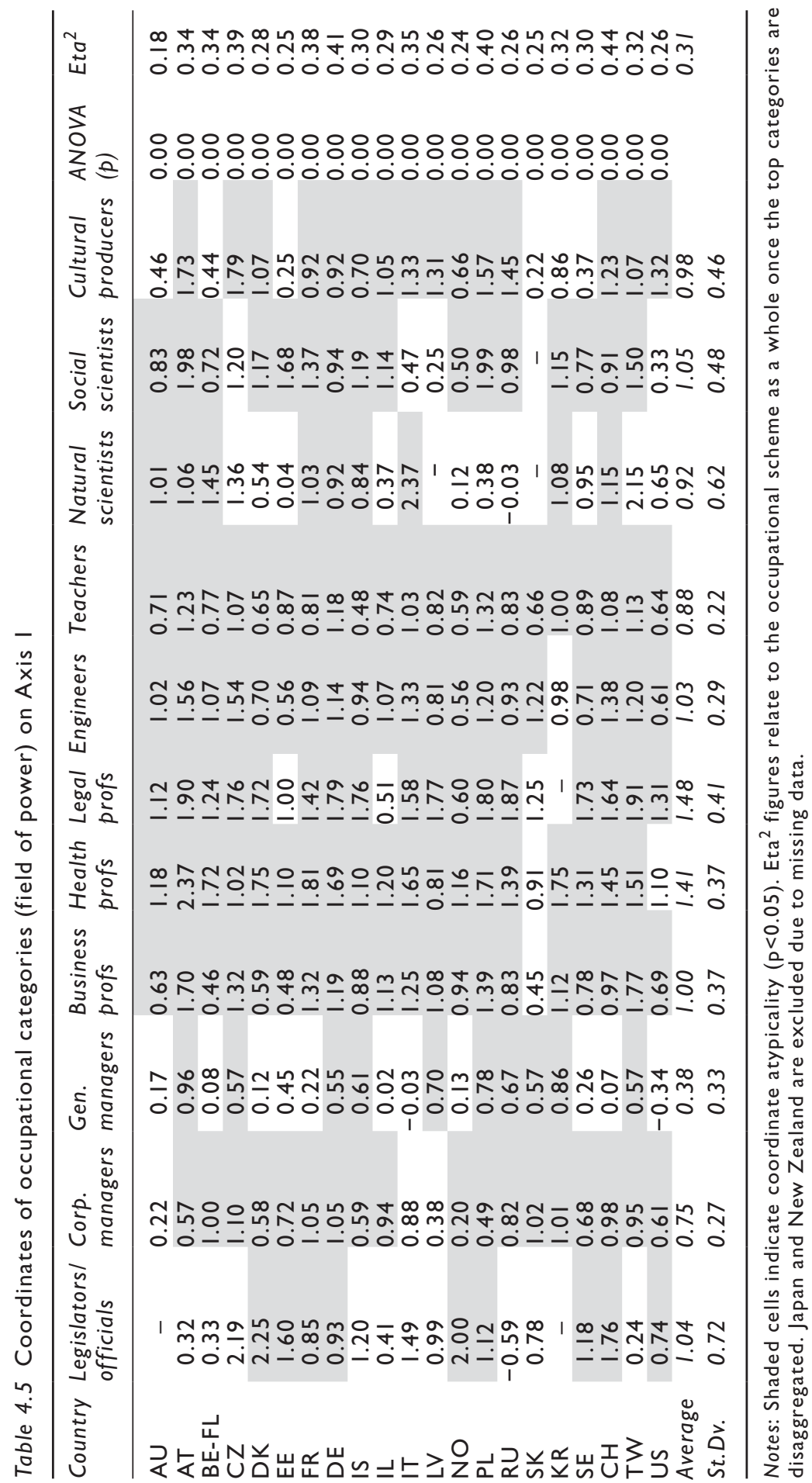




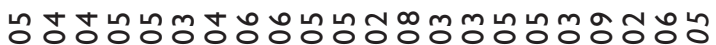
ó00000000000000000000

$\underset{5}{5}$

응ㅎㅇㅇㅇㅇㅇㅡ

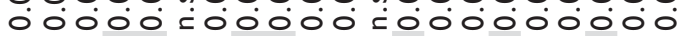

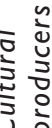

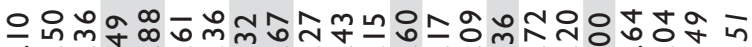
o. 0.000 .0000000

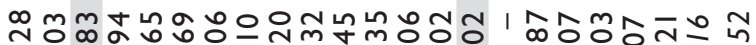

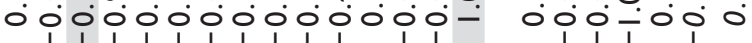

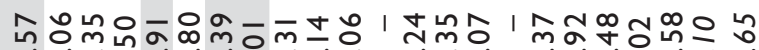
000-000-100 000 000-000

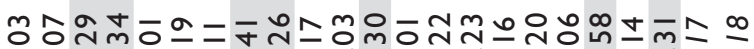
0000000000000000000000 (1)

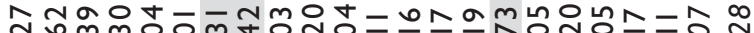

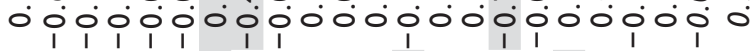

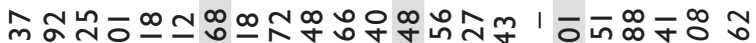

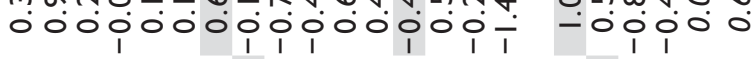

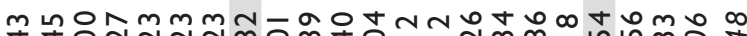

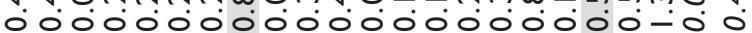
氙 $000000-00-0000000000000$

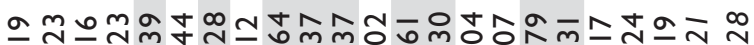
0

œ 00000000000000000000000

। $0-0 \frac{1}{0} 00-00=0-000010000$

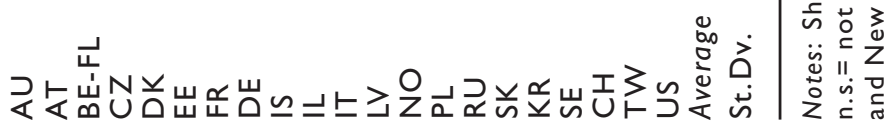

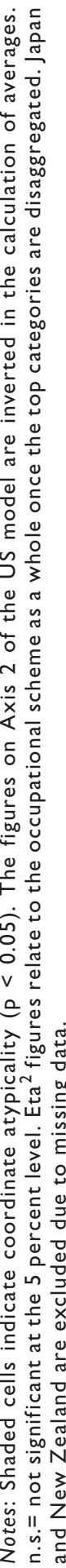


there is indeed considerable variation on both axes, specifically, and unsurprisingly, for the rarer modalities (Tables 4.5 and 4.6). The cross-model variation for the legislators and officials is so great as to render their average coordinate unreliable, and the same should probably be concluded for natural scientists. There are, however, some regularities warranting greater confidence in some of the correspondences at the aggregate level. The health professionals and legal professionals, for example, are consistently high on the primary axis, with statistically significant coordinates greater than 1 in the vast majority of cases, but more variably and centrally placed, rarely becoming atypical either way, on the wealth axis. The same is largely true of the engineers and business professionals, though they register an average coordinate lower than 1 in a few more models and the business professionals are a little more likely to register as atypical in one direction or another on the second axis.

The atypical association of teachers with high capital on the premier dimension of difference is significant in every model, though the typical coordinate is not as high as those of the players in the medical and legal fields, and are on the negative side of the second axis in 18 cases, significantly so in seven. Social scientists fluctuate a little more in their positioning on Axis 1, though they are atypically high on the dimension in most cases. They are nearly always on the negative side of the wealth axis - Australia, Latvia, Russia and South Korea are the exceptional cases - even if only marginally, confirming their centre-left positioning in the aggregate model, close to the teachers, and, therefore, their slight pull, on average, towards the cultural pole of the capital composition axis in the rotated models. The cultural producers are also a little more variable on Axis 1 but significantly atypical in most cases. On Axis 2 they are, again, nearly always on the negative side, often substantially (their coordinate exceeds -0.4 in 11 cases) and significantly so in seven cases, though the mean cross-sample location is evidently skewed by some models where their pull towards the low-wealth pole is great. In the rotated spaces, their coordinate on the capital composition axis exceeds -0.4 , and is thus markedly towards the cultural capital pole, in 17 cases, so it seems reasonable to conclude that, while there are exceptions, the particularly pronounced imbalance of capital stocks, as measured here, among cultural producers is a systematic cross-national tendency.

As for the two categories of manager, both are consistently on the positive side of the wealth axis across the national models - in 18 cases for the corporate managers (with coordinates above 0.4 in nine cases) and 16 cases for the managers of small enterprises - though not always significantly so. However, while the corporate managers are consistently strongly associated with the high-capital pole of Axis 1, the position of the general managers is much more variable. They descend below the origin of the axis in the Italian and US spaces, though not to a statistically significant degree, but are atypically high on the axis in ten other cases, including all the post-socialist and East Asian models as well as the Austrian, German and Icelandic spaces. 
Overall, the variety across the individual models means only a few inferences on the cross-national regularity of the internal structure of the field of power relative to the social space can be drawn with reasonable confidence. These include the close association of health and legal professions, and to a lesser extent engineers and business professionals, with inherited and acquired cultural capital (and high income); the tendency for teachers and social scientists to be pulled towards the cultural pole of the modelled capital composition axis, and for cultural producers to be pulled more substantially along it; and for managers - and employers, of course - to be more closely associated with higher holdings of economic capital than others, with those working for corporations typically characterised by a closer association with inherited and acquired cultural capital than those employed in smaller operations. The variability that otherwise emerges may be due in part to specificities of the national fields being proxied relative to their parent social spaces, or, more likely, an effect of analysing small numbers of individuals drawn from fields that are, in reality, highly dispersed. Either way, firmer conclusions will only come from systematic comparison of large-scale anatomisations of fields of power across numerous nations of the kind pioneered in France and Norway (Hjellbrekke et al., 2007; Denord et al., 2011; Flemmen, 2012) but so far lacking elsewhere.

\section{Conclusion}

There is a homology between the structure of capital and jobs or, put another way, the social space and the division of labour of domination. Perhaps the safest conclusion, confirming the first part of our hypothesis, is that there is a clear and consistent relationship between capital volume and employment position relative to the field of power. Those richest in capital are the originators and major mediators of the 'goods' - the ideas, the evaluations, the rules, the commodities - produced in the course of struggles and strategies within the field while those below them are more likely to be implementers and recipients alone. An intermediate level of capital is associated with being in the lower regions or at the fringes of its constituent sub-fields, especially the economic field and the bureaucratic field, whereas the jobs associated with the lower end of the social space are those that require and repay little capital and which doubtless, therefore, bring little symbolic power, i.e. recognised authority to challenge and determine what counts as the 'right' knowledge, 'good' taste, 'appropriate' working conditions or pay, the 'best' way to do things and so on.

Correspondences with capital composition are a little more varied across samples, but certainly regular enough to suggest that the field of power tends to be structured according to familiar principles across capitalist social orders old and new. The opposition between intellectuals, on the one hand especially cultural producers - and the agents of the economic field, on the other hand - especially employers - is generally steady and pronounced, the one aligned with cultural capital and the other aligned with economic 
capital. If there is indeed antagonism between the poles of the field of power in the battle to define the dominant principle of domination, and mutual rejection of each other's worldview, then these are likely to be key agents. Given the role of inherited capital on Axis 2, moreover, everything would seem to indicate that some positions or fields at the top of the social hierarchy are harder for those born outside the field of power to gain entry to than others. Medicine and law, in particular, tend to be bastions of social reproduction, as others have found before in national studies (Friedman and Laurison, 2019), while the economic field (or at least certain parts of it) would appear to be more 'open' to those tracing upwards trajectories in the social space.

Looking at things the other way, of course, the correspondences exposed indicate that those in the east and northeast zones of the spaces are not only characterised by high stocks of economic capital but disproportionately subject or attuned to the specific interests, doxa and effects of the economic field - inveigled by the logic of profits and the fundamental principle of 'business is business' (Bourdieu, 2000: 97), that is - while those in the north and northwest (and, to a lesser extent, the west) are not only typically lower in wealth holdings and higher in cultural capital than others but disproportionately interested or implicated in the stakes of fields which, for all their differences and internal divisions, tend to revolve around ideas at the expense of money. These field effects will compound class effects in generating principles and practice, and are also likely to come with differing relationships towards the state, or bureaucratic field, that is to say, a relationship of dependence (as teachers, scientists, doctors and socio-medical workers are more likely to be employed by the state) or of antagonism (as employers and managers in corporations and small enterprises negotiate state regulation) which may just manifest in contrasting position-takings on taxation, government intervention in the market and so on. Exploration of that thesis must wait until later, however, for there is still work to be done in unpicking the network of interconnected factors associated with the different axes and systematically modulating capital holdings within and beyond occupational categories.

\section{Notes}

1 Although the 2008 version of ISCO was available in the dataset, the 1988 version was used because its classifications (e.g. distinguishing managers of small enterprises from corporate managers) were deemed more sociologically satisfactory.

2 The scheme is indebted to and thus shares many similarities with those previously developed for the UK and Norway (Hansen et al., 2009; Atkinson, 2017), though it is not identical to either.

3 See the special issue of Actes de la Recherche en Sciences Sociales on 'La Spécialisation de la Médicine' $(2005,1 / 2)$.

4 The figure is even higher if the official European Union definition of a small enterprise, i.e. 10 or fewer employees, is applied. 
5 https://data.worldbank.org/indicator/SL.EMP.SELF.ZS? end= 2011\&locations=KR-AU-AT-BE-CZ-DK-EE-FR-DE-IS-IL-LV-IT-NO-PL-RUSK-SE-CH-US\&start=2009

6 The formulae for counter-clockwise rotation of coordinates are as follows. Where $\theta$ is the angle of the model's tilt in radians, $x^{\prime}=x \cos (\theta)-y \sin (\theta)$ and $y^{\prime}=$ $\mathrm{x} \sin (\theta)+\mathrm{y} \cos (\theta)$.

7 This no doubt partly - in conjunction with the fact that employment status, distinguishing employers, is a separate variable - explains the wide disparities in the Eta ${ }^{2}$ figures on Axes 1 and 2, with the figure typically being very substantial indeed on Axis 1 (far higher than any other structuring factor explored) but much more modest, though not insignificant, on Axis 2.

8 Comparison of standardised deviations reveals the distances between intellectuals and business executives to be statistically notable in all but eight cases. The effect of axis rotation might have something to do with the divergences, especially the cases of Italy and Australia where the difference between the two average points is notable on the premier axis instead. In Denmark and Sweden the distance is almost notable $(>0.35)$, but in these models and another four where the gap is small (Australia, Slovakia, Taiwan and the US) the distance between intellectuals and employers is nonetheless notable (or, in the case of Sweden, substantial). Only in the model for Russia does the distance between intellectuals and business executives/employers remain negligible, thanks largely to the unusual location of intellectuals.

9 The typical position of field members in the social space would indicate something of the state or balance of the field and its doxa around which all members of the field - no matter their individual positions in the field - would have to orient.

10 None of the categories are claimed to be a perfect match for the boundaries of the fields they stand in for, and not only because they are likely to vary from nation to nation, but are merely deemed broadly distinguishing enough to potentially generate results warranting further reflection.

11 Natural scientists, being more open to industry funding and employment (this is not the academic field more narrowly defined), are perhaps closer to the logic of the economic field, on average, than social scientists (economists excepted).

12 This makes them very much like the lower managers and proprietors distinguished in the UK (Atkinson, 2017). 


\section{Chapter 5}

\section{Homologies}

Occupation is, to repeat, associated with the distribution of capital possession in capitalist misrecognition orders because different positions in the division of labour of domination demand specific tokens or investments of capital for entry and, in turn, deliver different rates of pay, bonuses, perks and so on. Occupation is certainly not, however, the sole determinant of a person's capacity to convert and accumulate capital or maintain position in the social space, and not only because people possess and acquire symbols of worth even when they are not in paid employment - homemakers, the retired or the unemployed receiving economic support through significant others or state provision, or embarking on periods of study, and so on. Additional factors can facilitate or impede capital accumulation, setting two people otherwise sharing similar circumstances apart in the social space, differentiating the objective field of possibles open to them and, as a consequence, generating different perceptions of the possible and desirable thing to do - whether promotion is likely or unlikely, and thus worth going for or not, or whether this job, with its associated capital returns, is more 'suitable' for 'someone like me' than that job, and such like. The logical outcome is a structural homology between specific sectors of the social space and specific demographics which may just feed into everyday perception, labelling and denigration of those sectors and demographics and even, in many cases, generate false assumptions and theories about them.

Bourdieu (1984: 102ff) dubbed these additional factors or properties 'secondary', the idea being that volume and composition of capital are the primary determinants of position and movement in the social space, but the label had the unfortunate effect of giving the misleading impression that these additional factors are subordinate to the social space in the hierarchy of social structures or principles of vision and division that matter. This is nowhere more the case than in relation to gender, which some feminists have accused Bourdieu of downplaying as a differentiator of experience and perceptions of the possible - the claim being that he asserted expressions of gender differences vary in form and degree by class but not that being a man or woman can have its own specific effect on capital accumulation (see, e.g. 
Adkins and Skeggs, 2004). The reality of Bourdieu's position on this, however, is very different. From early on, in contrast to orthodox modes of class analysis that erased women from the picture entirely by taking the family, i.e. the occupation of the male 'head', as the 'unit of analysis' (see Atkinson, 2009), he emphasised that class and gender are mutually constitutive: an analytical class - its typical conditions of existence, its mode of reproduction and its manifestation in everyday perception and discourse - is inextricably defined by its gender ratio as much as experiences and perceptions of men and women are defined objectively and subjectively by their typical class positions and histories. This does not mean, however, that gender has no effects on capacities to accumulate or maintain capital in the social space distinguishable from the bare possession of economic, cultural and social resources or occupational effects, only that the way in which they do so is always refracted and differentiated by the class structure. If this is a major insight of the voluminous literature on 'intersectionality', then Bourdieu was ahead of the curve. Precisely how gender entwines with class, however, needs to be unpacked a little further.

\section{Men and women in social spaces}

The perceptual opposition between men and women, ingrained in the deepest layers of belief and the body, is pregnant with doxic notions of what men and women can and should do (Bourdieu, 2001; Atkinson, 2016). Rooted in a naturalisation (more specifically, a biologisation) of socially generated differences in practice, the prime effect of this doxa is to reproduce division by distinguishing the social stakes to which male and female libidos are typically channelled and to which it is widely believed - under the guise of what is 'right', 'appropriate', 'in their nature' or simply the 'done thing' - they ought be channelled. It thus underpins the basic desires, values and tastes of men and women but also informs the expectations and assumptions of others - some of which are highly consequential for capital accumulation when they feed into decisions and negotiations on hiring, project assignment or promotion. Historically - at least since the nineteenth century these differences have manifest most obviously in widespread assumptions, generating a sense of the feasible and unfeasible, that women are and should be oriented more towards childrearing and homemaking - i.e. the family as a field - and that their commitment to paid work, when they do undertake it, is less than that of men.

Yet beliefs and practices relating to gender are not globally homogenous. The degree to which women are filtered towards the familial field rather than paid employment, in contrast to men, varies considerably from nation to nation. A rich strain of research on welfare provision has long established that some social orders encourage female workforce participation to a greater extent than others via policy on maternal/paternal leave and pay, childcare 
support, flexible working arrangements, family-wage assumptions and such like, all ultimately rooted in the structure and history of each social order's field of power - including the relative power of the religious field and strategies to quell struggle in the social space - as well as the place of the nation state in the global field - generating strategies for maximising workforce participation or developing industrial specialisms. ${ }^{1}$ Precisely which nations are more encouraging than others, in what manner they are and how that might have changed over time are matters of intense debate and disagreement, but it is nearly always demonstrated that the social democratic Nordic countries are more facilitative of female workforce participation and East Asian and Southern European societies much less so.

Confirming that pattern, the ISSP data reveals that while there is a general tendency for women to assume the role of homemaker to a much greater extent than men, women are least likely to do so in the Nordic countries, as well as France and Russia, and more likely to do so in Japan and South Korea, as well as Italy (Table 5.1). As regards the rates of part-time working, this is generally much higher for women than it is for men across the board, even where homemaking is rare, but the figure is low in Denmark, Norway and the newly capitalist countries of East Europe where conservative beliefs about gender roles have perhaps been counteracted by the lingering effects of the productivist ethos of socialism and the higher proportion of working-age women (due to high mortality rates among men) in these social orders. Also instructive is the gap between the proportion of men who are university graduates and the proportion of women with the same level of institutional cultural capital. Although the gap is mostly modest, Japan and South Korea stand out for having lower rates of higher education among women (alongside Switzerland), whereas the Nordic countries (minus Denmark) and many of the post-socialist nations (especially Estonia and Latvia) are characterised by higher proportions of female university graduates. Everything would seem to indicate, therefore, that there are some systemic, structural differences in the extent to which women accumulate both cultural capital and their own economic capital via paid work across nations, but the overriding tendency is still for women to be differentiated from men in one way or another.

The channelling or men's and women's desires and expectations between family and paid work is not, however, the only effect of gendered schemes of perception. Also significant, and indeed evermore so given increased workforce participation of women across countries over the course of the twentieth century and beyond, are differences in the types of paid work considered fitting and appropriate for men and women (cf. Britten and Heath, 1983; England and Farkas, 1986; Esping-Andersen, 1993). Generalising the traditional domestic division of labour to the public sphere, accompanied by presuppositions concerning men's and women's respective skills or attributes - in reality a product of social forces, but often accepted as their 


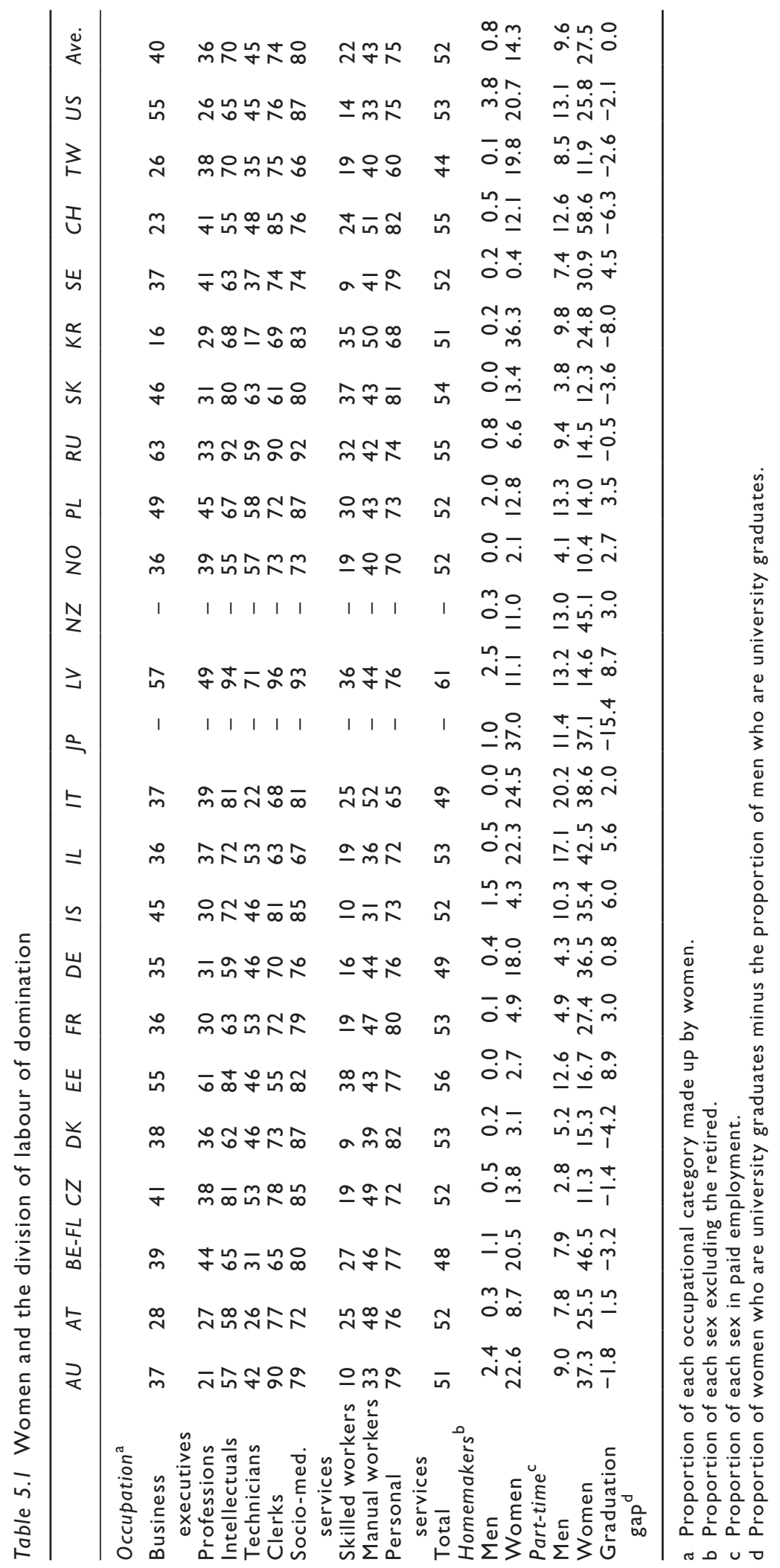


'nature' - women are assumed to be (and assume themselves to be) suited to roles involving care, administration and pedagogy (Bourdieu, 2001). This is given specific form by the level and species of cultural capital demanded for a role and the level of economic capital returned to it, differentiating, for example, the nursery worker or clerk from the secondary school teacher or social scientist. All these roles tend to depend on specific training or qualifications for entry to a greater degree than jobs associated with notions of male physicality or instrumental competitiveness - women must, therefore, succeed in the education system to an extent to attain any work above the most routine level, making educational strategies paramount for social reproduction or ascent in the social space - and everything seems to indicate that positions from the top to the bottom of the occupational structure become symbolically devalued, and paid less, the more they are feminised (England, 1992, 2010). The result, shown in Table 5.1, is a clear and consistent homology between the traditional domestic division of labour and the division of labour of domination across nations. Intellectual positions, clerical and socio-medical services and personal service work are all highly feminised, while membership of the economic field or the professions, as well as skilled work, are male-dominated. The extent of the polarisation, and where in the occupational structure it is most pronounced, certainly varies from sample to sample, but polarisation there always is.

We already know, however, that the homology between the division of labour of domination and the social space, as approximated by the CatPCA models, is variable across nations, so the consequences of the gendering of jobs for men's and women's typical positions in the social space are by no means obvious. Additional forces, moreover, may complicate the relationship, such as the gendered pay gap (the fact that women tend to be paid less than men for the same work), the 'glass ceiling' effect (the fact that women are underrepresented at the top end of career hierarchies) and differential rates of credentialisation (the possibility that women require higher qualifications than men to enter the same jobs). In fact, projection of gender categories into the spaces reveal that differences between men and women are fairly muted (Table 5.2). ${ }^{2}$ In only seven cases are the mean positions of men and/or women atypical on Axis 1 - in most cases placing men higher up the axis than women (Norway and Sweden are exceptions) - and in 13 cases men are significantly further towards the high-wealth pole of Axis 2 and/ or women further away from it. It is likely, however, that these significance levels are inflated by the large $n$ of the two categories in these instances, and a comparison of standardised deviations - i.e. a test of whether the distances between the two points in the spaces are negligible, notable or significant reveals that there are, in fact, no notable differences between men and women on any axis in any national space. ${ }^{3}$

The negligible rate of differential dispersion of men and women within the spaces may be due, on the one hand, to disparities in acquired cultural capital being counteracted by equivalent distributions of social origins on 


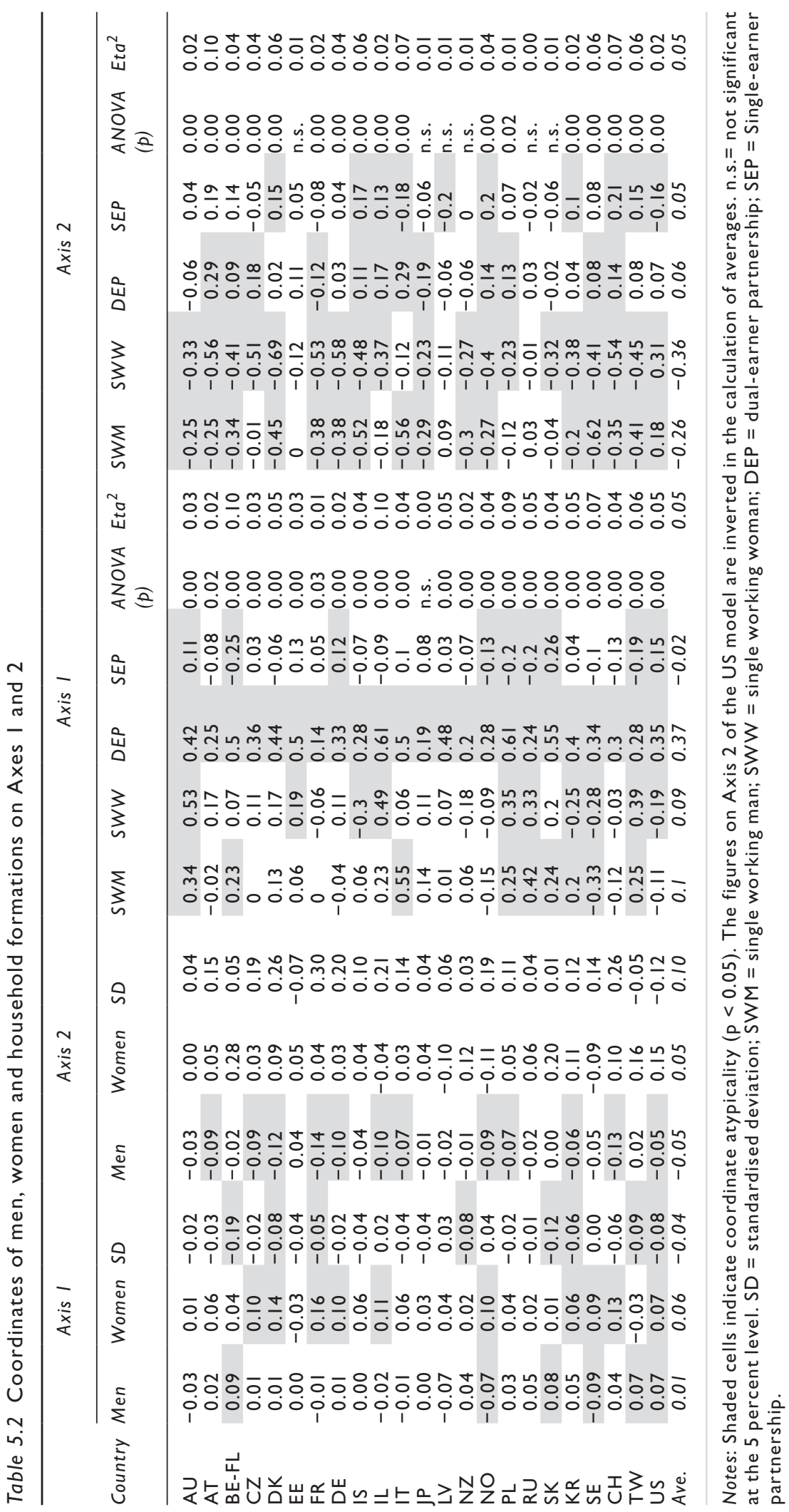


Axis 1 and, on the other hand, to the measures of wealth defining Axis 2, and of income co-constituting Axis 1, being recorded at the household level. Indeed, a different picture emerges once household composition is factored in, distinguishing single working men and women from dual-earner and singleearner partnerships (where the significant other may be a homemaker, unemployed, disabled or retired). Now it becomes clear that, on aggregate, those without partners, and associated access to shared earnings and accumulated personal wealth, are typically - there are a couple of exceptions further down Axis 1 than dual earning couples (differences between single men and women are highly variable on this dimension). They are also pulled substantially towards the low-wealth pole of Axis 2, but this is more the case for women than men, even where separation of men and women per se is minimal, perhaps indicating a greater ability among single men, due to higher earnings, to accumulate economic capital. The distance between single working men and women varies, for sure, with a few models (those for Estonia, Japan, Latvia, New Zealand, Russia, Slovakia) displaying only a modest and statistically non-significant difference between modalities on Axis 2, or occasional reversals of the usual pattern (e.g. Italy, Sweden). Where they are significant and in line with the general pattern, moreover, some gaps between single men and women (e.g. in the Czech, Austrian and Danish models) are larger than others (e.g. the Taiwanese or Belgian spaces). Still, the figures are enough to underscore not only the specific effect of partnering, as a particularly prevalent form of acquiring social capital, in shifting one's position in the social space and attenuating gender differences, as well as the association of single-earner households - whether being such through constraint or socialised desire - with somewhat lower capital holdings than dual earners. They also suggest that the effect is typically unequal for men and women, at least in relation to household wealth. Inevitably this raises the issue of differential access to and allocation of material resources at the domestic level (see Pahl, 1983, 1990; Vogler and Pahl, 1993, 1994), related to the gendered structure and dynamic of familial fields, but this cannot be addressed with the data available.

\section{Forces of attraction}

The specific effect of partnering, of course, depends on who exactly one partners with. And far from being a purely idiosyncratic or 'edifying expression of an independent self', as Jeffrey Alexander (1995: 142) would have it, matrimony and its non-institutionalised counterparts burgeoning in certain countries around the globe (cohabiting, 'living apart together', etc.) are soaked to the bone with social determinations. There are the formalised matchmaking practices imbued with family strategies aimed at improving or maintaining social position, like those Bourdieu (1996a, 2008) claimed prevailed in rural communities untouched by industrialisation and 
marketisation or amongst sections of the dominant class (i.e. the aristocracy and the business bourgeoisie) concerned with tending the status of their 'family name', but even in social orders where coupling is apparently based on individual choice, implicating a sense of similarity of tastes and interests or 'elective affinity' (Bourdieu, 1984: 241-4) - and thus social position, the consequence, long known by social scientists, is a persistent tendency towards homogamy or homophily.

This is not to say that attraction, amorous love and partnering are reducible to class. There is also 'assortive mating' on the basis of ethnicity or nationality, for one thing, implicating the relatively autonomous logic of the ethno-racial or ethno-national space of a social order, but also the possibility that specific physical properties can, under certain conditions, function as cross-class markers of sexual attractiveness the possession of which whether as one's own body or by proxy, i.e. 'possession' of the body of another - can operate as a source of value drawing people into relationships (and not just carnal encounters) (see Atkinson, 2020: 118-22). The dynamics of familial fields, moreover, from childhood onwards, have their specific impact on an individual's desire for love and the type of others - within but also, in certain instances, beyond the range of possibilities and desirabilities generated by class position - one might come to love. Nevertheless, there is no denying that class foists firm bounds upon the attractive and the unattractive, or the suitable and the unsuitable, no matter the social order, as demonstrated not only by extant research (e.g. Kuipers, 2015; Vandebroeck, 2016; Schmitz, 2017) but by the distribution in the spaces of partners' locations in the division of labour of domination (Tables 5.3 and 5.4, Figure 5.1). ${ }^{4}$

Most striking is the vertical relationship: the tendency for dominant to partner with dominant, intermediate to consort with intermediate and dominated to connect with dominated. A doubling of inequalities in conditions of existence is surely the result as high incomes, middling incomes or low incomes are combined to form household earnings (cf. Drobnič and Blossfeld, 2001), but also, since the spaces are about much more than income, an exacerbation of inequities in the availability within families of cultural resources parental (or grandparental) symbolic mastery, for example - facilitating intergenerational reproduction. True enough, the association between vertical social position and partner's occupation is, judging from the lower Eta ${ }^{2}$ figures on Axis 1, a little looser than that between vertical social position and the respondent's own place in the division if labour of domination. The inclusion of an extra, relatively heterogenous category, gravitating in most cases towards the lower end of the axis, for those without a partner in paid employment will have something to do with that. A couple of telling shifts in aggregate coordinates also emerge. Manual and skilled work, the former typically slightly more male-dominated and the later considerably and consistently so, move upwards in the composite space. Feminised personal service work and clerical work do too, and though the distance travelled 


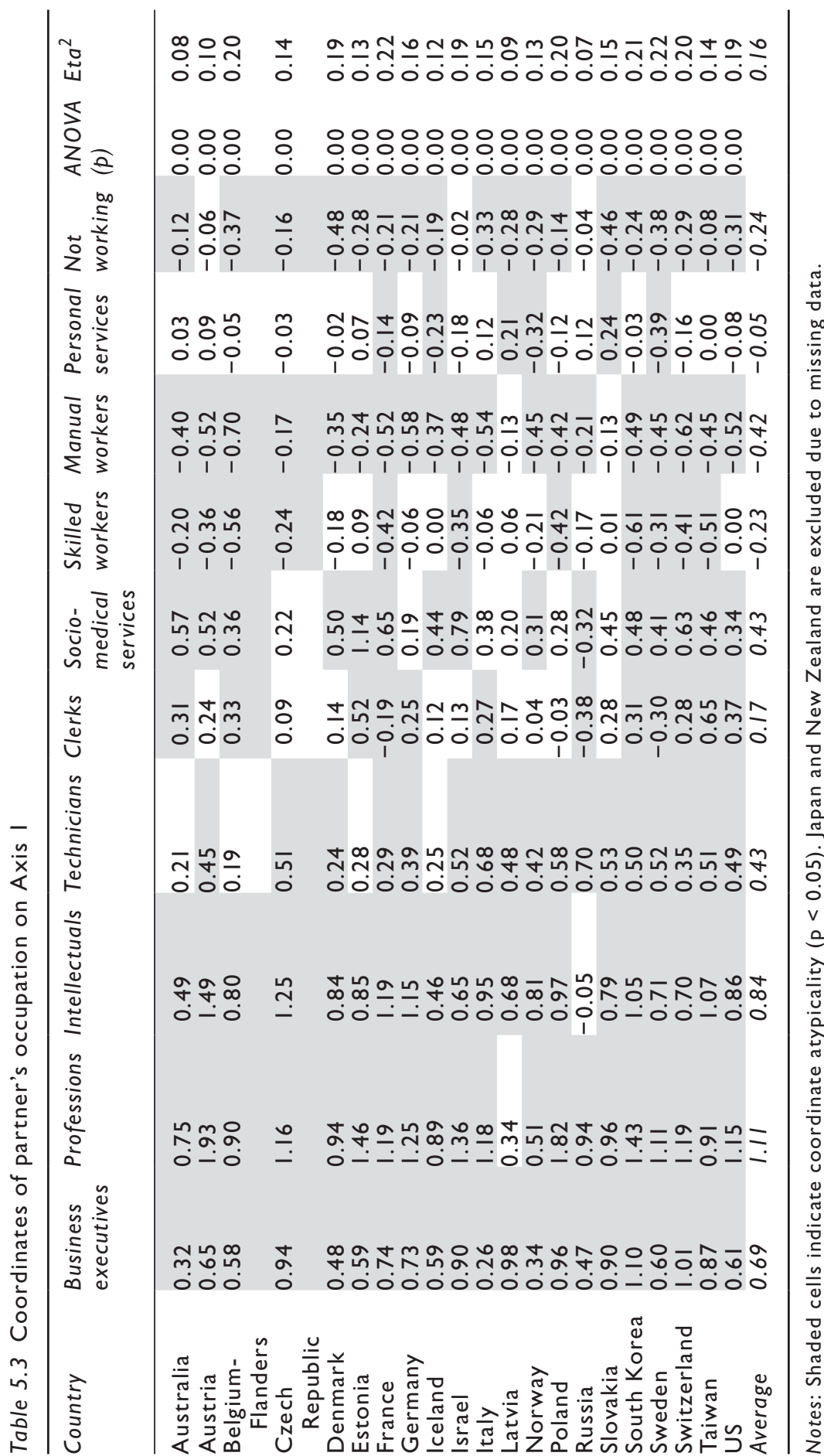




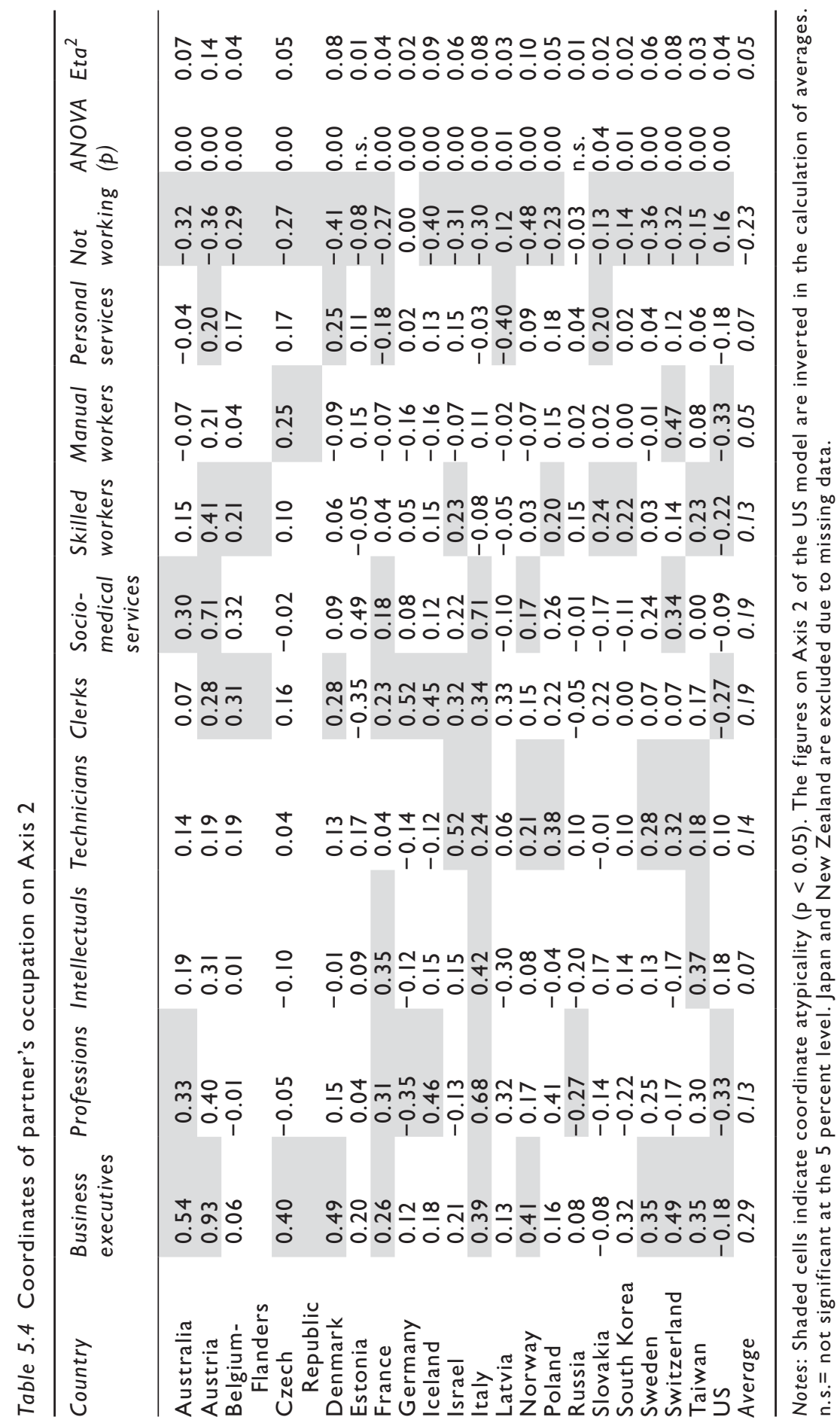




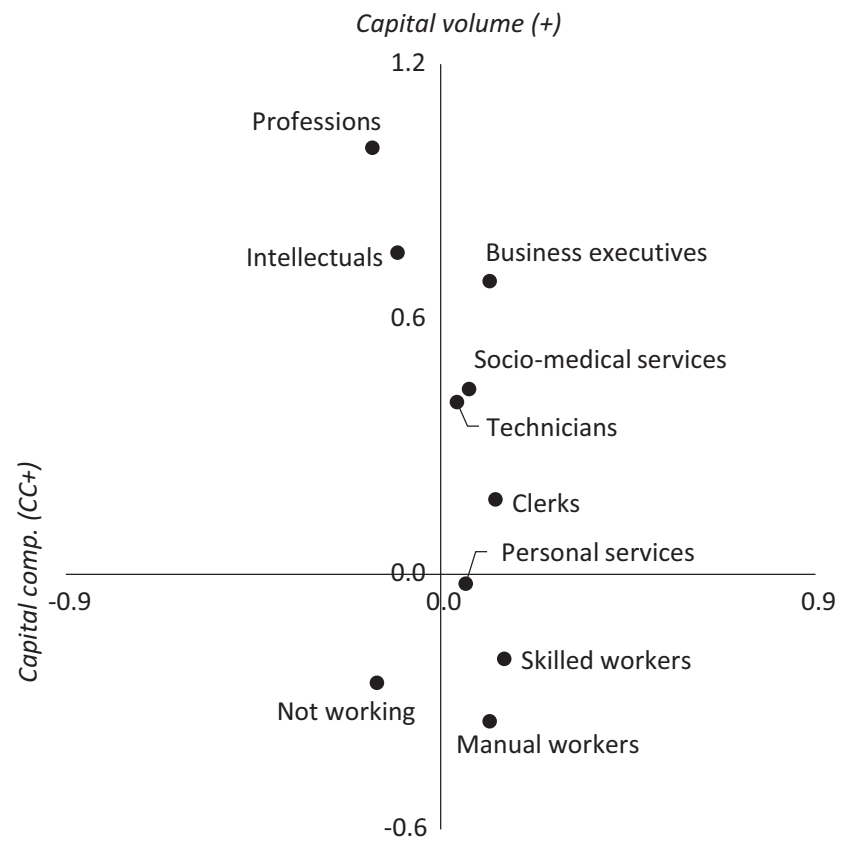

Figure 5.l Partner's occupation in the social space (aggregate model). Note: Based on average rotated coordinates across models.

is less these positions now become located more within the central zone of the space when they are held by partners than by respondents. There is, of course, some variation across national spaces in the nature and extent of these movements (especially among some of the post-socialist samples), and individual specificities across other categories, but they are regular enough and suggest a measure of fluidity in partnering, particularly within the middling regions of the spaces, in most nations (cf. Bourdieu, 1984: 111-12). Still, while some clerical workers might marry skilled workers while others wed business executives, for example, or while some personal service workers might partner with manual workers while others connect with technicians, creating divergent pools of resources, there is no escaping the overriding propensity for love, or at least choice of partner, to be powerfully structured by volume of capital.

A more noticeable deviation between respondent and partner positioning in the division of labour of domination occurs on the second axis, which translates into capital composition in the rotated models: there is, on the whole, a distinct narrowing of distances between categories and specifically, in many cases, a rightwards transfer in the space of occupational locations - 
especially the feminised categories (intellectuals, socio-medical workers and personal service workers) - towards the high-wealth or economic pole of the axis. This is, clearly, an indication of the homogenising effect, in terms of capital composition, of the conditions of men and women with household formation, and it follows from the gender imbalances in the division of labour of domination limiting the pool of potential partners of the opposite sex within one's line of work. In this sense, opposites have to attract. It is interesting, though, that intellectuals and the professions, despite travelling rightwards, remain most stubbornly to the left of the space, on aggregate, as if to signify a higher rate of endogamy within and between these groups due, perhaps, to similarities of taste and interest, relative antipathy to economic capital and its trappings and/or greater gender balance and thus possibilities for partnering with 'someone like me'. Having no working partner is also associated, at the collective level, with the lower-wealth pole of the secondary axis, as well as a lower position on the premier dimension, etching the emergent division between 'work-rich' and 'work-poor' households, as Esping-Andersen (2009) characterises it, into the typical capitalist social space.

Degrees and areas of dispersion along Axis 2 differ from model to model, of course, with Estonia and Russia being special cases. Overriding this, however, is the overall tendency for gender differences to be, to some extent, diminished in the spaces presented here, based on the variables they are (and thus, in might be inferred, in the social spaces they approximate), due to the effects of partnering. That does not mean that gender lacks its own relatively autonomous effect in differentiating access to capital, in the form of sexism or ingrained expectations of the feasible and the desirable in the labour market or the workplace, nor that mental schemas comprehending and labelling the objective divisions and associations of the social space are free of gendered connotations. The glaring segregation of the division of labour of domination, the latter corresponding as it does with the social space in regular ways, and differing rates of part-time employment suggest otherwise. It does mean, however, that grasping the full effects of masculine domination on access to capital requires exploration of domestic organisation, and the underpinning familial field: the allocation of economic resources, the expectations of who should take time out of the labour market to care for family members, the effect of women's loss of earnings on their symbolic power within the household regarding, for example, consumption, education and their own employment prospects, and so on. Partnering may appear to systematically attenuate differences between men and women in the social space, especially regarding the opposition of economic capital and cultural capital, but it may just be that the antagonism is relocated to an alternative site of struggle - the site of struggle, in fact, originating the gendering of the division of labour of domination in the first place. 


\section{The structure of belief}

Gender is not the only factor beyond plain possession of capital that can complicate, reinforce or symbolise, in indirect form, position and movement within a nation's social space. Race, ethnicity and nationality play their part, for example, as others have explored in their own ways (e.g. Hage, 1998; Wacquant, 1997, 2005; Emirbayer and Desmond, 2015; see Atkinson, 2020: $122-9),{ }^{5}$ but so too does a fundamental facet of human life, and point of struggle (frequently to the death), that is connected but irreducible to them: religious belief. At stake, after all, is not only the basic vision of how the world works, how it came to be and how one should act but judgement and treatment of others with contrasting visions. Regarded by most traditions of class research - especially in relation to politics - as a competitor source of division and identity to class, diluting or cross-cutting voting patterns (see, e.g. Lipset and Rokkan, 1967; Przeworksi and Sprague, 1986; Clark and Lipset, 2001), this aspect of human existence has been curiously neglected in most empirical investigations of class qua geometry of misrecognition and symbolic power. ${ }^{6}$ Yet everything in Bourdieu's oeuvre indicates that the contemporary salience and positioning of religiosity is, in fact, a fundamental marker of the long-term transformation of social spaces and the doxa, orthodoxies, heterodoxies and schemes of perception accompanying them.

There are two facets of Bourdieu's sociology of religion to bear in mind. The first is his notion of the religious field, comprised of all those agents perceived as legitimate purveyors of cosmologies and creeds - the monopolists of authority on matters spiritual as contrasted to the disempowered laity in whom, through preaching and writings, the agents of the religious field inculcate a 'religious habitus', or perceptual schemata for interpreting experience (Bourdieu, 1971b, 1971c, 1987b, 1987c; Bourdieu and Saint-Martin, 1982; see also Rey, 2007). These agents are, however, themselves engaged in relatively autonomous struggle over the legitimate definition of the religious worldview and the practices it demands, with heretical prophets (or missionaries) battling established orthodoxy and becoming particularly prominent within the field, often eventually absorbed into orthodoxy, when they harmonise with and articulate the ethos of a substantial section of the laity - the social space, that is - otherwise overlooked by or ill-fitting with extant doctrine. Such is the core model for understanding the birth of Christianity, for example, but also the Reformation sparked by Martin Luther in Germany and, along with the Counter-Reformation it elicited, eventually cleaving Europe broadly into a Protestant North (Scandinavia, England, etc.) and Catholic South (Italy, Spain, etc.), with some nations (Switzerland, Belgium, etc.) remaining more internally divided and former British colonies receiving diverse migrants (the US, Australia) becoming a little more heterogeneous. The legacy of these struggles is still visible at the dawn of the twenty-first century in the prevalence of Protestantism - specifically Lutheranism - in 
the Nordic samples, the substantial presence of Catholicism across large swathes of Europe and the more mixed picture in Germany, Switzerland and the Anglophone samples (Table 5.5). The impact of the old East/West Schism also persists in the substantial presence of Orthodox Christianity in parts of Eastern Europe, especially Russia, while the majority Jewish/ minority Muslim polarity dominates in Israel given its geopolitical history. The Far Eastern nations bear the traces of alternative influences and struggles, both amongst themselves and with China, manifest in the frequency of identification with Buddhism, introduced long ago by Chinese sages, and other Eastern religions (Taoism in Taiwan, Shinto in Japan). Only South Korea has a substantial Christian population, reflecting the relative success of European missionaries there and the role of that religion in historical struggles against both Japan and North Korea.

Underlying the dominance of any specific religion over others is, in most cases, a long and tragic chronicle of struggle and persecution, often involving symbolic marking and degradation (frequently with the force of law) as well as expulsion or execution. More contemporary waves of post-colonial migration from Muslim countries to the West, resulting in a visible presence, have reignited faith-based conflicts in the form of anti-Islamic sentiment, which reacts back on positioning in social space via discrimination as well as all manner of strategies and practices of assimilation or remittance (see Sayad, 2004). Today, however, there would seem to be a more fundamental opposition structuring belief and its homology with social spaces across the nations studied. Here we come to the second element of Bourdieu's analysis of religion: its declining salience in the modern period and the onset of secularisation. If religious oratores constituted one pole of the field of power in feudal social orders, they no longer do so now because agents of the bureaucratising state, as part of efforts over the longue durée to monopolise and centralise capital, took over many of their functions, particularly the provision of education and the definition of legitimate culture, and established a novel mode of legitimation distinct from the divine as well as the aristocratic, leading eventually to the emergence of a secular education system and intellectual field to replace or absorb, in reduced form, the religious field (Bourdieu, 2014; see also Bruce, 2002, 2013). Notwithstanding the recent 'post-secular' turn in some scholarly circles, legitimated constructions of the world and how to live are now offered by scientists, philosophers and journalists, and the practical services of religion - confession, comfort, advice are now, echoing Foucault, fulfilled by new cultural intermediaries (or socio-medical workers) such as, inter alia, social workers, therapists, counsellors and authors of self-help manuals (Bourdieu, 1987c: 117ff). ${ }^{7}$ Hence the adherence to 'no religion' is, as Table 5.5 shows, widespread, forming the major antagonist of the dominant religion(s) across social orders and the majority position in seven of the samples. ${ }^{8}$ Bearing out what has been found elsewhere (Woodhead, 2016), however, the position appears less prominent 


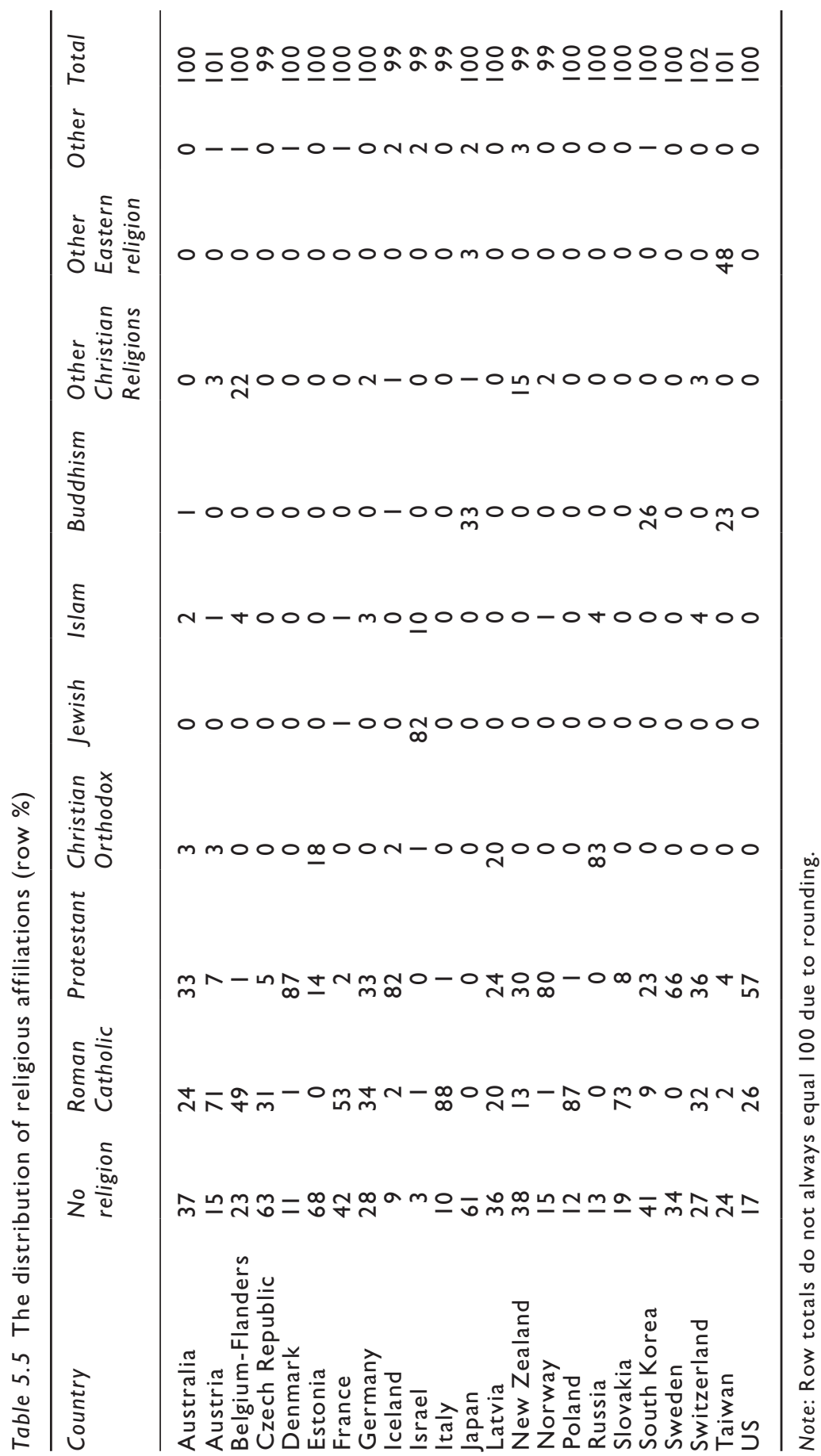


in the US and Italy, where Christianity still prevails; in parts of Eastern Europe, including Russia; and in the Nordic samples, where a lack of conflict between the Lutheran Church and the expanding state perhaps nourished a less antagonistic relationship between religious identity (and faith), on the one hand, and secular institutions (and modes of thought), on the other hand (see van Kersbergen and Manow, 2009) - but in all cases its presence is still considerable. Israel, given the ethno-religious principles of its foundation, is the sole exception.

When projected into the models of social spaces, it becomes immediately apparent that identification with no religion is consistently associated with possession of high capital and, in particular, with high stocks of cultural capital (Tables 5.6 and 5.7). Notwithstanding the case of Israel, where the irreligious clearly occupy dominated positions, adhering to no religion is positively associated with Axis 1, i.e. cultural capital and income, and to the point of atypicality in all but six samples, and negatively associated with Axis 2, i.e. wealth vs. cultural inheritance, registering atypicality in all but a few cases where it sits more centrally or, in Russia, on the positive side of the dimension. The effect of axis rotation must be born in mind in some of these divergent cases, however, including Italy (where the coordinate on the capital composition dimension of irreligiosity becomes a more substantial -0.29) and Russia (where irreligiosity settles into a more central coordinate on the capital composition axis of 0.04). In many of the models, moreover, if irreligiosity is not atypical on an axis - which, in some instances (e.g. Estonia, Japan, South Korea, Sweden), is plainly related to it being rife and, thus, less differentiating - then instead, contradicting Weber's (1968: 485-6) assertion that the dominated and the modern business bourgeoisie are the most religiously 'disinclined' in capitalist social orders, one or more of the major religions is atypical in the opposite direction: Buddhism in Japan and South Korea, Protestantism in Iceland and Sweden and Catholicism and Orthodox Christianity in Latvia. However, a comparison of standardised deviations suggests that, while there may be an overwhelming tendency for irreligiosity to correspond with the top left quadrant of the social space, as if to demark the historical locus of secularisation, the degree of polarisation in the space between belief and scepticism, fides et ratio, varies across nations. In several of the post-socialist nations, the most irreligious countries of the Far East, parts of the Lutheran North of Europe and the US there are, in fact, no notable differences, though it does come close in a few cases, and in some models (e.g. for New Zealand and Switzerland) it is only the secondary religion that is notably removed from lack of belief. ${ }^{9}$ In nine other cases, however - including the unusual case of Israel, but otherwise covering various parts of Europe as well as Taiwan and Australia - the opposition is more pronounced, statistically speaking, between the keepers of faith and those who perhaps, with Nietzsche (1994: s.113), view Christianity and other religions as a slice of antiquity intruding dissonantly on contemporary life. ${ }^{10}$ 


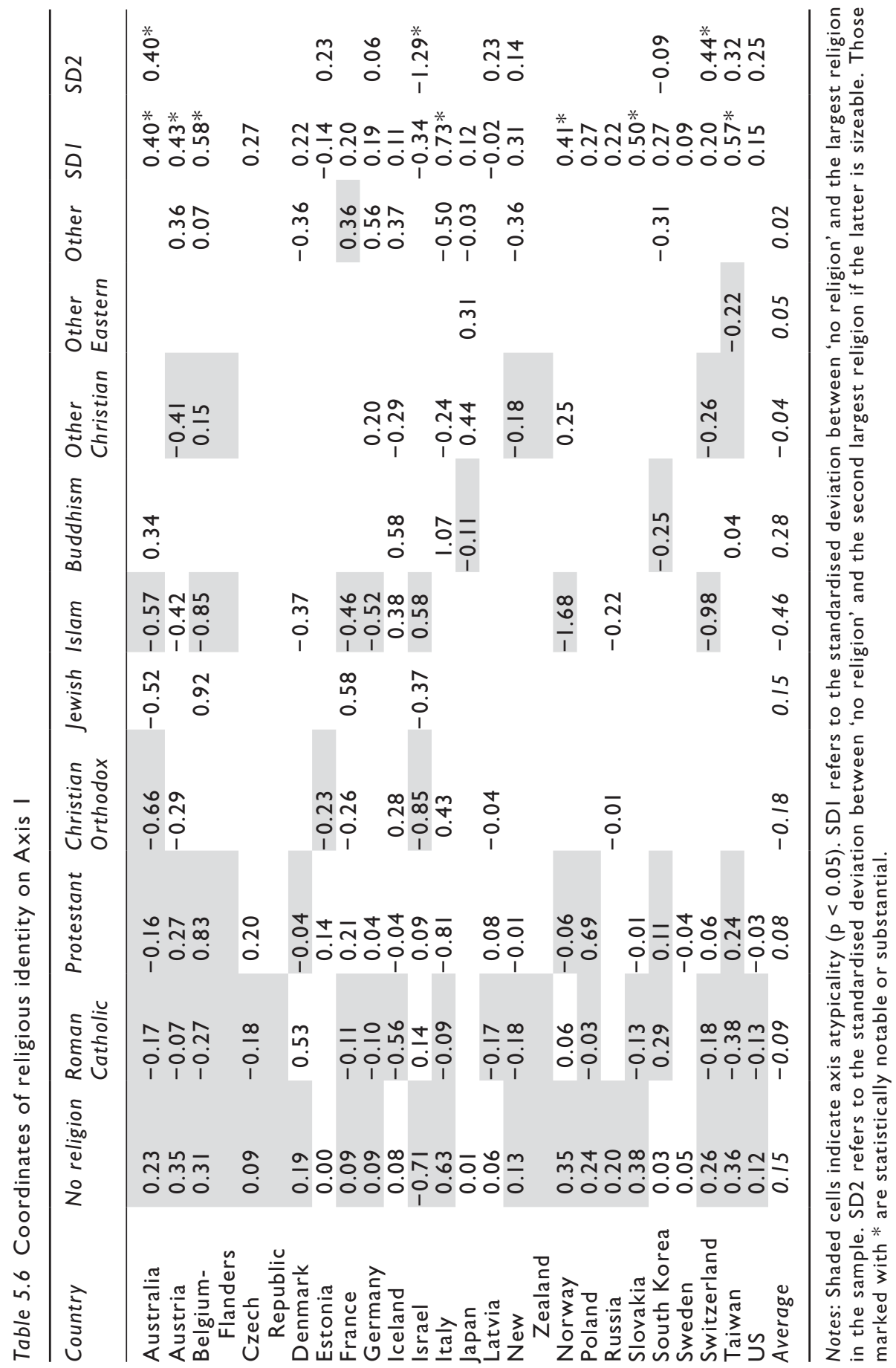




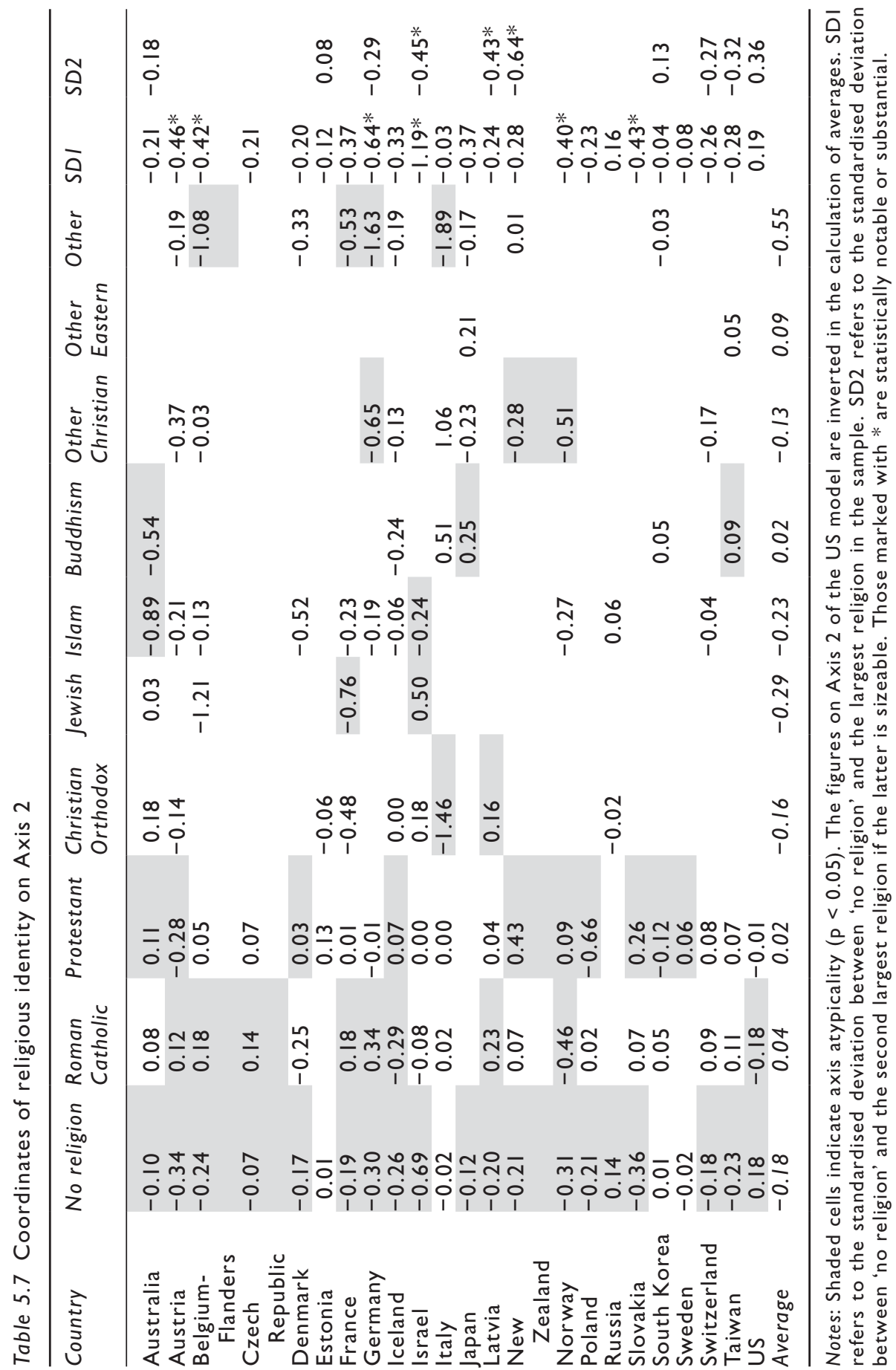


The correspondence of non-belief with cultural capital, as a trace of the battle between cultural capital and religious capital for supremacy as a structuring feature of misrecognition orders, and state and Church as the arbiters of value, concords with previous assertions that education, particularly higher education, goes hand-in-glove with doubt (Baker and Smith, 2015). Secular pedagogy dissipates faith, perhaps, by nourishing scepticism of the supernatural and resistance to dogma, as sacred texts and principles become objects of study rather than unchallengeable truths. Yet the positioning of irreligiosity on the second axis in many cases, pulled towards the pole of cultural inheritance, also alludes to its intergenerational 'stickiness'i.e. the strong tendency for non-believing parents, in conjunction with secular schooling, to inculcate non-belief in their children (Woodhead, 2017; Strhan and Shillitoe, 2019) - and suggests that classes defined by volume of capital are not, as unidimensional visions of stratification (with higher education simply at the top) would have it, all of a piece, but internally fractured to greater and lesser degrees, depending on national context, in their fundamental worldviews because of typical differences in social origin.

\section{Social space and geographical space}

There is another division within the typical capitalist social space running along similar tracks to the polarisation between homines religiosi and homines increduli; a division which also echoes the long-term transformation of social orders around the world; and a division which, if anything, is more definite and consistent across nations: the division between urban and rural populations, overlapping to differing degrees with the opposition between the capital city and the provinces, born of the long march of urbanisation and state-making characterising the last few centuries. Bourdieu (1984: 124) posited, in Distinction, a close homology between social space and physical space: a differential distribution of class fractions across 'socially ranked geographical space' to the extent that degree of physical distance from the means of acquiring and displaying capital - educational institutions, specific labour markets, consumption opportunities - becomes constitutive of their conditions of existence and, with that, a symbolic marker of social distance. Since capital flows to the capital, and urban centres more generally, the urban/rural or capital/province divides become co-determinative of and assimilated in perception to the dominant/dominated division. The relationship is not uniform and mechanical, of course: agents otherwise endowed with similar stocks of capital can, for one reason or another, occupy contrasting locations in physical space - a degree-educated intellectual residing in the city and another living in the countryside, for example - and that can, as Pahl (1975: 201ff) long ago noted, have its specific effect on structural possibilities, attendant experiences and, as a consequence, tastes 
and (self-)perceptions (see Atkinson, 2017). Nevertheless, a possessor of abundant capital is more likely to reside in an urban centre while those with less or little, though also populating the cities, constitute the bulk of the small-town and rural population.

The homology is a product of myriad struggles over time to appropriate space carried out by players within national fields of power and local fields of power, as players in economic fields but also, contrary to most Marxist accounts (e.g. Massey, 1995), players in bureaucratic and intellectual fields seek to derive 'profits of localisation' by occupying advantageous spaces (in terms of proximity to resources, networks and opportunities) which then, in a kind of snowball effect, concentrates capital - and capital-rich agents in expanding urban areas, the capital city above all (Bourdieu, 1999, 2005; on London, for example, see Atkinson, 2017: 90-1; Savage et al., 2018; Friedman and Laurison, 2019). Now more than ever, however, these strategies are pursued on the global stage, structured by the international field of power as firms, universities and so on seek opportune sites on foreign soil for specific operations and outposts - and the global space of states - as certain nations specialise in finance, knowledge production or other services, for example, while others focus on high- or low-tech manufacturing (e.g. Germany, South Korea, Taiwan) or maintain larger agrarian populations (e.g. parts of Eastern Europe). The result, one might suppose, is a dissimilar profile of urban specialisations, and thus degree and form of capital concentration in cities, across countries. ${ }^{11}$

In fact, the aggregate model suggests a powerful and consistent crossnational homology between capital possession and the urban/rural or capital/province binaries (Figure 5.2). ${ }^{12}$ In a nutshell, the higher one's capital, the more likely one is to reside in larger conurbations, namely cities and metropolises, as opposed to towns and villages. ${ }^{13}$ This almost linear relationship is, however, specified by the form of capital one commands more of (a relationship that becomes clearer once the spaces are rotated). Urban residence is connected to lesser wealth, and to inherited cultural capital, and all the properties associated with it, whereas rural or town dwelling is associated with higher personal wealth and lower cultural capital. The result is a series of correspondences: of the metropole (the home of 'intellectuality' according to Simmel) with the culturally richer section of the dominant class; of city life more generally, given all its opportunities for graduate employment, public services and satisfaction of cosmopolitan tastes, with higher (cultural) capital; and of town and village residence with the economically richer segments of the dominated class, though implicated within this relationship is the slightly greater orientation of the wealthier sections of the dominant class, compared to the culturally rich sections, towards rurality, as if to indicate an 'escape to the country', i.e. to the quiet and leafy commuter villages, among some of those who can afford it. 


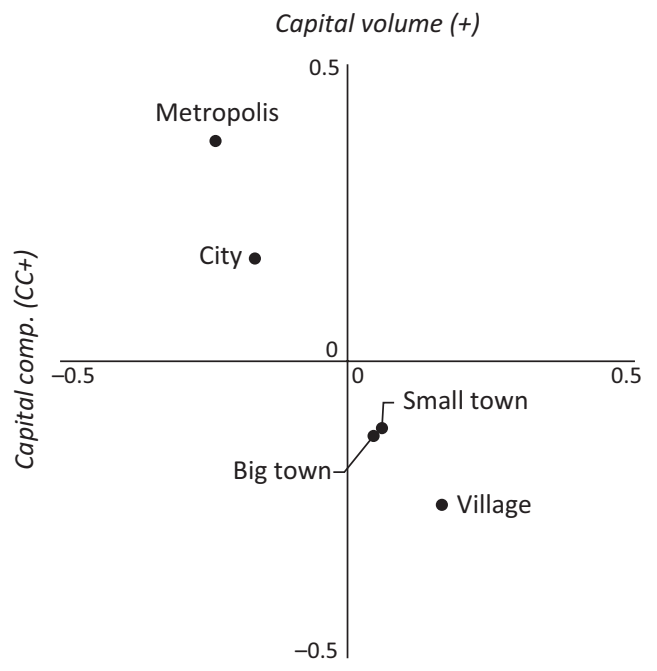

Figure 5.2 Place of residence in the social space (aggregate model). Note: Based on average rotated coordinates across models.

The strength of the relationship between residence and cultural capital is demonstrated by the rarity with which the location of and differences between coordinates on Axis 1 fail to register statistical significance and the geographical specificity of the cases where that occurs, i.e. the confinement of the Belgian sample to Flanders, the legacy of the East/West divide in Germany and the territorial disputes and segregation of Israel (Table 5.8). The US model is also a little different from others insofar as urban residence tends to hover around the centre of the axis. This is perhaps an effect of the sheer number and size of metropolises and cities across the US, with their heterogenous populations, but the opposition of urban (higher) and rural (lower) residence is still present, just relocated downwards within the space compared to elsewhere. Nevertheless, comparison across nations of coordinates on Axis 1 (and especially the Eta ${ }^{2}$ figures) does suggest that the correspondence between the urban/rural opposition, or metropole/province opposition, and the poles of the social space may be more salient in some countries than others. The relationship is particularly pronounced, for instance, across Eastern Europe, where agriculture and its associated village life are more prevalent, as well as in Taiwan and Austria, the latter with its low rate of urbanisation, but is much less prominent in the US, South Korea, Israel and parts of Western or Northern Europe, where fewer people live in the countryside relative to urban areas.

The distribution of modalities along Axis 2, distinguishing those high and low in wealth, is generally weaker, judging from the $\mathrm{Eta}^{2}$ figures, and a little 


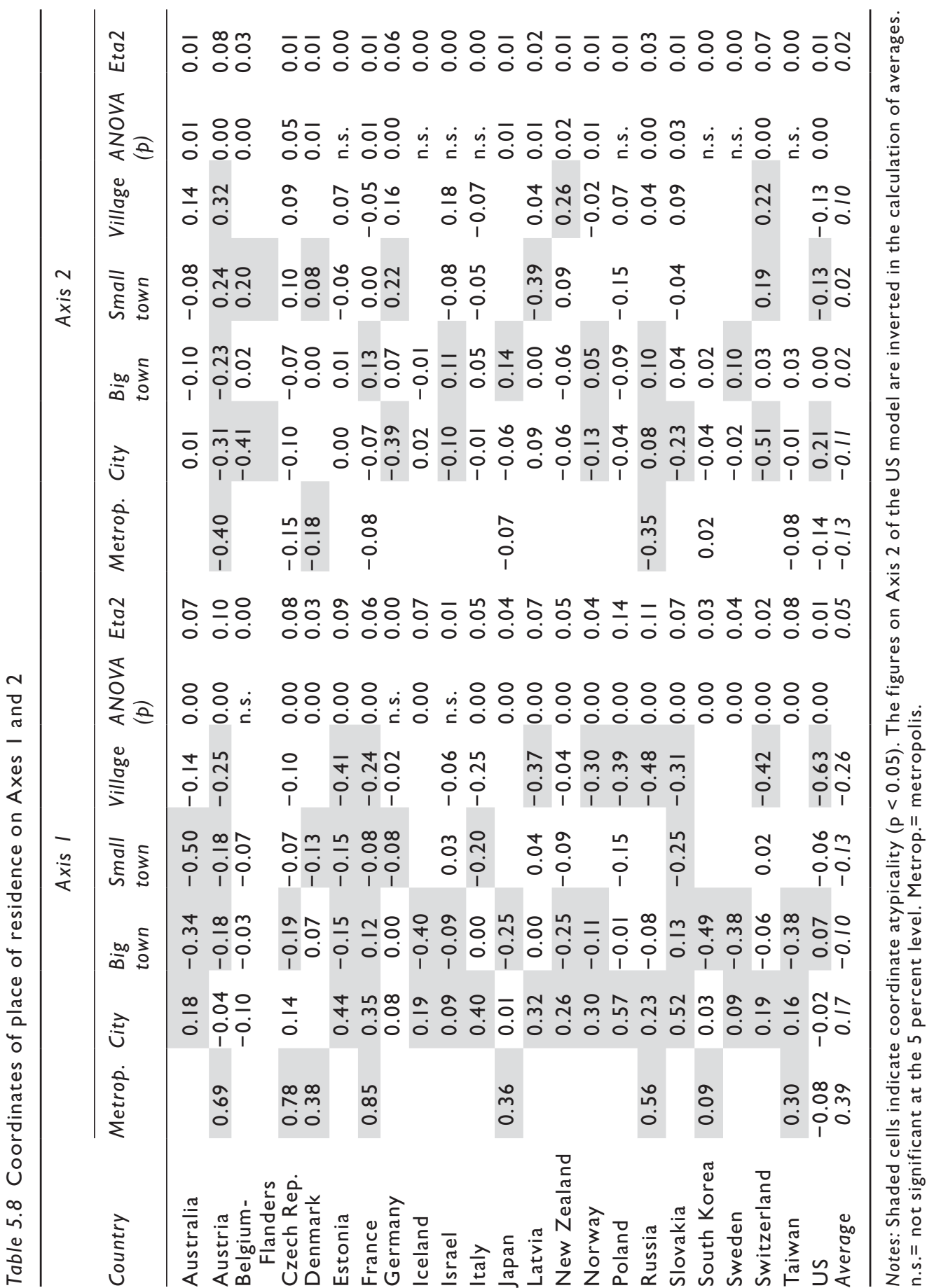


less consistent. In eight models the differences between coordinates are not significant, and in six of those there are no atypical locations either. The lack of a modality for village residence in the data for Iceland, Sweden, South Korea and Taiwan must be borne in mind, however, as must the effect of model rotation in the other cases. The horizontal distances between city or metropolitan life (towards the cultural pole) and village life (towards the economic pole), while limited on the respective CatPCA axes, become larger once the models are corrected to proxy capital volume and capital composition: 0.23 in Estonia and Italy, 0.29 in Poland and 0.31 in Israel (where differences by capital composition become more pronounced than those by capital volume). In three cases where differences are significant on Axis 2, moreover, there is deviation from the usual pattern: France, Latvia and the US. In the case of France, where the opposition seems to be between living in a large town (associated with economic capital) and elsewhere, model rotation again renders the positioning of modality coordinates less peculiar: -0.27 on the axis for Paris, -0.14 for other cities and 0.10 for large towns, with small towns $(0.02)$ and village life $(0.0)$ being associated with balanced stocks towards the middle or bottom of the space $(-0.08$ and -0.24 on the capital volume dimension, respectively). The same operation makes less difference in the US or Latvian spaces, but these would appear to be just two divergent cases, for whatever reasons, from an otherwise stable relationship across nations between the urban/rural divide and not just capital volume but capital composition.

\section{Conclusion}

The typical social space in twenty-first-century capitalist societies would seem to be overlaid with a series of oppositions specifying and complicating the effects of the division of labour of domination. Among these, as we have just seen, is the urban/rural divide, which corresponds not simply with the polarities of high/low capital but, more specifically, with high/ low cultural capital. Falling along very similar fault lines is the irreligious/ religious schism, even if sometimes the relationship is modest: it is those with higher holdings of cultural capital who are most closely associated with lack of religion - whether they be rationalists, humanists, agnostics, spiritualists or just plain indifferent - while others with less cultural capital, though not necessarily little cultural capital, are more likely to cling to traditional religious identities and, it might be inferred, the justificatory cosmology - divine ordination, for example - they entail. Gender, on the other hand, is only fairly weakly related to the structuring of capital possession, despite the evident disparities of male and female positioning in the division of labour of domination, and everything suggests that the social capital provided by partnering might play a role in this homogenisation of 
condition. This ineluctably suggests the implication of the life course in class positioning - of the entanglement of movement in the social space with different phases of life, that is - at the same time as the opposition between urban sceptics and rural believers, and its correspondence with high/low cultural capital, augurs the possibility of capital composition being inextricably tied to a division between the new and the old, or the rising and the declining. Both portend the substantial weight of trajectory effects in constituting the spaces, therefore, and so it is to these we must now turn.

\section{Notes}

1 See, for instance, Esping-Andersen (1990, 1999), Sainsbury (1999), Korpi (2000), Blossfeld and Drobnič (2001) and Ferragina and Seeleib-Kaiser (2014). On East Asia, see Yamashita (2010), Estevez-Abe (2013) and contributions to Izuhara (2013: Part III). On Southern Europe, see Ferrera (1996) and Trifiletti (1999). On Eastern Europe, see Cerami (2006) and Galligan et al. (2007).

2 Rotating the coordinates makes little difference in this regard.

3 To test whether this effect was due to women 'pooling' in specific yet contradictory regions of the spaces the models were cut into nine segments based on axis terciles and subject to $\mathrm{Chi}^{2}$ tests, but again there were few significant results.

4 Partner's occupation, reduced to four categories in the same manner as for parental occupations, could have been entered as an active variable in the CatPCAs. That option was trialled, but the variable was not, in the end, included because (i) the category for no working partner is commonly large (40 percent on average, but sometimes up to 50 or 60 percent) and, unlike for parental position, fairly heterogenous, since it includes the retired and those with no partners at all, which became even more problematic when the professional-managerial and intermediate categories had to be collapsed into one to counter low numbers (as they did in several samples); and (ii) in that state of aggregation the variable was deemed redundant given that the indicators of economic capital are measured at the household level. It was not possible to split partner's occupation, as a supplementary variable, by respondent's gender (partner's gender was not recorded) on the grounds that it produced unsatisfactorily low cell counts, though the effect of gender can still be inferred from the rates of feminisation of occupational categories. This is assuming the rate of same-sex partnerships is low.

5 It was not possible to explore the distribution of ethnic groups within the spaces using the ISSP dataset due to the available variable on ethnic origin yielding data of little use in all but a few national samples.

6 Rosenlund (2009: 152-3, 161-2), one of the few to give it any attention, submerged religious belief within a spiritualist-materialist index and found little relation with the Norwegian social space.

7 This is not to deny the legacy of religious creeds in secular intellectual production and education - the persistence in naturalised form of specific JudeoChristian principles, for example, in doxic views on gender and family in the West. Nor is it to deny, for that matter, that specific revolutions in the religious field (e.g. the advent of Protestantism, with what Durkheim [1970: 158] described as its 'spirit of free inquiry') may themselves, in the end, have facilitated secularisation (Berger, 1990). 
8 This is a well-documented trend (see, e.g. Baker and Smith, 2015; Woodhead, 2016). The label of 'no religion' is not to be directly equated with atheism or even agnosticism, even if it encompasses them, as it might include people with a 'spiritual' impulse or vague belief in a 'higher power' unattached to any established religious doctrine (see Lee, 2015; Woodhead, 2016, 2017). For that reason, identification with the category is best described as 'irreligiosity'. Equally, of course, people who identify with a religion may have varying degrees of belief in the supernatural elements of the creed (though see n.9).

9 Further tests in these cases to examine whether degree of piety amongst those who do profess a religious identity, via a variable measuring frequency of participation in religious services (weekly, monthly, yearly, never), varies by capital possession were carried out. In only a handful of cases, however, were differences statistically significant, including the US, where a lower position on Axis 1 correlated with higher frequency of participation; and Iceland and Poland, where frequency of participation correlated with higher positions on the wealth axis (in other cases the patterns were less clear).

10 It may seem counterintuitive that the Muslim minority in Israel appear higher in the space, on Axis 1, than the Jewish majority, even if they are, according to their respective positions on Axis 2, typically much less wealthy. This, however, should be read in conjunction with the fact that residence in the Arab quarter registers a coordinate of -0.72 on Axis 1 , compared to 0.22 for residence in one of Israel's capitals, thus broaching, in anticipation of the next section, a complicated intersection with geography.

11 There is also the question of the homology between the social space and physical space within cities, as certain districts and neighbourhoods become associated with specific capital profiles, but that cannot be explored with the data at hand. For examples from Norway and the UK, see Rosenlund (2009: Chapter 8) and Atkinson (2017: Chapters 5 and 6).

12 A 'metropolis' is defined as a conurbation with more than one million inhabitants; a city has between 100,000 and 999,999 inhabitants; a 'big town' has between 10,000 and 99,999 inhabitants; a 'small town' has between 2,000 and 9,999 inhabitants; and a 'village' has fewer than 2,000 inhabitants. In the samples for Austria, the Czech Republic, Denmark and France the metropolis refers specifically to the capital region.

13 Inspection of coordinates in the national models suggests the proximity of big and small towns in the aggregate space hides substantial variation in their respective locations across countries. They are indeed close on Axis 1 (separated by less than 0.1 units) in six models, and on Axis 2 in the same number (though not all the same ones), but more dispersed elsewhere. 


\section{Chapter 6}

\section{Trajectories}

Theoretically speaking, social spaces change from second to second, never mind day to day, month to month or year to year, as millions of implicated agents accumulate or convert increments - often micro-increments - of capital in the course of quotidian practice. Spending money, acquiring some new information or object or making and maintaining, or losing, contacts all contribute unceasingly to reshaping the field of force. Just as one never steps into the same river twice according to Heraclitus, a survey of capital today would yield different results from a survey tomorrow even with the same sample and questions, provided the measures and answers were precise enough. Bar moments of revolution, however, the transformation of a social space, like the changing height of a growing child or the evolution of species through history, is so gradual as to be imperceptible in the durée of everyday existence. It feels more or less stable, the world feels more or less the same from day to day (even if one's place within it might feel different in light of specific biographical events) because appreciable change is usually drawn out over the generations. It is only generally when we look back, as when we compare our lot to that of our successors (children) or antecedents (parents), that the morphology of the social space might enter consciousness cloaked in practical logic ('things were/are different then/now'). Similarly, the overall stability of the structure of social space through the multitude of individual manoeuvres means the extent and direction of mutation is better gauged analytically by using 'cut points' of appropriate temporal distance, as with decennial surveys, for example. In our case, the ISSP Social Inequality module repeats at routine intervals, yielding data for 1999, 1992 and 1987. Unfortunately, however, not only are different nations included in different instalments, but some variables change from round to round too, making for an unsatisfactory tool.

Yet repeat surveys are not the only way to get a handle on trajectories in, and the trajectories of, social spaces. Like the dendrochronologist inspecting tree rings, the sociologist can discern traces of the past state of the field in present structures too. This is possible via examination of the distribution of generations across the spaces and the patterning of social 
origins. As regards the latter of these, we have already seen the close association of inherited capital with acquired cultural capital and income across social orders, and thus the continued prominence of social reproduction in capitalist societies old and new, as well as the polarisation of those richer and poorer in inherited capital according to their accumulation of specific species of economic capital. This indicated the existence of both upwards and downwards trajectories at the individual level. Now, however, we can not only investigate the conjecture that this may be related to generational differences by examining the typical distribution of age groups in the first two dimensions of difference but drill a little further into the role played by social origin, and, with it, discernible patterns of social mobility, by examining its specific manifestation on the third axis of the models.

\section{The old and the young}

'Youth' may be just a word, but it is one which, as Bourdieu (1993b, 2019) emphasised, is constantly implicated in the struggles to legitimise and denigrate. Like 'rich' and 'poor' regarding income, or 'male' and 'female' regarding the distribution of sexual properties, 'young' and 'old' form a binary categorisation of a continuous reality homologous with countless perceptual oppositions revolving, ultimately, around a superior/inferior hierarchisation. The mental dividing lines between young and old are fuzzy, overlapping and variable from one social space to another, from one field to another and from one social position to another depending on the state of play, and their respective associations and evaluations - new/outdated, naïve/experienced, progress/tradition - are constantly invoked and challenged in the battle to conserve or subvert the rules of the game. If the analyst must rely on a categorisation of age groups as a rough proxy for stages of life and generations, therefore, it is with awareness that the cut points are arbitrary and subject to struggle but with conviction that, far from simply rendering analysis impossible, their patterning across a constructed space of difference should nevertheless reveal something meaningful regarding its temporal dimension.

When it comes to the relationship between age and a social space, defined by the major principles of misrecognition in a social order - economic and cultural capital in contemporary capitalism - this is structured by two separable yet interlocking social rhythms. On the one hand, there is the routine cyclical movement of agents within the social space over the life course. The young are likely to hold less economic capital since, at the outset of their working lives or careers, they tend to have lower earnings and to have accrued fewer assets. Accumulation of capital, as Bourdieu (1997) stressed, takes time - climbing the career hierarchy or supervisory chain, putting money aside into savings, getting on the property ladder - even where there is parental assistance. We might call this the 'seniority thesis', after 
Bourdieu's (1984) recognition that volume and weight of economic capital within a class - or at least the dominant and intermediate classes - increase with age. This is complicated, though, by post-retirement diminution of economic capital as pay is swapped for pensions and assets potentially chipped into to pay for care, though the rate of diminution - and indeed whether there is a reduction at all - is likely to depend on the benefits attached to pre-retirement position, especially pension schemes, and the degree of state assistance (Vincent, 1995, 2003; Storelli and Williamson, 2015; cf. Bourdieu, 1993b: 100).

The age structure of the class system is also linked, however, to longerterm mutations of social spaces cross-cutting and refracting the generational cycle of capital accumulation. One of these, hitting the lower end of the social space, is the growth of low-pay and low-security service industries in many nations to absorb young workers in place of traditional, well-paid, high-skill, unionised extractive or manufacturing jobs (France, 2016; Furlong et al., 2017). More important, though, is the expansion of education systems across capitalist social orders, including a supposed 'normalisation' of post-compulsory learning (even if the degree to which it is objectively and subjectively 'normal' still varies by social origin - see France and Roberts, 2017), and the resultant diffusion of cultural capital as a principle of misrecognition. The young are likely to be more closely associated with higher stocks of cultural capital than older people, therefore (Rosenlund, 2015). This includes not only the acquired, institutionalised cultural capital of educational qualifications but also - and crucially, given its apparent importance to the structure of social spaces - the inherited capital proxied by parental position and book ownership. As the education system has expanded over generations, and the shape of the occupational structure shifted with it, having a parent with specific markers of cultural capital becomes a more common characteristic among younger age cohorts. Taken together with the seniority thesis, then, the conjecture is that - as found by Savage et al. (2013) for the UK - those falling more on the social/cultural capital side of the models will be more closely associated with youth, and in a sense 'rising', and those on the economic side with older age, signalling an element of intergenerational decline playing off the intragenerational accumulation cycle.

Projection of age categories into the spaces reveals that, across the board, the young are indeed much more likely to be associated with higher levels of education and greater levels of inherited cultural capital (but also income) than older generations, and the latter are much more likely to have accumulated substantial wealth in the form of savings and domestic property ownership (Table 6.1 and Figure 6.1). Thus, on Axis 1 age always follows a negative trajectory, with younger people positioned on the positive side of the dimension and older people, especially those over 65 years of age, being located in the negative region. The placement of one or 
more age category is significantly atypical in every case, with the category for those over 65 years old being particularly prominent on the negative side and the category for those aged between 25 and 34 (and sometime 35 and 44) being salient on the positive side. The category for those aged between 18 and 24 is the most variable in its location, however, revealing the relative heterogeneity of condition and experience of those - some of whom will still live in parental households, some of whom will not - most readily associated with the label of 'youth'. In 11 cases they fall on the positive side of the premier dimension, sometimes substantially (and significantly so in six cases) but sometimes not. Otherwise they fall below the origin, though rarely by much and only significantly so in the Swiss space. Moreover, the gap between the generations in terms of cultural capital, and the misrecognition and opportunities it affords, is evidently more pronounced in some spaces than others, with those for South Korea, Italy and Australia being opposed to those for the US, Switzerland and New Zealand in this respect.

The relationship between age and capital is reversed on Axis 2, with higher age categories being associated with positive coordinates and youth corresponding with the negative pole. One or more categories are, once again, significantly atypical in every model, though the precise dividing line fluctuates from model to model. In most cases the category for those aged between 45 and 54 first nudges on to the higher-wealth side of the dimension, but in several spaces a contiguous category does so instead. Here too the gap between the young and the old is variable from space to space. Undoubtedly the most notable tendency is for the polarisation of generations to be less pronounced in the post-socialist models, as if to indicate that excluding those who, pursuing an exit strategy, have emigrated in search of better prospects - many of the young in these social orders, the novye Russkie and their homologues, have been presented with and benefitted from the novel objective and subjective possibles opened up by economic restructuring to accumulate property and savings, while the older population, who came of age under socialism, struggle to keep pace, at different rates depending on country-specific undercurrents in the transition to a market economy.

Rotated coordinates across models modify the aggregate positions of generations only slightly, but they do confirm a few general tendencies. First, the gap in terms of capital volume between younger age groups (18-44 years old) and those aged between 45 and 64 is only modest - the real polarisation is between those aged 65 or over, who sit low down the volume axis, and the rest. This is not reducible to an opposition between the retired and the employed, though that will contribute in some cases, since there are plenty of people aged 65 and over in work across the samples. Second, there is a clear and orderly correspondence between age and capital composition, with those aged between 18 and 44 much more likely to possess a greater 


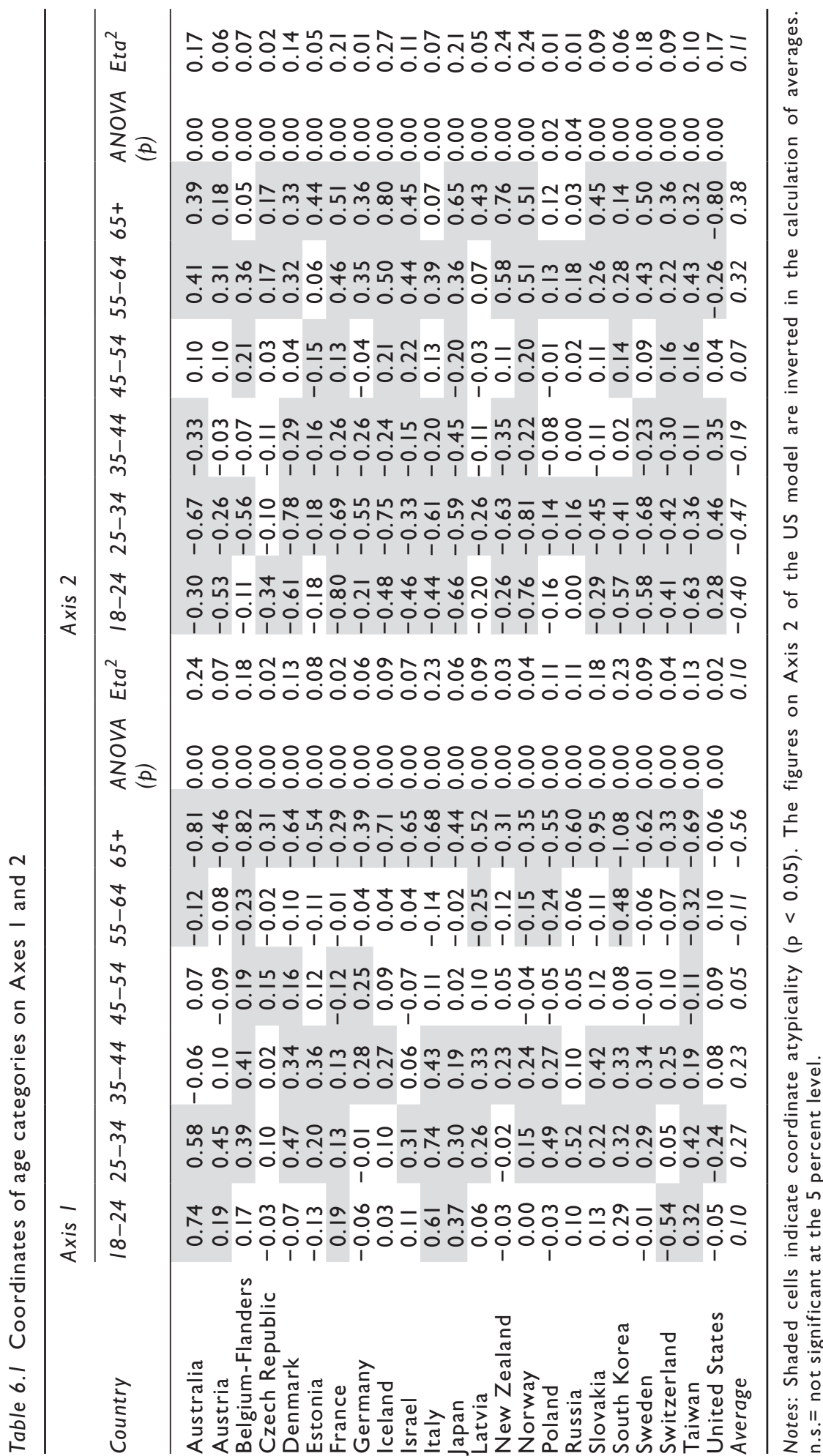



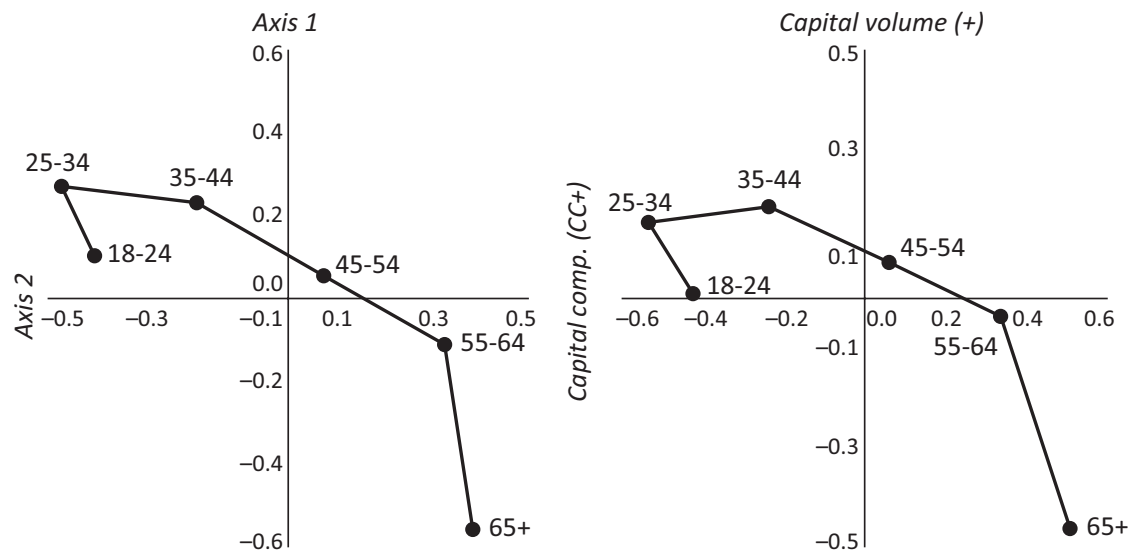

Figure 6.l Age groups in the social space (aggregate model).

Note: The figure on the left is based on average coordinates in the CatPCA spaces. The figure on the right is based on average rotated coordinates.

weight of cultural capital to economic capital and those aged 55 and over much more likely to have the reverse profile. The axes together, it might be concluded, signal the interaction of generational and life-course effects. The older population are much less likely to have acquired educational qualifications, to have had parents in professional-managerial occupations when they were young - the 1960s at the latest - or to have entered jobs with high pay levels since the state of the division of labour of domination was so different then compared to its equivalent in later service-led, 'human capital'-centred and pay-polarised social orders, but they are more likely to have accumulated personal wealth, in the form of domestic property ownership and savings, over their lifetime of labour than younger people - albeit not enough to place them in a more elevated position on the volume axis.

The patterning of generations across the spaces also confirms the suspicion aired in Chapter 5 that the oppositions between irreligiosity and religiosity, on the one hand, and between urban residents and small town or rural populations, on the other hand, both grafted on to the cultural-economic polarity to varying degrees, are oppositions of the new and the old. It is the youthful possessors of cultural capital, the recent graduates and those born of professional parents, who are more likely to reside in the growing cities, while the older populations linger in towns or the countryside. And it is the young, those who are more likely to have been subjected for longer periods of their lives to secular education or parental influences, who are associated with non-belief, while the older generation, perhaps feeling themselves on the decline, are more likely to cling to the comforting identities and cosmologies of the past or, in any case, less likely to question their veracity (Bourdieu, 1984: 111). 


\section{Age and the division of labour of domination}

All in all, then, trajectory is, as anticipated in previous chapters, heavily implicated in the structuring of the second axis of difference and, more specifically, the detectable mass of individuals characterised by high cultural capital and low wealth in many spaces. The pronounced and consistent patterning of age groups along the wealth axis, and the capital composition principle once the spaces are rotated, does, however, immediately raise the question of the relationship between age, or trajectory, and the division of labour of domination. Are the occupational categories placed where they are, especially along the second axis, primarily because of the age structure of the implicated occupations, and thus their connection to fading and emergent industries or disappearing and proliferating roles, or are there differences in demands and opportunities for capital accumulation attached to jobs that apply to old and young alike? Are there internal differences by age, such that the younger and the older holders of specific positions and members of specific fields, thanks to the education boom of the later twentieth century, are as divided from one another as members of different fields en bloc?

Examining the average age within occupational categories reveals only modest and inconstant differences across nations (Table 6.2). Perhaps the most consistent differences relate to the lower end of the social space, where those working in personal services tend to be younger than the sample norm and those working in manual or skilled work a little older - a finding which fits with the positions of the occupational categories and age categories in the spaces and possibly indicates the shifting structure of the division of labour of domination over time in the wake of deindustrialisation or, at the very least, growth of the service sector alongside industrial production through the last century. These capacious categories also tend, on average, to be a little more internally dispersed, as measured by standard deviations, than positions higher up the social space, though the aggregate differences are attenuated by cross-cutting variations by nation, as some (e.g. Australia, Russia) tend to be characterised by broader age dispersion across the board than others (e.g. South Korea, Taiwan). It is striking, finally, that business executives are, contrary to the common trend, typically a little younger than the sample as a whole across the post-socialist models, where the occupations this category denotes are likely to have multiplied in the wake of the transition to capitalism. Otherwise, however, it is hard to pinpoint stable relationships between position in the occupational division of labour and age, and thus to draw firm conclusions on cross-national tendencies in the trajectories of specific job types.

Inter-model correlations between the age structure of occupational categories and their coordinates on the two primary axes of the spaces, constrained as they are by certain conditions of statistical validity, ${ }^{2}$ suggest only a few notable relationships. Specifically, business executives, across spaces, 


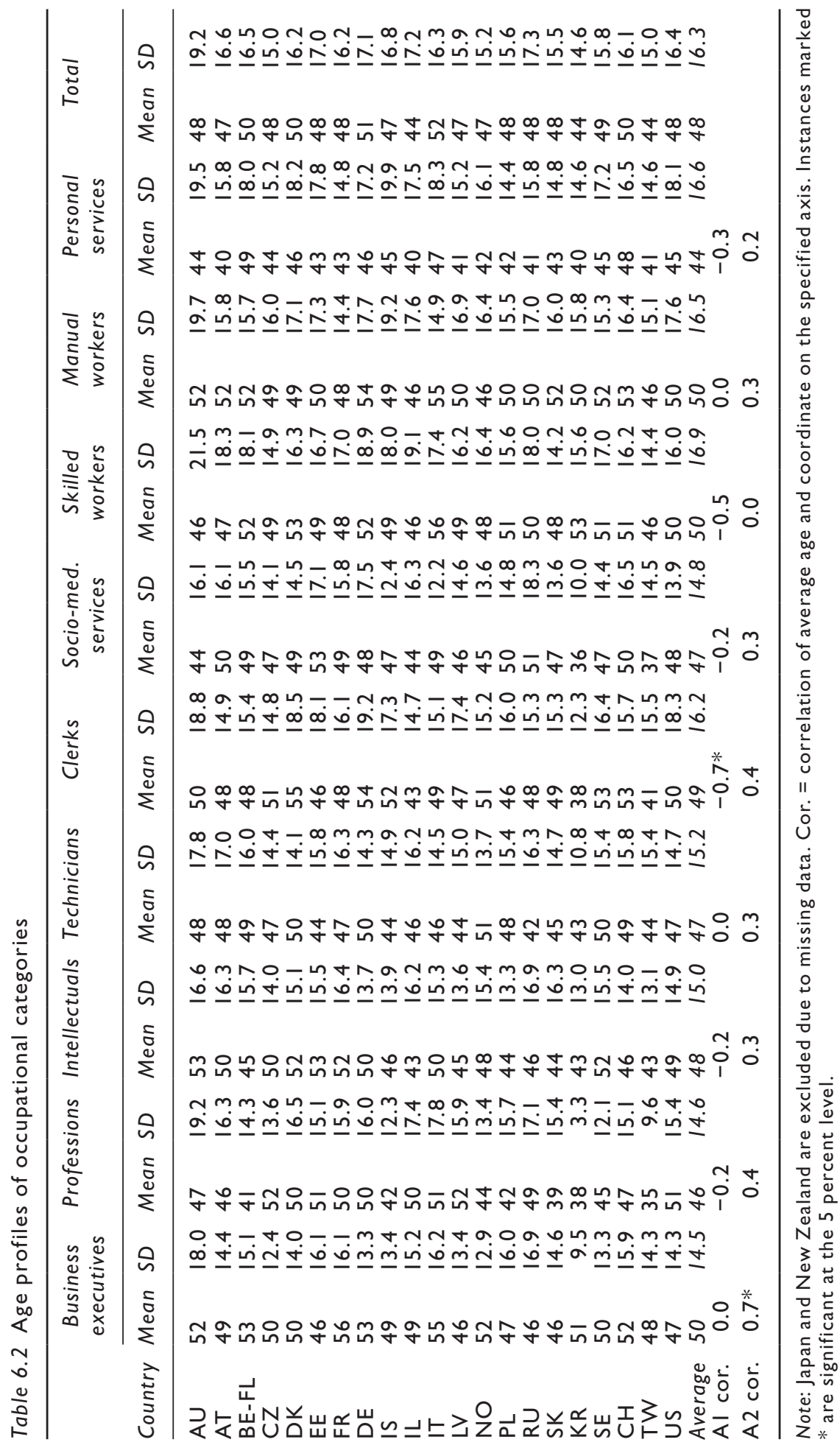


are consistently wealthier (and poorer in inherited capital), relatively speaking, the older they are on average, and clerks are consistently lower on the premier axis, i.e. lower in terms of cultural capital (and income), the older they are. The specific locations in the spaces of other occupational categories, however, cannot be confidently linked to their age profiles.

On the other hand, if younger and older members of the occupational categories - i.e. those aged under 45 and those aged 45 and over - are projected separately into the spaces, then the effect of age on social position is immediately visible (Figure 6.2). At the cross-national aggregate level, younger members of all the categories tend to be positioned higher up Axis 1, richer in cultural capital (and income), than their elders in the same groupings, and much further to the left, lower in personal wealth. There are some variations by category - younger professionals are not, at the cross-national level, much richer in cultural capital or income than their older counterparts but they are substantially less wealthy, and the same is true of young and old intellectuals. In fact, it would seem that vertical distance between the old and the young in each occupational category increases the lower the occupations are in the space while the horizontal difference between them shrinks. Put another way, the higher people are in the division of labour of domination, the more the young and the old are homogenous in terms of acquired cultural capital and advantaged social origins but the more dispersed they areas if marking the lateral poles of fields - in accumulated wealth. The lower they are, on the other hand, the more homogenous, relatively speaking, the young and the old are in terms of their wealth holdings. This, of course, follows the roughly conical distribution of individuals in the spaces.

There are still, however, evident horizontal and vertical differences between occupational categories despite separation by age. On Axis 1 the dominant/intermediate/dominated split of categories holds for both old and young alike, with professionals at the apex and manual workers at the nadir, even if the younger categories are all slightly higher up the axis than their older counterparts, and on Axis 2 the intellectuals are less wealthy than business executives among young and old alike. It is almost as if, in fact, there are two parallel and distinct divisions of labour of domination, one older and wealthier, following a general north-easterly vector, the other younger and less wealthy but richer in cultural capital, heading up toward the northwest, but with homologous internal oppositions. Within the space as a whole, this means that younger business executives, for example, may be wealthier than younger intellectuals, but - perhaps signalling areas of (geometric) overlap between specific fields in the social space - they are less wealthy than older intellectuals. They are also comparable in terms of cultural capital and income - an effect of educational expansion and rising credentialisation, no doubt, and another indication that education level alone, and possession of a degree in particular, may increasingly function as a less effective differentiator of capital composition compared to subject 


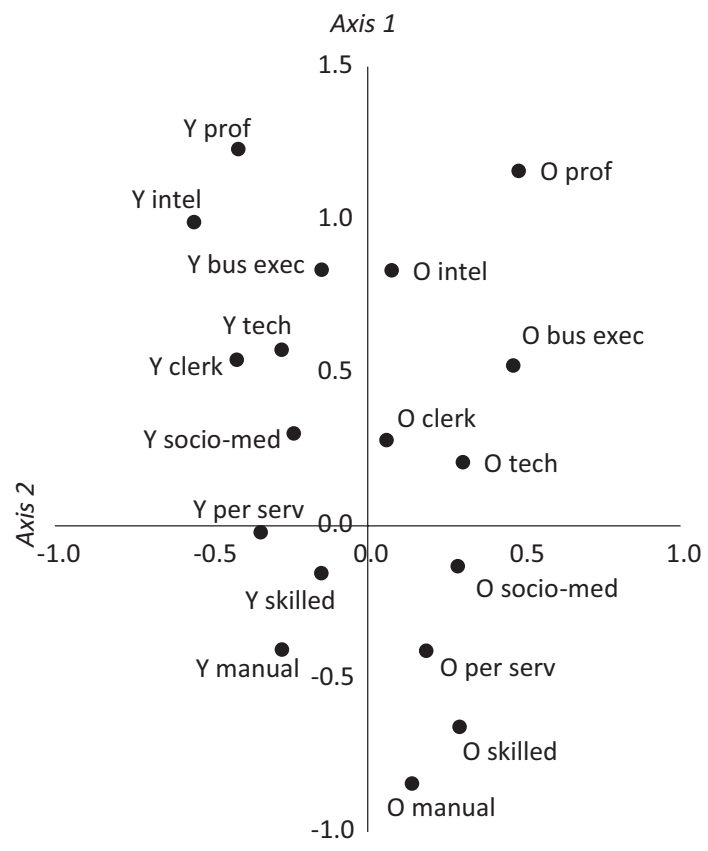

Figure 6.2 Age and the division of labour in the social space (aggregate model). Note: Based on average coordinates across $\mathrm{CatPCA}$ models. $\mathrm{Y}=$ younger; $\mathrm{O}=$ older.

or institution of study. Young skilled workers, meanwhile, are much richer in terms of cultural capital than their older counterparts as well as both younger and older personal service workers, but while they are wealthier than young personal service workers they are not as wealthy as older personal service workers. Taking age and occupation together, then, everything would appear to suggest that the greatest vertical polarisation - in terms of cultural capital/income - is typically between older manual workers and younger professionals, and the greatest lateral opposition - denoting wealth and, secondarily, inherited capital - between older business executives or professionals and younger intellectuals. ${ }^{3}$

Whether the intra-category differences between the old and the young are due to sectorial or field-specific differences is impossible to say - breaking down the categories further, as we did in Chapter 3, would produce smaller numbers and less reliable results than we already have. It could be, for example, that older skilled workers happen to be employed in specific industries or trades, like agriculture, with different returns of capital at different rates to their younger counterparts, or younger members of the 'intellectual' categories might tend disproportionately to be cultural producers or teachers. 
Equally, however, it could well be that, as Bourdieu (1993b: 100) suggested, the generational divide opposes two agents with the same job title, working side-by-side in the same office or on the same worksite: one with educational credentials and higher social origins, with all the dispositions and expectations for the future they bring, the other oriented toward the authority of experience and practice and with shorter temporal horizons but the possibilities, and interests, that come with home ownership and personal savings. Either way, the clash of generations, and the colliding evaluations, hopes and fears it implicates - the different 'generational consciousnesses', to use Karl Mannheim's term - are evidently as inseparable from the structure and struggles of class as the genesis and clash of ethos attached to zones of the social space are from the latter's age profiles. ${ }^{4}$

\section{Origins and destinations}

The countervailing rhythms of accumulation of capital over the life course and generational shifts in opportunities and necessities of capital acquisition do not, however, exhaust the propulsive forces of movement within the class structure but entwine with a third form of social space travel: deviation from the modal trajectory. There are some who would like to believe that the Bourdieusian vision of class is irredeemably flawed because it simply cannot account for social mobility - in this view, apparently, there should only ever be eternal reproduction over the generations, with children coming to occupy precisely the same positions as their parents via capital transmission and habitus inculcation, and anything else is a sure-fire refutation of the Frenchman's theory (e.g. Archer, 2007; Goldthorpe, 2007c). This reading was always dubious, but ever since Bourdieu rethought class from top to bottom in Distinction it has been crystal clear that, for him, differential rates and directions of social mobility over time and across sections of the social space are not only possible and ubiquitous but definitive of class. After all, an individual who rises or falls in social space at a different rate, or in a different direction, from the bulk of her generation is likely to develop a different habitus - a different sense of place and of the possible and desirable - and thus different tastes and politics than someone who has been more or less static in the same point in social space (see e.g. van Eijk, 1999; Friedman, 2012).

The nature and extent of atypical trajectories are not, however, entirely divorced from the changing structure of opportunity provided by a growing education system, credentialisation of professions and deindustrialisation. In Bourdieu's day, while the top and bottom of the French social space remained largely static over the generations, the intermediate class was cleft into fractions as much on the basis of trajectory as the capital composition bound up with it. The culturally rich pole, or 'new petite bourgeoisie', housed a glut of younger individuals originating from the dominant class 
who had failed to convert their inherited capital into the educational capital of qualifications increasingly necessary for admission into the professions securing membership of the dominant class, or whose qualifications were no longer worth what they once were thanks to a flooded market, and who sought to deny or disguise their social tumble with cultural experimentalism and leftist politics. The economically richer pole, on the other hand, were not only typically older but socially static and stuck in jobs declining in number and status. They represented the terminus of generations of craftworkers or shopkeepers, and consequently acquired a nostalgic and disaffected taste for things past - whether in relation to what they consumed or the state of the world. In between the two extremities was a fraction populated by large numbers of those climbing out of the shrinking working class and marked most strongly by both a cultural goodwill and a desire to keep the world as it is so as not to 'rock the boat' on which they and their families were sailing upwards. This was modulated by age, though: the older they were, the more like the static economic pole they became, and the younger they were, the more like the new petite bourgeoisie they appeared in their tastes and outlooks.

Few have followed up on Bourdieu's interest in social mobility qua trajectory. Most research on the move through education and into work inspired by him has tended to focus on the manifold means by which social reproduction is more or less secured through transmission of capital, even in the context of expanded higher education systems (e.g. Lareau, 2003; Devine, 2004; Reay et al., 2005; Lehmann, 2007), while some have explored the disorienting experience of the few who do ascend in social space (Lawler, 1999; Friedman, 2014, 2016; Lawler and Payne, 2018) or the lingering effects of class origins on capital accumulation (Laurison and Friedman, 2016; Friedman and Laurison, 2017, 2019; Freidman et al., 2017a). What Bourdieu-influenced quantitative research there has been on mobility rates, as insightful as it may be, is not only confined to a select few nations but overwhelmingly concerned with the constitution of the dominant class alone (O'Brien et al., 2016; Flemmen et al., 2017b; Friedman et al., 2017b; Toft and Flemmen, 2017; Melldahl, 2018; Friedman and Laurison, 2019). A comparative analysis of trajectories within social spaces more generally, therefore, has been elusive hitherto.

Traditional studies of social mobility across nations, meanwhile, have tended to fall into two camps. On the one hand, there are the reductive, unidimensional gradational approaches, whether mobilising occupational scales, as in most US sociology, or income, like Blanden et al. (2005), which focus on comparing (correlating/regressing) a person's position on the scale with their parents' position on the same scale when they were young. On the other hand, there are the 'nominal' approaches, including both Wright's (1997) positivist recasting of Marxism and the typical uses of the Erikson-Goldthorpe-Portocarero (EGP) scheme (Breen, 2004; Bukodi 
and Goldthorpe, 2018), which compare the respondent's class with their parent's class - the latter always being defined by one parent's position (often a father) alone. Cutting the model of the world into classes allows for different kinds of methods, not least comparison of inflow/outflow rates, log-modelling and, under certain conditions, sequence analysis. That can certainly have value if the classes are appropriately constructed, but when class is fully spatialised, as it is here, and when the model of that space is defined in part by indicators of parental positions - both father's and mother's position - the prospect arises for social mobility, or atypical trajectories more generally, to reveal its salience and form in a different manner, that is to say, geometrically. For it transpires that, according to the factor loadings and relative contributions of variables, the tertiary axis in all but one of the national models, accounting for between 12 and 18 percent of the inertia, distinguishes a principle of difference revolving around parental occupations (Table 6.3). ${ }^{5}$ However, notwithstanding the Icelandic model, which displays its own unique configuration (opposing mother's occupation and income to father's occupation and books in the family home), there are two major variants.

\section{The third dimension I: the specific effect of the gender revolution}

The first of these relates specifically to the status of having a mother who did not have paid employment when the respondent was in their adolescence. Seven cases fall into this mould, many of which were highlighted in Chapter 3 as slightly deviant from the typical pattern insofar as mother's occupation did not load significantly on the first axis, or did so in a very particular way: these are Germany, Japan, South Korea, Sweden, Switzerland, Taiwan and the US. The unifying feature is for mother's social position to run counter (even if not always very strongly) to father's social position, though the vector coordinates make clear that what this primarily comes down to is an opposition between having a mother who did not work versus mothers who worked in any position, and an association of having a mother who did not work with a professional/managerial father (Table 6.4). Everything would seem to indicate, therefore, that this is another face of advantage, distinguishing those hailing from higher regions of the social space whose mothers, no doubt facilitated by relative familial distance from necessity, opted to take time out of the labour market.

In the models for Japan, Sweden, Switzerland and the US, the pole defined by a non-employed mother and a professional-managerial father is also associated, to a degree, with considerable book ownership within the family, solidifying the interpretation that the originating households at this end of the polarity had sufficient resources for respondents to accumulate symbolic mastery, though there is no obvious relationship with the acquisition 
Table 6.4 Vector coordinates of mother's occupation on Axis 3

\begin{tabular}{lllcl}
\hline Country & Did not work & Routine & Intermediate & \\
& & & $\begin{array}{l}\text { Professional- } \\
\text { managerial }\end{array}$ \\
\hline Germany & -0.94 & 1.28 & 0.57 & - \\
Japan & -1.41 & 0.71 & 0.45 & - \\
South Korea & -0.32 & 0.62 & -0.96 & - \\
Sweden & -1.56 & 0.57 & 0.55 & 0.16 \\
Switzerland & -0.92 & 0.10 & 1.21 & - \\
Taiwan & -0.32 & 0.56 & -1.41 & - \\
US & -1.03 & 0.10 & 0.68 & 0.78 \\
\hline
\end{tabular}

Includes intermediate and professional-managerial roles in all models but those for Sweden and the US.

of institutionalised cultural capital and only a minor positive association with higher income. Contrasted with the pattern on Axis 1, then, it would appear that having a mother who took time out of the labour market when the respondent was a teen was less advantageous than having a mother in work (and the extra books in the home associated with it), even though mother's employment was relatively muted on that axis.

The models for South Korea and Taiwan - in which the effect of mother's occupation deviated most forcefully from the standard configuration in Chapter 3 - are slightly more complicated. In both cases the order of categories in the variable for mother's social position diverges from usual, with a mother not working falling between a mother in routine work and a mother in more advantageous positions in the occupational hierarchy. Vector coordinates suggest that this allows for a close association between those having a mother who did not work and those with a mother in non-routine work, as well as a father in an advantaged position, all standing opposed to those who had mothers (and fathers) in routine manual employment. In these cases, then, it would appear that having a mother who did not work is much more closely associated with higher social origins, or, put another way, it would seem as if having a mother working in routine jobs in these nations, conservative as they are on gender relations, is generated by and thus a symbol of familial proximity to necessity. However, the vector coordinates also indicate that having parents in routine work is associated, on this axis, with a high number of books in the family home (especially in South Korea), higher acquired cultural capital and even income, and is negatively correlated with wealth, although none of the loadings are above 0.4. Perhaps this indicates hidden resources, like highly educated parents working in jobs categorised as routine, or investment of what meagre capital poorer parents have in these rapidly developed and education-obsessed social orders in the schooling of children, but it nonetheless suggests the existence of a sizeable section of the sample characterised by a disjunction between inherited and 
acquired capital. Once again, however, this should be set against Axis 1, which in both models indicated the close connection between origins and destinations in most cases.

Inspection of atypical supplementary modalities on Axis 3 reveals some telling correspondences (Table 6.5). There are three cases where intellectuals are associated with having a non-working mother and several where clerical workers and social-medical workers correspond with having had a working mother, but otherwise relationships with occupation are inconstant. More consistent and obvious is the homology with age. Older people, especially those aged over 65 , are most likely to have had a mother who did not work when they were teenagers, while younger people - covering those aged between 18 and 54 - are more likely to have had mothers who did work (the Swedish case is a little more complicated). It may well be, therefore, that the opposition on Axis 3 in these models captures the specific effect of shifting gender relations over the course of the twentieth century, particularly feminisation of the workforce, especially from the 1960s onwards following developments in contraceptive methods. Without discounting the possible effects of differences in category coding, could it be that the pace of change has been pronounced enough in these specific nations - at least as far as these samples indicate - to drive an extra wedge between the old and the young? Might it have something to do with the conservative gender orders and welfare regimes long attributed to these countries - Sweden excepted that historically, but less so nowadays, direct women away from paid work and toward the familial field as their prime source of worth?

\section{The third dimension II: ascent and descent}

If the tertiary axis of the models for South Korea and Taiwan suggested the importance of movement in the social space, and the inherently dynamic nature of class, then this is even more the case for the remaining 12 spaces. Here the opposition is between, on the one hand, those from relatively advantaged social origins who are nonetheless poorly endowed with institutionalised capital and household income and, on the other hand, those who have acquired educational credentials and substantial income who hail from lower social origins. Both upwards and downwards mobility, in other words, appear to be captured in one swoop on a single dimension. Wealth is generally unimportant to this polarity, likely because its opposition to inherited capital came out, to an extent, on the second axis in all cases, but where it does almost reach a threshold it tends to be positively associated with parental position (perhaps an indicator of inherited economic capital or economic capital via social capital).

In most of these models, the hierarchies of mother's and father's occupations run in the same direction - Denmark and Estonia are exceptions, where mother's occupation runs slightly counter to father's social 
Table 6.5 Factors associated with Axis 3 I

Germany Japan South Sweden Switzerland Taiwan US Korea

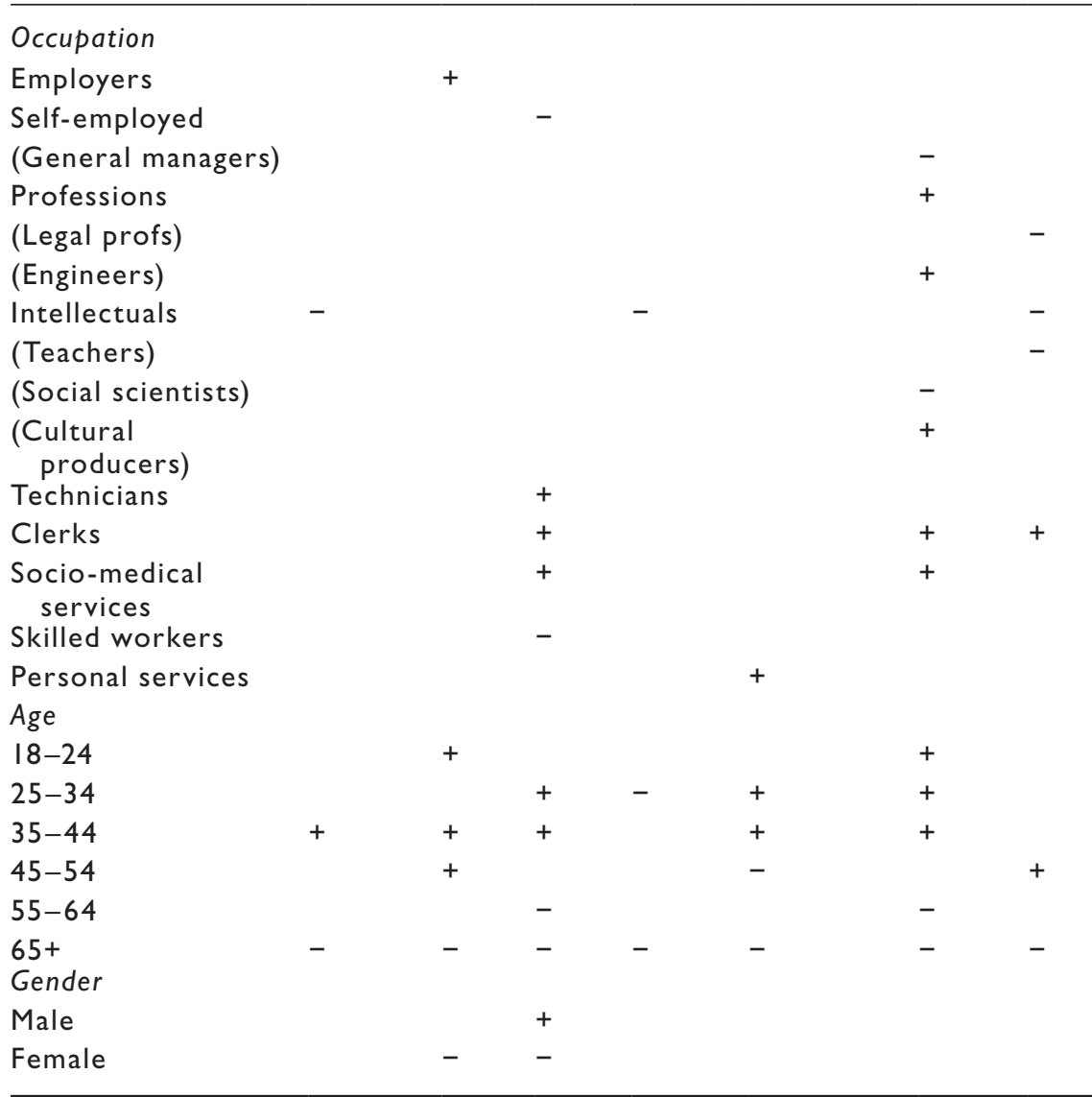

Notes: A plus (+) denotes category atypicality on the pole of Axis 3 identifying those whose mothers worked $(p<0.05)$. A minus $(-)$ denotes category atypicality on the pole of Axis 3 identifying those whose mothers did not work $(p<0.05)$.

position - but there is some variation as to whether it is the mother's or the father's position that makes the difference on the axis. In the spaces for Austria, Flanders, France and Norway it is the mother's occupation that loads above 0.4 and contributes above average to the axis inertia, but elsewhere it is the father's occupation. Vector coordinates make clear that the major oppositions across the models are between, on the one hand, mothers/ fathers in routine work or who did not work and, on the other hand, parents in professional-managerial positions, with intermediate positions sitting in 
the middle or close to (if not combined with) the professional-managerial category. The French and Flemish models offer variants insofar as having a mother who did not work occupies a middling position, sitting between having a mother in routine work and having a mother in professionalmanagerial work.

There is also some discrepancy over whether the opposition is most pronounced regarding respondent education or household income. In Austria and France it is institutionalised cultural capital that has a factor loading above 0.4 and functions as the explicative variable; in Norway and New Zealand both income and education are explicative, education more so than income in Norway and vice-versa in New Zealand; in the rest of the models household income is the key (this can be claimed for Israel, even though income loads just below 0.4 and falls just under the average contribution). One finding that emerges from this is a remarkable consistency across the four samples deriving from post-socialist social orders, where the opposition is plainly between father's occupation and household income and where education is much less prominent. It is as if a polarity exists here between those rising and falling in the social space, relative to their parents, in the period following the transition to capitalism, as old resources fail - perhaps because of a lack of, a devaluation of or a failure to convert political capital and new opportunities for economic enrichment unrelated to educational attainment proliferate. As ever, of course, the opposition between these specific groups - those failing to transmit or covert capital and the nouveau riche (or novye Russkie and their equivalents) - stands deep in the shadow of the premier dimension, wherein income was associated with inherited and acquired cultural capital, even if in only one of the post-socialist models in question, Slovakia, was income an explicative variable. Like all else that has been considered up until this point, moreover, this interpretation of the dimension, if it is to be confirmed, confuted or nuanced, must be taken in conjunction with the patterning of the generations over the space.

Inspection of supplementary modalities bearing statistically atypical locations suggests that those apparently experiencing downwards mobility are, unsurprisingly, more likely to be found in manual or skilled work, but also more likely to be self-employed or even an employer (Table 6.6). Most of the latter are small employers, of course, who may simply have relatively low household incomes despite property ownership in these cases, though the relative homogeneity of categories for both parents' and respondents' positions may hide more complex or subtle movements. On the other hand, the upwardly mobile tend to be found in intermediate or dominant positions in the division of labour of domination - they are technicians, sociomedical workers and clerks but also professionals and intellectuals (and employers in Australia). The Estonian model is a little different in that skilled workers - who are more closely associated with higher wealth here than in other national models - are also likely to be associated with lower social 
origins yet higher income. It is interesting that in the post-socialist models generally it is professional and intellectual positions that are atypical, despite the fact that the axis in these cases is more closely associated with income mobility than educational mobility, as if to signal that ascent into these positions delivers high pay levels without necessarily being associated with scholastic attainment.

Movement within the space is associated with age. The Austrian case notwithstanding (and Norway partially so), those aged 65 or over, and sometimes 55-64, are atypically associated with lower income and/or education yet higher social origins - and a degree of personal wealth, which may now be attributable in part to accumulation over the life course - while those aged between 18 and 54 are more likely to have acquired cultural capital and sizeable incomes (but less so savings and property) despite their lower social origins. Post-retirement diminution of household earnings may be part of this picture, but given the association with occupational categories too, as well as the likely divergences in pension entitlements attached to different positions in the division of labour of domination (reported household income is not restricted to earnings from paid employment), it hardly exhausts the opposition. Instead there is every reason to believe that the polarity reflects, in good part, the transformation of the relationship between the education system and occupational structure in these social orders though the twentieth century and beyond - that is to say, the expansion of the education system and the growth of professional-managerial work - with those aged 55 and over, who will have entered the labour market in the early 1970s at the latest, facing a radically different field of possibilities to those who came after. When set against the correspondence of age with the plane of Axes 1 and 2, it thus suggests the possible double disadvantage of older generations relative to younger ones: not only were they less likely to have had parents in white-collar or professional-managerial positions - not only, that is, were they less likely to have parents in or just outside the field of power - but even where they did the smaller size of the field of power, the more restricted education system and the bottom-heavy structure of the division of labour of domination meant that they were more likely to be downwardly mobile than their counterparts born in later decades, offset only modestly at best by inheritance or accumulation of wealth over the life course.

The pattern also confirms, moreover, the reading of the post-socialist spaces in which younger people have benefitted from the possibilities for accumulation of economic capital opened up by transition to a free market system, while the older population languish, though now it appears that an extra factor - one spotted early on by some observers (e.g. Aslanbeigui et al., 1994) - plays a part: men are more likely to have benefited from the capitalist revolution across Eastern Europe and women to have suffered. Before rushing to attribute this to the resurgence of traditionalist views on gender roles with the crumbling of the officially gender-blind workerist orthodoxy 


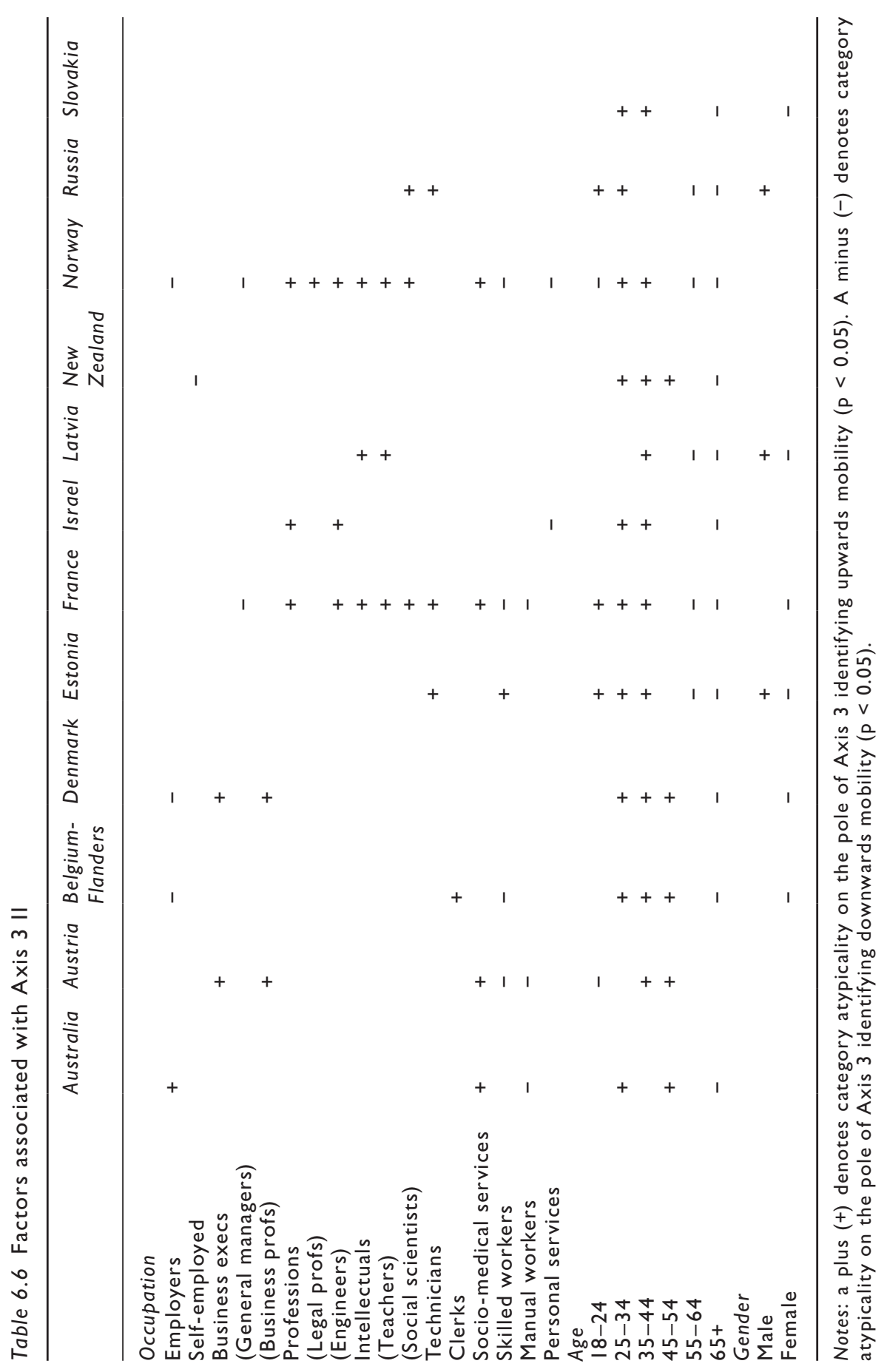


promoted within the political field under socialism, however, it should be made clear that while men and women may be atypicality located along the dimension, the differences between their mean positions are too small to be considered notable in any case.

All in all, it would appear that statistically detectable forms of movement in the space, as deviations from the dominant pattern of social reproduction, are less about what separates supposedly 'talented' individuals succeeding despite their origins or those lacking the 'merit' to reproduce parental positions from the rest and more about systemic shifts induced by structural transformation, whether that be the transition to capitalism in Eastern Europe or, in the case of long-standing capitalist social orders, the redistribution of lusiones regarding acquisition of institutionalised cultural capital or relatively highly remunerated jobs to match evolving industrial specialisations in the worldwide division of labour. Consequently, of course, the simple possession of specific forms of institutionalised cultural capital such as the university degree or of relatively well-paid professional-managerial work means something different now from what it did for previous generations. As the rate of possession or incumbency increases, the value of the credential or post per se decreases - such is the law of inflation. Space opens up for internal divisions to surface; divisions between disciplines and institutions attended, for example, but also, and perhaps most evidently, between those from advantaged backgrounds who saw university and professionalmanagerial positions as a more or less natural destiny or at least probable future - those who populate the top of Axis 1 - and the first-generation graduates or professionals/managers lacking the additional resources or expectations necessary to push ahead of the pack - those who populate one pole of Axis 3. Whatever the effect of internal differentiation among graduates and professionals, however, their proliferation ultimately serves to render those without higher forms of education or working in declining forms of employment not only evermore marginal compared to the bulk of the populace a shrinking minority now standing out because they lack something once considered rare - but evermore outdated - a relic of the past characterised, at the collective and the individual level, by lack of a future. The effects of all this on practice and perception, however, remain to be seen.

\section{Conclusion}

Trajectory was the third dimension of the social space in Bourdieu's heuristic model presented in Distinction. It was represented not geometrically but by bar charts indicating social origins, in the form of father's class position, and arrows representing rising or falling numbers in specific occupational categories. When the spatialisation of class inhering within Bourdieu's framework is taken seriously and modelled accordingly, however, the empirically derived construction comes out differently - at least with these indicators 
and categories of capital. In one sense trajectory is inseparable from the general distribution of economic and cultural capital insofar as accumulating economic capital takes time and the availability of educational credentials and the proportion of professional-managerial parents have transformed over the decades. Thus, we have seen that, typically, the cultural pole of the social space in mature capitalist social orders is characterised by youth - these are people who are still in the early stages of their life trajectory, in the process of accumulating their own capital, but who are more likely to have parents in the advantaged positions given the growth of professional-managerial work in post-industrial social orders. The economic pole, especially toward the bottom of the volume axis, is populated by older people - those without qualifications because they came through the system when qualifications were less necessary and widespread, and whose parents were less likely to be in professional-managerial employment because this was scarcer in the past, but who have spent their long lives accumulating property, savings and wage rises. The seniority thesis only holds up to a point, therefore: steady acquisition of one capital over the life course is cross-cut by lack of another capital gaining in importance after their transition into the world of work was done. In post-socialist societies it seems to hold even less, suggesting economic transformation has favoured the young.

The effect of structural transformation on trajectories in the social space came out on the third axis of the statistical models too. Here, in many cases, those who had seemingly risen or fallen from their starting points in the space, as best as that can be proxied, were polarised, but once again the major corresponding feature was age, indicating the effects of systemic shifts in the distribution of opportunities with industrial mutations in the context of the worldwide space of states and suggesting the possibility of, among other things, credential inflation. Such movements and transformations did not, however, emerge in all the spaces. In some cases, they were muscled out by the possible effects of transforming gender relations on the social space, specifically the opposition between those whose mothers did work and those whose mothers did not, which was once again homologous with age. Whether because most of these samples are drawn from nations with relatively conservative gender relations, or because the redistribution of educational or occupational possibilities over time has been less pronounced in these cases than elsewhere, or a mixture of both (and without ruling out the effect of variable categorisation), the failure of putative social mobility to register strongly enough to be included in the spaces is a telling feature of the models in itself.

Ultimately, the social space encapsulates, in one structure, successive states of the misrecognition order, indicating what was once sufficient is now degraded and what was once rare is becoming more common. It points to the major generational divide and, insofar as it contains both old-timers 
and newcomers, contains the past and the future. As time goes on, many of those at the cultural pole may steadily migrate rightwards in the social space, replacing those at the economic pole shuffling off this mortal coil and being replaced, in their turn, by newcomers brandishing some new form of distinction - more and more specific qualifications, or parents in more and more specific occupations. These are only possibilities written in the state of the current field, not inevitable destinies, but so long as human beings strive for recognition they will not only endeavour to accrue valued resources but find themselves differentiated in novel ways when old principles of opposition and antagonism dissolve in a sea of commonality.

\section{Notes}

1 Part of the variability may be due to the fact that full-time students are excluded from the models and that, therefore, the category is comprised of recent graduates and those who opted not to pursue tertiary education after schooling.

2 Namely an $r$ value greater than 0.58 to account for the sample size as well as a $\mathrm{p}$ value less than 0.05 .

3 Although the superabundance of coordinates prevents their presentation here, there are differences across models, of course, with the location of some categories being more variable across national spaces than others when broken down by age. The mean standard deviation of categories across models on Axis 1 is 0.24 , and on Axis 2 it is 0.22 . The most variable categories on Axis 1 are older clerks (st. dv. $=0.34$ ) and younger clerks $(0.30)$, and on Axis 2 they are the older professionals (0.36) and younger intellectuals $(0.31)$. The least variable categories on Axis 1 are the older manual workers (0.15), personal service workers (0.17) and skilled workers (0.18), and on Axis 2 they are the older personal service workers (0.13), technicians $(0.16)$ and skilled and manual workers (both 0.17). Notwithstanding the professionals, therefore, older workers tend to be less variable on both axes than young workers from model to model. Among younger workers, the business executives $(0.20)$ and the socio-medical workers, skilled workers and manual workers (all 0.22 ) are least variable on Axis 1 , and the socio-medical workers (0.18) and personal service workers $(0.20)$ are least variable on Axis 2.

4 For this reason, a supposed 'generational habitus' - a notion posited by some -is inseparable from class habitus (cf. Roberts and France, forthcoming).

5 Italy and the Czech Republic are excluded from analysis because 95 percent confidence intervals on the factor loadings on Axis 3 indicated instability, even though retaining the axis in the overall models improved the stability and interpretability of the first two axes. Poland is excluded because the equivalent oppositions emerged on a fourth axis, were again unstable and did not meet the criteria for axis retention set out in Chapter 3. 


\section{Political position-takings}

The point of mapping out class structures and their transformations is, ultimately, to better understand their effects. We may well have constructed and confirmed a model of the 'anatomy of capitalist societies', to borrow the title from one of John Urry's (1981) early works, or at least one of its primary organs, but without exploring its physiology - which is not to invoke functionalist reason, only the question of 'how it works' relative to 'what it looks like' - we are left guessing as to whether the differences and directions unveiled really matter. After all, the social space was, for Bourdieu (1984: 171), merely the first step in his causal model of practice: the supplier of variegated conditions of existence which, via the intermediary of habitus, underpin variegated tastes, interests and 'classifiable works' or, in sum, position-takings, which in turn not only signal our place relative to others but, in their own way (that is, insofar as they might win or lose capital), feed back into our class position.

One set of such position-takings are those described as 'political' or, more broadly, ethico-political. True enough, Bourdieu is most famed for his dissection of lifestyles - how differences in tastes for food, clothes, sports, music, film and art mark our place relative to others and act as vehicles of symbolic domination - but, as we saw in the Introduction, he also dedicated a long portion of Distinction to specifically ethico-political practice. There, without making it fully explicit, he joined a venerable debate over the relationship between class positions and voting patterns, party allegiances and moral stances. From Lipset's (1960) seminal contribution onwards, the established position from the mid-twentieth century was that a major - if not the major - cleavage distributing people on either side of the left/right fault line across capitalist social orders was class, understood in purely economic terms (see also Lipset and Rokkan, 1967). Those who are poor, or do not own the means of production, will be leftist in values and votes because state-led redistribution is the most feasible means of substantially improving their holdings of economic capital. Those rich in economic resources, or owners of the means of production, will lean right because low taxes and market deregulation are the optimal avenues to maintaining or increasing 
their financial standing. The Nuffield clan readily adapted this position, transposed onto a working class/service class opposition, as their guiding hypothesis (Goldthorpe, 1982, 1995).

Education level, falsely cleft from class, was always held to be a complicating factor. Those placed higher on the scale of educational attainment - or possessing greater degrees of symbolic mastery, we might say - tend to be liberal in their views on such matters as sexuality, gender roles and crime and punishment, while those lower down the scholastic hierarchy tend to be more conservative (Lipset, 1960; Houtman, 2003; Surridge, 2016; van der Werfhorst, 2020). If there is a specifically liberal party on the scene, therefore, this will split the vote at the top of the class structure, or if a leftist party adopts liberal positions and a rightist one sounds socially conservative notes then the alignment between class and party will begin to strain or even break. This is, indeed, what many claimed was happening through the latter stages of the twentieth century. ${ }^{1}$ As debates over material differences became less rancorous and prominent with rising living standards across the West, and as novel 'post-materialist' issues split by the education cleavage emerged - nuclear weapons, global warming, cosmopolitanism/nationalism and such like - the old relationship between class and party, and class and political outlook, was said to be waning. If not with scales and regression techniques, then this trend was demonstrated by tracing the Alford index - a simple measure based on the left/right split across the manual/non-manual work boundary - or noting the internal fracturing of the classes in the EGP scheme.

Whatever the substantive details of Bourdieu's own analysis - his case study was 1970s France - the logic of his conceptual position puts things in a different light. Education level taps into cultural capital, so it might be thought that degree of liberalism, environmentalism or cosmopolitanism tracks from a low point in the southeast of the social space to a high point in the northwest, while a right-wing sentiment on material issues, being linked to economic capital more than anything else, runs from a nadir in the southwest to an acme in the northeast. In fact this is exactly what has been found in the few studies keen to apply Bourdieu's logic and methods to their own nations - Harrits et al.'s (2010) study of Denmark, several investigations in Norway (Rosenlund, 2009; Flemmen, 2014; Flemmen and Haakestad, 2018), de Keere's (2018) breakdown of Flemish politics and my own analysis of Britain (Atkinson, 2017). The homology, approximated in these cases with multiple correspondence analysis, thus takes on a specific form: if the space of political position-takings is defined by a vertical left/right polarity on materialist issues - signalling their continuing divisiveness - and a horizontal axis opposing liberal-cosmopolitan attitudes and authoritarian-traditionalist dispositions regarding 'moral' issues, then it maps onto the social space at a roughly 45-degree angle: economic liberalism characterises the economically rich northeast, while socialist sentiment 
corresponds with cultural fractions of the dominated zone, and social liberalism characterises the culturally rich northwest of the social space while authoritarian-nationalism is more likely to be found in the economic region of the dominated sector. Jarness et al. (2019) have recently gone even further, suggesting that, in Norway at least, the usual relationship is rotated clockwise to the extent that the left/right divide is more closely related to capital composition than capital volume. The general model is complicated, however, by the importance of indifference, or disenfranchisement, in defining the outlook of the dominated class, which Bourdieu (1984) posited varies with the degree to which a party exists to offer or impose an official 'line' in tune with the ethos of the dominated class. Moreover, given that education level alone does not seem to be an efficient indicator of horizontal differentiation in most of the social spaces mapped herein, compared to gauges of inherited cultural capital, it could be that liberalism will appear more diffuse within the dominant class as a whole.

How all this plays out in party-political terms will vary in accordance with the structure of the political field - the system of positions between agents struggling to impose political visions of the world and how to govern it - in each nation (Bourdieu, 1991). As a basic indicator, Bourdieu (1998a: 5), freed from the constraints of the Alford index and the EGP scheme, suggested that the tendency to vote (and by extension, lean) left or right in France could be charted not as a high/low or economic/cultural capital binary, but as a curve in the social space. It is unclear whether, though probably not likely that, Bourdieu was including orientations on moral or post-materialist issues in this model, but in a two-party (or two-bloc) system where the leftist group (e.g. the Socialist Party) is often more liberal and cosmopolitan and the rightist one (e.g. the Republican Party) more conservative and nationalistic, this would make sense. Most political fields, however, are more complex than that nowadays, not least because of the steady rise of populist far-right politicians and parties since the 1980s offering vague, ambiguous or even broadly egalitarian rhetoric on material issues but spouting staunchly conservative-authoritarian views on moral matters and a xenophobic nationalism - a 'winning formula' for attracting the dominated, according to some, especially where social democratic parties have foregrounded social liberalism and watered down or de-emphasised their redistributive agenda in a bid to win broad-based support in deindustrialised economies (Kitschelt, 1994, 1995). ${ }^{2}$ The existence of an expressly liberal or centrist party with large electoral clout complicates things further, possibly creating pools of centrism in certain zones of a social space, and where national politics is dominated by specific issues - such as economic transformation (e.g. Eastern Europe) or geopolitics (e.g. Israel, Taiwan, South Korea) - or where socialism has long been pushed to the political margins (e.g. Japan), the homology between positions and parties may take entirely different forms or dissolve altogether. 
Dependence on the 2009 ISSP data limits what can be done to explore these issues. We cannot meaningfully construct 23 models of national spaces of political position-takings using geometric data analysis and project indicators of social position into them because a full range of appropriate variables necessary for that task is not available. There simply are no questions in the survey relating to views on moral or post-material topics. What we can do, however, is document the cross-national tendencies and variability in the homology between social spaces and political parties, or at least party 'families', via respondents' stated affiliations. Then we can begin to unpick some of the dispositions feeding into that homology by exploiting a set of questions in the 2009 survey targeting attitudes toward economic redistribution and social welfare - the classic stakes of 'class politics', that is. Examining the relation between the two sets of findings may then facilitate reflection on the possible role of liberalism and conservatism in the social rather than economic register, or indeed other factors, in shaping party preferences.

\section{Class, habitus, party}

Some national political fields are dominated, almost exclusively, by two rival parties with opposed ideologies, even if the degree to which they converge on certain issues - what becomes orthodox if not doxic, that is - can vary over time. Others, however, are populated by a dizzying multitude of warring and aligning smaller parties, some more commanding in the polling booth than others. Were we to focus on the full set of correspondences within each nation, therefore, we would certainly risk losing sight of the wood for the plethora of trees. This is not to say such a focus is always invalid - for nation-centred dissections, or targeted nation-to-nation contrast, they are indispensable - but, for the sake of parsimony in wide-scale comparative analysis of the type we have elected to pursue here, the complexity of individual cases must be reduced down to practical cross-national benchmarks. At the same time, however, we must resist the reverse temptation to over-homogenise by reducing party profiles to a binary left/right split, obscuring evident differences in policy profile and rhetoric, and likely correspondences with sections of the social space, between, for example, the centre-right and far-right. Fortunately the ISSP dataset contains a derived variable for party affiliation that steers a satisfactory middle course: parties are categorised as either far-left (communist and socialist parties), moderate or centre-left (social democratic parties), centrist (typically comprising socially liberal parties), moderate or centre-right (economically liberal and socially conservative parties) and far-right (nationalist and authoritarian parties). ${ }^{3}$ A lack of mainstream affiliation is also included in order to capture those disenchanted with conventional politics or caught in between camps, but there are two modalities here. On the one hand, there are those 
who opt for 'other', marginal parties, which include 'no clear specification' (e.g. citing a party that does not exist), and on the other hand, there are those who are put under the label of 'no party' because they either explicitly stated a lack of affiliation, indicated they did not know which party they would affiliate with or refused to answer the question altogether.

Table 7.1 displays the distribution of political alignments across national samples as an indicator of the prevalence of specific orientations. For context, the political leaning of the governing party, or leading party in a governing coalition, at the time of the survey is indicated in each case, as is the year of the last general election. ${ }^{4}$ Right-wing governments prevailed, with only six nations - including the US under Barack Obama - then having nominally left-wing parties or coalitions in charge, while Russia was experiencing the zenith of Vladimir Putin's United Russia party, here categorised (almost exclusively in the sample) as 'other' because of its lack of coherent ideology and focus instead on the personality and preferences of Putin himself. In some cases there are discrepancies between the balance of party alignments and the orientation of the ruling party or bloc, and this may be down to several factors in combination. These include differing propensities across the spectrum of political outlooks to actually vote, party competition splitting the left or right vote, peculiarities of the electoral system (see Iversen and Soskice, 2006), ${ }^{5}$ shifting individual affiliations between elections and the impact of floating voters, as well as whatever specific divergences between samples and national electorates there may be.

The distribution of political alignments discloses the extent to which a national electorate believes there is a line emanating from one party or another that consistently fits, at least to some degree, their ethos and, with that, reveals something of the state of the political field, i.e. the variable success of agents and parties of different persuasion in winning support as well as how much - notwithstanding tactics to woo people from other parties - there is yet 'to play for'. In fact, identification with no party is the most common response in most samples, as well as on average, often outweighing even the most popular party-ideological attachment in a sample. It seems to be particularly prevalent across Eastern Europe and in Taiwan, which can perhaps be attributed to a lack of historical attachment to parties, if not cynicism towards politics in general, given the relatively recent transition from single-party politics to multiparty democracy in these cases. In most of the Nordic countries, Flanders and, to a lesser extent, Germany and New Zealand, non-alignment appears to be much less common. It is almost non-existent in the US sample, but this is attributable to the 'centre' category comprising people who describe themselves as 'Independent', that is, unaffiliated to any particular party. What in many contexts looks like a lack of party-political identity is, in the US context, constructed as a strong and distinct political identity, but the outcome is the same: absence of affiliation with a party is the majority position. ${ }^{6}$ 
Table 7.I The distribution of party affiliations (row \%)

Party affiliation

\begin{tabular}{|c|c|c|c|c|c|c|c|c|c|}
\hline Country & $\begin{array}{l}\text { Last } \\
\text { national } \\
\text { election }\end{array}$ & $\begin{array}{l}\text { Far } \\
\text { left }\end{array}$ & Left & $\begin{array}{l}\text { Liberal } \\
\text { centre }\end{array}$ & Right & $\begin{array}{l}\text { Far } \\
\text { right }\end{array}$ & Other & None & Total \\
\hline Australia & 2007 & 0.0 & 40.2 & 1.5 & 35.6 & 0.9 & 0.0 & 21.8 & 100.0 \\
\hline Austria & 2008 & 2.0 & 30.4 & 0.0 & 17.5 & 12.6 & 0.9 & 36.6 & 100.0 \\
\hline Belgium-Flanders & 2007 & 0.3 & 24.8 & 14.8 & 44.8 & 9.5 & 0.9 & 4.9 & 100.0 \\
\hline Czech & 2006 & 10.3 & 22.6 & 7.5 & 15.5 & 0.8 & 4.0 & 39.4 & 100.1 \\
\hline Denmark & 2007 & 15.9 & 21.6 & 6.9 & 31.5 & 9.2 & 0.0 & 14.9 & 100.0 \\
\hline Estonia & 2007 & 0.0 & 2.4 & 1.4 & 2.0 & 0.0 & 0.0 & 94.2 & 100.0 \\
\hline France & 2007 & 6.5 & 28.6 & 0.0 & 25.3 & 1.7 & 0.5 & 37.4 & 100.0 \\
\hline Germany & 2009 & 7.4 & 42.1 & 5.0 & 21.9 & 0.7 & 2.3 & 20.5 & 99.9 \\
\hline Iceland & 2009 & 13.8 & 17.3 & 8.7 & 20.1 & 0.0 & 6.8 & 33.4 & 100.1 \\
\hline Israel & 2009 & 2.4 & 18.4 & 7.6 & 29.0 & 4.8 & 6.0 & 31.8 & 100.0 \\
\hline Italy & 2008 & 0.0 & 25.4 & 7.5 & 10.2 & 5.8 & 5.1 & 46.0 & 100.0 \\
\hline Japan & 2009 & 2.2 & I.I & 29.4 & 24.5 & 0.0 & 0.3 & 42.4 & 99.9 \\
\hline Latvia & 2006 & 2.1 & 13.2 & 12.2 & 4.4 & 0.8 & 0.7 & 66.5 & 99.9 \\
\hline New Zealand & 2008 & 8.2 & 24.6 & 0.4 & 41.4 & 2.3 & 1.2 & 21.9 & 100.0 \\
\hline Norway & 2009 & 1.8 & 32.0 & 12.9 & 36.7 & 0.0 & 0.8 & 15.8 & 100.0 \\
\hline Poland & 2007 & 5.7 & 3.4 & 25.3 & 0.7 & 13.5 & 0.6 & 50.9 & 100.1 \\
\hline Russia & 2007 & 8.0 & 3.6 & 0.6 & 0.1 & 4.6 & 38.1 & 45.0 & 100.0 \\
\hline Slovakia & 2006 & 1.6 & 25.1 & 12.1 & 5.2 & 0.0 & 11.0 & 44.9 & 99.9 \\
\hline South Korea & 2008 & 0.0 & 38.5 & 2.0 & 34.4 & 0.0 & 1.1 & 24.1 & 100.1 \\
\hline Sweden & 2006 & 5.7 & 38.2 & 14.4 & 24.8 & 3.3 & 7.0 & 6.6 & 100.0 \\
\hline Switzerland & 2007 & 1.0 & 24.0 & 5.3 & 26.9 & 0.9 & 1.2 & 40.7 & 100.0 \\
\hline Taiwan & 2008 & 0.0 & 0.2 & 8.0 & 21.2 & 0.0 & 0.1 & 70.6 & 100.1 \\
\hline United States & 2008 & 0.0 & 35.8 & 37.0 & 24.7 & 0.0 & 2.3 & 0.2 & 100.0 \\
\hline Average & & 4.1 & 22.3 & 9.6 & 21.7 & 3.1 & 4.0 & 35.2 & 100.0 \\
\hline
\end{tabular}

Notes: The ideological family of the governing party or coalition at the time of the survey is highlighted. Totals do not always equal 100 due to rounding.

The patterning of party orientations also exposes the form and varied strength of the orthodoxies and heterodoxies of the political field. Thus, among those who do state an unambiguous party affiliation, the core opposition is typically between the social democratic centre-left and the economically liberal centre-right. In some countries, like Australia, New Zealand or the US, this reflects a de facto two-party system, while in many other territories, especially across Europe, it is the product of gatherings of smaller parties with slightly different agendas and interests in the political field around similar orientations. There are, however, some exceptions to the general pattern. These include Taiwan, where the opposition, notwithstanding the majority denying any affiliation, is between the centre-right (led by the Kuomintang) and the centrists (led by the Democratic Progressive Party); Poland, where the opposition is one of centrism (including Donald Tusk's ruling Civic Platform party, which some might describe as 
centre-right) versus the far-right (i.e. the Law and Justice Party); and Japan, where the opposition is between the centre (the Democratic Party) and a coalition of centre-right parties.

Those displaying the core polarity vary among themselves, however, in the degree to which other positions challenge the orthodoxy. Centrist liberal parties, for example, appear to have greater weight in Flanders, Norway, Sweden and Latvia than elsewhere, though in actual fact many of the parties put under this category could, in these instances, be described as centre-right on many metrics. This is the case for Open VLD in Flanders, which exhausts the centrist leaning, ${ }^{7}$ and the three parties supposedly making up the centre-ground in Sweden: the Centre Party (despite its name), the Liberal Party and the Christian Democrat Party. Parties with the same three titles constitute the centre-ground category in Norway too, though only the Christian Democratic Party arguably leans more to the right than the categorisation might suggest. In Latvia the category is made up of a number of smaller parties, most of which could be characterised as centre-right (Latvia First Party, New Era, Civic Union) if not simply rightwing (Alliance for Fatherland and Freedom). This raises questions about the precision of the categorisation of some parties in the ISSP dataset, possibly based on divergent interpretations of the key labels (liberal, conservative, etc.) in different national contexts (Jowell, 1998), but there may also be a discrepancy between within-nation and between-nation yardsticks for determining relative positions. Yet another layer of caution must be applied to some of the results that follow, therefore.

Far-left parties - socialists and communists of various description - attract notable support (i.e. 5 percent or more of the samples) in nine countries. The far-right, meanwhile, attracts considerable support in Poland, as already mentioned, but also in Austria (The Freedom Party), Flanders (Vlaams Belang) and Denmark (The Danish People's Party) and, to a lesser extent, Israel (Mafda1/Jewish Home), Italy (Lega Nord) and Russia (The Liberal Democratic Party). In other nations people are less likely to explicitly affiliate with a far-right party, if they do so at all, though that does not mean that nationalist or authoritarian parties lack significant presence in political and media discourse or substantial vote shares at elections. Vilification of far-right parties and their leaders, as well as instability in party constitution and labelling, may lead to underreporting of allegiance or sympathy (a manifestation of symbolic violence), for example, but it could also be that media attention gives a distorted view of the prominence of nationalist parties in the political field, where numbers of members and voters are a stake in the struggle. Le Front National in France, for instance, has been a constant talking-point in national elections for decades but attracts little stated support within the French sample, and indeed 2007-11 was a low point in the party's electoral and financial standing.

The question remains, however, of the homology between political parties and social spaces, and thus who, i.e. what kinds of people, are 'to play for' 
in the political field, what kinds of people correspond with the political orthodoxies and heterodoxies, whether the left-right division cleaves across the capital volume and capital composition axes and the nature and extent of cross-national convergence or divergence. Table 7.2, displaying the coordinates in the plane of Axes 1 and 2 of political affiliations as supplementary modalities within each model, offers an approximation of the homologies. What at first looks like a mixed picture does, on close inspection, reveal a number of regularities. First, it transpires that the opposition between the centre-right and the centre-left on the premier axis - which, to recall, polarises those high and low in cultural capital (and secondarily income) in most instances - is generally relatively modest. A centre-left affiliation is typically fairly close to the origin, with a statistically significant positive or negative coordinate registering in fewer than half of the samples. It appears relatively high on the axis in Italy, Switzerland and Germany, and lower in Sweden, Poland and New Zealand. Far-left parties, where they have substantial support, are even more variable on the first dimension, possibly on account of the varying appeal (e.g. liberal socialism or workerism) of the component parties, their central average coordinate being explained by their high positive and negative coordinates from model to model - Norway, Poland and Denmark versus the Czech Republic, Germany and Russia - balancing one another out. A right-wing affiliation, on the other hand, is much more likely to appear on the positive side of the axis, to have a higher overall coordinate and to be significantly associated with the high capital pole, the correspondence being most pronounced in the Czech model and, to a lesser degree, the French and Swedish spaces. For the most part, however, the coordinate is still less than 0.2, and in only three cases - the Czech Republic, Sweden and Taiwan (where a left-wing affiliation is extremely rare) - does the standardised deviation between the centre-left and centre-right parties on the first axis register as notable (and in only two, the Czech Republic and Sweden, is the deviation between the far-left and centre-right notable or substantial).

If the left/right opposition, constituting the political orthodoxy in most cases, and even the far-left/right opposition, to extend towards a more heterodox political stance, bear only a weak and variable correspondence with the axis polarising those high and low in cultural capital and income, it is because another opposition takes centre stage here instead: that between centrist-liberal parties, typically associated with higher cultural capital (and income), and alignment with no party or, secondarily, alignment with the farright, associated with lower capital. Everything would appear to suggest, therefore, that we have some confirmation of the postulated correspondences of liberalism with high cultural capital and of the authoritarianism and nationalism associated with the far-right, or disengagement and a sense of no party articulating one's ethos, with low cultural capital. Thus, in only three cases are centrist alignments atypically negative on Axis 1, and in one of these - the US - we know that this centrism may in fact be a cipher for lack of alignment. In the remaining spaces centrist liberalism is positively 


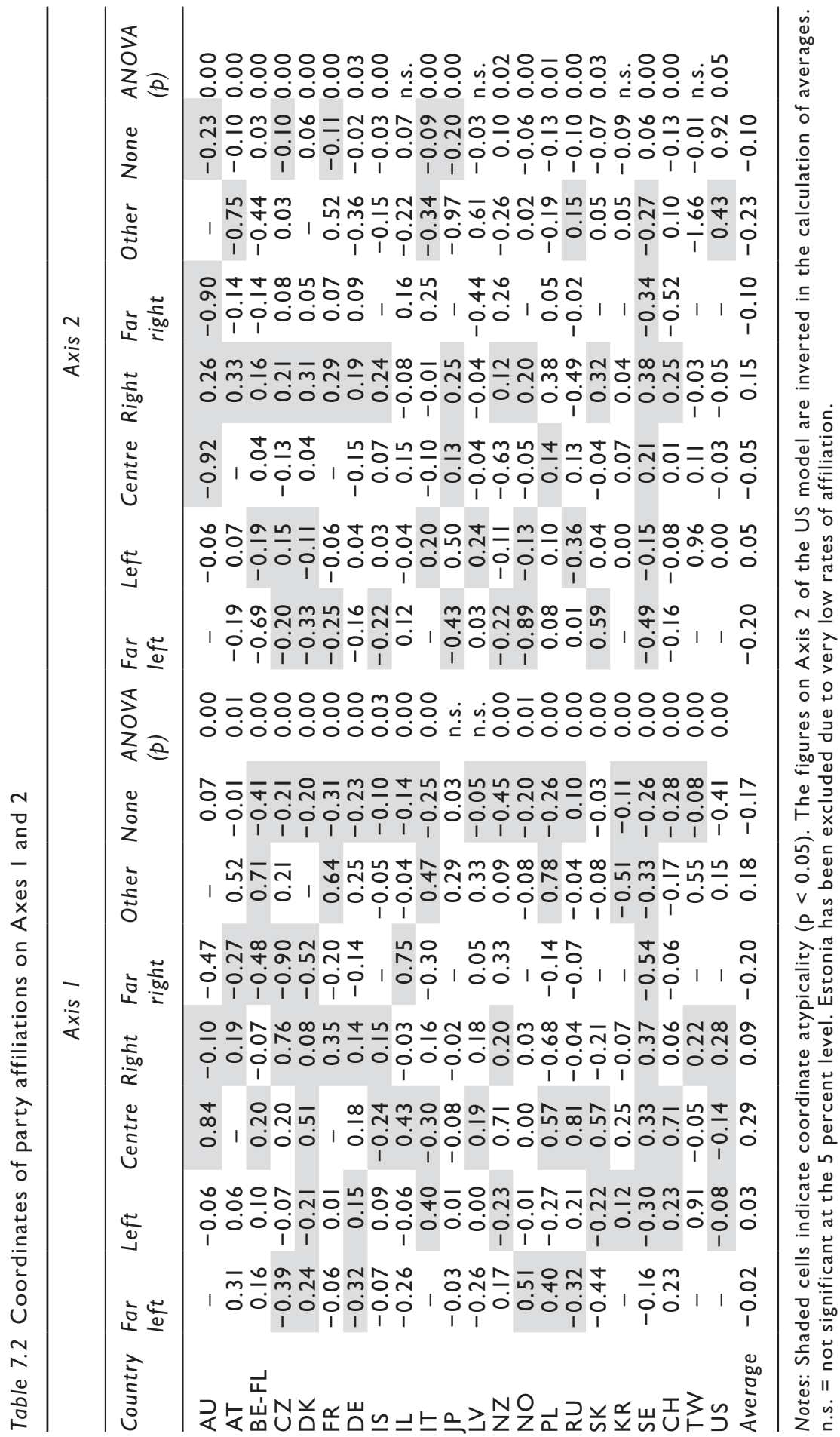


related to higher cultural capital, and relatively strongly so in most instances. Lack of alignment, on the other hand, is negatively associated with the primary axis, and significantly so, in the vast majority of cases. ${ }^{8}$ The far-right, though a modest presence in most instances, has a negative coordinate in all but a few spaces, the latter including the special case of Israel where religious nationalism plays a specific role in the political field.

The second axis, meanwhile - that is, the axis opposing those high and low in economic capital and, secondarily and inversely, inherited cultural capital - is characterised by the reverse set of oppositions. Thus, the three alignments characterising the premier dimension of difference - centrism, lack of alignment and far-right sympathies - are, on aggregate, fairly centrally located on the second dimension. Notwithstanding the Australian and New Zealand cases, which may be products of low numbers, liberal or centrist parties are only slightly more likely to fall on the positive side of the axis and rarely do so in atypical fashion. Far-right sympathies, meanwhile, are characteristically located just on the positive side of the axis or slightly further toward the negative pole, though only atypically so compared to the samples as wholes in two cases: Australia and Sweden. Lack of party-political affiliation is a little more likely to fall on the negative side, associated with lower economic capital, more so in some cases (e.g. Australia, Japan, Poland and Switzerland) than others (Taiwan, Iceland, Norway), and in this instance its atypicality on the axis is commonly significant. Still, when looking at the cross-national pattern, its location on the axis is less consistent or prominent than those of the party-political alignments that were modestly distributed on Axis 1, that is to say, those constituting the (far) left/right polarity.

The most constant feature of the second dimension, which is not to say there are no noteworthy exceptions, is the correspondence between higher economic capital and right-wing affiliations - alignments with parties, that is, which tend to cater to the interests and ethos of the economically rich through tax cuts, privatisation of public services and such like but which are also frequently characterised by a form of social conservatism likely to appeal to the older generations atypically associated with the richer pole of this axis. ${ }^{9}$ Its structural opposite, however, tends not to be the centre-left. On aggregate, centre-left proclivities are not all that far removed from right-wing inclinations, though this hides some variation, occasionally attributable to low numbers (e.g. Japan and Taiwan), from model to model. They seem almost equally likely to fall on the negative or positive side of the axis, and to do so atypically, but the coordinate is frequently lower than $+/-0.1$ and the standardised deviation from right-wing affiliation becomes notable in only two cases: Denmark (with a deviation of 0.43) and Sweden (0.53). Instead, two minoritarian alignments tend to correspond more sharply with lower economic capital and function as the opposites of right-wing affiliation. The first of these is with the far-left. In nearly all models where it appears - the 
exceptions are Israel, with its very specific political field orienting around relations with Palestine, and most of the Eastern European countries, where far-left parties are associated with the state-socialist past - an affiliation with far-left parties falls furthest or far toward the negative, cultural pole of the axis, significantly so in eight cases. ${ }^{10}$ The second - with all caveats concerning the constitution of the category and its rarity in the samples - is association with 'other' parties. There are, indeed, some cases, like France and the US, where the few people in this category tend to fall on the positive side of the axis. The most prominent example, though, is Russia, where the 'other' category is substantial, represents United Russia and might be said to be assuming the structurally equivalent place of right-wing parties on the axis. More commonly, however, the category tends to be pulled toward the negative pole of the second axis, and often substantially so, though it only becomes significant in a few cases.

If there is an aggregate homology between the social space and the space of party-political leanings, and thus political position-takings, it can be summed up as a correspondence of high/low cultural capital with liberalism/unaffiliated-authoritarianism cross-cut by a correspondence of high/ low economic capital with right-wing/far-left-wing (and 'other') leanings. By no means, however, is it a structural invariant. It is merely a regularity, with the precise oppositions varying from one nation to another and some samples being closer to the combined tendency than others. The spaces for Taiwan and South Korea, for one thing, display variants of the typical pattern on their first axes but no significant differences on their second axes, while in the Japanese case there are no significant differences on the first axis and the second axis contains some deviations (notably the rare left-wing party affiliation). In the Israeli space, too, the second axis yields no significant differences, and the first axis is characterised by an opposition between the nationalist far-right and the far-left or unaffiliated. Eastern Europe, moreover, has its peculiarities, notably the weak homology in the Latvian space, the unusual placement of the far-left parties in several models thanks to the state-socialist past and the unique configuration in the Russian case, not to mention the rates of non-affiliation in Estonia. The Czech model, on the other hand, appears closest to the overall tendency approximated in most long-standing capitalist nations - a finding that accords with previous research on the class-party relationship across European democracies old and new (Gijsberts and Nieuwbeerta, 2000), though with the added nuance that its similarity with the West is multidimensional.

For the above reasons the figures for East Asia, Eastern Europe (excepting the Czech Republic) and Israel are removed from the combined model of the homology between class and party, including the rotation of coordinates to approximate the axes for capital volume and composition, in Figure 7.1.11 There are still clear divergences within specific national models, of course, such as the placement of a leftwards-lean in Italy, and only a detailed analysis of the structure of and strategies within the implicated political fields 
would be able to unveil their sociogenetic principles - if indeed they were confirmed in research with larger samples or different methods - in full. The model provides, nevertheless, an approximation of the core correspondences characterising long-standing Western capitalist democracies from which specific cases vary.

Perhaps the most telling result is that, while sympathy for right-wing parties is associated with higher economic capital (and thus the economic field), its opposition to the social democratic left, the traditional antagonist of conservative parties and typically rooted in labour movements, is muted on both dimensions. Possibly - we would need historical data to confirm it - this is an effect of convergence over time in the policy, rhetoric and social composition of mainstream parties and an abandonment of the working class as an electoral base within social democratic parties in a bid to claim the "middle ground', as famously pursued in Britain under New Labour but also in analogous ways in the US, Australia, New Zealand and much of Western Europe in the 1990s and early 2000s (Kitschelt, 1994; Kriesi et al., 2008). The lack of affiliation amongst the dominated, or the turn to the far-right where parties so-designated are prominent enough, could thus be effects of the loosening fit between class ethos and the explicit line provided by (liberal, more centrist) social democratic parties - a foreshadowing of the nationalist populist 'backlash' that was to erupt a few years later (Norris and Inglehart, 2016; Eatwell and Goodwin, 2018). Of course, the disconnect between the working class and social democratic parties on 'moral' matters was already spotted by Bourdieu decades ago in Distinction, and broached even longer ago by Lipset (1960), but the increased focus on social liberalism and economic centrism characteristic of 'third way' social democratic parties in the intervening years is likely to have exacerbated this split and opened up space within
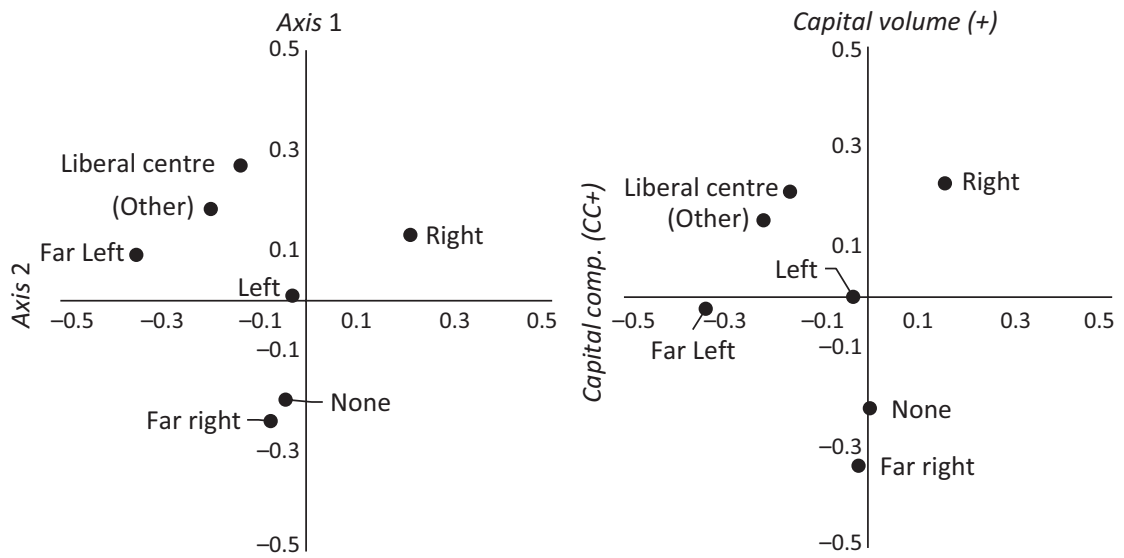

Figure 7.I Party affiliations in the social space (aggregate model).

Note: The figure on the left is based on averate ccoridnates across CatPCA models. The figure on the right is based on average rotated coordinates 
the political field for far-right parties to accumulate support (on the UK, for example, see Atkinson, 2017). Heterodox far-left allegiances, meanwhile, tend to be most closely associated with those who are relatively divested of economic capital but - Germany and the Czech Republic excepted - in possession of a modicum of cultural capital, who also, as we know, are typically younger than average. Perhaps it is a rejection of the value of economic capital, the temporal other to cultural capital, and/or a sense that financial prospects are so poor that only a thoroughgoing change of the game will improve their lot, but it may also be that the measure of cultural capital among those few leaning far-left is enough to turn them away from the nationalism and authoritarian traditionalism of the far-right and give them confidence to attach themselves to a minority heretical party where one is prominent enough within the political field.

\section{Class ethos}

So far we have inferred or conjectured possible factors mediating the correspondence between social position and party-political position: the economically rich, and players in the economic field, leaning right because of a preference for low taxes and privatisation as means for augmenting their prime resource; the dominated feeling politically homeless or turning to far-right parties because their left-authoritarian ethos is being catered to by social democratic parties less than ever; and far-left sympathies being anchored in cultural outlook as much as economic interest. It is possible to move beyond speculation, however, and map empirically some of the interceding dispositions by examining the distribution of political stances, shorn of identification with a party, within the spaces. The absence of indicators of attitudes toward 'moral' questions within the ISSP dataset - sexuality, gender roles, crime and punishment and so on - constrains what can be done in this respect, for sure, but the availability of questions soliciting perspectives on economic policy makes it possible to deduce the degree to which (dis)affiliation with parties is premised on the old left/right divide or implicates something else. If, for example, the dominated are full-bloodedly left-wing on material matters across the board then we could provisionally infer that their sympathy for far-right parties lies more in their moral conservatism and nationalism than anything else.

A number of the questions on economic policy in the ISSP dataset implicate the situation in the respondent's country - asking respondents to rate the tax system imposed by their government, or whether differences in income in their countries are too large - and thus anchor the responses in the socio-economic specificities of the various nations. Whatever the insights from such questions for country-specific or small-scale comparative research, they are less practical for broader-scale cross-national analysis. Instead, therefore, the focus is on items in the survey probing to a greater extent (of course they are still contextualised by country-specific policies and 
struggles) into generic principles. Specifically, there are three statements with which respondents were requested to rate their level of agreement and one question:

Q1. It is the responsibility of the government to reduce the differences in income between people with high incomes and people with low incomes. (redist)

Q2. Do you think people with high incomes should pay a larger share of their income in tax than those with low incomes? (richpay)

Q3. The government should provide a decent standard of living for the unemployed. (unemp)

Q4. The government should spend less on benefits for the poor. (lessben)

Responses to the statements were measured on five-point Likert scales running from strong agreement $(++)$ through neutrality $(n)$ to strong disagreement (--), while responses to Q2 could be 'much larger' $(++)$, 'larger' $(+)$, 'the same' (n), 'smaller' (-) or 'much smaller' (--). Q1 and Q2 are clearly about income redistribution, splicing political ethos with practical perceptions of 'high' and 'low' earnings (Weakliem and Biggert, 2013), while the other statements relate to state welfare. While differing welfare regimes between countries have been linked to peculiarities of historical class struggles by Esping-Andersen (1990), previous research on the space of political position-takings in Britain suggested that attitudes toward income redistribution and welfare ran along different tracks (Atkinson, 2017). The former tended to be polarised according to possession of economic capital, with those rich in the resource seeking to protect it, but views on the latter tended to be polarised by cultural capital. To be specific, a pro-welfare attitude characterised the (young, public-sector dependent) culturally rich and an anti-welfare attitude corresponded with those lower in cultural capital but not necessarily divested of economic capital - the upper-dominated and petit bourgeoisie disposed toward 'getting on' through grafting, saving and cutting back (in short, through sacrificing) and thus opposed to what they likely perceive as 'free handouts' to 'undeserving layabouts' because these undermine their whole ethos by seemingly rewarding precisely that which they define themselves against (Bourdieu, 1984). This may be related to the nationalist 'welfare chauvinism' many claim characterizes the same sections of the class structure, that is, the notion, given articulation by far-right parties, that social welfare should be reserved for national citizens and immigrants left to fend for themselves (de Koster et al, 2013), but since the ISSP questions specifically nominate 'the poor' and 'the unemployed' a connection between responses and nationalist sentiment cannot be assumed.

In order to gain an initial insight, as parsimoniously as possible, into differences across national contexts, i.e. the state and balance of national 
orthodoxies and heterodoxies on economic policy, a simple operation has been undertaken. For Q1 and Q3 the proportion of respondents in each sample registering disagreement with the statement, whether it be mild or strong, is subtracted from the proportion registering agreement. For Q4 the operation is reversed (disagreement minus agreement), in line with the direction of the question, while for Q2 the proportion answering 'smaller' or 'much smaller' is subtracted from the proportion answering 'larger' or 'much larger'. In each case the product is a basic left/right index. A higher score, up to a limit of 100, indicates more progressive position-takings and a lower score, with a floor of -100 , a more right-wing ethos. Inspection of the total national averages reveals that relatively progressive views - an acceptance of or desire for some degree of income redistribution and welfare, that is - are commonly preponderant (Tables 7.3). There is, in fact, only one negative score in the table: the US on income equalisation.

There are, however, variations across the questions and across nations. Regarding the former, for example, progressive taxation finds wide support but the notion that the government should be responsible for reducing income inequality in any other way (through, for instance, salary caps or minimum wages), tends to be less popular. Regarding nations, moreover, there are

Table 7.3 Left/right index scores across national samples for four questions

\begin{tabular}{lccccc}
\hline Country & $Q 1$ & $Q 2$ & $Q 3$ & $Q 4$ & Average \\
\hline Australia & 24 & 71 & 25 & 59 & 45 \\
Austria & 63 & 77 & 38 & 57 & 59 \\
Belgium-Flanders & 60 & 67 & 17 & 54 & 50 \\
Czech Republic & 46 & 62 & 42 & 32 & 46 \\
Denmark & 21 & 65 & 77 & 69 & 58 \\
Estonia & 65 & 66 & 87 & 75 & 73 \\
France & 70 & 83 & 47 & 8 & 52 \\
Germany & 41 & 82 & 43 & 68 & 59 \\
Iceland & 60 & 75 & 71 & 83 & 72 \\
Israel & 70 & 55 & 55 & 62 & 61 \\
Italy & 81 & 93 & 63 & 76 & 78 \\
Japan & 38 & 86 & 60 & 57 & 60 \\
Latvia & 82 & 78 & 81 & 67 & 77 \\
New Zealand & 6 & 52 & 14 & 27 & 25 \\
Norway & 28 & 68 & 71 & 69 & 59 \\
Poland & 68 & 64 & 52 & 49 & 58 \\
Russia & 85 & 79 & 79 & 64 & 77 \\
Slovakia & 69 & 70 & 48 & 34 & 55 \\
South Korea & 65 & 92 & 74 & 69 & 75 \\
Sweden & 40 & 71 & 73 & 60 & 61 \\
Switzerland & 41 & 85 & 65 & 74 & 66 \\
Taiwan & 44 & 84 & 62 & 71 & 65 \\
United States & -22 & 59 & 13 & 45 & 24 \\
Total average & 50 & 73 & 55 & 58 & 59 \\
\hline
\end{tabular}


some, like New Zealand and Australia, that are clearly, on the whole, more right-leaning than others. The limit case is the US, which also happens to be the current hegemon in the space of nation states and doubtless wields disproportionate symbolic power to impose its own policy orthodoxy welfare retrenchment, flat or regressive taxes, etc. - as the global standard (see Atkinson, 2020). In Italy, Iceland and parts of Eastern Europe, on the other hand, a progressive ethos seems more pervasive. Denmark, Norway and Sweden, exemplary social democratic regimes according to EspingAndersen's (1990) famed typology, are seemingly pro-welfare without being so pro-redistribution (cf. Aalberg, 2003), while South Korea and traditionally dirigiste France exhibit the opposite proclivities.

Whatever the merits of the indexes for casting light on national contexts and international convergences and divergences, they are less useful for examining correspondences of political outlook and position in a social space, not least because they exclude the often sizeable and potentially revealing middling category in each case of 'neither agree nor disagree' (or, in the case of Q2, 'the same'). Instead, therefore, the categories of each question have been projected into the CatPCA models as supplementary modalities in order to determine their association with social positions. Since right-wing views - especially extreme right-wing views - are relatively rare in the majority of samples, risking misleading results, the two pertinent categories have been collapsed into one for all questions. The resulting right-wing categories are still of variable size from nation to nation, though for Q1, Q3 and Q4 they average, respectively, 17 percent, 13 percent and 12 percent (as opposed to a few percent) across samples. The view that the rich should pay less tax, whether a little or a lot, is still, however, extraordinarily uncommon (averaging 1 percent), and its positioning must be treated with utmost caution (as should the associated tests of significance).

Examination of the distribution of responses on the first dimension reveals a strong and consistent relationship between relative possession of cultural capital and income, on the one hand, and progressive or regressive views, on the other hand (Table 7.4). In only a handful of cases are the differences between categories not significant (Israel and Japan being standout cases), and in most instances the nature of the polarisation is evident: the more capital one has, the more right-wing one's views tend to be. Stances on government redistribution of income are the most regular from nation to nation in this regard, with extremity categories being atypically placed in almost all cases, though the separation between egalitarianism and laisser-faire attitudes ranges from the modest (e.g. South Korea) to the stark (e.g. Poland, Latvia, Sweden). ${ }^{12}$ The central location of pro-interventionism in the Israeli and Italian models demonstrating its popularity among the dominated and middling regions of the spaces - reduces the distance between progressive and regressive dispositions substantially. In the Italian case, where right-wing views are scarce (6 percent), those higher up the axis are more likely to sit on the fence instead. 


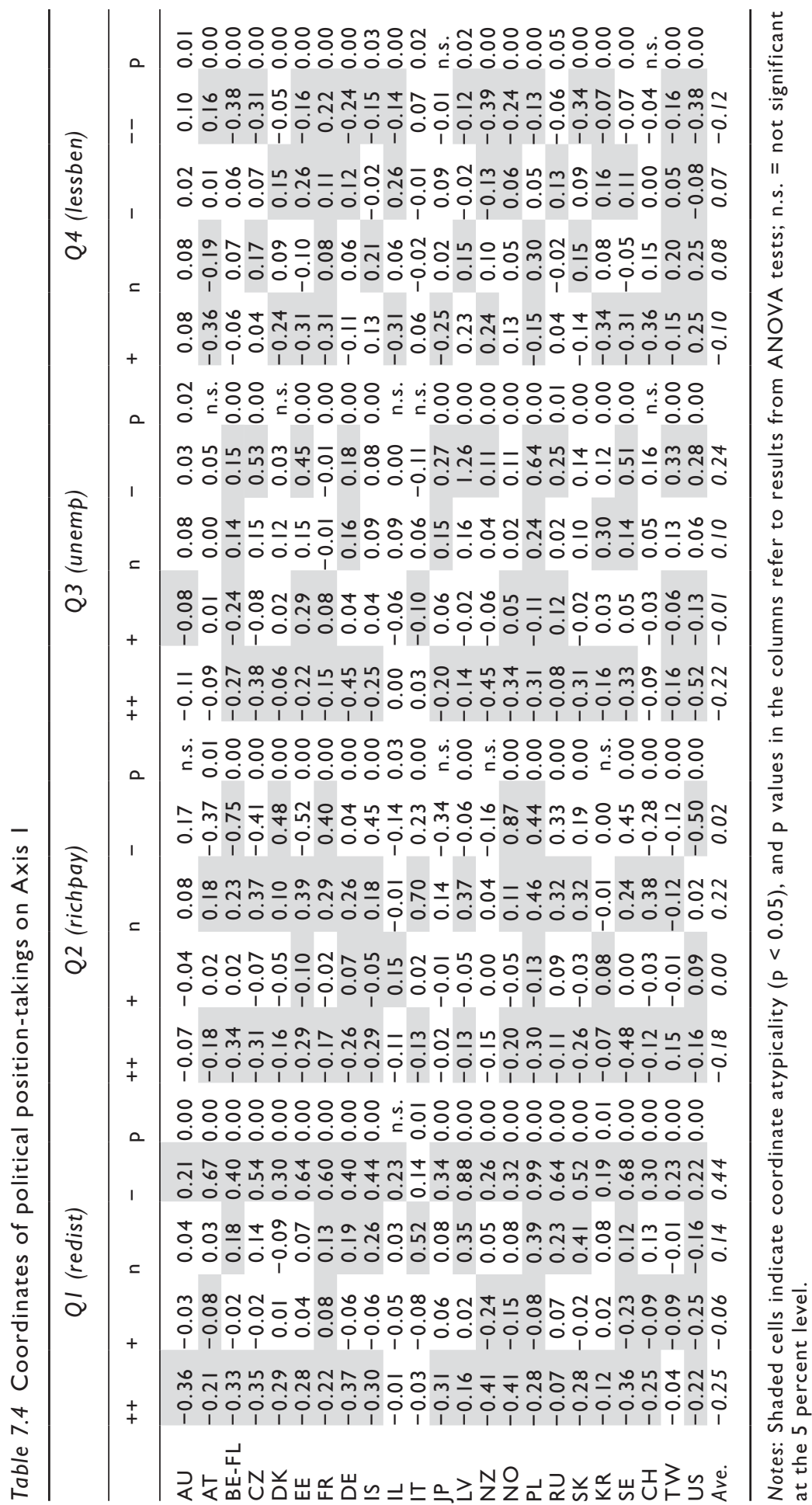


The question on taxation of the rich is slightly more complex. The capital-rich on Axis 1 are reluctant, it would seem, to suggest they should pay less tax - a much more controversial and provocative assertion, given the balance of opinion, than overtly or tacitly supporting the status quo. The wild variation from one model to another of where exactly those who do believe the rich should pay less tax are located is no doubt linked to its extreme rarity and should be treated with suspicion - wherever the modality sits, it cannot be said to represent the majority view of the people in that area of the space. More regular, however, is the positioning of those who believe the rich should pay more tax: with the exception of Taiwan, they fall lower down the space, mostly significantly so. The core opposition, therefore, is between a pro-tax capital-poor zone and those richer in capital who are content with the current state of play, which is, in its own manner, a form of economic conservatism.

Orientations toward welfare for the unemployed generally follow the same pattern as orientations toward government redistribution. While a mildly pro-welfare attitude often sits fairly centrally, its prevalence rendering it a sort of middling, uncontentious 'common sense' in capitalist social orders, those lower down the space - and perhaps more exposed to the risks of job loss - are more likely to be strongly in favour of state provision and those higher up the axis - for whom unbuffered unemployment is a less probable fate - are rather less keen. The dispersion of views is not always so pronounced, however, sometimes failing to register significance (Israel being the limit case), but in the Czech, Latvian, Polish, Swedish and US spaces the polarisation is considerable.

The correspondence between positions on Axis 1 and position takings on state benefits for 'the poor' seems to be the most varied across national models. For the most part strong disagreement with the notion that the government should spend less on benefits has a negative coordinate on the dimension, often significantly so, while mild disagreement - again, given the prevalence of the response, marking it out as the 'common sense' or 'middle ground' view - usually occupies a more central, or slightly elevated, location. However, while there are several instances where a negative perception of state benefits for 'the poor' lies higher up the axis (the US, Latvia, New Zealand), characterising those richer in capital, or around the centre (Flanders, the Czech Republic), there are a number of models where opposition to state support bears a negative coordinate and is, therefore, associated with the dominated (e.g. Austria, France, Estonia). In some instances this is, in fact, part of a more or less linear relationship between positions on the axis and position-takings, with pro-welfarism - similar to the UK case - being associated with slightly higher cultural capital/income and anti-welfarism corresponding with the dominated (e.g. Austria, France), yet in others both strong pro- and anti-welfare stances characterise those with lower capital (e.g. Estonia, Germany, Poland, Slovakia, Taiwan). This might seem 
paradoxical at first, but everything depends on the respondent's practical sense of what constitutes the category of 'the poor' and one's relation to it - whether the label, that is, refers to 'people like me' (including people one knows) or whether it refers to discreditable 'others' against which one defines one's own sense of worth ('layabouts', 'scroungers', etc.). The division internal to the dominated is, in any case, always one between a majority in favour of support for 'the poor' and a minority - vocal or otherwise opposed.

As for Axis 2, or the dimension opposing the (older) economically wealthy and the (younger) cultural inheritors, immediately apparent is the weaker tendency for position-takings to be differentiated according to this secondary polarisation: in six spaces (Estonia, Germany, Israel, Japan, Russia and South Korea) there are no significant differences, despite a few atypical coordinates, and in four more (Austria, Flanders, Switzerland and the US) there is only one variable, always relating to welfare, registering significant difference (Table 7.5). Nevertheless, where differences in views on government intervention, taxation of the rich or state support for the unemployed or poor are significant on the axis they usually follow the same pattern: leftwing views fall to the left of the space and right-wing views fall to the right, sometimes moderately but often substantially. Higher income and cultural capital relative to others may increase the probability of exhibiting a conservative disposition, therefore, but so too does substantial wealth holdings including, it might be added, in many of those cases where those with less capital on the first axis, or a small section of them at least, are against state support for 'the poor' (especially Denmark and Slovakia, but also compare e.g. Germany, Israel and Taiwan). Now it transpires that it is often those with a modicum of wealth, and less inherited cultural capital, that are in favour of the government spending less on benefits for the poor even where or perhaps because - they have lower (taxable) incomes themselves.

There are, for sure, some cases where the relation between position and position-taking on the second axis is, on the whole, a little fuzzy, as with Taiwan and the US, or divergent, as with Italy, where the sheer rarity of right-wing views must be borne in mind. On the other hand, however, there are spaces where responses to all or most questions are strongly dispersed, fairly neatly arranged and significant along the wealth axis. Everything would seem to indicate, therefore, that in several nations the homology between social positions and position-takings on issues of 'class politics' is multidimensional. It is perhaps no coincidence, moreover, that the paragons of multidimensionality are Denmark, Norway and, to a slightly lesser extent, Iceland and Sweden - social democratic Nordic countries marked by relatively balanced primary and secondary axes of differentiation.

It may seem counterintuitive, at first, that the left/right opposition on economic redistribution is more closely related to positions on Axis 1, which primarily opposes those high and low in inherited and acquired cultural capital, and only secondarily income, than Axis 2, which polarises the wealthy and 


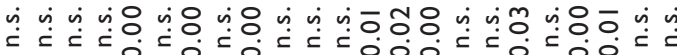

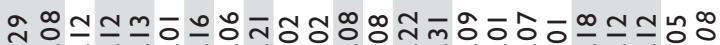
- i i i i i i i i o i o i i i i i o i i i i

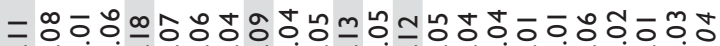
- o i i 0.0000

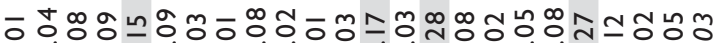
0

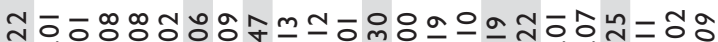
- $0_{0} 000000000000000010000$

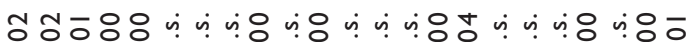
a 0000

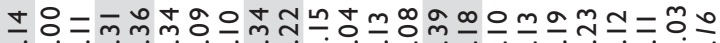
000000000000000000000000

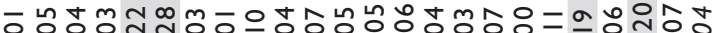
o. 0000000000000000000

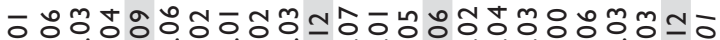

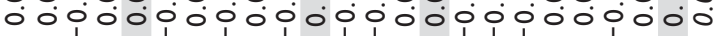

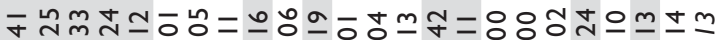

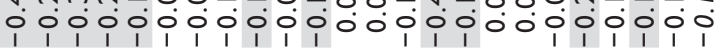

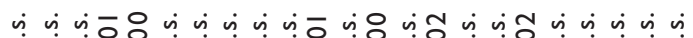

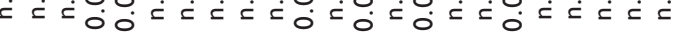

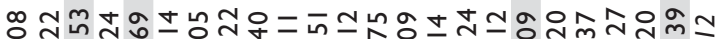

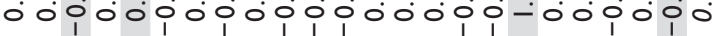

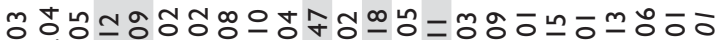
- ío

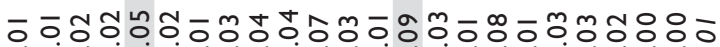

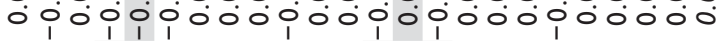

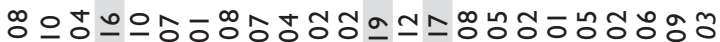

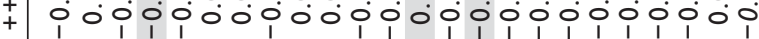

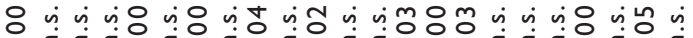
a o = = = ปับัニ ○000000000 0.000000000000

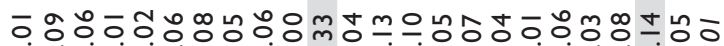

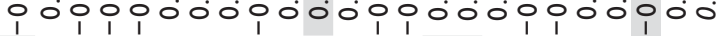

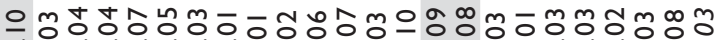

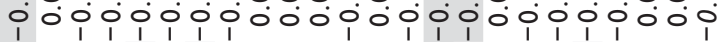

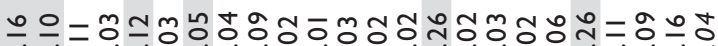

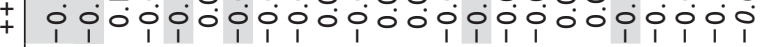

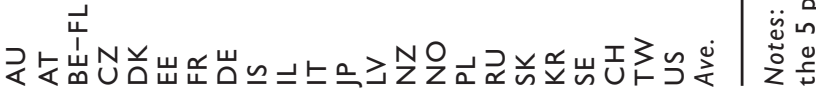




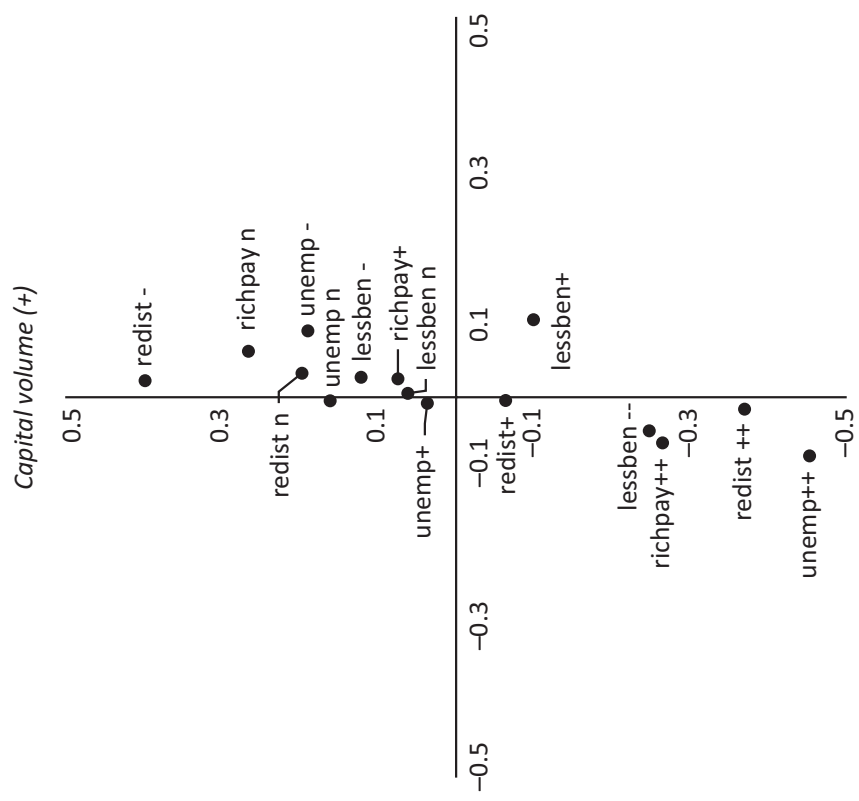

(+כJ) dmo

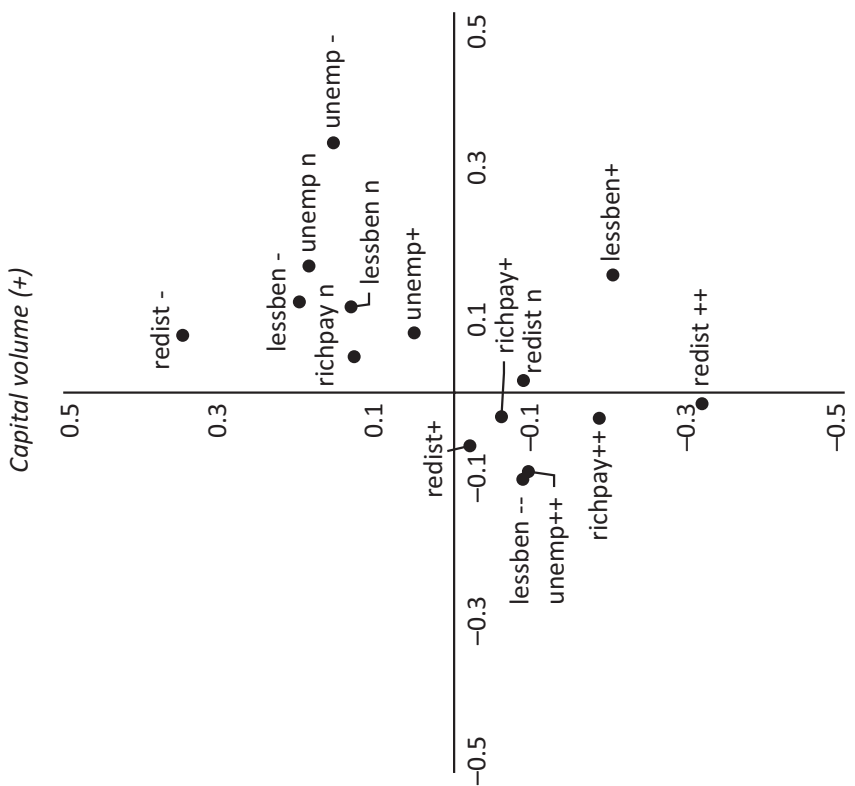

(+כว) $\cdot d$ moว

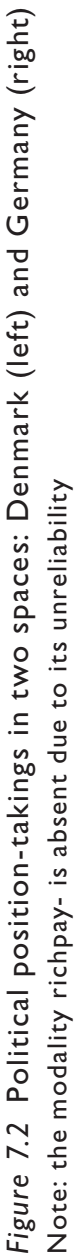


the less wealthy. Rotating the coordinates to proxy the conceptual model, however, reveals that the prime factor of differentiation is always capital volume, with the degree of modulation by capital composition - the extent to which, that is, classes are internally divided on the state/market relationship - being the prime basis of variation across models. This becomes clear when comparing rotated models from nations at either end of the spectrum: Germany, where the left-right opposition follows volume of capital closely, and Denmark, where it is more evidently inflected by capital composition (Figure 7.2).

\section{Conclusion: principles of party preference}

Comparison of the locations of position-takings on economic redistribution and party preferences in the major plane of the models yields two inferences on the relationship between class ethos in capitalist social orders and the official 'lines' forged in national political fields. The first bears on the lower portions of the social spaces - the dominated, in other words. They are, it would seem, consistently characterised by an egalitarian ethos when it comes to state-led reallocation of economic resources, doubtless because, from their vantage point in the social space, this is the most conceivable mode of ameliorating their conditions of existence and diminishing the distance between social positions and, with that, perceived worth. They are, admittedly, sometimes opposed to or internally divided on welfare for 'the poor', perhaps because of specific or clashing constructions and uses of that label in contemporary symbolic struggles. Save a few cases like Denmark or New Zealand, however, there is a disconnect between the egalitarian ethos toward the bottom of the social space and the position of social democratic parties. Sitting more centrally in the space, the latter's rhetoric and policies for all the diversity in their specific substance across nations - evidently offer only a partial or loose concordance with the redistributive ethos of the dominated but appeal to dispositions born of possession of higher (cultural) capital. Perhaps, it seems reasonable to conjecture, this is because of the ideological passage since the 1980s toward the 'centre-ground' on economic policy and a pronounced liberalism on social matters, generating, among the dominated, uncertainty, disenfranchisement, disengagement and a receptivity to others seemingly articulating their concerns and possible solutions - an opening for the nationalist-populists in political fields who would transition from spectres haunting Europe and beyond to prominent players and power holders in subsequent years. By contrast, there is a more consistent correspondence between higher capital holdings, an economically liberal ethos and centrist or right-wing parties. Though the vote might be split by warring parties within these two ideological categories, the capital-rich are nevertheless more likely to feel they have adequate political representation and, with that, political efficacy.

The second conclusion relates to the degree to which the homology between social spaces, position-takings and political parties can be surmised 
to differ according to capital composition as well as capital volume. There certainly are many instances, the Nordic spaces above all, in which both party alignments and attitudes toward economic redistribution and/or welfare are differentiated across the two primary axes in a manner roughly fitting previous Bourdieu-inspired research. Propensities to lean and vote left or right would thus seem in these cases to be underpinned, at least in part, by differences on traditional 'class politics' linked to balances as well as total amounts of capital, with all the contrasting relationships with age, geography and the state (via the division of labour of domination) they entail, even if capital volume, contra Jarness et al.'s (2019) findings, clearly remains a more powerful differentiator than capital composition.

Yet in some cases, like Germany or Russia, a multidimensional distribution of party preferences, even if moderate, contrasts with an effectively unidimensional distribution of attitudes on economic matters, suggesting that other principles of difference - stances on 'moral' matters perhaps, or religion $^{13}$ - may be key to co-shaping party alignments. In other cases, like South Korea, a unidimensional distribution of attitudes corresponds with a unidimensional distribution of political party leanings, which is not to say that secondary oppositions would not be found with different measures. It could be, for example, that lateral dispersion in the social spaces would correspond with opposed stances on other matters - 'moral' issues or geopolitical struggles - and that, if party perspectives on these matters are invisible or undifferentiated, other forms of political participation or lack thereof activism, 'clicktivism' and so on - might emerge as salient polarisers instead (cf. Jung and Gil, 2019). Still other cases, particularly Italy and Israel, display idiosyncratic class-ethos-party relationships, possibly attributable to specific social conditions (e.g. economic crisis and political turmoil in Italy), political histories (e.g. relations with Palestine in Israel) or quirks of the samples but, in any case, in need of further investigation before any firm conclusions can be drawn. In place of universal rules or rigid isomorphism, therefore, we rest content with regularities and variations on core themes which, given the relative autonomy of national political fields and the differing constitution of social spaces, are precisely what we would have expected.

\section{Notes}

1 See, for example, Parkin (1968), Inglehart (1977, 1990, 1997), Giddens (1991, 1994), Pakulski and Waters (1996), Clark and Lipset (2001), Evans (1999), Evans and Tilley (2016).

2 For research confirming or specifying the connection between the dominated and the far-right, with varying modes of measurement and explanation, see Achterberg and Houtman (2006), Houtman et al. (2008), van der Waal et al. (2007, 2010), Oesch (2008a, 2008b), Kriesi et al. (2008, 2012), Rydgren (2013), Norris and Inglehart (2016), Gidron and Hall (2017), Atkinson (2017) and Eatwell and Goodwin (2018). There has been research to suggest that far-right parties in Europe are now strategically adopting more socially liberal stances 
(pro-gender equality, for example) in order to paint non-European (especially Muslim) migrants and their beliefs as 'backwards', and thus unwelcome (Duina and Carson, 2019), but this is a shift largely postdating the ISSP data.

3 This categorisation has the disadvantage of obscuring specifically ecological interests, as green parties are classified according to their stance on economic matters (they tend to be either on the left or centrist). The categories were constructed manually for Israel and Taiwan. There were also a few cases (France, Italy, Russia, South Korea) where the categorisation did not tally with the disaggregated nation-specific measure of party affiliation, which was checked as a matter of course, with those claiming alignment with a specific party being distributed across different political categories. This seems to have been due to the nation-specific measures in these instances (except Russia) targeting respondent self-placement on the scale rather than relying on expert placement of affiliated parties on the continuum.

4 If an election was held in 2009 it is cited as the last election even if it took place several months after the survey was delivered. In these instances political affiliation yields an imperfect handle on voting intention.

5 In Norway, for example, right-wing parties secured the most votes in the 2009 general election, reflecting their favour in the sample, but the social democratic Red-Green alliance attained more seats in parliament and continued in government.

6 Describing 'Independents' as automatically centrist is misleading because it masks the heterogeneity of political orientations, effectively rendered 'homeless' in the two-party system, that might go under that banner. Take, for instance, Senator Bernie Sanders, whose politics are far to the left in the US context but who is often described as an Independent (even if, for convenience, he campaigned for presidential election under the Democratic banner).

7 In de Keere's (2018) analysis of the Flemish space of political position-takings in 2013, Open VLD were the party most closely associated with right-wing views.

8 Although the popularity of the 'none' option in many of these cases may inflate its statistical significance, it is worth noting that in all but three cases where it is significant (Denmark, Iceland and Norway) the test value is greater than 3.29, making it significant at the 0.1 percent level.

9 Again, the atypicality of right-wing views on the axis falls below a critical value of $3.29(p=0.001)$ in only three cases where it is significant (the Czech Republic, New Zealand and Slovakia) and below $3.09(\mathrm{p}=0.002)$ in only one of those (Slovakia).

10 The distance between the far-left and the right, measured by standard deviations, is notable or substantial in nine cases.

11 In recognition of its specific status, moreover, the coordinates for centrism in the US model have been attributed to the 'none' category.

12 As with party preferences, it should be borne in mind, given the popularity of response categories, that, Italy and Israel apart, the atypical positionings on the axis of disagreement as well as agreement and/or strong agreement with the proposition are significant at the 0.1 percent level in all cases except South Korea and Russia, where the relevant categories are significant at slightly lower thresholds.

13 It is worth remembering from Chapter 5 that the young and cultural-capitalrich northwest region of the spaces, which appear empty in the models of the homology between the class structure and 'class politics', are commonly associated with irreligiosity and thus, it might be reasonably inferred, lack of attachment to tradition or dogma concerning sexuality, gender, etc. 


\section{Chapter 8}

\section{Class sense and symbolic violence}

A social space is a space of value. Structural distance, via practical sense, generates perceptions of social distance, and since the capitals defining class are systematically misrecognised as indicators of 'success', 'talent', 'legitimacy' and so on, objective differences always translate into differences of perceived worth too. That applies to evaluation of others - seeing people as richer/poorer, smarter/stupider, significant/insignificant and such like to varying degrees - but it also applies, necessarily, to our intuition of not only our own place but our own merit or importance within the social order. The ways in which we communicate this in quotidian existence are remarkably varied - insults or praise, or efforts at explanation, rationalisation or justification of events - and the tactics people deploy to present themselves in a certain way - trying to pass themselves off as 'higher' than they really feel themselves to be in one way or another, or showing false modesty - may be multiple, but there is an awareness and ever a lexicon to communicate a sense of being high or low, worthy or less worthy, in the misrecognition order.

Those toward the top of the social space, said Bourdieu, seek to justify their place with certain narratives and tropes: they 'made it' (even if their parents had already 'made it' before them) because of their own intellectual 'gifts', business nous or 'hard work', and those below them evidently lacked these traits, perhaps, they might claim, because of low IQ, lack of aspiration or laziness. Since these same people at the peak of the social space possess the properties securing symbolic power - the capacity to have one's definitions of the world taken seriously and even institutionalised - these self-validating narratives and tropes, or 'sociodicies' as Bourdieu dubbed them, infiltrate the populace at large. What follows is symbolic violence: even though positions and trajectories are made possible and impossible by structured conditions of existence, the dominated often accept the dominant worldview and see their disadvantageous and denigrated positions as 'only natural', 'fair enough' and so on since they were 'no good at school' or 'didn't try hard enough'. They come to see themselves as failures, in other words, and even accept and naturalise the way the world is more than the 
dominant themselves. Bourdieu put this particularly clearly in conversation with Terry Eagleton (1992: 114), where he stressed that "people living in poor conditions' are 'prepared to accept much more than we would have believed' and 'put up with a great deal'. This, he continued, is at the core of his notion of doxa: 'there are many things that people accept without knowing'. $\mathrm{He}$ offered an example:

When you ask a sample of individuals what are the main factors of achievement at school, the further you go down the social scale the more they believe in natural talent or gifts - the more they believe that those who are successful are naturally endowed with intellectual capacities. And the more they accept their own exclusion, the more they believe they are stupid, the more they say 'Yes, I was no good at English, I was no good at French, I was no good at mathematics.' Now that is a fact in my view it is an appalling fact - one that intellectuals don't like to accept, but which they must accept.

Such was Bourdieu's view, based on his research on mid-twentieth-century France (Bourdieu, 1984: 387-90). How well has the contention been borne out in other countries and several decades on? There is certainly a rich vein of work in Anglophone sociology exploring not only the manner in which people draw 'symbolic boundaries' - taking certain lifestyle practices or ethico-political outlooks as markers dividing 'people like me' and 'people not like me', people who are 'better' or 'worse', 'right' or 'wrong' in what they do - but how descriptions of self and others across the class structure are loaded with visceral battles for recognition (Sennett and Cobb, 1977; Lamont, 1992, 2000; Skeggs, 1997; Charlesworth, 2000; Savage et al., 2001; Sayer, 2005; Irwin, 2015, 2016). It may be that the dominated feel shame, guilt and embarrassment as they inescapably regard their lives through the worldview of those above them in the social space (whether via media depiction, political discourse or interaction with educators), or struggle to salvage some form of dignity by distancing themselves from those even further below them. Most of this research, however, is of British or American provenance, and while there is some evidence that class sense and symbolic violence pervade everyday existence in countries as dissimilar as Russia, Brazil and India (Salmenniemi, 2016; Dickey, 2016; Lamont et al., 2016), the extent and form of their cross-national presence is unclear.

The majority of studies dissecting symbolic boundaries, moreover, are so fixed on the struggles between dominant and dominated sections of the social space - essentially between the top half and bottom half, often simply described as 'middle class' and 'working class' - that they neglect the possible specifying effect of capital composition. An exception is Jarness's (2017, 2018) exploration of symbolic boundaries in Norway, where the antagonism between those rich in economic capital and those rich in cultural capital 
was all too clear (see also Skjøtt-Larsen, 2012). Whether this antagonism is confined to that nation, and possibly other Nordic social orders, on account of its pronounced capital composition principle, or whether it exemplifies a struggle ubiquitous across diverse social spaces, we do not know. Nor do we know from this work whether the antagonism is asymmetrical or hierarchical: the extreme fractions of the dominant class may reject one another's lifestyle, but do people at one pole still tend to perceive themselves as superior at a greater rate than those at the other? After all, the capital composition dimension was, for Bourdieu (1984), not just a principle of difference but a principle of domination, a struggle to impose one source of misrecognition as the prime source of misrecognition in a social order in which one fraction can emerge as dominant, flush in the most valued resource and seen by themselves and others as truly 'successful', and another becomes dominated, perceiving themselves to be further down the scale of worth, despite the misrecognition they may enjoy from those lower than them in the social space. Despite his fame as the man who conceived cultural capital, Bourdieu, for his part, was in no doubt that in contemporary capitalist social orders, and even more so in neoliberal ones, the economic fraction of the dominant class is the dominant fraction and its cultural counterpart the dominated fraction.

On top of all this, Bourdieu has long drawn fire for seemingly ruling out the possibility of resistance. Marxists like Jacques Rancière have been at the front of the lengthy queue to eagerly lay this charge at Bourdieu's door, and even those unearthing the variety of class-based boundaries and judgements people draw are often decidedly unhappy with the apparent pessimism of Bourdieu's general perspective. People find alternative sources of value, they assert, or refuse and reinvent the labels cast on them by others. The major challenge to Bourdieu on this front, however, comes from one of his erstwhile collaborators: Luc Boltanski (2011, 2012; Boltanski and Thévenot, 2006). Whatever the ontological shifts he claims are loaded into it, and whatever the byzantine vocabulary he seeks to weave around it, Boltanski's substantive argument, worked out in a string of influential case studies and conceptual reflections, is that people from top to bottom of society actually have a profound sense of justice and injustice. They do not, as Bourdieu seems to claim, internalise their domination, but frequently feel wronged and, in one way or another, seek to dispute or challenge the way they or events have been framed. That might be rejecting accusations that they are 'lazy' or that their educational trajectory is down to their 'stupidity', but it also extends to contention over whether 'the system' in general is just. We have, of course, already glimpsed in the last chapter that the dominated often tend to be more left-wing on questions of income redistribution, and it might be said that this presupposes precisely the kind of sense of injustice Boltanski is spotlighting.

Boltanski's point and the critics' reservations are not as incompatible with Bourdieu's relational phenomenology as might be supposed, however. 
The social space is, at the end of the day, a field, and that means it is a space of struggle and a space of strategies in the all-too-human quest for recognition. Resistance and critique among the dominated (and everyone else) of aspects of the 'game' and its players, no matter how mundane, piecemeal and cynical, should come as no surprise, therefore - as even Bourdieu later made clear in The Weight of the World (Bourdieu et al., 1999). Whether the dominated internalise and unquestioningly accept their domination, and the degree to which they do so, it seems to me, is ultimately an empirical question. In certain social orders, at certain junctures, the dominant may indeed manage to impose their sociodicies (which will differ by class fraction) as utterly doxic across vast expanses of the social space - and Bourdieu, wanting to rid intellectuals of their stifling myths, doubtless tended to (over)emphasise this scenario - but in others, perhaps at times of social crisis, their narratives, or at least elements of them, may constitute only an orthodoxy open to dissent to different extents in different zones of the social space (Bourdieu, 1977).

The ISSP dataset contains a selection of variables allowing us to explore some of these questions. In no way is the data available a replacement for or advance on the detailed analysis of indigenous constructions of social reality, practical negotiations of difference and situated value judgements undertaken in qualitative research, but for the sake of assessing the breadth of applicability of Bourdieu's general theses cross-nationally it certainly suffices. This stands in regard to the question of how far sociodicies and symbolic violence are internalised or contested, but also in relation to the intuition of one's location within the social order.

\section{A sense of one's place}

Respondents were asked to think about 'the groups tending toward the top and bottom of society' and to place themselves in relation to them on a ten-point scale, with ten denoting the highest group and one representing the lowest. There was no suggestion in the question as to how those groups should be defined - it was open to interpretation by the respondent, meaning they were mobilising their own sense of what makes a person 'high' or 'low' in their nation's social space, though of course they may have been swayed by other questions in the survey. ${ }^{1}$ Since the scale is unidimensional it raises the question of how it will interplay with capital composition: does it follow capital volume exclusively, with cultural and economic fractions registering equivalent standing, or will it be pulled laterally at different points depending on the weight of capital? Is the 'top' of society in people's minds equivalent to the central apex of the social space, or is it pulled to one side? The scale was treated as a supplementary multiple nominal variable - so as to allow free variations of categories across the spaces - and its homology with the CatPCA models analysed for every country. Very few respondents were willing to place themselves in the top three categories, perhaps in part 
because of wariness of accusations of arrogance or 'getting above oneself', or because of differing definitions of what constitutes the (near) 'top' of society, so these were aggregated into one category for all national samples. In direct parallel, this time doubtless as a strategy of self-presentation (and self-defence), people were extremely reluctant to place themselves into the bottom three categories (i.e. barely a few percent did), necessitating their combination too. ${ }^{2}$ There are six exceptions where, for one reason or another, respondents were rather more likely to position themselves at the foot of the putative social scale: Italy, Japan, Latvia, Russia, South Korea and Taiwan. In order to avoid skewing the results, therefore, the bottom categories have not been aggregated in these samples.

The aggregate model, yielding a loose tangent running at roughly 20 degrees clockwise from the vertical axis, reveals the perception of one's place to be arrayed along both dimensions of the CatPCA spaces (Figure 8.1). The first axis is, undoubtedly, the major principle of differentiation of self-evaluation, with the bottom category having a mean coordinate of $-0.75(-0.89$ in the disaggregated cases) and the top category a coordinate of 0.77 , but the second axis, polarising the wealthy and the non-wealthy (the latter also commonly being cultural inheritors), nonetheless plays a part too, with a typical gap between the top and bottom categories of 0.55 . In only two cases - Latvia and Taiwan - are differences between categories on the second axis non-significant, though typicality tests make it clear that fewer categories (commonly one or two higher or lower categories) tend to be atypically placed on the second dimension compared to the premier axis across the board (Table 8.1).
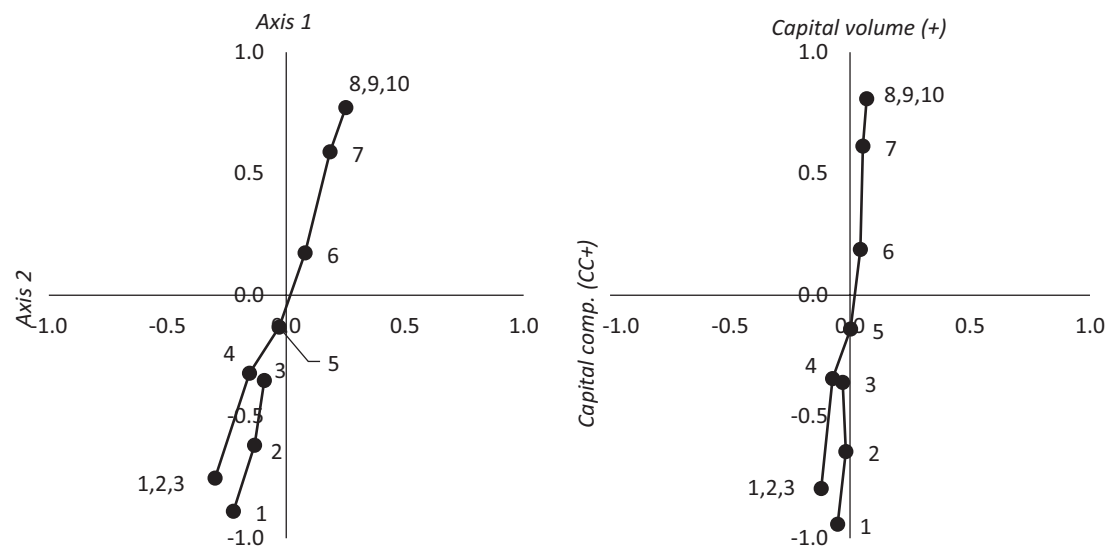

Figure 8.I Perceived place in the social space (aggregate model).

Note: The figure on the left is based on average coordinates across CatPCA models. The figure on the right is based on average rotated coordinates. 


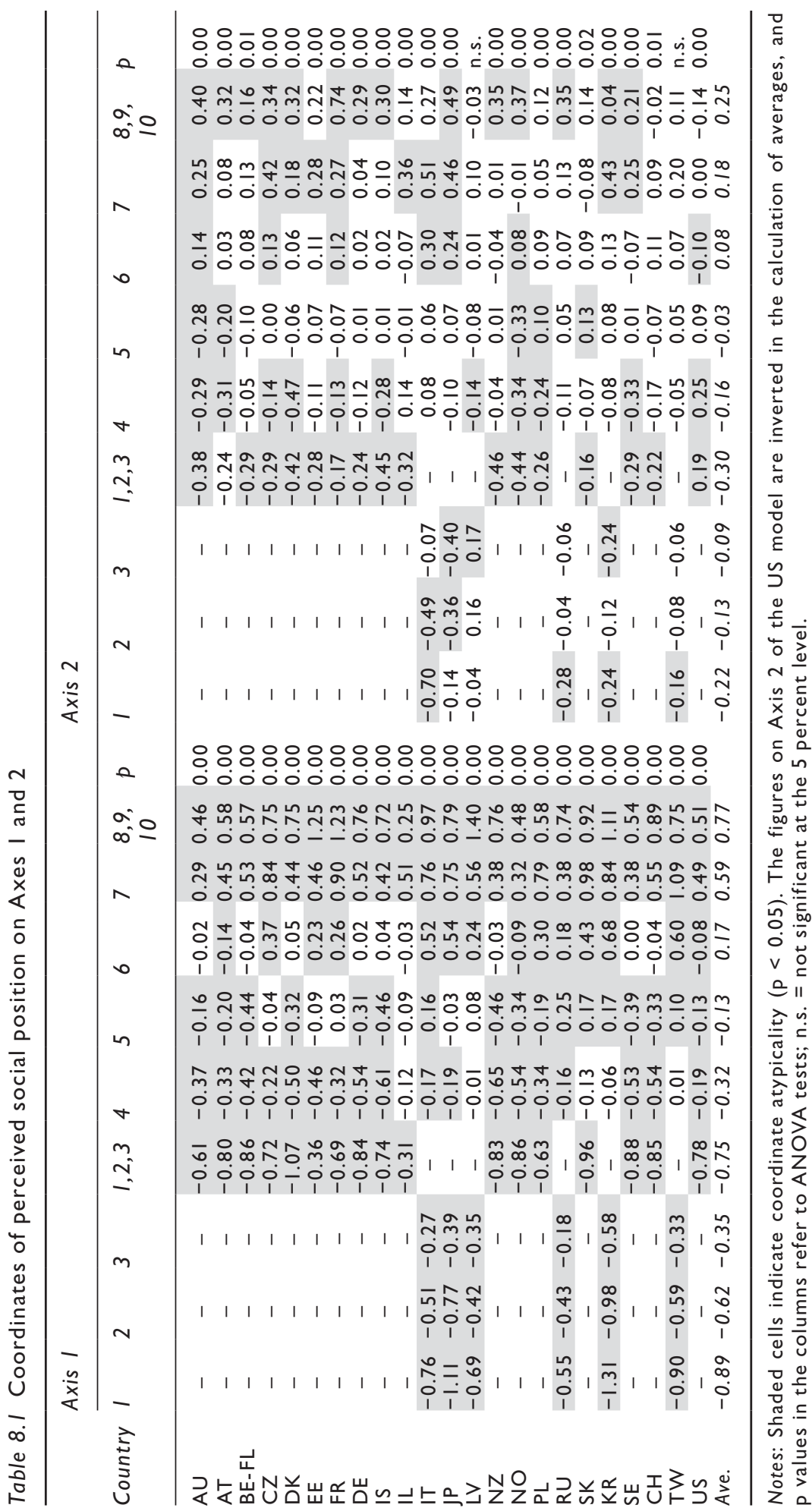


When the space is spun to proxy capital volume and capital composition, following the formula from previous chapters, the hierarchy of perceived social locations clings closely to the centre line for capital volume, with only the slightest modulation by capital composition - perception of oneself as being at or near the top of society falls just to the right of the volume axis, toward the economic/older pole of the capital composition dimension, while the lowest self-perceptions (at least in the models where the bottom categories are combined) are pulled a little toward the less-wealthy/younger pole of the dominated section of the space. This could be read as a stark reminder that, whatever struggles may be fought between the holders of economic capital and cultural capital, the contemporary bellatores and oratores in capitalist social orders, they are dwarfed by the sense of social distance both feel from the dominated, or laboratores, and whatever sway over the field of power the possessors of powers temporal may enjoy compared to the possessors of powers spiritual, they are both still powers furnishing a sense of superiority or advantage over others. The source of misrecognition may be different, but misrecognition they still both evidently profit from. ${ }^{3}$

The aggregated model does, however, hide variation in lateral dispersion of rotated coordinates across national samples. True enough, there are some models - namely those for Taiwan, Russia, Flanders and Austria - where the distance between coordinates for higher and lower categories on the capital composition dimension is never greater than around 0.2 , just as in the aggregate model. In other spaces, however, such as those of Estonia, Germany, Italy and the US, the distance is greater than 0.4 , and in yet others - those of the Czech Republic, France, Japan, New Zealand and South Korea - the gap is greater than 0.5 . There is some variability, though, as to whether the distance is due primarily to the bottom one or two categories being particularly associated with the cultural side of the axis (as in the Danish space), the uppermost categories being located particularly far toward the economic pole (as in the French model) or both (as in the Japanese space). In any case, one or both of the two top categories in the ranking (that is, 7 or 8 through 10) has a coordinate greater than 0.2 on the axis in all the spaces where the total distance is larger than 0.5 , as well as in the German space, with the limit case being the top category in France (0.45) followed by the same modality in Japan (0.34). ${ }^{4}$ One or both of the two bottom categories, meanwhile, have a coordinate less than -0.2 in the models for the Czech Republic, Denmark, Estonia, Iceland, Italy, Japan, New Zealand (the lowest, at -0.3), Norway and the US. ${ }^{5}$ That said, the distance between categories on the composition axis is never greater than the distance between the top and the bottom categories on the volume axis, which averages 1.75 . It may well be, therefore, that money is the prime principle of misrecognition in capitalist social orders, the dominant principle of domination and the primary 'measure of all things', including one's place in the world (cf. Harrits and Pedersen, 2018), such that it opens up differences in self-perception within 
classes, especially at the top and bottom of the social space. This may be enough to stir intra-class struggles over 'final distances', but it should not blind us to the much larger distances between dominant and dominated and the fact that those with least are uniformly compelled to see themselves as the 'bottom' of society, or as close to it as they can admit without selfinflicting psychological wounds, with all its connotations of lack, powerlessness and insignificance. ${ }^{6}$ The degree to which they see that location as their just deserts or a social wrong, however, depends on how they believe they got there.

\section{Sociodicy as doxa}

Respondents were asked how important, on a five-point scale (1 being 'essential', 5 being 'not important at all'), they believed a range of factors were in 'getting ahead', which in the context of the survey is implied to refer to general socio-economic 'success', or, we might say, a dominant position within the misrecognition order. Amongst these factors are 'having wealthy parents' - i.e. inherited economic capital - 'having educated parents' i.e. inherited cultural capital - and 'knowing the right people' - i.e. social capital. These are inevitably subject to the respondent's interpretation. While 'educated parents' is perhaps the least malleable phrase - university or post-compulsory education are likely to act as consistent benchmarks ${ }^{7}-$ 'wealthiness' and 'connections', as linguistic tools of differentiation, can nearly always be interpreted as something one does or did not have compared to others even if one possesses stocks of capital securing an elevated position in the social space.

Also among the proffered factors of success are 'hard work' and 'ambition'. Stripped of its folk connotations and reconstructed in the language of Bourdieu's relational phenomenology, 'ambition' is, of course, nothing other than a practice-orienting projection of a future based on protention of the possibilities and impossibilities written into the present given past experience - the feel for the game, that is, or the 'subjective expectation of objective probability', as the habitus is sometimes summarised. 'Hard work', in the sense of voluntarily 'putting in extra hours', 'persisting', 'making sacrifices' and so on, is also inescapably framed by the same practical sense of the possible and impossible (including potential 'escape routes' and strategies of ascent, as for the rising petite bourgeoisie in Distinction). Yet both 'ambition' and 'hard work', as tropes in popular discourse, are irrevocably charged with individualistic undertones - all one needs to 'make it' is aspiration, a dream, grit and determination and so on, no matter who one is or where one comes from (see Roberts and Evans, 2012; Stahl, 2015). They are, as elements of the latter part of the infamous formula 'talent plus effort', major planks of the popular claim that individual merit is the prime mover of trajectories, and the components that couple supposedly innate or 
'divine' gifts with simple willpower untouched by social conditionings. From this we can conjecture the following: the more the dominant class appear to believe in the power of hard work and ambition over capital, the more we might say its members construct a sociodicy of their own privilege; the more widespread and effusive this same sentiment is across the space, the more doxic we might deduce the sociodicy is. Conversely, the more the intermediate and dominated regions believe in the importance of capital to get ahead, the more contested and tenuous we might say the sociodicy is.

General differences between social orders themselves provide necessary context. Is a belief in ambition and hard work as the motors of success rather than manifestations of capital firmer in some nations than others, which is to say, is the individualistic, merit-based sociodicy of privilege more pervasive and taken-for-granted as a means of making sense of positions and movements across some social spaces more than others? Table 8.2 displays the proportions of each national sample believing the separate factors to be broadly important (covering 'essential', 'very important' and the rather less committed 'fairly important') and, demonstrating greater certainty, very important or essential. In every single sample, ambition and hard work are seen as important by virtually everybody, and are much more likely to be described as such or as very important than having educated parents or wealthy backgrounds, frequently by a considerable margin. Despite being the dominant principle of domination and a fundamental engine of social reproduction, in other words, the power of money is mystified, as is inherited cultural capital, and individual-level attributes are accepted as paramount to 'getting ahead' or 'falling behind' as these are defined in the contemporary capitalist misrecognition order. This could be testament to the global spread of individualistic, neoliberal doxa since the 1970s, but it could also simply signal the inculcation of credos - that 'anyone can make it', that we are free to be 'what we want' and so on - long-foundational to capitalist social relations worldwide. If there is a capital appearing to everyday perception as salient, it is the social capital of connections, but even this is rarely as likely to be considered as important as ambition and hard work.

That general theme aside, however, there appear to be national differences in the extent to which belief in merit overpowers recognition of capital's efficacy (cf. Marshall et al., 1999; Larsen, 2016; Roex et al., 2019). Everything would seem to indicate that in Nordic social orders, for example, there is a stronger sense that capital does not matter - perhaps linked to the social democratic ethos ruling the political field and the policy mechanisms in place to ostensibly tame the power of capital - compared to ambition and hard work than in other social orders, even though possibilities in the social space are as dependent on relative conditions of existence there as anywhere else. Conversely, in many other nations of Europe there is greater readiness to acknowledge the role of wealth and inherited cultural capital in securing positions at the top of the social space. Affluent parents are particularly 


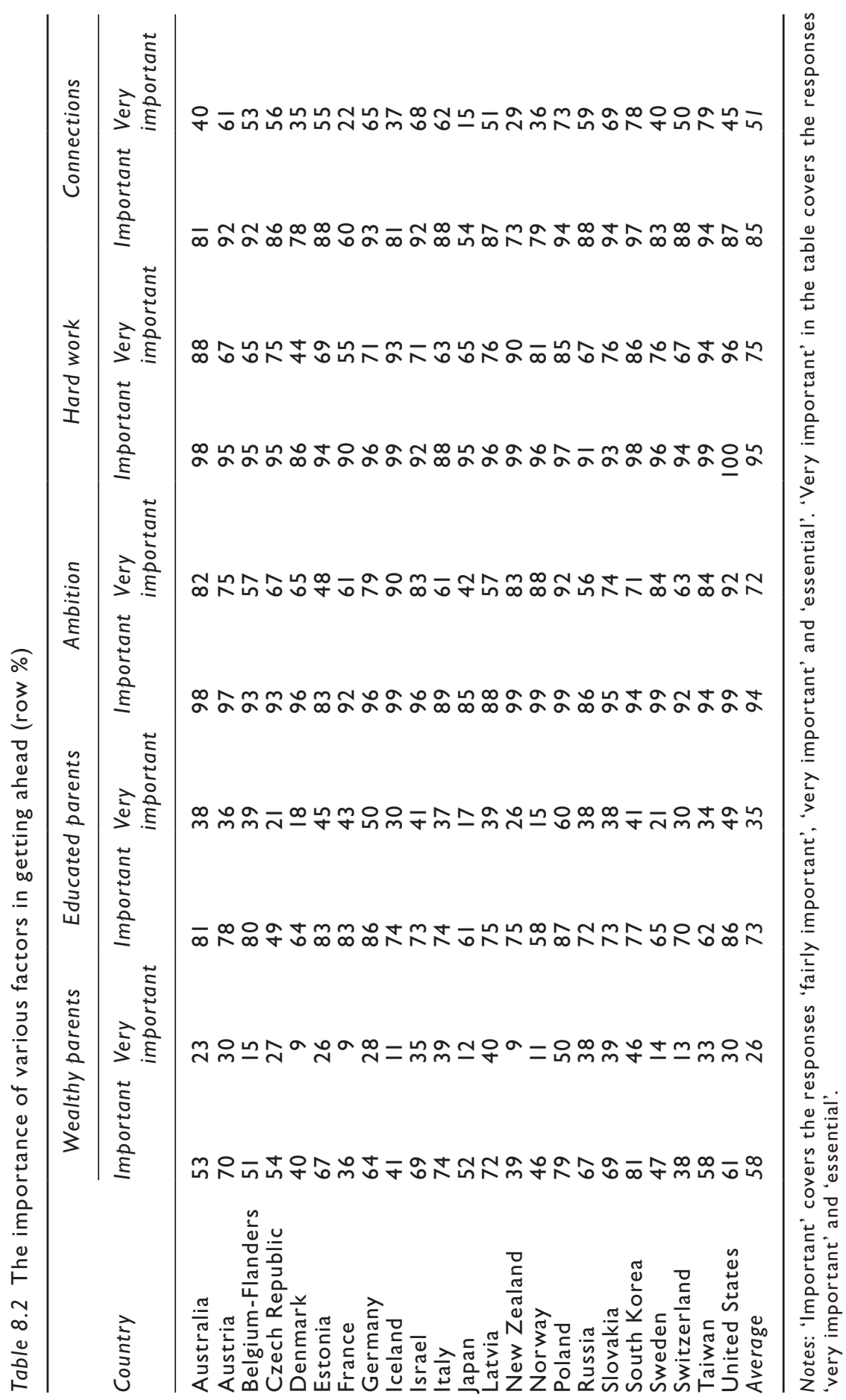


likely to be pinpointed as important in the post-socialist East (including Germany), where conversion of capital in the transforming social space may be patent; in Italy, where the economic crisis of the late 2000s hit hard and sowed discontent; in South Korea, where wealth is brazenly mobilised to secure educational advantages for offspring (Seth, 2002); as well as in Austria and Israel. Parental education is likely to be flagged as important in many of the same countries too, though respondents in the US and France are also relatively inclined to identify cultural patrimony as paramount. Connections, finally, are less widely seen as making a difference in Japan, France, Australia and the US, alongside the Nordic countries, but seem to be considered more important in Eastern Europe, where both communal and political networks were crucial under state socialism, and, especially, in Taiwan and South Korea, where the cultivation of interpersonal networks guanxi in Taiwan, kwankye in South Korea - assumes substantial cultural prominence (King, 1991; Yeung and Tung, 1996; Gold et al., 2002).

All this pales in comparison to the overriding tendency to see ambition and hard work as more important than indicators of capital. Yet even the pillars of meritocracy are viewed differently from country to country. Respondents in Japan and most of Europe, for instance, appear less convinced of the centrality of ambition than the Nordic countries, Taiwan, the US and, anomalously, Poland. Meanwhile, Americans, Australians and New Zealanders appear to be firm believers in the importance of hard work, dovetailing with the blunt liberalism of their political cultures and long-held self-perception as 'lands of opportunity' (Lipset and Bendix, 1959; Bloom and Jones, 1976; Bénabou and Tirole, 2006), in contrast to Japan and various parts of Europe, as do respondents in Taiwan and South Korea. Some might rather sweepingly (and famously) attribute the faith in hard work in these last two cases to the confluence of a purported Confucian work ethic and the spirit of capitalism in the latter part of the twentieth century (e.g. Hofstede and Bond, 1988), but in so doing they overlook the intermediating role of the state and its selective promotion of specific nationalist and Confucian principles of dedication and effort in service to the strategy, played out both at the national level and in the global space of states, of industrialisation and economic development (on South Korea, see Kim and Park, 2007). The particular place of education strategies in the system of intergenerational reproduction/accumulation strategies in these countries, already mentioned at several points, may also play into the sentiment.

What, then, of differences by position in social space? In fact, the immediately apparent tendency, on examination of correspondences, is the tight clustering of most modalities around the centre point of the aggregate models, both unrotated and rotated, suggesting that dispersion of views on what it takes to get ahead is typically relatively modest (Figure 8.2, Tables 8.3 and 8.4). This is especially so in relation to Axis 2, where differences 


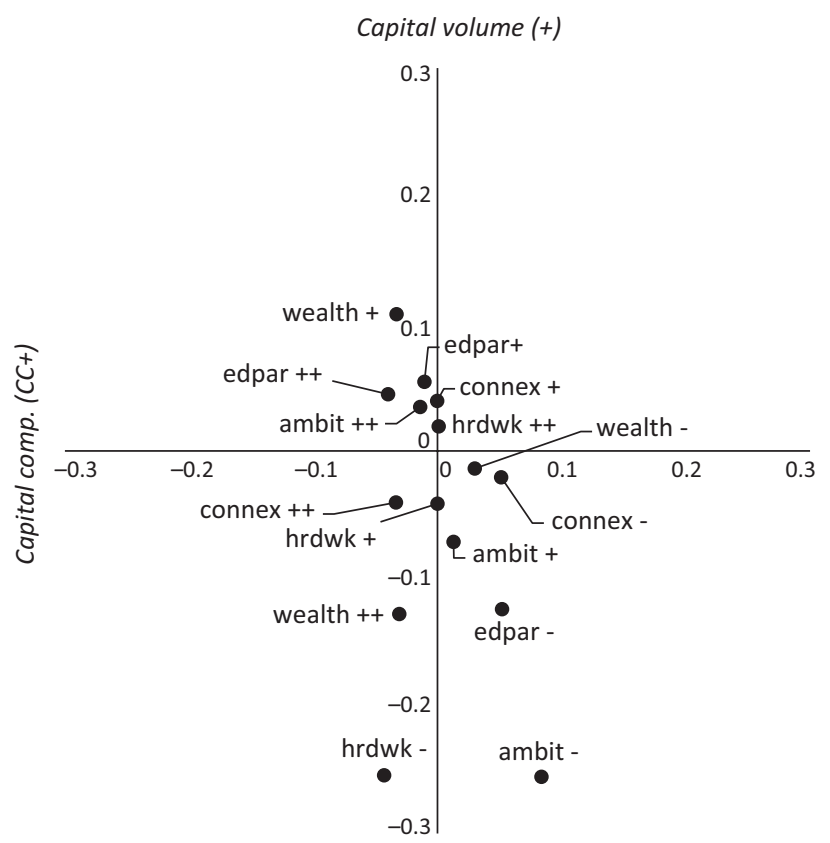

Figure 8.2 Perceptions of what it takes to 'get ahead' in the social space (aggregate model).

Note: Based on average rotated coordinates.

between modalities (especially regarding hard work) regularly fail to register statistical significance. The major deviations from the central crowd of categories are the indicators of divergence from the widespread belief in meritocracy - the responses, that is, that ambition and/or hard work are not particularly important for 'getting ahead', and to a lesser extent (in terms of average coordinate) that having wealthy parents, and sometimes connections, is very important. These are mostly associated with the negative pole of Axis 1 and, once rotated, with lower capital volume. Yet it has to be remembered that rejection of the efficacy of ambition and hard work is a minority view - typically characterising no more than 5 percent of the samples and that, therefore, while those who do reject them may well tend to be in the dominated class, rejecting them is not a prevailing tendency within the dominated class (in many cases, on this basis, the differences in opinion are not statistically significant). We have no way of knowing, moreover, whether this rejection of ambition and/or hard work takes the form of an active challenge to the very principle of meritocracy or a more individualised, fatalistic resignation. Given the typical distance of the dominated from the field 


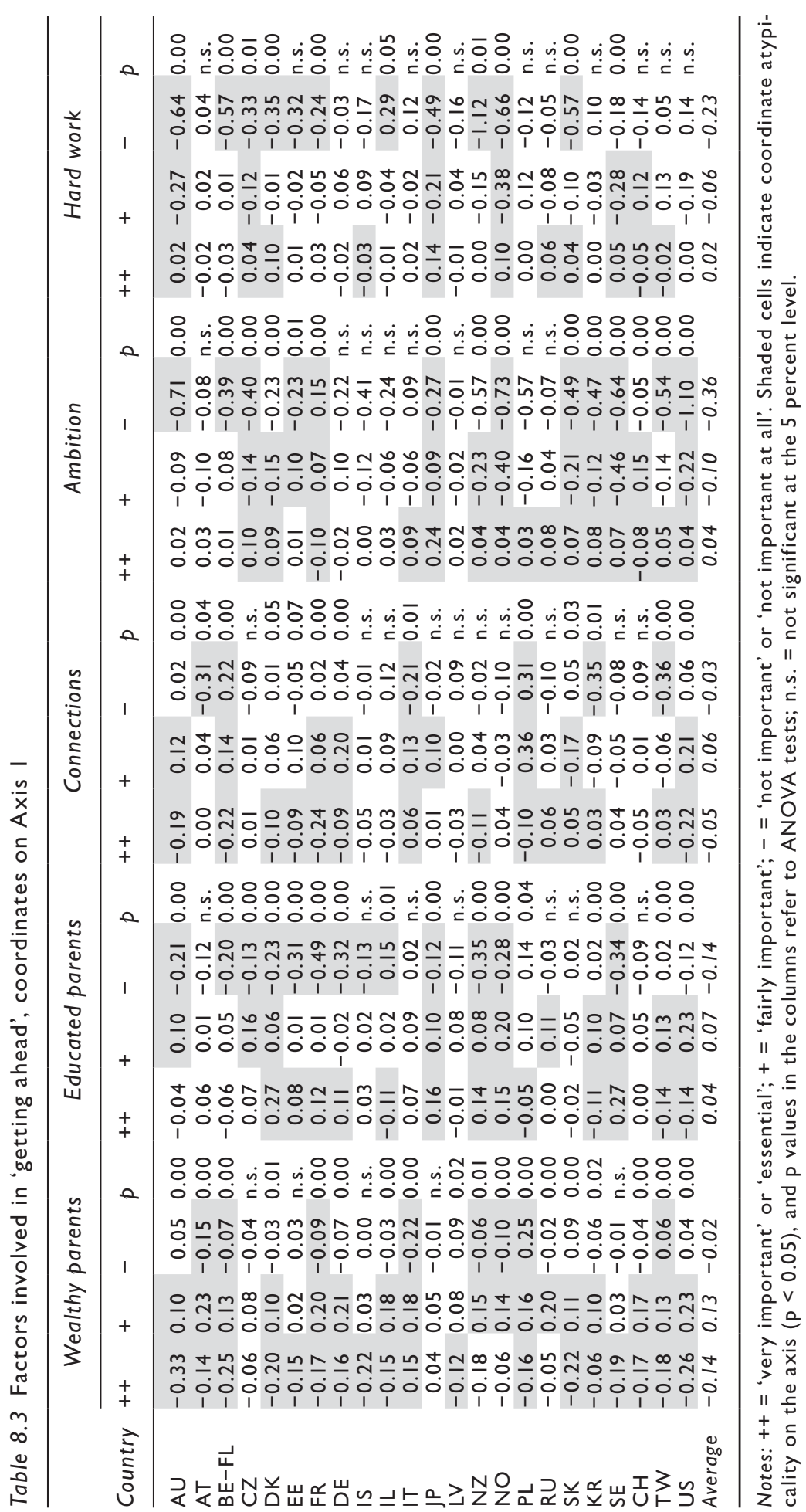




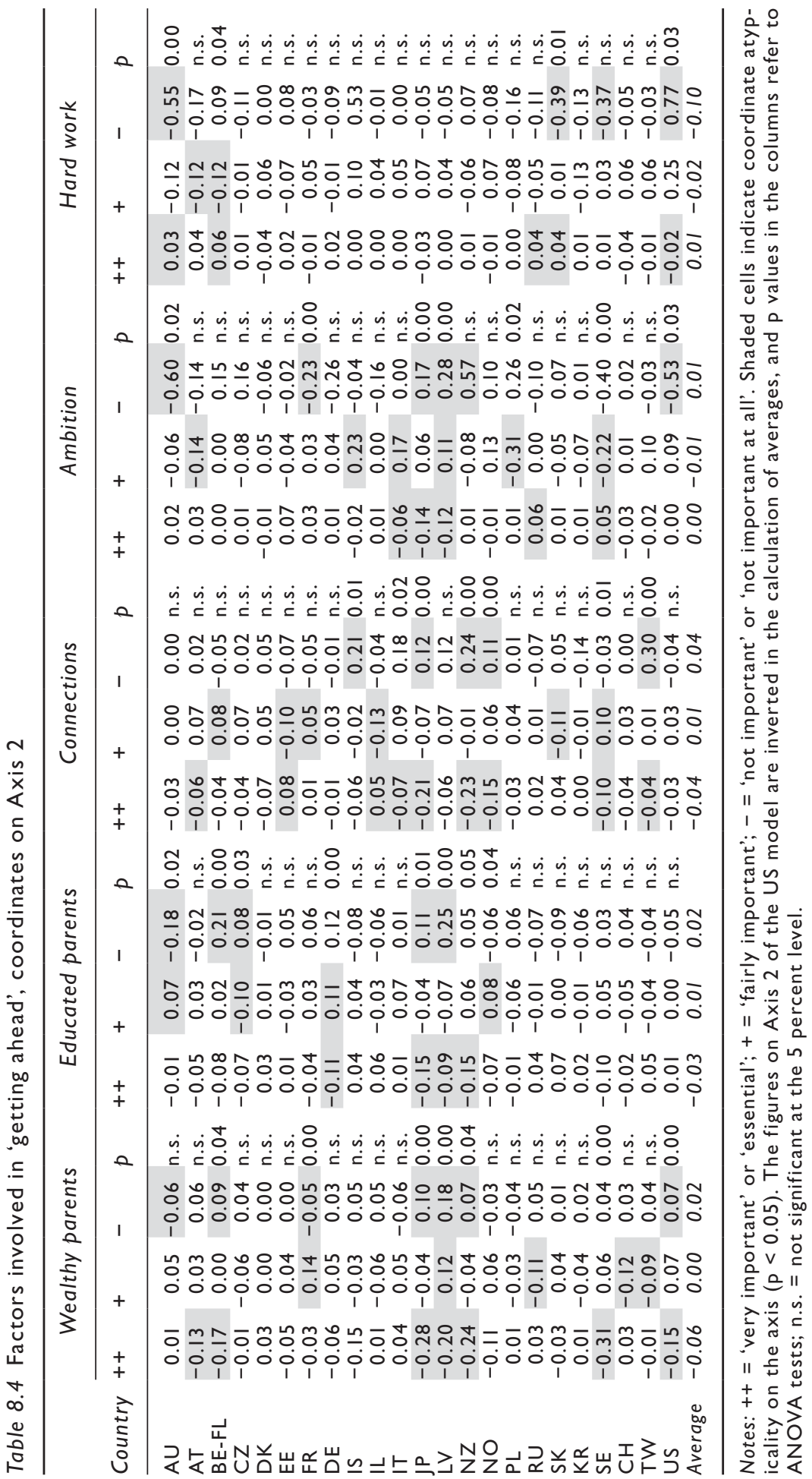


of power, and the symbolic power and access to platforms it delivers, and their frequent disaffiliation with institutionalised politics, it seems highly unlikely that these discontented few are enough to lift the belief in ambition and hard work from the level of generalised doxa, where it might otherwise be said to dwell, to the realm of open, public contestation.

Additionally, it would appear that a lower position in the social space is typically (and in over half the cases significantly) associated with the belief that having educated parents does not matter for 'getting ahead' - a minority view, for sure, but much more prevalent than lack of belief in ambition and hard work. ${ }^{8}$ While some of those perceiving themselves to be at or near the bottom of the social order acknowledge the importance of the transmission of economic capital, then, the importance of the transmission of cultural capital - a subtler, more obscure process operating through the slow inculcation of dispositions in the long course of private family life - is frequently rejected. Perhaps this is based on a sincere view, anchored in an individualised vision of parental expectations and desires, that even lesser-educated mothers and fathers can provide solid foundations for 'getting ahead' so long as they are 'loving' and 'encouraging'. Or perhaps, following the slope of perceived positions in the typical capitalist social space, it flows from a specific vision of 'getting ahead' as securing a sky-high income or profits rather than, say, scholastic achievement (which, given the expansion of higher education and low-pay graduate jobs, may seem like less of a secure entry ticket to the top tier). One mode of reproduction, possibly associated with a small, wealthy elite overtly passing on economic inheritance or investing in opportunities for their children, is thus decried while another, much more prominent and pervasive in contemporary capitalist social orders, including for the reproduction of political and economic leaders, is denied. The upshot of this, of course, is that while the probability is greater that the dominated in these cases perceive their lowly self-rated location as the product, in part, of a misfortune not to have been born into wealth, the lack of cultural capital that contributes to defining their structural location (especially as proxied by Axis 1) is likely - how else could it be framed? - to be misperceived as the product of their own inabilities and lack of interest or, equally misdirected, those of their mothers and fathers ('I blame the/my parents'). 9

\section{A sense of injustice}

That transmission and investment of economic capital is indeed frequently decried, or 'denounced' to use Boltanski's language, is confirmed in responses to a question in the survey on whether it is just or unjust that 'people with higher incomes can buy better education for their children than people with lower incomes'. Measured on a five-point scale ranging from 'very just, definitely right' to 'very unjust, definitely wrong' (with a middling 
category for 'neither' or 'mixed feelings'), the query is open to some interpretation, specifically in relation to what counts as 'better' education, though it is highly likely that respondents will assume it refers to private schooling rather than, say, extra tuition or subsidising university studies. In any case, it quickly transpires that most people across the majority of the samples do, in fact, consider such capital conversion unjust or very unjust and that those who consider it very just are a clear minority (Table 8.5). There are differences between countries, however. In a selection of European samples (e.g. Flanders, France, Germany, Iceland) the well-remunerated ploughing economic capital into a child's education is more likely to be condemned as wrong, whereas in the East Asian nations, where investment in education has been a prominent family strategy, as well as in Australia, Israel, New Zealand and the US, i.e. social orders characterised by a pronounced liberal orthodoxy on economic matters, denizens would appear to be rather more accepting of the financially flush paying for 'better' education.

Table 8.5 The distribution of responses to the rich paying for better education (row \%)

\begin{tabular}{|c|c|c|c|c|c|c|}
\hline Country & Very just & Just & Mixed & Unjust & $\begin{array}{l}\text { Very } \\
\text { unjust }\end{array}$ & Total \\
\hline Australia & 9 & 18 & 19 & 26 & 28 & 100 \\
\hline Austria & 3 & 10 & 20 & 35 & 32 & 100 \\
\hline $\begin{array}{l}\text { Belgium- } \\
\text { Flanders }\end{array}$ & 2 & 4 & 17 & 35 & 42 & 100 \\
\hline $\begin{array}{l}\text { Czech } \\
\text { Republic }\end{array}$ & 8 & 15 & 19 & 29 & 29 & 100 \\
\hline Denmark & 3 & 10 & 19 & 24 & 44 & 100 \\
\hline Estonia & 8 & 18 & 19 & 28 & 28 & 101 \\
\hline France & 3 & 4 & 16 & 32 & 45 & 100 \\
\hline Germany & 2 & 8 & 15 & 42 & 33 & 100 \\
\hline Iceland & 1 & 8 & 12 & 31 & 48 & 100 \\
\hline Israel & 10 & 22 & 19 & 22 & 27 & 100 \\
\hline Italy & 6 & 9 & 12 & 23 & 51 & 101 \\
\hline Japan & 13 & 23 & 23 & 16 & 26 & 101 \\
\hline Latvia & 2 & 9 & 17 & 29 & 43 & 100 \\
\hline New Zealand & II & 26 & 27 & 24 & 12 & 100 \\
\hline Norway & 3 & 14 & 22 & 26 & 35 & 100 \\
\hline Poland & 3 & 15 & 20 & 40 & 23 & 101 \\
\hline Russia & 7 & 13 & 21 & 25 & 34 & 100 \\
\hline Slovakia & 3 & 9 & 24 & 31 & 33 & 100 \\
\hline South Korea & 9 & 24 & 26 & 26 & 15 & 100 \\
\hline Sweden & 4 & 9 & 18 & 27 & 42 & 100 \\
\hline Switzerland & 2 & 10 & 21 & 43 & 24 & 100 \\
\hline Taiwan & 12 & 51 & 12 & 18 & 7 & 100 \\
\hline United States & 13 & 25 & 20 & 25 & 18 & 101 \\
\hline Average & 6 & 15 & 19 & 28 & 31 & 99 \\
\hline
\end{tabular}

Note: Row totals do not always equal 100 due to rounding. 
There are also differences by social position, even if the ubiquity of denunciation means polarisation of opinion by class position tends to be modest. On aggregate, those who consider paying for 'better' education to be somewhat just stand opposed to those describing it as very unjust along both Axis 1 and, to a lesser extent, Axis 2, with those possessing greater quantities of the capital each dimension distinguishes being more likely to see it as just (Figure 8.3). This translates into a moderate correspondence with capital volume once the spaces are rotated, with only the slightest clockwise tilt, that is to say, a subtle tendency for the just/unjust opposition to map onto high/low economic capital relative to cultural capital. Mixed feelings, meanwhile, are close to the view that paying for better education is just, suggesting ambivalence or (possibly strategic) noncommitment among some of those richer in capital, while the common response that economic investment in schooling is somewhat unjust and the rare opinion that it is very just sit almost right in the middle of the collective space.

Examination of the individual coordinates constituting the aggregate picture more or less confirms the correspondence of the just/unjust polarity with high/low capital on Axis 1, since the commonest opposition, particularly in terms of atypical positionings, is between seeing it as just (sometimes very unjust), which is associated with higher capital, and seeing it as very unjust (and occasionally merely somewhat unjust), which is linked to lower capital (Table 8.6). The distance between the key modalities, and

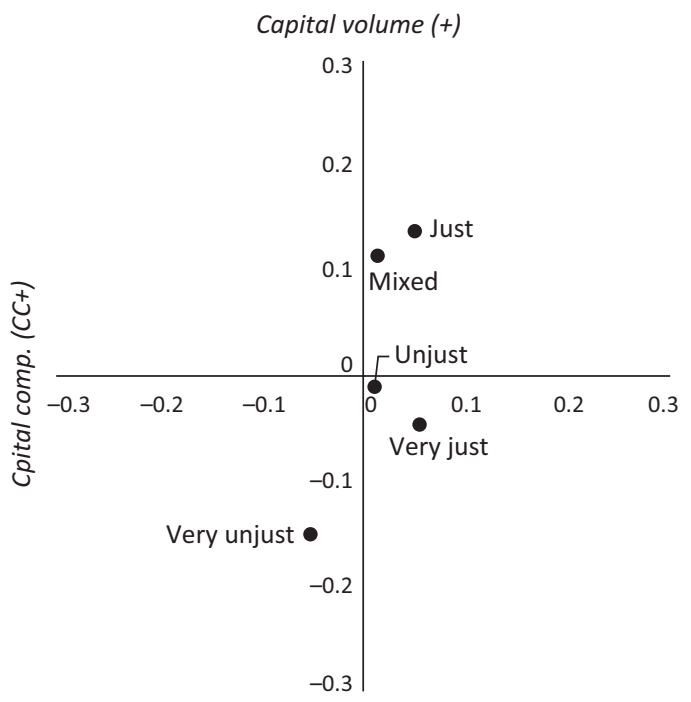

Figure 8.3 Is the rich paying for education just or unjust? (aggregate model). Note: Based on average rotated coordinates. 


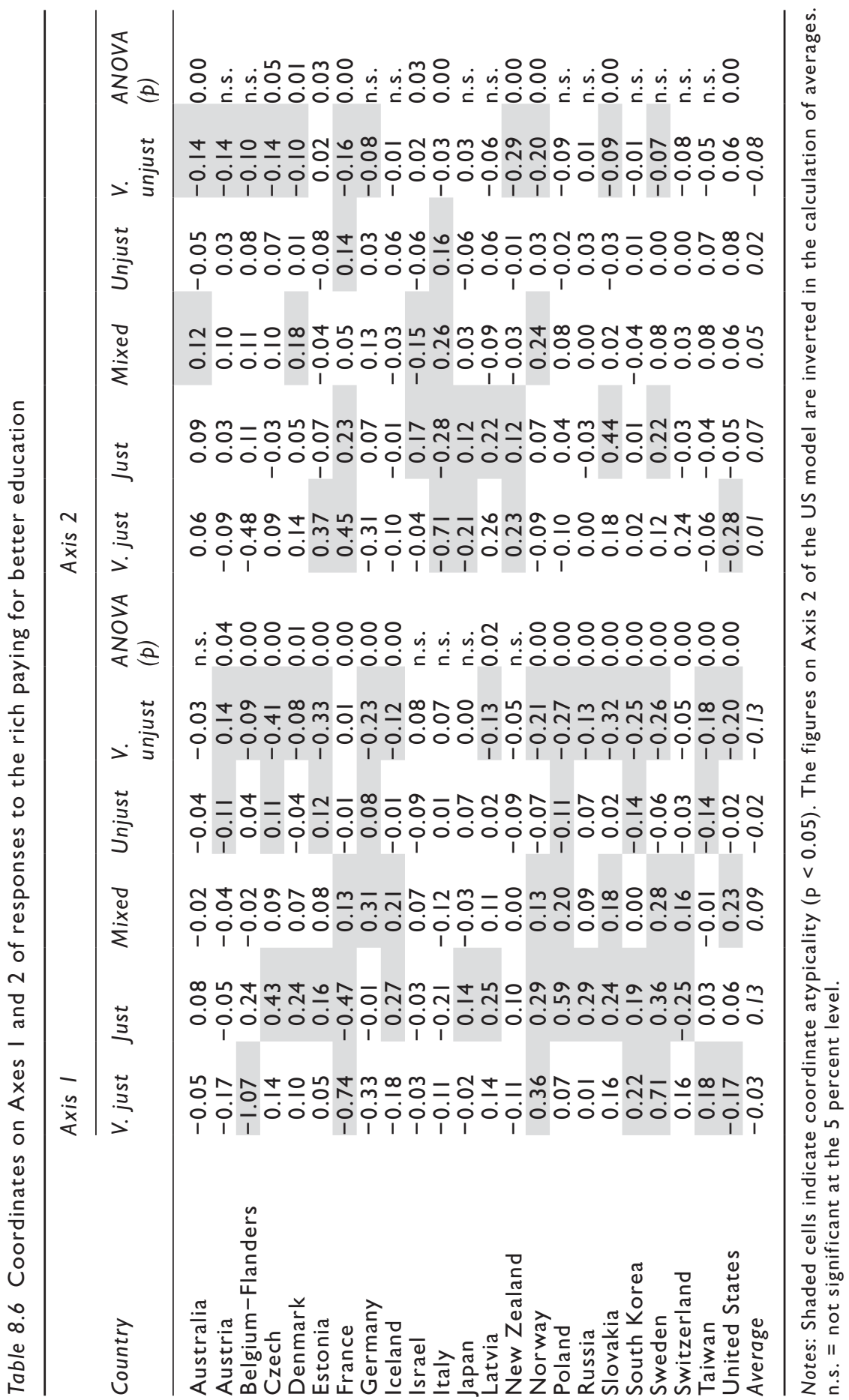


thus the polarisation of opinion, appears to be greatest in several Eastern European and Nordic countries, as well as South Korea and Taiwan. There are, however, deviations: in Australia, Israel, Italy and New Zealand - three social orders characterised by a powerful liberal orthodoxy and one (Italy) by widespread condemnation of capital conversion - no modality has an atypical location on the premier dimension, and analyses of variance suggest differences between positions are effectively null. There are, moreover, some instances where the pattern is wholly or partially reversed, especially Austria, Flanders, France, Italy and Switzerland. Indeed, the considerable variability of the rare 'very just' category on the axis, which is less likely to be significantly atypical because of its diminutive size, is doubtless the reason why it occupies a central location in the aggregate space. In the German and US models, furthermore, the major opposition on Axis 1 would appear to be between ambivalence or noncommitment among those richer in capital and more extreme views - seeing capital investment as very just and very unjust - among those lower in capital.

Differences on Axis 2 are, without a doubt, generally weaker than on Axis 1 , but it is common, nevertheless, for the view that capital investment is very unjust to be associated with lower wealth and the belief that it is just or very just to be related to higher wealth. It also emerges that in some cases - namely France and the US - where seeing it as very just scored a negative coordinate on Axis 1 it has an atypically positive association with higher wealth, placing the modality in the lower-right zone of the space. In other words, the view that investing accumulated economic capital in the schooling of one's children is right and proper corresponds with those who are economically rich but not necessarily well endowed with cultural capital (especially inherited cultural capital) or income, as if in defence of a strategy of intergenerational social reproduction only opened up by a lifetime of labour ('giving them the opportunities I never had'), and in both cases sits opposite the contrasting conviction that such a strategy is very unjust. The seemingly anomalous case of Italy, furthermore, is placed in new perspective once the coordinates are rotated in the space, correcting for the model's extreme tilt, to proxy capital volume and capital composition: now the view that capital conversion is very just scores a coordinate of -0.64 on the volume axis but a coordinate of 0.31 on the composition axis, and the 'just' category registers equivalent respective coordinates of -0.26 and 0.12 , placing them among that same south easterly region of the space and at remove from mixed feelings $(0.24,-0.12)$ as well as a sense of it being unjust $(0.14,-0.07)$ or, at the heart of the space, very unjust $(-0.03,0.01)$.

\section{Conclusion}

There is, as Bourdieu (1996a) put it, a concordance of social structures and mental structures, or objective divisions and subjective (di)visions, inasmuch as people have a keen sense of their place within the social space. Greater or 
lesser possession of the specific properties defining the misrecognition order of capitalist societies - money, education certificates, etc. - generates a perception of one's standing, or 'rank', relative to others. Few people are likely to mobilise ten-point scales in everyday life, when describing or articulating their practical experience of difference and domination to others, but the fact that there is a clear and consistent correspondence between social position and perceived position across nations suggests people are, nevertheless, all too aware of their location in the whole when asked and - since that location is defined by properties denoting 'success' and legitimacy within society - their esteem and symbolic power relative to others. And let there be no mistake, while the primacy of money in capitalist social orders frequently introduces some modulation by capital composition and trajectory, setting fractions of the dominant class against one another, and while people often resist placing themselves 'too low' or 'too high' when faced with a probing survey interviewer, it is those with most who perceive themselves at or near the top, with all the comforting feelings of self-validation, of having 'done well' in life and of being 'somebody' that is likely to generate (whatever else ails them), and it is those with less capital, by virtue of the cards (or capitals) they were dealt at birth and all the closed doors and decreased likelihoods that brought with it, who see themselves at the bottom. They had and have fewer opportunities, or worse 'life chances', no doubt, with consequences for their housing, their physical and mental health, their children's lives and more, but they also suffer the symbolic violence of seeing and believing themselves to be the lowest, the unsuccessful, the unremarkable, at least in relation to the core capitals defining the misrecognition order, with all the possibilities for shame, embarrassment and worthlessness that can, as others have amply demonstrated, bring.

Yet do those divested of capital, across capitalist nations, perceive their place as a product of their own failings or are they ready to denounce the system of allocating people to places as unjust? Do they misrecognise social elevation as a product of merit, breathing in 'like air' the doxa that 'getting ahead', or up, simply depends on daring vision and determination (Bourdieu and Eagleton, 1992: 115), or do they grasp and condemn the structural principles of social reproduction? The answer may be not one or the other, but both. Where the efficacy of ambition and hard work, the cornerstones of merit, is questioned or rejected, it is usually those with less capital who are more likely to be doing the questioning and rejecting. Where the role of wealthy parents and connections are flagged as essential, it is frequently those with less capital who are more likely to do so. And there is widespread condemnation of the economically rich investing their money in educational advantage for their children, with those lacking economic capital typically being the most censorious. There is, in short, some doubt about the principles of meritocracy and criticism of the advantages of the wealthy amongst the dominated.

Given the relatively egalitarian ethos of the dominated seen in the last chapter, especially among those possessing less economic capital, a critical 
disposition toward the rich perhaps comes as no surprise. It is, one might assume, a legacy of the traditional 'class politics' of the twentieth century, wherein socialist parties and trade unions claiming to speak for the dominated under one label or another across a number of nations, operating with economistic visions of domination and struggle, painted the wealthy as antagonists. Though that discourse or party line may have diluted or dissipated in the wake of deindustrialisation and the rightwards drift of social democratic parties across so many social orders from the 1980s onwards, it still resonates, however dimly, in the schemes of perception and evaluation of at least some of those populating the broad areas of the social space it once corresponded with. Some may continue to hopefully, or reluctantly, align their critical view with nominally leftist parties; many others, as we know, find no party caters sufficiently to their specific ethos any longer; yet others turn to nationalist far-right parties blaming their lowly position, and any blocks on ambition or effort, on ethno-racial/national 'others' (via 'stealing' jobs or school places, for example) and whose vague and partial populist construction of a 'liberal elite' might just capture and rearticulate any anti-wealth or anti-rich sentiment.

The timing of the ISSP module must also be borne in mind. Being delivered in 2009, in the wake of the economic crisis that shook the world at the dawn of the millennium and during the turbulent period that would eventually breed the global Occupy movement, the popular notion of 'the 99 percent' and the rapid rise of far-left populist parties or figures across Europe, perhaps the survey reflects, at least in some cases, the greater questioning of the practices of the economically rich in worldwide public discourse at the time - the upswell of critical heterodoxy challenging the neoliberal backcloth of the last decade or so that was, in the end, fated to last only a brief moment, leaving only the faintest contemporary legacy, before populist nationalism reared its head and usurped its place.

All this being said, however, the capacity for critique must not be exaggerated. Scepticism regarding ambition and/or hard work, for example, is plainly the disposition of a minority no matter the country, and sometimes an almost infinitesimal one. People across contemporary capitalist social spaces, including the dominated, are much more likely to accept that supposedly free-willed aspiration and endeavour are not only important but crucial to determining who gets ahead and who does not - so likely, in fact, that belief in the power of 'get-up-and-go' can be confidently described as doxic in many cases and, given their sense of place, this can only mean the dominated assume they did not 'get ahead' because they lacked this magical property. In this sense, then, Bourdieu was surely right. Added to this is the observed tendency in many samples, especially across Western Europe, for lower capital to be associated with denial of the efficacy of parental cultural capital and all the strategies and investment it incites. Whatever the reason for that denial, it suggests that while there may indeed be some denunciation of a small, 
wealthy elite (the 'one percent', perhaps) paying for their children to attend exclusive schools leading toward the top slice of the field of power, finding few outlets in organised politics, the much more pervasive phenomenon of differential success within the mainstream education system, and entry into other sections of the field of power it can open up, is misrecognised as of little consequence, despite the extensive symbolic power at stake, or as a matter of merit rather than, as research consistently shows, the transmission, through the most mundane of everyday activities, of unequally distributed resources.

\section{Notes}

1 There are a number of questions about income, for instance. However, the immediately preceding question, interested in perceptions of conflict between social groups, explicitly distinguished 'poor people and rich people', 'working class and middle class' and 'management and workers' from 'people at the top of society and people at the bottom' as ways of carving up the world. The implication, perhaps inferred by respondents, is that these are not all quite the same the top and the bottom are not quite equivalent with economically rich and poor - and the last principle of division is much more open to the respondent's interpretation. Respondents were also asked, shortly before, what they thought it takes to 'get ahead' (i.e. to the top of society) - money, education, connections, etc. - further opening up the possibility for a multidimensional perception of hierarchy (see later). Moreover, the target question was part of a sequence asking respondents to compare their occupational 'status level' - which might implicate notions of 'prestige' (i.e. associated symbolic capital) - with their father's. All this is hopefully enough to minimise the kind of survey bias that bedevilled Marshall et al.'s (1988) analysis of class identity (see Savage, 2000: 35).

2 The underrepresentation of extremity categories in the scale has been noted before (Evans and Kelly, 2004), and perhaps reflects a widespread inclination to present oneself as 'ordinary' in a bid to maintain self-worth (Savage, 2000), but of course the differing propensity by social position to select middling categories to that end is in question.

3 This is enough to problematise regression analyses of self-perception which find a relationship with both education and income (e.g. Evans and Kelly, 2004; Lindemann and Saar, 2014): without examining the homology between social structures and mental structures spatially, the contrasting principles of the same self-placement (only combined for those with balanced capital stocks) are obscured.

4 It is not always the uppermost category $(8,9,10)$ that is furthest toward the economic pole. Sometimes, as in the models for Estonia, Israel, South Korea and Sweden, the penultimate category (seven) is furthest along the axis while the top category, still highest on the volume axis, is pulled back toward the middle of the composition axis as if to signal the higher self-worth of those who can match ample economic capital with ample cultural capital.

5 There are few anomalous correspondences across the rotated spaces, breaking from the broad pattern, and the ones that do seem divergent are not without explanation or caution, whether a particularly low-n (and non-significant) category (e.g. Italy) or an effect of category aggregation (in the Swiss space, for example, the very top category falls on the right but the others with which it is combined pull it to the left). 
6 There is a compounding effect of trajectory in 10 of the 12 models where Axis 3 distinguishes the upwardly and downwardly mobile (Australia and Flanders are the exceptions): social ascent is significantly associated with higher selfplacement categories, as if to signal a sense of having 'made it', and descent with lower (and usually the lowest) categories, suggesting a keen intuition of having fallen in the social space.

7 Since the question is about parents being 'educated' rather than 'intelligent', it arguably puts specific emphasis on their experience of education rather than any notion of genetically inherited 'talent'.

8 That three post-socialist samples (Poland, Russia and Slovakia) diverge from the general tendency may indicate the relative transparency of capital conversion and capital transmission strategies in the transition to capitalism. Likewise, that South Korea and Taiwan are among the clutch of spaces missing this relationship might be attributable to their rapid development and intense educational competition. In these two cases, in fact, it is the efficacy of social capital, generally acknowledged to be so important, that is disproportionately denied by the dominated instead (this is also true of Austria and Italy, however, precluding any reduction to cultural specificity).

9 Some additional insight is provided in four cases - Austria, Germany, Iceland and the Czech Republic - where a question on whether respondents 'performed to the best of my ability' at school was included in the survey. In all samples the majority (between two thirds and four fifths) agreed they had, and the differences in agreement rate between the top, middle and bottom 'classes' on Axis 1, as defined in Chapter 3, were minimal: 1 percentage point in Austria, 3 percentage points in Germany, 4 percentage points in Iceland and 9 percentage points in the Czech Republic. Crucial here is the perception of 'my ability': if those in the bottom category left the education system with fewer qualifications it was, in their minds, because their 'ability', as well as interest (both products of particular social conditions, lest we forget), was simply not the same as that of those leaving the education system much later. 


\section{Chapter 9}

\section{Conclusion}

'The measured object', wrote Bachelard (2002: 213), 'is little more than a particular degree of approximation in the method of measurement. Scientists believe in the realism of the method rather than in the reality of the object', which is so much to say that when we talk of a 'social space' we can never know it beyond the particular output and synoptic descriptions of inquiry, that these outputs and synopses can be more or less adequate to the task and that we must, therefore, be sensitive to our instruments of investigation. To that end we start with the caveats. The two-dozen models of social spaces constructed here using geometric methods of data analysis, and underpinning all else, are neither definitive nor exhaustive. With an eye on the cross-national picture rather than intra-national detail they have been assembled under broad constraints of comparability, yet the modalities and variables could not be precisely the same from nation to nation due to sample and variable specificities. Indeed, the very fact that we have, of necessity, harnessed secondary data means we have been dealing with pre-constructed variables, that is to say, measures designed by someone else with a different conception of what matters. Not only have we had to tolerate pre-existing cut points and categories, therefore, but we have lacked gauges which might otherwise have yielded a more nuanced insight into the distribution of capitals, such as parental education level or subject studied at university. Sample sizes, moreover, were often modest, even if they were weighted to generate representative selections from the populaces. The models are thus tentative, doubtless amenable to refinement and, lest we forget, just that: models. They are not direct reflections of reality, mirrors of what exists, but only hoped to be 'well-ordered approximations' of the kind Bachelard (2002: 69) held constitute the constructions of the object all scientists trade in.

What conclusions, then, do these approximations allow us to reasonably draw? First, the class structure can indeed, contrary to the traditional preference for singular socio-economic scales or unidimensional hierarchies, the 'destroyers of structures' in Bourdieu's (1984: 125) terms, be rendered as a multidimensional space in a wide variety of capitalist nations and, second, these spaces are characterised by a remarkable degree of congruence 
in their core axes of differentiation. The primary axis typically discloses a close correlation between not only education and income but also, as a sure sign of the prominence of social reproduction in contemporary social orders, between those factors and indicators of social origins, particularly inherited cultural capital. The secondary axis, meanwhile, distinguishes the wealthy and the non-wealthy, the latter also tending to be cultural inheritors. True, this twin polarisation does not directly replicate the conceptual model of the social space laid out by Bourdieu in Distinction, but it only takes cocking one's head slightly, like a curious dog, to see the vectors for capital volume and capital composition clear as day and a little geometry to model them satisfactorily. Furthermore, wealth and inherited cultural capital are much more important to defining the capital composition principle than income and education levels alone, but that only suggests that acquired cultural capital on its own is perhaps nowadays - in light of expanding education systems and mutating reproduction strategies - a less powerful measure for tapping into lateral oppositions within the social space than it may once have been.

The balance of inertia between the axes was not everywhere the same: in some spaces the secondary axis was weaker compared to the premier dimension than in others. That this variation is irreducible to quirks of the analyses was suggested by its correlation with a number of structural characteristics of the social orders analysed. In a nutshell, the smaller the proportion of people working in services and professional-managerial roles and, allied to that, the greater the degree of educational exclusivity, the more differentiating become acquired and inherited cultural capital relative to wealth. Hence - perhaps confirming but going beyond Brousse's (2017) assessment and situating previous Danish, Norwegian and British studies in context - the opposition between Nordic countries and recently industrialised capitalist social orders like those of Eastern Europe or Taiwan.

It cannot be ruled out that there are other nation-specific properties not captured by the ISSP indicators that would bring out secondary principles of opposition more fully in Eastern Europe or Taiwan - specifications of this or that capital, for example, or other bases of misrecognition altogether (on Poland, for example, cf. Zarycki, 2009). On the other hand, it may well be that these cases illuminate something of the recent history of social spaces, viz. that in earlier phases of capitalism - before the post-industrial turn, before the neoliberal obsession with fostering 'human capital', before the advent of consumer society - the typical social space may indeed have been closer to being unidimensional, with only divisions in the field of power between spiritual and temporal powers cross-cutting volume of capital (cf. Rosenlund, 2009: 208ff; 2015). By Distinction's day, the fissure between economic and cultural capital had seemingly enlarged and filtered down into the intermediate class in France, but not so much the dominated class, and today might be said to remain unevenly spread from nation to 
nation depending on the state of the struggle within fields of power, where management of economic and cultural capital is at stake.

This brings us to the third observation: congruence in the core dimensions of differentiation across capitalist social spaces is matched by congruence in their relationship with the occupational division of labour and, more specifically, the division of labour of domination. Professionals and managers constitute the dominant class, routine workers of varying skill level and industry comprise the dominated and socio-medical workers, technical workers and clerical workers - though they tend to be more variable in their location - make up the intermediate zone. Orthogonal to this vertical polarisation, however, is the separation of class fractions by capital composition, with employers, business executives and skilled workers typically arrayed on the economic flank and standing opposed to intellectuals and socio-medical workers on the cultural wing. When digging deeper into the categories in and around the field of power, moreover, the horizontal division at the top of the social space, polarising the two prime fonts of worth in capitalist societies, becomes more clearly, in most cases, defined at the extreme points by employers and managers on one side and cultural producers on the other - the masters of the economic field, that is, and the players of the field of cultural production, today's embodiments of the ancient division between powers temporal and powers spiritual, or bellatores and oratores.

The occupational division of labour is profoundly and consistently gendered in a manner that mirrors the division of familial labour. The differences between men and women in the actual spaces, however, were found to be modest, largely because of the homogenising effect of household formation on capital holdings, though in the process of demonstrating this effect the cross-national tendency for class-based homogamy presented itself with resolution. Two other factors, on the other hand, evinced a more pronounced and telling relationship with the social spaces. The first of these was religious belief, or, more precisely, lack of religious belief since this particular characteristic, and the broad scheme of perception it denotes, corresponded with higher holdings of cultural capital - close, ironically, to the seat of today's equivalent of powers 'spiritual'. Even more pronounced was the division between urban residence, which once again tended to gravitate toward higher cultural capital, and rural life, which fell toward the bottom of the space and further toward the economic pole.

The structure of (non)belief and the homology with geographical space both pointed toward the opposition between the old and the new, the 'traditional' (faith, countryside) and the 'modern' (secular, urban), and its entwinement with the social space and, above all, the capital composition dimension. Examining the patterning across the spaces of generations, or age groups at any rate, confirmed this entanglement: notwithstanding the special case of Eastern Europe, where the transition to a market economy appears to have forged a closer connection between (some) younger 
people and economic capital, the cultural/economic polarity dovetails with the youth/older opposition, as personal wealth increases with age yet the probability of boasting acquired or inherited cultural capital decreases. Temporality cannot, therefore, be readily filtered out of the secondary principle of differentiation, as neat as that would be, but is instead inextricably interwoven with the battle between cultural capital and economic capital, as Bourdieu (1993b) insinuated, no doubt due to the rapid and relentless growth of education systems across the richer nations of the world in the latter part of the twentieth century and beyond.

This interrelation of age and class is enough to caution against misinterpreting generational struggles as merely a question of biological age; the battles between the old and the young are, in reality, battles between two capital profiles and two trajectories - one typically higher educated, with higher educated parents, living in the cities, turning away from ancient beliefs and with the most part of their future ahead of them; the other less educated, less likely to be from professional-managerial stock, but having steadily acquired a degree of personal wealth over a lifetime that now lies largely behind them. Of course many younger people do not acquire higher education, or hail from advantaged social origins, or lack in economic capital, or display the associated lifestyle, and many older people do, but the polarisation was sufficient to effectively cleave the occupational division of labour into two parallel systems - a stark reminder that occupational titles are only ever labels for greater or lesser areas of dispersion and struggle within the social space.

Breaks from the modal pathway were, nevertheless, common enough to define the tertiary axes of many of the spaces - confirming, in a fashion, Bourdieu's assertion that the third dimension of class is trajectory and undercutting crude claims that social mobility is somehow incompatible with his framework. On the one hand there were those (typically younger) people who, despite not hailing from advantaged social origins, had managed to acquire higher levels of education and/or income, and, on the other hand, there were those (typically older) people who, despite having hailed from more advantaged social origins, now found themselves consigned to the dominated class - a corollary, it would seem, of the transformation of opportunity structures, or the distribution of lusiones, over the course of the twentieth century. Then again, such movement in the social space was not sufficiently widespread in many other spaces to overpower an alternative opposition on the third axis: that between younger people whose mothers worked when they were teenagers and older people whose mothers did not work - an opposition primarily amongst those originating from higher sections of the social space and intimating, instead, feminisation of workforces over the last 60 years or so.

As for the possible effects of social positions, and the conditions of existence they designate, on dispositions and position-takings, the focus was 
on political stances. It transpired that, though there is some cross-national variation - with East Asia, Israel and post-socialist nations being the most divergent - the two most pronounced and constant correspondences between the social space and the space of political parties were, on the one hand, that between the economically rich and right-wing parties and, on the other hand, that between a lower position in the space and a lack of affiliation with any party. The social democratic left frequently occupied a more central position, reflecting its effort across many countries to secure a broad appeal - a long-time necessity for electoral success, according to Przeworski and Sprague (1986), but taking the form in recent years of a shift towards neoliberal principles and socially liberal values. The far-left, moreover, was a modest presence and, where it did vie more effectively for support, seemed to appeal to those with a modicum of cultural capital. Digging a little deeper into the orientations that may undergird party alignment, limited as we were by the data, it was discovered that position-takings on classic issues of 'class politics' are certainly, in most cases, differentiated by capital volume the dominated are still more likely to exhibit an egalitarian ethos, making the failure of the centre- and far-left parties to connect with them all the more revealing - and, in many cases (particularly the Nordic social orders), by capital composition too, especially regarding the issue of social welfare.

Finally, traversing the territory of class sense and symbolic violence, we discovered that the perception of one's place in the world is, unsurprisingly, closely connected to capital volume, but is also, in most cases, modulated by capital composition and all that goes with it: the economically rich are more likely to see themselves as having 'made it' than the culturally rich and/or the most economically deprived are most likely to place themselves at the bottom of society - testament to the power of economic capital in contemporary capitalist societies to define worth and its dominance over cultural capital. Moreover, while the degree to which individualistic or meritocratic tropes casting one's position in the world as self-made is empirically variable, the overwhelming tendency is for the sociodicy of privilege to be widely ingrained. Perhaps, as Marx (1955: 186) argued, the dominated can, under certain conditions, prove themselves not to be "the dupes of the illusions or lies' of the dominant, yet indicators of supposed merit far outweigh inequalities of capital in popular judgements of how to get ahead, people usually vary little in this belief and, where they do, the dominated are at best a little less effusive than others and, at worst, readier to deny the role of capital than even the dominant themselves. That does not stop the dominated from criticising the overt investment of economic capital in the reproduction of social position among the rich, in line with their egalitarian ethos, but the subtle and pervasive processes of social reproduction are thoroughly mystified and, we might infer, a lowly social position attributed to one's own individual failures.

All in all, then, a synoptic model of the ideal-typical contemporary capitalist social space can be posited in which capital volume is bisected by 
capital composition and onto which map a series of homologous oppositions: cultural production/economic production, young/old, urban/rural, liberal-left/traditionalist-right. It is worth underscoring that this construction, or 'particular case of the possible' as Bourdieu would put it, appears to be realised to different degrees in different nations: more so in the Nordic nations, less so in more recently industrialised or marketised nations. Not all spaces are equally multidimensional, meaning that simple hierarchical measures of difference, like the EGP scheme, may appear to perform better or worse as a means of explaining certain differences from one social order to the next. Still, it takes a multidimensional mindset to determine that, it may well be that there are other factors missed by the indicators used here that would sharpen horizontal divides and, of course, elements of the ideal-typical model still stick even in the most divergent cases. There is variation across spaces, but only within certain bounds.

\section{Lifestyles and lifeworlds}

Countless issues remain unsettled, including the role of class in structuring stances on 'moral' or 'post-material' matters (sexuality, women's roles, etc.), and their effect on party preferences across diverse social orders, or the precise reasons for specific national deviations unearthed here and there if, indeed, they are confirmed in further inquiry. More profound, perhaps, is the question of whether and how what has been found here bears out in territories that escaped scrutiny, especially those of South America and Africa or the major ascendant nations within the space of states like China and India. Like an atlas from the age of European exploration, the image we currently have comprises a patchwork of lands, some of whose contours are known in some detail - like Norway - and some of whose are more sketchily traced out, beyond which lie the gaping voids marked terra incognita (or 'here be sea monsters'), or realms known through specific on-the-ground expeditions, i.e. qualitative research, but yet to be mapped with the tools of social cartography. Another way forward, however, is to build on the foundations now laid and switch back from breadth to depth. With the general regularities now sketched out, at least for large sections of the globe, the details of specific targeted cases - particularly those still currently belonging to the dominant region of the space of states, like the US or Germany - can be picked through, effectively subjecting them to the same (or similar) level of scrutiny as Norway so as to confirm, refine and extend on what has been limned here.

Probably the most obvious augmentation would be to examine the homology of social spaces with lifestyles, since the latter, as prime vehicles of misrecognition and symbolic violence, are so central to the Bourdieusian vision of the struggles and desires that characterise human existence. No one can miss the swelling tide of studies examining class and lifestyles, for 
sure, but relatively few - mostly targeting Northern Europe - have adhered to the relational logic of Bourdieusian sociology and deployed the geometric methods with which it harmonises, and those that have usually (though not always) jar with the prevailing orthodoxy. Where others depict rampant omnivorousness of myriad forms atop the symbolic hierarchy, the social cartographers see familiar oppositions of the exclusive and the common, the intellectual and the material and, inescapably bound up with them, the feminine and the masculine. Could it be that, when investigated with geometric data analysis using purpose-built variables, omnivorousness is wiped from the map in even the crucible of its discovery, the US, like the phantom landmasses that haunted the cosmographies of yore, or will it prove itself to be a stubborn terra firma?

Yet this is not all. It would be a mistake to think that the study of class stops at the mapping of a social space, its doxa and its homologies. The former is not reducible to the latter, principally because peoples' lives in contemporary misrecognition orders are not reducible to their positioning in a class structure alone, no matter how large it might loom. There are a multitude of spaces, i.e. fields, vying for our desire and attention, shaping the multiple forces and pressures structuring our everyday lives and conflicting or harmonising in diverse ways and to different degrees (Atkinson, 2016, 2020). They may well constitute one or more field in the field of power - of business or politics, for example - or even, where there has been migration, other social spaces, but, more pervasively, there are the smaller-scale spaces of struggle defining workplace relations or familial, domestic practices. These too form microcosms of misrecognition and contention, and for the majority, surely, they are the most phenomenologically salient ones, front and centre of the lifeworld and crucial to the range of ambitions, hopes and fears defining their being, their practice and their sense of themselves. Part of the study of class, therefore, must be the examination of how class, as a space of desires and of striving, plays off the forces of other spaces; how the drive to 'make it', 'get ahead', 'be someone', 'know one's place', 'make money' or be 'cultivated' and so on, and the lifestyle practices, political inclinations and self-perceptions they give rise to, feed into and underpin, or are offset and complicated by, the strategies spurred by the state of struggle in relation to the quest to be recognised by one's peers, to be an authority in the workplace or to demonstrate love for and be loved by significant others. Feminists in various traditions have been doing something like this for decades, of course, but Bourdieusians must too, not only because they boast precision tools for unpacking the intersection of myriad forms of domination but because, far from being a niche topic, untangling the (im)balance of forces in individual lives - work/family, public/private and so on - and the common blocks, incursions and clashes in the inescapable pursuit of a reason to be they entail is fundamental to unpicking some of the most profound sources of misery for the multitude. 

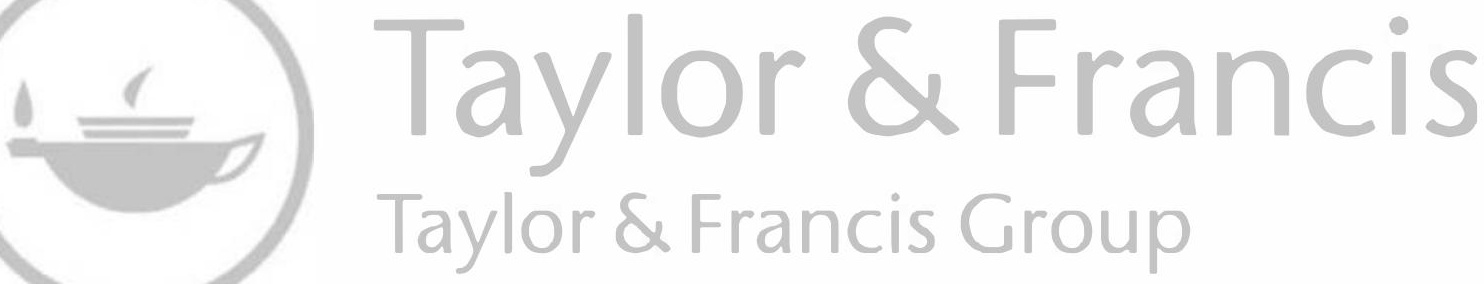
http://taylorandfrancis.com 


\section{References}

Aalberg, T. (2003) Achieving Justice: Comparative Public Opinion on Income Distribution. Leiden: Brill.

Achterberg, P. and Houtman, D. (2006) 'Why Do So Many People Vote 'Unnaturally'?' European Journal of Political Research, 45(1): 75-92.

Adkins, L. and Skeggs, B. (Eds) (2004) Feminism after Bourdieu. Oxford: Blackwell. Alexander, J. (1995) Fin de Siecle Social Theory. London: Verso.

Archer, M. (2007) Making Our Way through the World. Cambridge: Cambridge University Press.

Aslanbeigui, N., Pressman, S. and Summerfield, G. (Eds) (1994) Women in the Age of Economic Transformation. London: Routledge.

Atkinson, T. (2015) Inequality. Cambridge, MA: Harvard University Press.

Atkinson, W. (2009) 'Rethinking the Work-Class Nexus' Work, Employment and Society, 43(5): 896-912.

Atkinson, W. (2010) 'Class, Individualisation and Perceived (Dis)Advantages' Sociological Research Online, 15(4): www.socresonline.org.uk/15/4/7.html.

Atkinson, W. (2012) 'Economic Crisis and Classed Everyday Life' in W. Atkinson, S. Roberts and M. Savage (Eds) Class Inequality in Austerity Britain. Basingstoke: Palgrave Macmillan, pp. 13-32.

Atkinson, W. (2013) 'Class Habitus and Perception of the Future: Recession, Employment Insecurity and Temporality' British Journal of Sociology, 64(4): 643-61.

Atkinson, W. (2016) Beyond Bourdieu. Cambridge, MA: Polity Press.

Atkinson, W. (2017) Class in the New Millennium. London: Routledge.

Atkinson, W. (2020) Bourdieu and After. London: Routledge.

Atkinson, W. and Rosenlund, L. (2014) Mapping the British Social Space: Toward a Bourdieusian Class Scheme. SPAIS Working Paper No. 02-14.

Bachelard, G. (2002) The Formation of the Scientific Mind. Manchester: Clinamen Press.

Baker, J. and Smith, B. (2015) American Secularism. New York: New York University Press.

Beck, U. and Sznaider, N. (2006) 'Unpacking Cosmopolitanism for the Social Sciences' The British Journal of Sociology, 57(1): 1-23.

Bénabou, R. and Tirole, J. (2006) 'Belief in a Just World and Redistributive Politics' Quarterly Journal of Economics, 121: 699-746.

Bennett, T., Savage, M., Silva, E., Warde, A., Gayo-Cal, M. and Wright, D. (2009) Culture, Class, Distinction. London: Routledge. 
Benzécri, J.-P. (1992) Correspondence Analysis Handbook. New York: Marcel Dekker Inc.

Berger, P. (1990) The Sacred Canopy. New York: Anchor Books.

Blanden, J., Gregg, P. and Machin, S. (2005) Intergenerational Mobility in Europe and North America. London: Centre for Economic Performance, LSE.

Blasius, J. and Greenacre, M. (Eds) (2014) Visualization and Verbalization of Data. London: CRC Press.

Blasius, J. and Thiessen, V. (2018) 'Perceived Corruption, Trust and Interviewer Behaviour in 26 European Countries' Sociological Methods \& Research. doi:10.1177/0049124118782554.

Bloom, L. and Jones, F. (1976) Opportunity and Attainment in Australia. Canberra: ANU Press.

Blossfeld, H.-P. and Drobnič, S. (Eds) (2001) Careers of Couples in Contemporary Societies. Oxford: Oxford University Press.

Boltanski, L. (2011) On Critique. Cambridge, MA: Polity Press.

Boltanski, L. (2012) Love and Justice as Competences. Cambridge, MA: Polity Press.

Boltanski, L. and Thévenot, L. (2006) On Justification. Cambridge, MA: Polity Press.

Bourdieu, P. (1971a) 'Intellectual Field and Creative Project' in M. Young (Ed.) Knowledge and Control: New Directions in the Sociology of Knowledge. London: Macmillan, pp. 61-88.

Bourdieu, P. (1971b) 'Genèse et Structure du Champ Religieux' Revue Francaise de Sociologie, 12(3): 295-334.

Bourdieu, P. (1971c) 'Une Interpretation de la Théorie de la Religion Selon Max Weber' European Journal of Sociology, 2(1): 3-21.

Bourdieu, P. (1977) Outline of a Theory of Practice. Cambridge: Cambridge University Press.

Bourdieu, P. (1984) Distinction. London: Routledge.

Bourdieu, P. (1987a) 'What Makes a Social Class?' Berkeley Journal of Sociology, 32: 1-17.

Bourdieu, P. (1987b) 'Legitimation and Structured Interests in Weber's Sociology of Religion' in S. Whimster and S. Lash (Eds) Max Weber, Rationality and Modernity. London: Allan and Unwin, pp. 119-36.

Bourdieu, P. (1987c) Choses Dites. Paris: Minuit.

Bourdieu, P. (1988) Homo Academicus. Cambridge, MA: Polity Press.

Bourdieu, P. (1990) The Logic of Practice. Cambridge, MA: Polity Press.

Bourdieu, P. (1991) Language and Symbolic Power. Cambridge, MA: Polity Press.

Bourdieu, P. (1993a) The Field of Cultural Production. Cambridge, MA: Polity Press.

Bourdieu, P. (1993b) Sociology in Question. London: Sage.

Bourdieu, P. (1996a) The State Nobility. Cambridge, MA: Polity Press.

Bourdieu, P. (1996b) The Rules of Art. Cambridge, MA: Polity Press.

Bourdieu, P. (1997) 'The Forms of Capital' in A.H. Halsey, H. Lauder, P. Brown and A. Wells (Eds) Education: Culture, Economy, Society. Oxford: Oxford University Press, pp. 46-58.

Bourdieu, P. (1998a) Practical Reason. Cambridge, MA: Polity Press.

Bourdieu, P. (1998b) Acts of Resistance. Cambridge, MA: Polity Press.

Bourdieu, P. (1999) 'Site Effects' in P. Bourdieu et al., The Weight of the World. Cambridge, MA: Polity Press, pp. 123-29. 
Bourdieu, P. (2000) Pascalian Meditations. Cambridge, MA: Polity Press.

Bourdieu, P. (2001) Masculine Domination. Cambridge, MA: Polity Press.

Bourdieu, P. (2004) 'From the King's House to the Reason of State' Constellations, 11(1): 16-36.

Bourdieu, P. (2005) The Social Structures of the Economy. Cambridge, MA: Polity Press.

Bourdieu, P. (2008) The Bachelors' Ball. Cambridge, MA: Polity Press.

Bourdieu, P. (2014) On the State. Cambridge, MA: Polity Press.

Bourdieu, P. (2019) Classification Struggles. Cambridge, MA: Polity Press.

Bourdieu, P. and Boltanski, L. (1975) 'The Educational System and the Economy' in C. Lemert (Ed.) (1981) French Sociology. New York: Columbia University Press, pp. 141-51.

Bourdieu, P. and Delsaut, Y. (2002) 'Entretien sur l'Esprit de la Recherche' in Y. Delsaut and M.-C. Rivière (Eds) Bibliographie des Travaux de Pierre Bourdieu. Paris: Les Temps de Cerises, pp. 177-239.

Bourdieu, P. and Eagleton, T. (1992) 'Doxa and Common Life' New Left Review, 191: 111-21.

Bourdieu, P. and Passeron, J.-C. (1990) Reproduction in Education, Society and Culture. London: Sage.

Bourdieu, P. and Saint-Martin, M. de (1982) 'La Sainte Famille' Actes de la Recherche en Sciences Sociales, 44-5: 2-53.

Bourdieu, P. and Wacquant, L. (1992) An Invitation to Reflexive Sociology. Cambridge, MA: Polity Press.

Bourdieu, P. and Wacquant, L. (1993) 'From Ruling Class to Field of Power' Theory, Culture \& Society, 10(3): 19-44.

Bourdieu, P., Chamboredon, J.-C. and Passeron, J.-C. (1991) The Craft of Sociology. New York: de Gruyter.

Breen, R. (Ed.) (2004) Social Mobility in Europe. Oxford: Oxford University Press.

Breen, R. and Rottman, D. (1998) 'Is the National State the Appropriate Geographical Unit for Class Analysis?' Sociology, 32(1): 1-21.

Britten, N. and Heath, H. (1983) 'Women, Men and Social Class' in E. Gamarnikov, D. Morgan, J. Purvis and D. Taylorson (Eds) Gender, Class and Work. London: Heinemann, pp. 46-60.

Brousse, C. (2017) 'L'Union Européene, Un Espace Social Unifié?' Actes de la Recherche en Sciences Sociales, 219: 12-41.

Bruce, S. (2002) God Is Dead: Secularization in the West. New York: Wiley.

Bruce, S. (2013) Secularization: In Defence of an Unfashionable Theory. Oxford: Oxford University Press.

Bryson, B. (1996) “"Anything but Heavy Metal”: Symbolic Exclusion and Musical Dislikes' American Sociological Review, 61(5): 884-99.

Bukodi, E. and Goldthorpe, J. (2018) Social Mobility and Education in Britain. Cambridge: Cambridge University Press.

Bukodi, E., Dex, S. and Goldthorpe, J. (2011) 'The Conceptualization and Measurement of Occupational Hierarchies' Quality \& Quantity, 45: 623-39.

Cannadine, D. (1998) Class in Britain. London: Penguin.

Cerami, A. (2006) Social Policy in Central and Eastern Europe. Berlin: Lit.

Chan, T.W. and Goldthorpe, J.H. (2004) 'Is There a Status Order in Contemporary British Society?' European Sociological Review, 29(5): 383-401. 
Chan, T.W. and Goldthorpe, J.H. (2007a) 'Class and Status: The Conceptual Distinction and Its Empirical Relevance' American Sociological Review, 72(4): 512-32.

Chan, T.W. and Goldthorpe, J.H. (2007b) 'Social Status and Newspaper Readership' American Journal of Sociology, 112(4): 1095-134.

Chan, T.W. and Goldthorpe, J.H. (2010a) 'Social Stratification of Cultural Consumption across Three Domains' in T.W. Chan (Ed.) Social Status and Cultural Consumption. Cambridge: Cambridge University Press, pp. 204-31.

Chan, T.W. and Goldthorpe, J.H. (2010b) 'Introduction' in T.W. Chan (Ed.) Social Status and Cultural Consumption. Cambridge: Cambridge University Press, pp. 1-27.

Charlesworth, S. (2000) A Phenomenology of Working Class Experience. Cambridge: Cambridge University Press.

Chiche, J., Le Roux, B., Perrineau, P. and Rouanet, H. (2000) 'L'Espace Politique des Électeurs Français à la Fin des Années 1990' Revue Française de Science Politique, 50(3): 463-88.

Clark, T.N. and Lipset, S.M. (Eds) (2001) The Breakdown of Class Politics. Baltimore: The John Hopkins University Press.

Crompton, R. (2006) Employment and the Family. Cambridge: Cambridge University Press.

Cvetičanin, P. and Popescu, M. (2011) 'The Art of Making Classes in Serbia' Poetics, 39: 444-68.

Cvetičanin, P., Nedeljković, J. and Krstić, N. (2012) 'Social Space in Serbia' in P. Cvetičanin (Ed.) Social and Cultural Capital in Serbia. Niš: Centre for Empirical Cultural Studies of South-East Europe, pp. 53-70.

De Keere, K. (2018) 'Political Distinction: Searching for a Structural Similarity between Class and Politics in Flanders (Belgium)' European Societies, 20(3): $375-400$.

De Koster, W., Achterberg, P. and van der Waal, J. (2013) 'The New Right and the Welfare State' International Political Science Review, 34(1): 3-20.

Denord, F., Lagneau-Ymonet, P. and Thine, S. (2011) 'Le Champ du Pouvoir en France' Actes de la Recherche en Sciences Sociales, 190: 24-57.

Devine, F. (2004) Class Practices. Cambridge: Cambridge University Press.

Dickey, S. (2016) Living Class in Urban India. New Brunswick: Rutgers University Press.

DiFranco, D. (2016) 'Multiple Correspondence Analysis: Only One or Several Techniques?' Quality and Quantity, 50(3): 1299-315.

Domanski, H. (2000) On the Verge of Convergence: Social Stratification in Eastern Europe. Budapest: Central European University Press.

Dorling, D. (2014) Inequality and the 1\%. London: Verso.

Drobnič, S. and Blossfeld, H.-P. (2001) 'Careers of Couples and Trends in Inequality' in H.-P. Blossfeld and S. Drobnič (Eds) Careers of Couples in Contemporary Societies. Oxford: Oxford University Press, pp. 371-86.

Duby, G. (1978) The Three Orders. Chicago: University of Chicago Press.

Duina, F. and Carson, D. (2019) 'Not so Right after All? Making Sense of the Progressive Rhetoric of Europe's Far-Right Parties' International Sociology, 35(1): 3-21.

Duncan, O.D. (1961) 'A Socioeconomic Index for All Occupations' in J. Reiss (Ed.) Occupations and Social Status. Glencoe: The Free Press, pp. 109-38. 
Durkheim, E. (1970) Suicide. London: Routledge and Kegan Paul.

Eatwell, R. and Goodwin, G. (2018) National Populism. London: Penguin.

Elias, N. (2000) The Civilizing Process. Oxford: Blackwell.

Emirbayer, M. and Desmond, M. (2015) The Racial Order. Chicago: University of Chicago Press.

England, P. (1992) Comparable Worth. London: Transaction.

England, P. (2010) 'The Gender Revolution: Uneven and Stalled' Gender and Society, 24(2): 149-66.

England, P. and Farkas, G. (1986) Households, Employment and Gender. London: Transaction.

Erikson, R. and Goldthorpe, J.H. (1992) The Constant Flux. Oxford: Clarendon.

Esping-Andersen, G. (1990) Worlds of Welfare Capitalism. London: Polity Press.

Esping-Andersen, G. (Ed.) (1993) Changing Classes. London: Sage.

Esping-Andersen, G. (1999) Social Foundations of Postindustrial Economies. Oxford: Oxford University Press.

Esping-Andersen, G. (2009) Incomplete Revolution. Cambridge, MA: Polity Press.

Estevez-Abe, M. (2013) 'An International Comparison of Gender Equality: Why Is the Japanese Gender Gap So Persistent?' Japan Labor Review, 10(2): 82-100.

Evans, G. (Ed.) (1999) The End of Class Politics? Class Voting in Comparative Perspective. Oxford: Oxford University Press.

Evans, G. and Tilley, M. (2016) The New Politics of Class. Oxford: Oxford University Press.

Evans, M. and Kelley, J. (2004) 'Subjective Social Location' International Journal of Public Opinion Research, 16(1): 3-38.

Eyal, G. (2003) The Origins of Post-Communist Elites. Minneapolis: University of Minnesota Press.

Eyal, G., Szelenyi, I. and Townsley, E. (2001) Making Capitalism without Capitalists. London: Verso.

Ferragina, E. and Seeleib-Kaiser, M. (2014) 'Determinants of a Silent (R)evolution' Social Politics, 22(1): 1-37.

Ferrera, M. (1996) 'The "Southern Model" of Welfare in Social Europe' Journal of European Social Policy, 6(1): 17-37.

Filhon, A., Deauvieau, J., de Verdalle, L., Pelage, A., Poullaouec, T., Brousse, C., Mespoulet, M. and Sztandar-Sztanderska, K. (2016) 'European Classification Project: An Assessment of National Variations in the Perception of Social Space' Comparative Sociology, 15(3): 275-99.

Flemmen, M. (2012) 'The Structure of the Upper Class' Sociology, 46(6): 1039-58.

Flemmen, M. (2013) 'Putting Bourdieu to Work for Class Analysis' The British Journal of Sociology, 64(2): 325-43.

Flemmen, M. (2014) 'The Politics of the Service Class' European Societies, 16(4): 543-69.

Flemmen, M. and Haakestad, H. (2018) 'Class and Politics in Twenty-First Century Norway’ European Societies, 20(3): 401-23.

Flemmen, M., Hjellbrekke, J. and Jarness, V. (2017a) 'Class, Culture and Culinary Taste' Sociology, 52(1): 128-49.

Flemmen, M., Toft, M., Andersen, P.L., Hansen, M.N. and Ljunggren, J. (2017b) 'Forms of Capital and Modes of Closure in Upper Class Reproduction' Sociology, 51(6): 1277-98. 
Flemmen, M., Jarness, V. and Rosenlund, L. (2018) 'Social Space and Cultural Class Divisions' The British Journal of Sociology, 69(1): 124-53.

Flemmen, M., Jarness, V. and Rosenlund, L. (2019) 'Class and Status: On the Misconstrual of the Conceptual Distinction and a Neo-Bourdieusian Alternative' The British Journal of Sociology, 70(3): 816-66.

France, A. (2016) Understanding Youth in the Global Economic Crisis. Bristol: Policy Press.

France, A. and Roberts, S. (2017) Youth and Social Class. Basingstoke: Palgrave.

Friedman, S. (2012) 'Cultural Omnivores or Culturally Homeless?' Poetics, 40(5): 467-89.

Friedman, S. (2014) 'The Price of the Ticket: Rethinking the Experience of Social Mobility' Sociology, 48(2): 352-68.

Friedman, S. (2016) 'Habitus Clivé and the Emotional Imprint of Social Mobility' The Sociological Review, 64(1): 129-47.

Friedman, S. and Laurison, D. (2017) 'Mind the Gap: Financial London and the Regional Class Pay Gap' The British Journal of Sociology, 68(3): 474-511.

Friedman, S. and Laurison, D. (2019) The Class Ceiling. Bristol: Policy Press.

Friedman, S., O'Brien, D. and Laurison, D. (2017a) "Like Skydiving without a Parachute': How Class Origin Shapes Occupational Trajectories in British Acting' Sociology, 51(5): 992-1010.

Friedman, S., Laurison, D. and Macmillan, L. (2017b) Social Mobility, the Class Pay Gap and Intergenerational Worklessness. London: Social Mobility Commission.

Furlong, A., Goodwin, J., Hadfield, S., Hall, S., Lowden, H., O'Connor, H. and Plugor, R. (2017) Young People in the Labour Market. London: Routledge.

Galligan, Y., Clavero, S. and Calloni, M. (2007) Gender Politics and Democracy in Post-Socialist Europe. Opladen: Barbara Budrich.

Ganzeboom, H., de Graaf, P. and Trieman, D. (1992) 'A Standard International Socio-Economic Index of Occupational Status' Social Science Research, 21(1): 1-56. Giddens, A. (1991) Modernity and Self-Identity. Cambridge, MA: Polity Press.

Giddens, A. (1994) Beyond Left and Right. Cambridge, MA: Polity Press.

Gidron, N. and Hall, P. (2017) 'The Politics of Social Status' The British Journal of Sociology, 68(s1): 57-84.

Gifi, A. (1990) Nonlinear Multivariate Analysis. New York: Wiley.

Gijsberts, M. and Nieuwbeerta, P. (2000) 'Class Cleavages in Party Preferences in the New Democracies in Eastern Europe' European Societies, 2(4): 397-430.

Go, J. (2008) 'Global Fields and Imperial Forms' Sociological Theory, 26(3): 201-29

Goffman, E. (1951) 'Symbols of Class Status' The British Journal of Sociology, 2(4): 294-304.

Gold, D., Guthrie, D. and Wank, D. (Eds) (2002) Social Connections in China. Cambridge: Cambridge University Press.

Goldthorpe, J.H. (1980) Social Mobility and Class Structure in Modern Britain. Oxford: Clarendon.

Goldthorpe, J.H. (1982) 'On the Service Class, Its Formation and Future' in A. Giddens and G. McKenzie (Eds) Social Class and the Division of Labour. Cambridge: Cambridge University Press, pp. 162-85.

Goldthorpe, J.H. (1995) 'The Service Class Revisited' in M. Savage and T. Butler (Eds) Social Change and the Middle Classes. London: UCL Press, pp. 313-29.

Goldthorpe, J.H. (2007a) On Sociology (Vol. 2). Stanford: Stanford University Press. 
Goldthorpe, J.H. (2007b) On Sociology (Vol. 1). Stanford: Stanford University Press.

Goldthorpe, J.H. (2007c) 'Cultural Capital: Some Critical Observations' Sociologia, 1(2). doi: $10.2383 / 24755$.

Goldthorpe, J.H. and Hope, K. (1974) The Social Grading of Occupations. Oxford: Clarendon.

Greenacre, M. and Blasius, J. (Eds) (2006) Multiple Correspondence Analysis and Related Methods. London: Chapman \& Hall.

Grusky, D. and Galescu, G. (2005) 'Foundations of a Neo-Durkheimian Class Analysis' in E.O. Wright (Ed.) Foundations of Class Analysis. Cambridge: Cambridge University Press, pp. 51-81.

Grusky, D. and Weeden, K. (2001) 'Decomposition without Death: A Research Agenda for a New Class Analysis’ Acta Sociologica, 44(3): 203-18.

Güveli, A, Need, A. and de Graaf, N.D. (2007) 'The Rise of New Social Classes within the Service Class in the Netherlands' Acta Sociologica, 50(2): 129-46.

Hage, G. (1998) White Nation. London: Routledge.

Hansen, M.N., Flemmen, M. and Andersen, P.L. (2009) The Oslo Register Data Class Scheme. Final Report from the Classification Project, Memorandum No. 1.

Harrits, G. and Pedersen, H. (2018) 'Class Categories and the Subjective Dimension of Class: The Case of Denmark’ The British Journal of Sociology, 69(1): 67-98.

Harrits, G., Prieur, A., Rosenlund, L. and Skjøtt-Larsen, J. (2010) 'Class and Politics in Denmark' Scandinavian Political Studies, 33(1): 1-27.

Hauser, R and Warren, J.R. (1997) 'Socioeconomic Indexes of Occupations: A Review, Update, and Critique' Sociological Methodology, 27(1): 177-298.

Hay, I. and Beaverstock, J. (Eds) (2016) Handbook on Wealth and the Super-Rich. Cheltenham: Edward Elgar.

Hjellbrekke, J. (2019) Multiple Correspondence Analysis for the Social Sciences. London: Routledge.

Hjellbrekke, J., Le Roux, B., Korsnes, O., Lebaron, F., Rosenlund, R. and Rouanet, H. (2007) 'The Norwegian Field of Power Anno 2000' European Societies, 9(2): 245-73.

Hofstede, G. and Bond, M. (1988) 'The Confucius Connection: From Cultural Roots to Economic Growth' Organizational Dynamics, 16(4): 5-21.

Houtman, D. (2003) Class and Politics in Contemporary Social Science. New York: Aldine de Gruyter.

Houtman, D., Achterberg, P. and Derk, A. (2008) Farewell to the Leftist Working Class. New Brunswick: Transaction.

Hugrée, C., Penissat, E. and Spire, A. (2011) Les Classes Socialies en Europe. Marseille: Agone.

Huisman, J. Smolentseva, A. and Froumin, I. (Eds) (2018) 25 Years of Transformations of Higher Education Systems in Post-Soviet Countries. Basingstoke: Palgrave Macmillan.

Inglehart, R. (1977) The Silent Revolution. Princeton: Princeton University Press.

Inglehart, R. (1990) Culture Shift in Advanced Industrial Society. Princeton: Princeton University Press.

Inglehart, R. (1997) Modernization and Postmodernization. Princeton: Princeton University Press.

Irwin, S. (2015) 'Class and Comparison' The British Journal of Sociology, 66(2): 259-81. 
Irwin, S. (2016) 'Lay Perceptions of Inequality and Social Structure' Sociology, 52(2): 211-27.

Iversen, T. and Soskice, D. (2006) 'Electoral Institutions and the Politics of Coalitions' American Political Science Review, 100(2): 165-81.

Izuhara, M. (Ed.) (2013) Handbook on East Asian Social Policy. London: Edward Elgar.

Jambu, M. (1991) Exploratory and Multivariate Data Analysis. Boston: Academic Press.

Jarness, V. (2017) 'Cultural vs Economic Capital: Symbolic Boundaries within the Middle Class' Sociology, 51(2): 357-73.

Jarness, V. (2018) 'Viewpoints and Points of View: Situating Symbolic Boundary Drawing in Social Space' European Societies, 20(3): 503-24.

Jarness, V., Flemmen, M. and Rosenlund, L. (2019) 'From Class Politics to Classed Politics' Sociology, 53(5): 879-99.

Jodkha, S., Rehbein, B. and Souza, J. (2018) Inequality in Capitalist Societies. London: Routledge.

Jowell, R. (1998) 'How Comparative Is Comparative Research?' American Behavioural Scientist, 42(2): 168-77.

Jung, H. and Gil, J. (2019) 'Does College Education Make People Politically Liberal?' Social Science Research, 81: 209-20.

Keister, L. (2014) 'The One Percent' Annual Review of Sociology, 40: 347-67.

Kim, A.E. and Park, G. (2007) 'Nationalism, Confucianism, Work Ethic and Industrialization in South Korea' Journal of Contemporary Asia, 33(1): 37-49.

King, A. (1991) 'Kuan-hsi and Network Building: A Sociological Interpretation' Daedalus, 120(2): 63-84.

Kitschelt, H. (1994) The Transformation of European Social Democracy. Cambridge: Cambridge University Press.

Kitschelt, H. (1995) The Radical Right in Western Europe. Ann Arbor: The University of Michigan Press.

Konrad, G. and Szelenyi, I. (1978) The Intellectuals on the Road to Class Power. New York: Harcourt, Brace and Jovanovich.

Korpi, W. (2000) 'Faces of Inequality: Gender, Class and Patterns of Inequalities in Different Types of Welfare States' Social Politics, 7(2): 127-91.

Kriesi, H., Grande, E., Lachat, R., Dolezal, M., Bornschier, S. and Frey, T. (2008) West European Politics in the Age of Globalization. Cambridge: Cambridge University Press.

Kriesi, H., Grande, E., Dolezal, M., Helbling, M., Höglinger, D., Hutter, S. and Wüest, B. (2012) Political Conflict in Western Europe. Cambridge: Cambridge University Press.

Kuipers, G. (2015) 'Beauty and Distinction? Poetics, 53(1): 38-51.

Lamont, M. (1992) Money, Morals and Manners. Chicago: University of Chicago Press. Lamont, M. (2000) The Dignity of Working Men. New York: Russell Sage Foundation.

Lamont, M. and Lareau, A. (1988) 'Cultural Capital' Sociological Theory, 6(2): 153-68.

Lamont, M., Silva, G.M., Welburb, J., Guetzkow, J., Mizrachi, N., Herzog, H. and Reis, E. (2016) Getting Respect. Princeton: Princeton University Press.

Lareau, A. (2003) Unequal Childhoods. Berkeley: University of California Press. 
Lareau, A. (2008) 'Introduction: Taking Stock of Class' in A. Lareau and D. Conley (Eds) Social Class: How Does It Work? New York: Russell Sage Foundation, pp. 1-24.

Larsen, C. (2016) 'How Three Narratives of Modernity Justify Economic Inequality' Acta Sociologica, 59(2): 93-111.

Laurison, D. and Friedman, S. (2016) 'The Class Pay Gap in Higher Professional and Managerial Occupations' American Sociological Review, 81(4): 668-95.

Lawler, S. (1999) 'Getting Out and Getting Away': Women's Narratives of Social Mobility’ Feminist Review, 63(1): 3-24.

Lawler, S. and Payne, G. (Eds) (2018) Social Mobility for the 21st Century. London: Routledge.

Lebaron, F. and Le Roux, B. (Eds) (2015) La Methodologie de Pierre Bourdieu en Action. Paris: Dunord.

Lebart, L., Morineau, A. and Piron, M. (1995) Statistique Exploratoire Mulitdimensionelle. Paris: Dunord.

Lee, L. (2015) Recognizing the Non-Religious. Oxford: Oxford University Press.

Lehmann, W. (2007) Choosing to Labour? Montreal: McGill-Queen's University Press.

Lenski, G. (1966) Power and Privilege. New York: McGraw-Hill.

Le Roux, B. (2014) Analyse Géometrique des Données Multidimensionnelles. Paris: Dunod.

Le Roux, B. and Rouanet, H. (2004) Geometric Data Analysis. Dordrecht: Kluwer.

Le Roux, B. and Rouanet, H. (2010) Multiple Correspondence Analysis. London: Sage.

Le Roux, B., Bienaise, S. and Durans, J.-C. (2020) Combinatorial Inference in Geometric Data Analysis. London: CRC Press.

Le Roux, B., Rouanet, H., Savage, M. and Warde, A. (2008) 'Class and Cultural Division in the UK' Sociology, 42(6): 1049-71.

Lindemann, K. and Saar, E. (2014) 'Contextual Effects on Subjective Social Position' International Journal of Comparative Sociology, 55(1): 3-23.

Linting, M. and van der Kooij, A. (2012) 'Nonlinear Principal Components Analysis with CATPCA' Journal of Personality Assessment, 94(1): 12-25.

Linting, M., Meulman, J., Groenen, P. and van der Kooij, A. (2007a) 'Nonlinear Principal Components Analysis' Psychological Methods, 12: 336-58.

Linting, M., Meulman, J., Groenen, P. and van der Kooij, A. (2007b) 'Stability of Nonlinear Principal Components Analysis' Psychological Methods, 12: 359-79.

Lipset, S.M. (1960) Political Man. London: Heinemann.

Lipset, S.M. and Bendix, R. (1959) Social Mobility in Industrial Society. Berkeley: University of California Press.

Lipset, S.M. and Rokkan, S. (1967) Party Systems and Voter Alignments. New York: The Free Press.

Marshall, G. Newby, H., Rose, D. and Vogler, C. (1988) Social Class in Modern Britain. London: Hutchinson.

Marshall, G., Swift, A., Routh, D. and Burgoyne, C. (1999) 'What Is and What Ought to Be: Popular Beliefs about Distributive Justice in Thirteen Countries' European Sociological Review, 15(4): 349-67.

Marx, K. (1955) The Poverty of Philosophy. Moscow: Progress Publishers. 
Massey, D. (1995) Spatial Divisions of Labour. London: Routledge.

Melldahl, A. (2018) 'Modes of Reproduction in the Swedish Economic Elite' European Societies, 20(3): 424-52.

Melldahl, A. and Borjesson, M. (2015) 'Charting the Social Space: The Case of Sweden' in P. Coulangeon and J. Duval (Eds) The Routledge Companion to Bourdieu's Distinction. London: Routledge, pp. 135-56.

Meulman, J., van der Kooij, A. and Hieser, W. (2004) 'Principal Components Analysis with Optimal Scaling Transformations for Ordinal and Nominal Data' in D. Kaplan (Ed.) Handbook of Quantitative Methodology for the Social Sciences. London: Sage, pp. 49-70.

Myles, J. and Turegun, A. (1994) 'Comparative Studies in Class Structure' Annual Review of Sociology, 20: 103-24.

Nietzsche, F. (1994) Human, All Too Human. London: Penguin.

Norris, P. and Inglehart, R. (2016) Cultural Backlash. Cambridge: Cambridge University Press.

O'Brien, D., Laurison, D., Miles, A. and Friedman, S. (2016) 'Are the Creative Industries Meritocratic?' Cultural Trends, 25(2): 116-31.

Oesch, D. (2006) Redrawing the Class Map. Basingstoke: Palgrave Macmillan.

Oesch, D. (2008a) 'Explaining Workers' Support for Right-Wing Populist Parties in Western Europe' International Political Science Review, 29(3): 348-73.

Oesch, D. (2008b) 'The Changing Shape of Class Voting' European Societies, 10(3): $329-55$.

Oh, I. (2010) 'Education and Development: Why Are Koreans Obsessed with Learning?' Comparative Sociology, 9(3): 308-27.

Pahl, J. (1983) 'The Allocation of Money and the Structuring of Inequality within Marriage' The Sociological Review, 31(2): 237-62.

Pahl, J. (1990) 'Household Spending, Personal Spending and the Control of Money in Marriage' Sociology, 24(1): 119-38.

Pahl, R. (1975) Whose City? Harmondsworth: Penguin.

Pakulski, J. and Waters, M. (1996) The Death of Class. London: Sage.

Parkin, F. (1968) Middle Class Radicals. Manchester: Manchester University Press.

Parkin, F. (1972) Class Inequality and Political Order. London: Paladin.

Peterson, R. and Simkus, A. (1992) 'How Musical Tastes Mark Occupational Groups' in M. Lamont and M. Fournier (Eds) Cultivating Differences: Symbolic Boundaries and the Making of Inequality. Chicago: University of Chicago Press, pp. $152-86$.

Picketty, T. (2014) Capital in the Twenty-First Century. Cambridge, MA: Harvard University Press.

Pinto, L. (2015) 'The Field: A Leibnizian Perspective in Sociology' in M. Hilgers and E. Mangez (Eds) Bourdieu's Theory of Social Fields. London: Routledge, pp. $102-18$.

Polanyi, K. (1944) The Great Transformation. Boston: Beacon Press.

Pop, L. (2018) 'Bourdieu in the Post-Communist World' in T. Medvetz and J. Sallaz (Eds) The Oxford Handbook of Pierre Bourdieu. Oxford: Oxford University Press, pp. 129-58.

Poulantzas, N. (1975) Classes in Contemporary Capitalism. London: Verso.

Prieur, A., Rosenlund, L. and Skjøtt-Larsen, J. (2008) 'Cultural Capital Today: A Case Study from Denmark' Poetics, 36(1): 45-71. 
Przeworksi, A. and Sprague, J. (1986) Paper Stones. Chicago: University of Chicago Press.

Ragin, C. (Ed.) (1991) Issues and Alternatives in Comparative Social Research. Leiden: Brill.

Ragin, C. (2014) The Comparative Method. Berkeley: University of California Press.

Ragin, C. and Zaret, D. (1983) 'Theory and Method in Comparative Research' Social Forces, 61(3): 731-54.

Reay, D., David, M. and Ball, M. (2005) Degrees of Choice. Stoke-on-Trent: Trentham Books.

Rey, T. (2007) Bourdieu on Religion. London: Routledge.

Roberts, S. and Evans, S. (2012) 'Aspirations and Imagined Futures' in W. Atkinson, S. Roberts and M. Savage (Eds) Class Inequality in Austerity Britain. Basingstoke: Palgrave Macmillan, pp. 70-89.

Roberts, S. and France, A. (forthcoming) 'Problematizing Prominent Panaceas' The Sociological Review.

Roex, K., Huijts, T. and Sieben, I. (2019) 'Attitudes toward Income Inequality: 'Winners versus 'Losers' of the Perceived Meritocracy' Acta Sociologica, 62(1): 47-63.

Rosenlund, L. (2009) Exploring the City with Bourdieu. Saarbrücken: VDM Verlag.

Rosenlund, L. (2015) 'Working with Distinction: Scandinavian Experiences' in P. Coulangeon and J. Duval (Eds) The Routledge Companion to Bourdieu's Distinction. London: Routledge, pp. 157-86.

Rydgren, J. (2013) 'Introduction: Class Politics and the Radical Right' in J. Rydgren (Ed.) Class Politics and the Radical Right. London: Routledge, pp. 1-9.

Sainsbury, D. (Ed.) (1999) Gender and Welfare State Regimes. Oxford: Oxford University Press.

Saint-Martin, M. de (2015) 'From 'Anatomie du Gôut' to La Distinction' in P. Coulangeon and J. Duval (Eds) The Routledge Companion to Bourdieu's Distinction. London: Routledge, pp. 15-28.

Salmenniemi, S. (Ed.) (2016) Rethinking Class in Russia. London: Routledge.

Sánchez-Mira, N. and O'Reilly, J. (2019) 'Household Employment and the Crisis in Europe' Work, Employment and Society, 33(3): 422-43.

Savage, M. (2000) Class Analysis and Social Transformation. Buckingham: Open University Press.

Savage, M., Bagnall, G. and Longhurst, B. (2001) 'Ordinary, Ambivalent and Defensive: Class Identities in the Northwest of England' Sociology, 35(4): 875-92.

Savage, M., Hanquinet, L., Cunnignham, N. and Hjellbrekke, J. (2018) 'Emerging Cultural Capital in the City' International Journal of Urban and Regional Research, 42(1): 138-49.

Savage, M., Cunningham, N., Devine, F., Friedman, S., Laurison, D., Mckenzie, L., Miles, A., Snee, H. and Wakeling, P. (2015) Social Class in the 21st Century. London: Penguin.

Savage, M., Devine, F., Cunningham, N., Taylor, M., Li, Y., Hjellbrekke, J., Le Roux, B., Friedman, S. and Miles, A. (2013) 'A New Model of Social Class?' Sociology, 47(2): 219-50.

Sayad, A. (2004) The Suffering of the Immigrant. Cambridge, MA: Polity Press.

Sayer, A. (2005) The Moral Significance of Class. Cambridge: Cambridge University Press. 
Sayer, A. (2015) Why We Can't Afford the Rich. Bristol: Policy Press.

Schmitz, A. (2017) The Structure of Digital Partner Choice. Cham: Springer.

Schmitz, A. and Witte, D. (2020) 'National, International, Transnational and Global Fields' in C. Schmidt-Wellenburg and S. Bernhard (Eds) Charting Transnational Fields: Methodology for a Political Sociology. London: Routledge, pp. 79-97.

Schmitz, A., Flemmen, M. and Rosenlund, L. (2017) 'Social Class, Symbolic Domination, and Angst: The Example of the Norwegian Social Space' The Sociological Review, 66(3): 623-44.

Sennett, R. and Cobb, J. (1977) The Hidden Injuries of Class. Cambridge: Cambridge University Press.

Seth, M. (2002) Education Fever: Society, Politics and the Pursuit of Schooling in South Korea. Honolulu: University of Hawaii Press.

Skeggs, B. (1997) Formations of Class and Gender. London: Sage.

Skjøtt-Larsen, J. (2012) 'Cultural and Moral Class Boundaries in a Nordic Context' European Societies, 14(5): 660-83.

Skopek, N., Buchholz, S. and Blossfeld, H.-P. (2014) 'National Patterns of Income and Wealth Inequality' International Journal of Comparative Sociology, 55(6): 463-88.

Sorokin, P. (1927) Social Mobility. New York: Harper and Row.

Stahl, G. (2015) Identity, Neoliberalism and Aspiration. London: Routledge.

Stewart, A., Prandy, K. and Blackburn, R. (1980) Social Stratification and Occupations. London: Macmillan.

Storelli, E. and Williamson, J. (2015) 'Class, Pensions and Old-Age Security' in M. Formosa and P. Higgs (Eds) Social Class in Later Life. Bristol: Policy Press, pp. 113-32.

Strhan, A. and Shillitoe, R. (2019) 'The Stickiness of Non-Religion?' Sociology, 53(6): 1094-110.

Surridge, P. (2016) 'Education and Liberalism: Pursuing the Link' Oxford Review of Education, 42(2): 146-64.

Szelenyi, I. and Szelenyi, S. (1995) 'Circulation or Reproduction of Elites during Postcommunist Transformation of Eastern Europe' Theory and Society, 24(5): 615-38.

Toft, M. and Flemmen, M. (2017) 'The Gendered Reproduction of the Upper Class' in O. Korsnes, J. Heilbron, J. Hjellbrekke, F. Bühlmann and M. Savage (Eds) New Directions in Elite Studies. London: Routledge, pp. 113-32.

Trieman, D. (1977) Occupational Prestige in Comparative Perspective. New York: Academic Press.

Trifiletti, R. (1999) 'Southern European Welfare Regimes and the Worsening Position of Women' Journal of European Social Policy, 9(1): 49-64.

Urry, J. (1981) The Anatomy of Capitalist Societies. Basingstoke: Macmillan.

Vandebroack, D. (2016) Distinctions in the Flesh. London: Routledge.

Van der Waal, J., Achterberg, P. and Houtman, D. (2007) 'Class Is Not Dead - It Has Been Buried Alive' Politics \& Society, 35(3): 403-26.

Van der Waal, J., Achterberg, P., Houtman, D., de Koster, W. and Manevska, K. (2010) 'Some are More Equal than Others' European Journal of Social Policy, 20(4): 350-63.

Van der Werfhorst, H. (2020) 'Are Universities Left-Wing Bastions?' The British Journal of Sociology, 71(1): 47-73. 
Van Eijk, C. (1999) 'Socialisation, Education and Lifestyle' Poetics, 26: 309-28.

Van Kersbergen, K. and Manow, P. (Eds) (2009) Religion, Class Coalitions and Welfare States. Cambridge: Cambridge University Press.

Vincent, J. (1995) Inequality and Old Age. London: UCL Press.

Vincent, J. (2003) Old Age. London: Routledge.

Vogler, C. and Pahl, J. (1993) 'Social and Economic Change and the Organisation of Money within Marriage' Work, Employment and Society, 7(1): 71-95.

Vogler, C. and Pahl, J. (1994) 'Money, Power and Inequality within Marriage' The Sociological Review, 42(2): 263-88.

Wacquant, L. (1997) 'For an Analytic of Racial Domination' Political Power and Social Theory, 11(1): 221-34.

Wacquant, L. (2005) 'Race as Civic Felony' International Social Science Journal, 57: 127-42.

Wacquant, L. (2009) Punishing the Poor. Durham: Duke University Press.

Weakliem, D. and Biggert R. (2013) 'Not Asking for Much: Public Opinion and Redistribution from the Rich' Comparative Sociology, 12(1): 66-94.

Weber, M. (1968) Economy and Society. Berkeley: University of California Press.

Weber, M. (1991) From Max Weber: Essays in Sociology. London: Routledge.

Woodhead, L. (2016) 'The Rise of 'No Religion' in Britain' Journal of the British Academy, 4: 245-61.

Woodhead, L. (2017) 'The Rise of 'No Religion': Towards and Explanation' Sociology of Religion, 78(3): 247-62.

Wright, E.O. (1985) Classes. London: Verso.

Wright, E.O. (1997) Class Counts. Cambridge: Cambridge University Press.

Yamashita, J. (2010) 'Managing or Generating Social Risks?' in K. Raymond, L. Wang and M. Takahashi (Eds) Risk and Public Policy in Changing Asian Societies. Aldershot: Ashgate, pp. 147-61.

Yeung, Y. and Tung, R. (1996) 'Achieving Business Success in Confucian Societies: The Importance of Guanxi (Connections)' Organization Dynamics, 25(2): 54-65.

Young, M. and Wilmott, P. (1962) Family and Kinship in East London. Harmondsworth: Penguin.

Zarycki, T. (2009) 'The Power of the Intelligentsia' Theory and Society, 38(6): 613-48. 

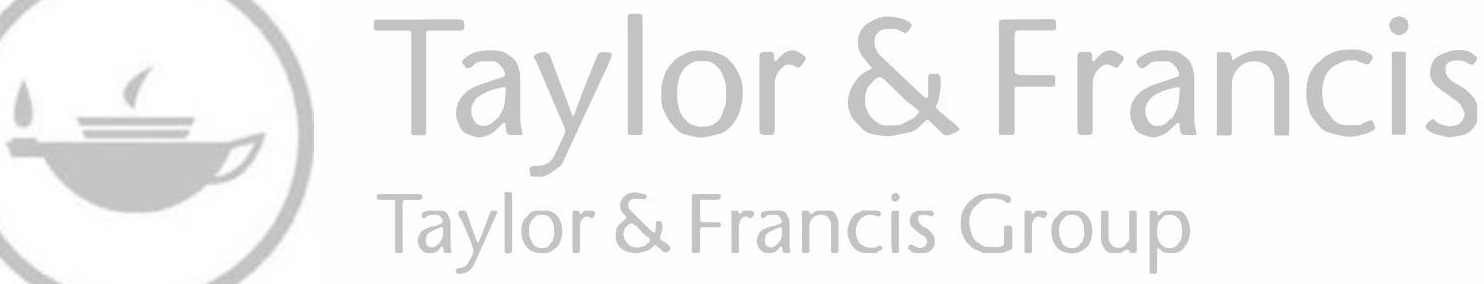
http://taylorandfrancis.com 


\section{Index}

Note: Country appearances in tables are marked in bold and page numbers followed by " $n$ " denote endnotes

Africa 19,186

age $7-8,14,29,112-13,122$; and the division of labour of domination 117-21, 133n 3 ; in the social space $113-16,126,129-30,132,156,183-4$; see also seniority thesis; trajectory Alexander, J. 92

ambition 165-72, 177-8, 187; see also hard work; merit/meritocracy

analysis of variance (ANOVA) 31-2, $36 \mathrm{n} 10$

approximation 18-20, 30, 34, 141, 145,181

assortive mating see homogamy; partnering

Australia 20, 21, 33; age 114, 115, 117 , 118, 128; class sense 163, 180n6; division of labour (of domination) 67, 70, 71, 73, 77, 80, 81, 82, 85n8; gender 89,91 ; partnering 94,95 ; politics 139 , $139,142,143,145,148,149,150,153$; religion $98,100,101,102,103$; sense of injustice $173,173,175,176$; social space $38-9,39,40,41,42,45,47,49$, $50,51,54-5$; sociodicy $167,168,170$, 171 ; third axis 124,130 ; urban-rural divide 107

Austria 20, 21, 33; age 115, 118; class sense 163,164; division of labour (of domination) $67,68,70,71,73,77,80$, 81, 82; gender $89,91,92$; partnering 94, 95; politics 139, 140, 142, 148, 150 , 151-2, 153; religion 100, 102, 103; sense of injustice $173,175,176$; social space $38,39,40,41,42,43,45,47$, 49, 50, 51, 54-5; sociodicy 167,168 , $170,171,180 \mathrm{n} 8,180 \mathrm{n} 9$; third axis 124 , 127-9, 130; urban-rural divide 106, 107,110 n12

Bachelard, G. 3, 18, 26, 181

Belgium-Flanders 11, 20, 21, 33; age 115, 118; class sense 163, 164, 180n6; division of labour (of domination) 67, 70, 71-2, 73, 77, 80, 81; gender 89, 91; partnering 94,95 ; politics 135 , $138,139,140,142,148,150,151,152$, $153,157 \mathrm{n} 7$; religion $100,102,103$; sense of injustice 173, 173, 175, 176; social space $39,40,41,42,45,50,51$, 54-5, 60n6; sociodicy 167, 170, 171; third axis $124,127-8,130$; urban-rural divide 106, 107

Boltanski, L. 160-1, 172

books see family, and books

Bourdieu, P. 2-3, 15, 16n1, 16n2, 65, $92-3,165,176,181,182,186$; on age 112-13, 121, 184; on classification 62-3; Distinction 1-2, 5, 10, 11, 12, 14, $15,27,28,53,104,121,131,134,145$, 165,182 ; epistemology 14,18 ; and GDA $28,30,35$; on gender $86-7$; on lifestyles 9, 134; model of class 5-14, $23,27,59,79,131,134$; on physical space 104-5; on politics 9-10, 16, 134-6, 145; on religion 98-9; on social mobility $121-2,184$; on the state 22 ; on symbolic violence 158-61, 178 
Brousse, C. 13-14, 182

business executives $65-76,85 \mathrm{n} 8,96$, $117-20,133 n 3,183$

\section{Cambridge School 7}

capital: accumulation 53, 78, 79, 86-7, 88, 92, 111-14, 116-17, 119, 121-3, 129, 132, 168; human 4, 116, 182; indicators 24-6, 33, 36n5; military 22; physical 8; political 9; religious 8; social $6,12,24,25,38,55,92$, 108, 126, 165, 166, 180n8; symbolic $7,8,179$ n1; see also cultural capital; economic capital; field capitalism 1-3, 7-9, 10, 14-16, 19-22, $24,35,46,53,58,59,86,88,97,104$, $108,112-13,132,168,181-3,185$; and occupational classification $62-3,75$, 79, 83; and politics 134, 144-5, 151, 155 ; and religion 101; and symbolic violence $160,164-6,172,177-8,185$; transition to $8-9,20-2,180 \mathrm{n} 8,117$, $128-9,131$; varieties of 22

categorical principal components analysis (CatPCA) 29-31; versus MCA $31-5$

China 19, 99, 186

cities see urbanisation; urban-rural divide

classification, principles of $25,36 \mathrm{n} 6$, 62-6, 75-6

class politics $137,152,156,157 \mathrm{n} 13$, 178,185

class sense 16, 159, 161-5, 185; see also self-perception/worth

comparative sociology $22-4$

cultural capital 2, 6-8, 11-12, 13-14, $17 \mathrm{n} 10,22-3,60 \mathrm{n} 4,60 \mathrm{n} 7$; and age 112 $21,132,184$; and the division of labour (of domination) 63-5, 69, 71-2, 75, 78-9, 82-4, 183; on first axis; 38-43, $46-7,49,52-4,56-9,182-3$; and gender $87-8,90,112$; indicators $24-6$, 36n5, 55; inherited 13-14, 25-6, 33, 38-9, 41, 43, 45-7, 52-3, 56-9, 60n3, $69,71-2,78-9,83-4,105,112-13$, 119-20, 122, 125-6, 128, 136, 143, $152,165-6,168,176,182,184$; and partnering 93,97 ; and politics 10,12 , 135-6, 141, 143-4, 146-7, 149, 151-2, $155,157 \mathrm{n} 13,185$; and religion 101 , 104, 108-9, 157n13, 183; on second axis; 43-7, 49, 52-4, 56-9, 60n3, 182-3; and symbolic violence 159-60, 164-6, 172, 174, 176, 178, 179n4, 185; on third axis 123-31; and the urban-rural divide 105-6, 108-9, 183; see also educational attainment/level cultural producers $65,75,78-83$, 120, 183

Czech Republic 20, 21, 33; age 115, 118; class sense 163, 164; division of labour (of domination) 67, 68, 70, 72, 73, 77, 80, 81; gender 89, 91, 92; politics 139, 141, 142, 144, 146, 148, 150, 151, 153, $157 \mathrm{n} 9$; religion $\mathbf{1 0 0}, \mathbf{1 0 2}, \mathbf{1 0 3}$; sense of injustice 173, 175; social space $38, \mathbf{3 9}$, 40, 41, 42, 43, 45-6, 47, 50, 51, 54, 56; sociodicy $167, \mathbf{1 7 0}, \mathbf{1 7 1}, 180 \mathrm{n} 9$; third axis 133n5; urban-rural divide 107, 110n12; see also Eastern Europe; postsocialist countries

deindustrialisation $8,53,55,57,117$, 121, 136, 178

Denmark 11, 13, 21, 33, 182; age 115, 118; class sense 163,164 ; division of labour (of domination) 67, 68, 70, 71, 73, 77, 80, 81, 85n8; gender 88, 89, 91, 92; partnering 94, 95; politics 135, 139, 140, 141, 142, 143, 149, 149, 150, 152, 153, 155, 157n8; religion $100,102,103$; sense of injustice 173 , 175; social space $\mathbf{3 9}, \mathbf{4 0}, \mathbf{4 2}, 44, \mathbf{5 0}, \mathbf{5 1}$, $54-5$; sociodicy $167,170,171$; third axis 124, 126, 130; urban-rural divide 110n12, 107; see also Nordic countries division of labour (of domination) $1,7,15,22,59,61,86,88-90$, 108, 156, 183; and age 116-21, 184; and classification 62-6, 75-8; correspondence with social space 68-75, 78-83, 128-31; distribution of individuals $66-8,76-7$; and partnering 93-7, 108-9

doxa $55,84,85 \mathrm{n} 9,87,98,159,165-6$, $172,177,187$; see also orthodoxy/ heterodoxy

Duby, G. 8

Duncan, O.D. 4, 6, 26

Durkheim, E. 3, 22, 109n7

Eagleton, T. 159

Eastern Europe 3, 9, 16n6, 22, 38, 88, 99, 101, 105-6, 109, 129, 131, 136, 138, 144, 149, 168, 182-4; see also 
post-socialist countries; individual country entries

economic capital 2, 6-10, 12-14, 17n10, 22-4, 182-3; and age 112-13, 116, $132-3,184$; and the division of labour (of domination) 63-6, 72, 75, 78-9, 83-4; on first axis 38-43, 46-7, 49, 52-4, 57, 59; and gender 87-8, 90, 92; indicators 24-6, 33, 55, 60n7, 104n9; and partnering 97, 109 4 ; and politics 134-6, 143-7, 155, 185; on second axis 43-7, 49, 52-4, 57, 59; and symbolic violence $159-60,164,165,172-4$, 176-7, 179n4, 185; on third axis 123-31; and the urban-rural divide 105,108

economic crisis $19,156,168,178$

educational attainment/level 1-2, 4-7, 9-12, 28, 61, 69, 75, 79, 119, 122, 125, $126,131,179,180 \mathrm{n} 9,181$; and age $113,116,121,184$; country differences 20-1, 23, 55-7; and gender 88-90, 97; indicators of 24-5, 33, 36n5; and politics 135-6; and religion 99, 104, $109 \mathrm{n} 7$; in the social spaces $38-46,58$, 128-9, 182; and symbolic violence 160, 165, 168, 172-6, 177, 180n7; see also cultural capital

education system $14,41,53,90,99,179$, 180n9; expansion of $8,22,53,64,113$, $117,121-2,129,132,172,182,184$ employers $63,65,68,71-5,79,83-4$, $85 n 7,85 n 8,128,183$

Erikson-Goldthorpe-Portacarero (EGP) scheme 4-5, 11, 16n7, 27, 62, 64, 122, $135,136,186$

Elias, N. 8

elites 7, 16n6, 172, 178, 179

elective affinity see homophily

employers 63, 65, 68, 71-5, 79, 83-4, $85 \mathrm{n} 7,85 \mathrm{n} 8,128,183$

Esping-Andersen, G.3, 97, 109n1, 147, 149; see also welfare regimes

Estonia 20, 21, 22, 33; class sense 163, 164, 179n4; division of labour (of domination) 67, 68, 69, 70, 71, 73, $\mathbf{7 7 , ~ 8 0 , ~ 8 1}$; gender $88, \mathbf{8 9}, \mathbf{9 1}, 92,97$; partnering 94, 95; politics 139, 142 , 144, 148, 150, 151-2, 153; religion 100, 101, 102, 103; sense of injustice 173, 175; social space $38, \mathbf{3 9}, \mathbf{4 0}, 41, \mathbf{4 2}, 43$, 50,51 ; sociodicy 167, 170, 171; third axis 124, 126, 128, 130; urban-rural divide 107, 108; see also Eastern Europe; post-socialist countries ethos 2, 10, 15, 59, 88, 98, 121, 136, $138,141,143,145,146-55,156,166$, $177-8,185$

family $6,8,39,55,66,87-8,92-3$, $97,109 \mathrm{n} 7,122,123,125,126,172$, 173, 183, 187; and books 25, 38, 41-5, 60n3, 123-5; values 10, 12; see also field, family; strategies, family/ reproduction feminism 86,187

field $6,26,61,65-6,76,82,85 n 9,111$, 112, 117, 119-20, 133, 161, 187; bureaucratic 9, 83-4; of cultural production $61,65,72,76,183$; economic 8-9, 22, 63-4, 72, 76-9, 83-4, 85n11, 90, 105, 145-6, 183; family $87,92-3,97,126$; intellectual 8, 22, 61, 63, 72, 76-9, 99, 105; political 76, 79, 131, 136-41, 143-6, 155-6, 166; of power $8,10,14,15$, 16n $4,22-3,58,61,63,65,68,75-84$, $88,98-9,105,129,164,170-2,179$, 182-3, 187; religious 88, 98-9; see also space of states

Finland 35

Flanders see Belgium-Flanders

Flemmen, M. 9

France 1-2, 8, 11, 13, 20, 21, 23, 27, 33, 182; age 115, 118; class sense 163, 164; division of labour (of domination) 67, $68, \mathbf{7 0}, 71, \mathbf{7 3}, \mathbf{7 7}, \mathbf{7 9}, \mathbf{8 0}, \mathbf{8 1}, 83$; gender 88, 89, 91; partnering 94, 95; politics 135-6, 139, 140, 141, 142, 144, 148, 149, 150, 151, 153, 157n3; religion 100, 102, 103; sense of injustice 173, 173, 175, 176; social mobility 121 ; social space $\mathbf{3 9}, \mathbf{4 0}, \mathbf{4 2}, \mathbf{4 5}, \mathbf{5 0}, \mathbf{5 1}$; sociodicy 167, 168, 170, 171; symbolic violence 159; third axis 124, 127-8, 130; urbanrural divide 107, 108, 110n12

Friedman, S. 76

Ganzeboom, H. 4

gender 9, 14, 15, 39, 86, 98, 109n4, 109n7, 129-31, 135, 146, 157n2, 157n13; Bourdieu on 86-7; and occupation 88-90, 97, 183; regime $55,59,87-8,126$; revolution 123-6, 132; in social spaces $11,13,59,90-2$, 97, 108 
generations $15,38,53,59,111-16$, 121-2, 128-33, 133n4, 143, 183-4; see also age

Geometric data analysis (GDA) 3, 15, 26-35, 36n 7, 36n10, 60n4, 76, 137, 181, 187; see also categorical principal components analysis (CatPCA); multiple correspondence analysis (MCA)

Germany 12, 16n8, 20, 21, 33, 35n1, 105, 186; age 115, 118; class sense 163, 164; division of labour (of domination) 67 ,

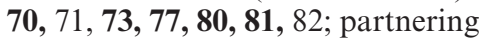
94, 95; politics $138, \mathbf{1 3 9}, 141, \mathbf{1 4 2}$, 146, 148, 150, 151, 152, 153, 155, 156; religion $98-9, \mathbf{1 0 0}, \mathbf{1 0 2}, \mathbf{1 0 3}$; sense of injustice $173, \mathbf{1 7 5}, 176$; social space 38, 39, 40, 42, 45-6, 47, 50, 51, 56; sociodicy 167, 168, 170, 171, 180n9; third axis $123, \mathbf{1 2 4}, \mathbf{1 2 5}, \mathbf{1 2 7}$; urbanrural divide 106, 107

Giddens, A. 156n 1

Gini coefficient 20-1, 23, 55, 57

Global field see space of states

Goffman, E. 61

Goldthorpe, J.H. 4-6, 9, 11, 27; see also Erikson-Goldthorpe-Portacarero (EGP) scheme

Great Britain see United Kingdom

Great British Class Survey 11

Gross Domestic Product (GDP) 20-1, 23, 55, 57

Grusky, D. 4

habitus $2,9,10,12,13,15,16 \mathrm{n} 8,59,61$, 75-6, 79, 121, 133n4, 134, 137, 165; religious 98; see also ethos

hard work 158, 165-72, 177, 178; see also ambition; merit/meritocracy

Harrits, G. 135

Hauser, R. 4

Hegel, G. 3

heterodoxy see orthodoxy/heterodoxy

Hjellbrekke, J. 36n7

homogamy 95,185

homology see age; division of labour (of domination); ethos; gender; religion; political parties; urban-rural divide

homophily 93

household, effect of formation on position 92-7

Hugrée, C. 17n10, 23
Iceland 21, 33; age 115, 118; class sense 163, 164; division of labour (of domination) 67, 68, 69, 70, 71, 73, 77, $\mathbf{8 0 , 8 1}, 82$; gender 89, 91; partnering 94, 95; politics 139, 142, 143, 148, 149 , 150, 152, 153, 157n8; religion 100, 101, 102, 103, 110n9; sense of injustice $173, \mathbf{1 7 3}, \mathbf{1 7 5}$; social space $\mathbf{3 9}, \mathbf{4 0 , 4 2}$,

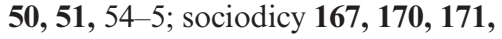
$180 \mathrm{n} 9$; third axis $123, \mathbf{1 2 4}$; urbanrural divide 107, 108; see also Nordic countries

income see economic capital

Inglehart, R. 156n1, 156n2

intellectuals $6,7,9,65,66-8,83,159$, 161 ; in the social space $69-72,85 \mathrm{n} 8$, $126,128,183$; partners 97 ; young and old 119-20, 133n3

International Labour Organization (ILO) 25, 64, 68

International Standard Classification of Occupations (ISCO) 25, 64-6, 76, 84n1 injustice see justice

Israel 20, 21, 33; age 115, 118; class sense 163, 179n4; division of labour (of domination) 67, 68, 70, 71, 73, $\mathbf{7 7 , 8 0 , 8 1}$; gender 89, 91; partnering 94, 95; politics 136, 139, 140, 142, 143, 144, 148, 149, 150, 151, 152, 153, $156,157 \mathrm{n} 3,157 \mathrm{n} 12,185$; religion 99 , 100, 101, 102, 103, 110n10; sense of injustice 173, 173, 175, 176; social space $38, \mathbf{3 9}, \mathbf{4 0}, \mathbf{4 2}, 45,47, \mathbf{5 0}, \mathbf{5 1}$, 54 ; sociodicy 167, 168, 170; third axis 124, 128, 130; urban-rural divide 106, 107, 108

Italy $20, \mathbf{2 1}, \mathbf{3 3}$; age $114, \mathbf{1 1 5}, \mathbf{1 1 8}$; class sense $162,163,164,179 \mathrm{n} 5$; division of labour (of domination) 67, 68-9, 70, 71-2, 73, 77, 80, 81, 82, 85n8; gender 88, 89, 91, 92; partnering 94, 95; politics 139, 140-1, 142, 144, 148, 149, 150, 152 , 153, 156, 157n $3,157 \mathrm{n} 12$; religion 98 , $100,101,102,103$; sense of injustice 173, 175, 176; social space 38, 39, 40, 41, 42, 44-5, 47, 50, 51, 54; sociodicy $167,168,170,171,180 \mathrm{n} 8$; third axis 133n5; urban-rural divide 107, 108

Japan 13, 20, 33; age 115, 118; class sense 162, 163, 164; gender 88, 89, 91, 92; politics 136, 139, 140, 142, 143-4, 
148, 149, 150, 152, 153; religion 99, 100, 101, 102, 103; sense of injustice 173, 175; social space $38, \mathbf{3 9}, \mathbf{4 0}, \mathbf{4 2}$, 44, 50, 51, 54; sociodicy 167, 168, $\mathbf{1 7 0}$, 171; third axis $123, \mathbf{1 2 4}, \mathbf{1 2 5}, \mathbf{1 2 7}$; urban-rural divide $\mathbf{1 0 7}$

Jarness, V. 12, 136, 156, 159-60

Jodkha, S. 12

justice, sense of 160, 172-6

Keere, K. de 11, 135, 157n7

Latvia 20, 21, 22, 33; age 115, 118; class sense 162, 163; division of labour (of domination) 67, 68-9, 70, 72, 73, $\mathbf{7 7}, \mathbf{8 0}, \mathbf{8 1}, 82$; gender $88, \mathbf{8 9}, \mathbf{9 1}, 92$; partnering $\mathbf{9 4}, \mathbf{9 5}$; politics $\mathbf{1 3 9}, 140$, 142, 144, 148, 149, 150, 151, 153; religion $\mathbf{1 0 0}, 101, \mathbf{1 0 2}, \mathbf{1 0 3}$; sense of injustice 173, 175; social space 38,39 , $\mathbf{4 0}, 41, \mathbf{4 2}, 43-5, \mathbf{5 0}, \mathbf{5 1}$; sociodicy $\mathbf{1 6 7}$, 170, 171; third axis 124, 130; urbanrural divide 107, 108; see also Eastern Europe; post-socialist countries

Laurison, D. 76

life course see age

lifestyles 2, 4, 5, 9, 11-13, 15, 19, 28, 35, $61,134,159-60,184,186-7$

lifeworlds 66, 187

Lipset, S.M. 26, 134, 145, 156

love $93,96,187$

lusiones 131, 184

managers see business executives; classification, principles of; division of labour (of domination)

Mannheim, K. 121

Marshall, G. 179n1

Marx, K. 1, 2, 3, 185

Marxism 4, 7, 62, 64, 105, 122, 160

Melldahl, A. 11

merit/meritocracy 131, 158, 165-6, $168-72,177,179,185$

micro-classes 4, 75-6

middle class 1, 159, 179n1; see also service class

misrecognition 2, 7, 9, 14, 62, 69, 98, 158, 160, 164, 177, 179, 182, 186, 187; and age 112-14; order(s) 7, 11, 58, 65, 16n4, 86, 104, 132, 158, 165-6, 177 multiple correspondence analysis (MCA) 28-31, 36n12; versus CatPCA 31-5, 60n3; see also categorical principal components analysis; Geometric data analysis

New Zealand 20, 33; age 114, 115, 118; class sense 163, 164; gender 89, 91, 92; politics 138-9, 139, 141, 142, 143, 145, 148, 149, 150, 151, 153, 155, 157n9; religion $100,101,102,103$; sense of injustice 173, 173, 175, 176; social space $39,40,42,50,51$; socodicy 167 , $168, \mathbf{1 7 0}, \mathbf{1 7 1}$; third axis $\mathbf{1 2 4}, \mathbf{1 2 8}, \mathbf{1 3 0}$

Nietzsche, F. 101

nonlinear principal components analysis see categorical principal components analysis

Nordic countries 2, 13-14, 20, 24, $35 \mathrm{n} 2,182$; division of labour (of domination) 66, 68; gender 88 ; religion 99 , 101; politics 138,152 , 156,185 ; social spaces $47,49,55,186$; symbolic violence 160, 166, 168, 176; see also individual country entries

Norway 11, 13, 17n9, 21, 33, 110n11, 182, 186; age 115, 118; class sense $159,163,164$; division of labour (of domination) 67, 68, 70, 71, 73, 77, 80, 81, 83, 84n2; gender 88, 89, 90, 91; partnering 94, 95; politics 135-6, 139, 140, 141, 142, 143, 148, 149, 150, 152 , $\mathbf{1 5 3}, 157 \mathrm{n} 5,157 \mathrm{n} 8$; religion 100, 102, 103, 109n6; sense of injustice 173, 175; social space $\mathbf{3 9}, \mathbf{4 0}, 41, \mathbf{4 2}, 43,45$, $\mathbf{5 0}, \mathbf{5 1}, 54-5$; sociodicy $167, \mathbf{1 7 0}, \mathbf{1 7 1}$; third axis 124, 127-9, 130; see also Nordic countries

Obama, B. 138

occupation see classification, principles of

Occupy movement 178

omnivore thesis 11-12, 187

orthodoxy/heterodoxy 2, 87, 98, 129, 137, 139-41, 146, 148-9, 161, 173, 176, 178, 187; see also doxa; sociodicy

Pahl, R. 104

Parkin, F. 2, 156n1

partnering, effect of 92-7; patterns of 93-7; see also gender; household

Peterson, R. 11

Piketty, T. 7 
Poland 20-1, 21, 33, 182; age 115, 118; class sense 163; division of labour (of domination) 67, 68-9, 70, 73, 77, 80, 81; gender 89, 91; partnering 94, 95; politics 139, 139-41, 142, 143, 148, $149, \mathbf{1 5 0}, 151$; religion $\mathbf{1 0 0}, \mathbf{1 0 2}, \mathbf{1 0 3}$, 110n9; sense of injustice 173, 175; social space $38, \mathbf{3 9}, \mathbf{4 0}, \mathbf{4 2}, 44-5, \mathbf{5 0}$, 51, 54-5; sociodicy 167, 168, 170, 171, 180n8; third axis $60 \mathrm{n} 2,133 \mathrm{n} 5$; urban-rural divide 107, 108; see also Eastern Europe; post-socialist countries

Polanyi, K. 8

political parties 134-7, 147, 155-6, 157n3, 157n5, 157n6, 157n7, 178; distribution of affiliations 137-40; correspondence with social space 9-10, 16, 141-6, 185-6; far-left 137, 140-6, 157n10, 178; far-right 16,136 , 137, 140-6, 147, 156n2, 178; see also class politics; ethos; field, political political position-takings see class politics; doxa; ethos; political parties; welfare, attitudes toward; individual country entries

populism see political parties, far-right Portugal 35n2

post-materialist politics $12,135-7,186$ post-socialist countries $9,12,13,16 \mathrm{n} 7$, $20-2,38,68,82,88,96,101,114,117$, 128-31, 132, 168, 180n8, 185; see also Eastern Europe; individual country entries

Poulantzas, N. 62

Prieur, A. 11

principal components analysis (PCA)

29-30; see also categorial principal components analysis

professions see classification, principles of; division of labour (of domination)

Przerworski, A. 185

Putin, V. 138

Ranciere, J. 160

religion $1,8,15,16 \mathrm{n} 3,16 \mathrm{n} 5,61,88$, 109n7, 110n8, 116, 143, 156, 157n13; in the social space 98-104, 108, 109n6, 110n9, 183; see also capital, religious; field, religious; habitus, religious Rosenlund, L. 11, 36n7, 109n6, 110n11 ruling class 7
Russia 9, 20-2, 21, 33; age 115, 117 , 118; class sense 159, 162, 163, 164; division of labour (of domination) 67, 68-9, 70, 71-2, 73, 80, 81, 82, 85n8; gender 88, 89, 91, 92, 97; novye Russkie 114, 128; partnering 94, 95; politics 138, 139, 140-1, 142, 144, 148, 150, 152, 153, 156, 157n $3,157 \mathrm{n} 12$; religion $99, \mathbf{1 0 0}, 101, \mathbf{1 0 2}, \mathbf{1 0 3}$; sense of injustice 173, 175; social space $38, \mathbf{3 9}, \mathbf{4 0}, 41, \mathbf{4 2}, 43-5,47, \mathbf{5 0}, \mathbf{5 1}$; sociodicy $167,170,171,180 \mathrm{n} 8$; third axis 124, 130; urban-rural divide 107; see also Eastern Europe; post-socialist countries

\section{Savage, M. 113}

savings see economic capital

Scandinavia see Nordic countries; individual country entries

self-employment $65,68,71-2,128$

self-perception/worth 2, 3, 7, 65, 126, $152,155,158,160,164-5,177,179 \mathrm{n} 2$, 179n3, 179n4, 183, 185, 187; see also class sense

seniority thesis $8,112-13,132$

service class $4,7,10,135$

service sector $5,20-2,55-7,68,72,105$, 117,182

Simmel, G. 105

Slovakia/Slovak Republic 20, 21, 33; age 115,118 ; class sense 163 ; division of labour (of domination) 67, 69, 70, 71-2, 73, 77, 80, 81, 85n8; gender 89, 91, 92; partnering 94, 95; politics 139, 142, 148, 150, 151-2, 153, 157n9; religion 100, 102, 103; sense of injustice 173, 175; social space $38, \mathbf{3 9}, \mathbf{4 0}, 41, \mathbf{4 2}$, $45, \mathbf{5 0}, \mathbf{5 1}, 54$; sociodicy $\mathbf{1 6 7}, \mathbf{1 7 0}, \mathbf{1 7 1}$, 180n8; third axis 124, 128, 130; urbanrural divide 107; see also Eastern Europe; post-socialist countries social mobility $4,7,14,15,76,90,112$, 121-31, 132, 165, 184, 180n6 social origins $56,78-9,90,111-12,119$, 121-31, 182, 184

social space see capital; trajectory; individual country entries social reproduction $7,16 \mathrm{n} 5,16 \mathrm{n} 6,26,41$, $53,58,61,84,87,90,93,112,121-2$, 131, 166, 168, 172, 176, 177, 182, 185; see also strategies 
sociodicy 158, 161, 165-72, 185; see also doxa; orthodoxy/heterodoxy

socio-economic scales 1, 4, 7, 26, 37, 181

Sorokin, P. 16n3

South America 19, 186

South Korea 20, 21, 33; age 114, 115, 117, 118; class sense $162, \mathbf{1 6 3}$, 164,179 n 4 ; division of labour (of domination) 67, 68-9, 70, 71, 73,

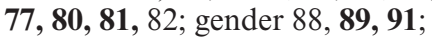
partnering 94, 95; politics 136, 139, 142, 144, 148, 149, 150, 152, 153, 156, $157 \mathrm{n} 3,157 \mathrm{n} 12$; religion $99, \mathbf{1 0 0}, 101$, 102, 103; sense of injustice 173, 175, 176; social space 38-9, 39, 40, 41, 42, 44-7, 50, 51, 54, 56; sociodicy $\mathbf{1 6 7}$, $168, \mathbf{1 7 0}, \mathbf{1 7 1}, 180 \mathrm{n} 8$; third axis 123 , 124, 125, 125-6, 127; urban-rural divide 105-6, 107, 108

space of states 22-3, 57-9, 66, 88, 105, $132,168,186$

Spain 35n2, 98

Sprague, J. 185

status 3-5, 9, 11-12, 61, 93, 122, 179n1

strategies $24,83,88,99,114,144$, 156n2, 161, 165, 180n8, 187; family/ reproduction $12,90,92,168,173,176$, 178,182 ; self-presentation 65,162 , 168 ; space of states $57-8,66,105$

Sweden 11, 21, 33; age 115, 118; class sense 163, 179n4; division of labour (of domination) 67, 68, 70, 71, 73, 77, $\mathbf{8 0 ,} \mathbf{8 1}, 85 \mathrm{n} 8$; gender 89, 90, 91, 92; partnering 94, 95; politics 139, 140-1, 142, 143, 148, 149, 150, 151-2, 153; religion 100, 101, 102, 103; sense of injustice $\mathbf{1 7 3}, \mathbf{1 7 5}$; social space $\mathbf{3 9}$, 40, 42, 50, 51, 54; sociodicy 167, 170 , 171; third axis 123, 124, 125, 126, 127; urban-rural divide 107, 108; see also Nordic countries

Switzerland 21, 33; age 114, 115, 118; class sense 163, 179n5; division of labour (of domination) 67, 68, 70, $71, \mathbf{7 3}, \mathbf{7 7}, \mathbf{8 0}, \mathbf{8 1}$; gender $88, \mathbf{8 9}, \mathbf{9 1}$; partnering 94, 95; politics 139, 141, 142, 143, 148, 150, 152, 153; religion 98-9, 100, 101, 102, 103; social space $38, \mathbf{3 9}, \mathbf{4 0}, 41, \mathbf{4 2}, 43,45, \mathbf{5 0}, \mathbf{5 1}, \mathbf{5 4}$; sociodicy $167,170,171$; sense of injustice 173, 175, 176; third axis 123, 124, 125, 127; urban-rural divide 107 symbolic power $61,63,65,66,83,97,98$, $149,158,172,177,179$

symbolic violence 16, 140, 158-9, 161, $177,185,186$

Taiwan 20, 21, 33, 182; age 115, 117, 118; class sense 162, 163, 164; division of labour (of domination) 67, 68-9, $\mathbf{7 0 ,} 71, \mathbf{7 3}, \mathbf{7 7}, \mathbf{8 0}, \mathbf{8 1}, 85 \mathrm{n} 8$; gender $\mathbf{8 9}$, 91, 92; partnering 94, 95; politics 136 , 138-9, 139, 141, 142, 143-4, 148, 150, 151-2, 153, 157n3; religion 99, 100, $101, \mathbf{1 0 2}, \mathbf{1 0 3}$; sense of injustice 173, 175, 176; social space $38-9, \mathbf{3 9}, \mathbf{4 0}, 41$, $\mathbf{4 2}, 43-5,47, \mathbf{5 0}, \mathbf{5 1}, 54-5$; sociodicy 167, 168, 170, 171, 180n8; third axis $123, \mathbf{1 2 4}, \mathbf{1 2 5}, 125-6, \mathbf{1 2 7}$; urban-rural divide 105-6, 107, 108

teachers $6,25,64-5,76-8,82-3,84$, 90,120

trajectory $7-8,15,26,37,53,58,59$, 84, 109, 121, 131-3, 158, 160, 165, 177, 180n6; and age 113-21, 184; measuring 112-13; and the third axis of the social spaces 123-31, 184; see also age; generations; social mobility

Trieman, D. 4

typicality tests $30,69,162$

United Kingdom 14, 35n2, 76, 98, 135, $145,147,182$

United States (US) 1, 3, 13, 20, 21, 26, 33, 186-7; age $114, \mathbf{1 1 5}, \mathbf{1 1 8}$; class sense 159, 163, 164; division of labour (of domination) 67, 68-9, 70, 71, $\mathbf{7 3}, \mathbf{7 7}, \mathbf{8 0}, \mathbf{8 1}, 82,85 \mathrm{n} 8$; gender $\mathbf{8 9}$, 91; partnering 94, 95; politics 138-9, 139, 141, 142, 144-5, 148, 148-9, 150, 151-2, 153, 157n6, 157n11; religion 98, 100, 101, 102, 103, 110n9; sense of injustice $173, \mathbf{1 7 3}, \mathbf{1 7 5}, 176$; social mobility 122 ; social space $38, \mathbf{3 9}, \mathbf{4 0}$, 41, $\mathbf{4 2}, 43-7, \mathbf{5 0}, \mathbf{5 1}, 56$; sociodicy $\mathbf{1 6 7}, 168, \mathbf{1 7 0}, 171$; third axis 123 , 124, 125, 127; urban-rural divide 106, $\mathbf{1 0 7}, 108$

urbanisation 20-1, 104

urban-rural divide 15, 104-9, 116, 183,186

Urry, J. 134

variable choice $11-13,16 \mathrm{n} 9,18-19,24-6$ 
Warner, W.L. 26

Warren, J. R. 4

wealth see economic capital

Weber, M. 1-5, 20, 101

welfare, attitudes toward 10,16, 137,

$147-56,185$; regimes $3,13,22$,

$87-8,126$
Wilmott, P. 26

working class $16 \mathrm{n} 7,122,135,145,159$, 179n1

Wright, E.O. 4, 62, 122

Young, M. 26

youth see age 